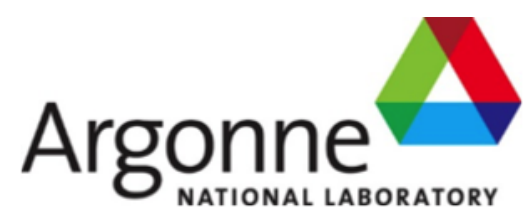

ANL-ART-134

\title{
Finite element analysis of compliant cladding and base metal systems
}

Applied Materials Division 
About Argonne National Laboratory

Argonne is a U.S. Department of Energy laboratory managed by UChicago Argonne, LLC under contract DE-AC02-06CH11357. The Laboratory's main facility is outside Chicago, at 9700 South Cass Avenue, Argonne, Illinois 60439. For information about Argonne and its pioneering science and technology programs, see www.anl.gov.

\section{DOCUMENT AVAILABILITY}

Online Access: U.S. Department of Energy (DOE) reports produced after 1991 and a growing number of pre-1991 documents are available free at OSTI.GOV (http://www.osti.gov/), a service of the U.S. Dept. of Energy's Office of Scientific and Technical Information

Reports not in digital format may be purchased by the public from the

National Technical Information Service (NTIS):

U.S. Department of Commerce

National Technical Information Service

5301 Shawnee Rd

Alexandria, VA 22312

www.ntis.gov

Phone: (800) 553-NTIS (6847) or (703) 605-6000

Fax: (703) 605-6900

Email: orders@ntis.gov

Reports not in digital format are available to DOE and DOE contractors from the Office of Scientific and Technical Information (OSTI)

U.S. Department of Energy

Office of Scientific and Technical Information

P.O. Box 62

Oak Ridge, TN 37831-0062

www.osti.gov

Phone: (865) 576-8401

Fax: (865) 576-5728

Email: reports@osti.gov

\section{Disclaimer}

This report was prepared as an account of work sponsored by an agency of the United States Government. Neither the United States Government nor any agency thereof, nor UChicago Argonne, LLC, nor any of their employees or officers, makes any warranty, express or implied, or assumes any legal liability or responsibility for the accuracy, completeness, or usefulness of any information, apparatus, product, or process disclosed, or represents that its use would not infringe privately owned rights. Reference herein to any specific commercial product, process, or service by trade name, trademark, manufacturer, or otherwise, does not necessarily constitute or imply its endorsement, recommendation, or favoring by the United States Government or any agency thereof. The views and opinions of document authors expressed herein do not necessarily state or reflect those of the United States Government or any agency thereof, Argonne National Laboratory, or UChicago Argonne, LLC. 


\section{Finite element analysis of compliant cladding and base metal systems}

Applied Materials Division

Argonne National Laboratory

July 2018

Prepared by

M. C. Messner, Argonne National Laboratory

V.-T. Phan, Argonne National Laboratory

B. Barua, Argonne National Laboratory

T.-L. Sham, Argonne National Laboratory

R. I. Jetter, R. I. Jetter Consulting 



\section{Abstract}

This report describes a roadmap towards a design method for high temperature nuclear cladded components that does not require long term testing of clad materials. Molten Salt Reactors (MSRs) will operate using corrosive fuel or coolant salts. The existing Class A metallic materials qualified for ASME Boiler and Pressure Vessel Code Section III, Division 5 design are not optimal for corrosion resistance when exposed to MSR salts. Corrosion could then severely limit the service life of MSRs. One option to alleviate this could be to Code qualify new corrosion resistant materials. However, this is a lengthy and expensive process and MSR developers have a near term need for a design solution that enables reactor designs with long service lives.

An alternative would be to use cladded components - overlay some existing Class A material with a thin layer of some corrosion resistant material. This report describes the outlines of a design strategy that would enable this approach. The strategy relies on approximate design analysis methods for certain types of clad/base systems that avoids requiring long-term mechanical properties for the clad materials. This would allow the use of cladded components in the near term, without requiring long testing programs. However, it will limit the types of clad materials that can be used.

This report describes the design framework, demonstrates the effectiveness of the approximate analysis methods, and confirms the approach using full scale finite element analysis of prototypical cladded high temperature components. It also describes a roadmap towards a complete design method and surveys available clad materials and bonding methods for suitably, considering only mechanical and not environmental effects. 



\section{Table of Contents}

Abstract

Table of Contents $\quad$ iii

List of Figures $\quad$ V

List of Tables $\quad$ Xv

1 Introduction 1

1.1 Cladded components for high temperature nuclear service . . . . . . . . . . 1

1.2 Existing rules in Section III, Division 5 . . . . . . . . . . . . . 1

1.3 Report Overview . . . . . . . . . . . . . . . . . . 2

1.4 Bonding methods . . . . . . . . . . . . . . . . . . . . . . . 3

2 Bounding analysis strategies and conceptual design methods for cladded components $\quad 5$

2.1 Analysis methods . . . . . . . . . . . . . . . . . . . 5

2.1.1 Elastic clads . . . . . . . . . . . . . . . . . . 6

2.1.2 Compliant clads . . . . . . . . . . . . . . . . . . . . 7

2.1 .3 Intermediate cases . . . . . . . . . . . . . . . . . . . . . . . . . . . . . . . . . . .

2.2 Conceptual design methods . . . . . . . . . . . . . . . . . . . . . . . . . . . . . . . . . . . . .

2.2.1 Primary load design and buckling . . . . . . . . . . . . . . . . 9

2.2.2 Creep-fatigue and ratcheting limits . . . . . . . . . . . . . . 10

2.2.3 Clad failure modes . . . . . . . . . . . . . . . . 11

3 Simplified modeling methods 13

3.1 Developing the simplified model . . . . . . . . . . . . . . . . . . 13

3.1.1 Simplified kinematics . . . . . . . . . . . . . . . . 13

3.1.2 Discretizing the problem . . . . . . . . . . . . . . 16

3.1.3 Efficient solution methods ................... 19

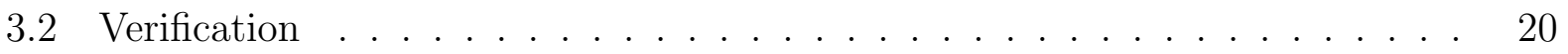

4 Simple representative models 23

4.1 Clad on inner diameter only . . . . . . . . . . . . . . . . . . . 24

4.1.1 Comparison to compliant clad analysis . . . . . . . . . . . . 25

4.1 .2 Elastic cladding . . . . . . . . . . . . . . . . . . . . . . . . . . . . . . . . . . . . . . . . .

4.2 Cladded IHX tube . . . . . . . . . . . . . . . . . . . . . . . . . . . . . . . . . . . . . . . . . . . . . . . 43

4.2.1 Creep compliant cladding . . . . . . . . . . . . . . . 43

4.2 .2 Elastic cladding . . . . . . . . . . . . . . . . . . . . 49

4.3 Summary . . . . . . . . . . . . . . . . . . . . . . 49

5 Full component analysis $\quad 57$

5.1 Axisymmetric analysis of a tubesheet . . . . . . . . . . . . . . . . 57

5.2 Full 3D analysis of a bent heat exchanger tube . . . . . . . . . . . 60

6 Conclusions $\quad 77$

$\begin{array}{ll}\text { Acknowledgments } & 79\end{array}$

Bibliography $\quad 81$

A Mechanical properties of potential clad materials $\quad 87$

Distribution List $\quad 91$ 



\section{List of Figures}

2.1 Example of a connection detail that would fail the compliant clad analysis and a corresponding design fix. The connection on the left requires the clad material to bear shear to transmit the load from the two base material sections. A compliant analysis of this system would fail as it would predict infinite deformation in the clad. The connection detail on the right resolves the issue by transmitting the force directly into the base material. The compliant analysis method prevents designers from making an actual design mistake: relying on the clad material strength. . . . . . . . . . . . . . . . . . . .

3.1 Schematic drawing showing the model simplifications from a closed cylindrical vessel, to an axisymmetric representation, to the 1D simplified model developed here. . . . . . . . . . . . . . . . . . . . . .

3.2 Example problem used to compare full axisymmetric analysis to the simplified analysis method . . . . . . . . . . . . . . . . . .

3.3 Comparison between the simplified model (solid lines) and the full axisymmetric analysis (dashed lines) for the problem described by Fig. 3.2. The corresponding dashed/solid lines are essentially identical, meaning the two modeling methods are producing nearly identical results. These results are plotted at the end of the hold during the final load cycle. . . . . . . . . . . .

4.1 The times for the isothermal case are similar except the load is applied simultaneously with the initial temperature ramp. For both cases $T_{0}=700^{\circ} \mathrm{C}$ and $\Delta T=$

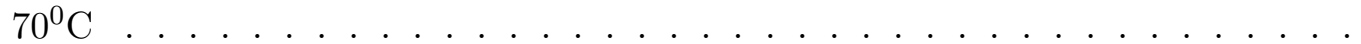

4.2 Design chart illustrating the difference in the average creep damage, $\left\{\bar{D}_{\mathrm{c}}\right\}_{\text {infinite compliance }}-$ $\left\{\bar{D}_{\mathrm{c}}\right\}_{\text {full inelastic }}$, in the base region during the hold of the last cycle (a) and the minimum difference of ASME equivalent strain range, $\{\Delta \varepsilon\}_{\text {infinite compliance }}-\{\Delta \varepsilon\}_{\text {full inelastic }}$, in the clad region over the last cycle (b) as a function of $E$ and $\sigma$ in the clad $/ 800 \mathrm{H}$ base system for the gradient load case. . . . . . . . . . . . . . . . 26

4.3 Design chart illustrating the difference in the average creep damage, $\left\{\bar{D}_{\mathrm{c}}\right\}_{\text {infinite compliance }}-$ $\left\{\bar{D}_{\mathrm{c}}\right\}_{\text {full inelastic }}$, in the base region during the hold of the last cycle (a) and the minimum difference of ASME equivalent strain range, $\{\Delta \varepsilon\}_{\text {infinite compliance }}-\{\Delta \varepsilon\}_{\text {full inelastic }}$, in the clad region over the last cycle (b) as a function of $E$ and $\alpha$ in the clad/800H base system for the gradient load case. . . . . . . . . . . . . . . . . . . . 26

4.4 Design chart illustrating the difference in the average creep damage, $\left\{\bar{D}_{\mathrm{c}}\right\}_{\text {infinite compliance }}-$ $\left\{\bar{D}_{\mathrm{c}}\right\}_{\text {full inelastic }}$, in the base region during the hold of the last cycle (a) and the minimum difference of ASME equivalent strain range, $\{\Delta \varepsilon\}_{\text {infinite compliance }}-\{\Delta \varepsilon\}_{\text {full inelastic }}$, in the clad region over the last cycle (b) as a function of $E$ and $\dot{\varepsilon}$ in the clad/800H base system for the gradient load case. . . . . . . . . . . . . . . . . . . 27

4.5 Design chart illustrating the difference in the average creep damage, $\left\{\bar{D}_{\mathrm{c}}\right\}_{\text {infinite compliance }}-$ $\left\{\bar{D}_{\text {c }}\right\}_{\text {full inelastic }}$, in the base region during the hold of the last cycle (a) and the minimum difference of ASME equivalent strain range, $\{\Delta \varepsilon\}_{\text {infinite compliance }}-\{\Delta \varepsilon\}_{\text {full inelastic }}$, in the clad region over the last cycle (b) as a function of $\sigma$ and $\alpha$ in the clad $/ 800 \mathrm{H}$ base system for the gradient load case. . . . . . . . . . . . . . . 27 
4.6 Design chart illustrating the difference in the average creep damage, $\left\{\bar{D}_{\mathrm{c}}\right\}_{\text {infinite compliance }}{ }^{-}$ $\left\{\bar{D}_{\text {c }}\right\}_{\text {full inelastic }}$, in the base region during the hold of the last cycle (a) and the minimum difference of ASME equivalent strain range, $\{\Delta \varepsilon\}_{\text {infinite compliance }}-\{\Delta \varepsilon\}_{\text {full inelastic }}$, in the clad region over the last cycle (b) as a function of $\sigma$ and $\dot{\varepsilon}$ in the clad/800H base system for the gradient load case. . . . . . . . . . . . . . . . . . . 28

4.7 Design chart illustration the difference in the average creep damage, $\left\{\bar{D}_{\text {c }}\right\}_{\text {infinite compliance }}{ }^{-}$ $\left\{\bar{D}_{\text {c }}\right\}_{\text {full inelastic }}$, in the base region during the hold of the last cycle (a) and the minimum difference of ASME equivalent strain range, $\{\Delta \varepsilon\}_{\text {infinite compliance }}-\{\Delta \varepsilon\}_{\text {full inelastic }}$, in the clad region over the last cycle (b) as a function of $\alpha$ and $\dot{\varepsilon}$ in the clad $/ 800 \mathrm{H}$ base system for the gradient load case. . . . . . . . . . . . . . . . . . 28

4.8 Design chart plotting the difference in the average creep damage, $\left\{\bar{D}_{\mathrm{c}}\right\}_{\text {infinite compliance }}-$ $\left\{\bar{D}_{\mathrm{c}}\right\}_{\text {full inelastic }}$, in the base region during the hold of the last cycle (a) and the minimum difference of ASME equivalent strain range, $\{\Delta \varepsilon\}_{\text {infinite compliance }}-\{\Delta \varepsilon\}_{\text {full inelastic }}$, in the clad region over the last cycle as a function of $E$ and $\sigma$ in the Nickel clad/800H base system for the gradient load case. . . . . . . . . . . . . . . . .

4.9 Design chart plotting the difference in the average creep damage, $\left\{\bar{D}_{\mathrm{c}}\right\}_{\text {infinite compliance }}-$ $\left\{\bar{D}_{\text {c }}\right\}_{\text {full inelastic }}$, in the base region during the hold of the last cycle (a) and the minimum difference of ASME equivalent strain range, $\{\Delta \varepsilon\}_{\text {infinite compliance }}-\{\Delta \varepsilon\}_{\text {full inelastic }}$, in the clad region over the last cycle as a function of $E$ and $\alpha$ in the Nickel clad/800H base system for the gradient load case. . . . . . . . . . . . . . . . . 30

4.10 Design chart plotting the difference in the average creep damage, $\left\{\bar{D}_{\text {c }}\right\}_{\text {infinite compliance }}-$ $\left\{\bar{D}_{\mathrm{c}}\right\}_{\text {full inelastic }}$, in the base region during the hold of the last cycle (a) and minimum difference of ASME equivalent strain range, $\{\Delta \varepsilon\}_{\text {infinite compliance }}-\{\Delta \varepsilon\}_{\text {full inelastic }}$, in the clad region over the last cycle as a function of $E$ and $\dot{\varepsilon}$ in the Nickel clad/800H base system for the gradient load case. . . . . . . . . . . . . . . . . .

4.11 Design chart plotting the difference in the average creep damage, $\left\{\bar{D}_{\mathrm{c}}\right\}_{\text {infinite compliance }}-$ $\left\{\bar{D}_{\mathrm{c}}\right\}_{\text {full inelastic }}$, in the base region during the hold of the last cycle (a) and the minimum difference of ASME equivalent strain range, $\{\Delta \varepsilon\}_{\text {infinite compliance }}-\{\Delta \varepsilon\}_{\text {full inelastic }}$, in the clad region over the last cycle as a function of $\sigma$ and $\alpha$ in the Nickel clad/800H base system for the gradient load case. . . . . . . . . . . . . . . . .

4.12 Design chart plotting the difference in the average creep damage, $\left\{\bar{D}_{\mathrm{c}}\right\}_{\text {infinite compliance }}-$ $\left\{\bar{D}_{\mathrm{c}}\right\}_{\text {full inelastic }}$, in the base region during the hold of the last cycle (a) and the minimum difference of ASME equivalent strain range, $\{\Delta \varepsilon\}_{\text {infinite compliance }}-\{\Delta \varepsilon\}_{\text {full inelastic }}$, in the clad region over the last cycle as a function of $\sigma$ and $\dot{\varepsilon}$ in the Nickel clad/800H base system for the gradient load case. . . . . . . . . . . . . . . . .

4.13 Design chart plotting the difference in the average creep damage, $\left\{\bar{D}_{\mathrm{c}}\right\}_{\text {infinite compliance }}{ }^{-}$ $\left\{\bar{D}_{\mathrm{c}}\right\}_{\text {full inelastic }}$, in the base region during the hold of the last cycle (a) and the minimum difference of ASME equivalent strain range, $\{\Delta \varepsilon\}_{\text {infinite compliance }}-\{\Delta \varepsilon\}_{\text {full inelastic }}$, in the clad region over the last cycle as a function of $\alpha$ and $\dot{\varepsilon}$ in the Nickel clad/800H base system for the gradient load case. . . . . . . . . . . . . .

4.14 ASME equivalent strain range, plotted over the vessel thickness, over the last cycle for the gradient load case (a) and the isothermal load case (b). The figure compares the full inelastic analysis with the bounding, infinite compliance analysis in the Nickel clad $/ 800 \mathrm{H}$ base system. . . . . . . . . . . . . . . . . . 
4.15 (a) Sketch showing the physical location of the stress relaxation profiles and (b) the figure compares the stress relaxation profiles between the full inelastic (dashed lines) and infinite compliance analysis (solid lines) for the thermal gradient load in the Nickel clad $/ 800 \mathrm{H}$ base system. . . . . . . . . . . . . . . . . . .

4.16 (a) Sketch showing the physical location of the stress relaxation profiles and (b) the figure compares the stress relaxation profiles between the full inelastic (dashed lines) and infinite compliance analysis (solid lines) for the isothermal load in the Nickel clad $/ 800 \mathrm{H}$ base system. . . . . . . . . . . . . . . . . . . . . .

4.17 Design chart illustrating the difference in the average creep damage, $\left\{\bar{D}_{\mathrm{c}}\right\}_{\text {elastic cladding }}-$ $\left\{\bar{D}_{\mathrm{c}}\right\}_{\text {full inelastic }}$, in the base region during the hold of the last cycle (a) and the minimum difference of ASME equivalent strain range, $\{\Delta \varepsilon\}_{\text {elastic cladding }}-\{\Delta \varepsilon\}_{\text {full inelastic }}$, in the clad region over the last cycle (b) as a function of $E$ and $\sigma$ in the clad/800H base system for the gradient load case. . . . . . . . . . . . . . . . .

4.18 Design chart illustrating the difference in the average creep damage, $\left\{\bar{D}_{\text {c }}\right\}_{\text {elastic cladding }}-$ $\left\{\bar{D}_{\mathrm{c}}\right\}_{\text {full inelastic }}$, in the base region during the hold of the last cycle (a) and the minimum difference of ASME equivalent strain range, $\{\Delta \varepsilon\}_{\text {elastic cladding }}-\{\Delta \varepsilon\}_{\text {full inelastic }}$, in the clad region over the last cycle (b) as a function of $E$ and $\alpha$ in the clad $/ 800 \mathrm{H}$ base system for the gradient load case. . . . . . . . . . . . . . . .

4.19 Design chart illustrating the difference in the average creep damage, $\left\{\bar{D}_{\mathrm{c}}\right\}_{\text {elastic cladding }}-$ $\left\{\bar{D}_{\mathrm{c}}\right\}_{\text {full inelastic }}$, in the base region during the hold of the last cycle (a) and the minimum difference of ASME equivalent strain range, $\{\Delta \varepsilon\}_{\text {elastic cladding }}-\{\Delta \varepsilon\}_{\text {full inelastic }}$, in the clad region over the last cycle (b) as a function of $E$ and $\dot{\varepsilon}$ in the clad/800H base system for the gradient load case. . . . . . . . . . . . . . . . . . .

4.20 Design chart illustrating the difference in the average creep damage, $\left\{\bar{D}_{\mathrm{c}}\right\}_{\text {elastic cladding }}-$ $\left\{\bar{D}_{\text {c }}\right\}_{\text {full inelastic }}$, in the base region during the hold of the last cycle (a) and the minimum difference of ASME equivalent strain range, $\{\Delta \varepsilon\}_{\text {elastic cladding }}-\{\Delta \varepsilon\}_{\text {full inelastic }}$, in the clad region over the last cycle (b) as a function of $\sigma$ and $\alpha$ in the clad $/ 800 \mathrm{H}$ base system for the gradient load case. . . . . . . . . . . . . . . . . . . . . .

4.21 Design chart illustrating the difference in the average creep damage, $\left\{\bar{D}_{\mathrm{c}}\right\}_{\text {elastic cladding }}-$ $\left\{\bar{D}_{\mathrm{c}}\right\}_{\text {full inelastic }}$, in the base region during the hold of the last cycle (a) and the minimum difference of ASME equivalent strain range, $\{\Delta \varepsilon\}_{\text {elastic cladding }}-\{\Delta \varepsilon\}_{\text {full inelastic }}$, in the clad region over the last cycle (b) as a function of $\sigma$ and $\dot{\varepsilon}$ in the clad/800H base system for the gradient load case. . . . . . . . . . . . . . . . . . . . . .

4.22 Design chart illustration the difference in the average creep damage, $\left\{\bar{D}_{\mathrm{c}}\right\}_{\text {elastic cladding }}-$ $\left\{\bar{D}_{\mathrm{c}}\right\}_{\text {full inelastic }}$, in the base region during the hold of the last cycle (a) and the minimum difference of ASME equivalent strain range, $\{\Delta \varepsilon\}_{\text {elastic cladding }}-\{\Delta \varepsilon\}_{\text {full inelastic }}$, in the clad region over the last cycle (b) as a function of $\alpha$ and $\dot{\varepsilon}$ in the clad/800H base system for the gradient load case. . . . . . . . . . . . . . . . . . .

4.23 Design chart plotting the difference in the average creep damage, $\left\{\bar{D}_{\mathrm{c}}\right\}_{\text {elastic cladding }}-$ $\left\{\bar{D}_{\text {c }}\right\}_{\text {full inelastic }}$, in the base region during the hold of the last cycle (a) and the minimum difference of ASME equivalent strain range, $\{\Delta \varepsilon\}_{\text {elastic cladding }}-\{\Delta \varepsilon\}_{\text {full inelastic }}$, in the clad region over the last cycle as a function of $E$ and $\sigma$ in the TZM Molybdenum clad $/ 800 \mathrm{H}$ base system for the gradient load case. . . . . . . . . . . . 
4.24 Design chart plotting the difference in the average creep damage, $\left\{\bar{D}_{\mathrm{c}}\right\}_{\text {elastic cladding }}-$ $\left\{\bar{D}_{\mathrm{c}}\right\}_{\text {full inelastic }}$, in the base region during the hold of the last cycle (a) and the minimum difference of ASME equivalent strain range, $\{\Delta \varepsilon\}_{\text {elastic cladding }}-\{\Delta \varepsilon\}_{\text {full inelastic }}$, in the clad region over the last cycle as a function of $E$ and $\alpha$ in the TZM Molybdenum clad $/ 800 \mathrm{H}$ base system for the gradient load case. . . . . . . . . . . .

4.25 Design chart plotting the difference in the average creep damage, $\left\{\bar{D}_{\text {c }}\right\}_{\text {elastic cladding }}-$ $\left\{\bar{D}_{\mathrm{c}}\right\}_{\text {full inelastic }}$, in the base region during the hold of the last cycle (a) and the minimum difference of ASME equivalent strain range, $\{\Delta \varepsilon\}_{\text {elastic cladding }}-\{\Delta \varepsilon\}_{\text {full inelastic }}$, in the clad region over the last cycle as a function of $E$ and $\dot{\varepsilon}$ in the TZM Molybdenum clad $/ 800 \mathrm{H}$ base system for the gradient load case. . . . . . . . . . .

4.26 Design chart plotting the difference in the average creep damage, $\left\{\bar{D}_{\mathrm{c}}\right\}_{\text {elastic cladding }}-$ $\left\{\bar{D}_{\mathrm{c}}\right\}_{\text {full inelastic }}$, in the base region during the hold of the last cycle (a) and difference of ASME equivalent strain range, $\{\Delta \varepsilon\}_{\text {elastic cladding }}-\{\Delta \varepsilon\}_{\text {full inelastic }}$, in the clad region over the last cycle as a function of $\sigma$ and $\alpha$ in the TZM Molybdenum clad $/ 800 \mathrm{H}$ base system for the gradient load case. . . . . . . . . . . . . .

4.27 Design chart plotting the difference in the average creep damage, $\left\{\bar{D}_{\mathrm{c}}\right\}_{\text {elastic cladding }}-$ $\left\{\bar{D}_{\mathrm{c}}\right\}_{\text {full inelastic }}$, in the base region during the hold of the last cycle (a) and the minimum difference of ASME equivalent strain range, $\{\Delta \varepsilon\}_{\text {elastic cladding }}-\{\Delta \varepsilon\}_{\text {full inelastic }}$, in the clad region over the last cycle as a function of $\sigma$ and $\dot{\varepsilon}$ in the TZM Molybdenum clad $/ 800 \mathrm{H}$ base system for the gradient load case. . . . . . . . . . .

4.28 Design chart plotting the difference in the average reep damage, $\left\{\bar{D}_{\text {c }}\right\}_{\text {elastic cladding }}-$ $\left\{\bar{D}_{\mathrm{c}}\right\}_{\text {full inelastic }}$, in the base region during the hold of the last cycle (a) and the minimum difference of ASME equivalent strain range, $\{\Delta \varepsilon\}_{\text {elastic cladding }}-\{\Delta \varepsilon\}_{\text {full inelastic }}$, in the clad region over the last cycle as a function of $\alpha$ and $\dot{\varepsilon}$ in the TZM Molybdenum clad $/ 800 \mathrm{H}$ base system for the gradient load case. . . . . . . . . . . . . .

4.29 ASME equivalent strain range, plotted over the vessel thickness, over the last cycle in the TZM Molybdenum clad/800H base system for the gradient load case (a) and the isothermal load case (b). The figure compares the full inelastic analysis with the bounding, elastic cladding analysis. . . . . . . . . . . . . .

4.30 a) Sketch showing the physical location of the stress relaxation profiles and b) the figure compares the stress relaxation profiles between the full inelastic (dashed lines) and infinite compliance analysis (solid lines) in the TZM Molybdenum clad/800H base system for the thermal gradient load. . . . . . . . . . . . . . . . . . .

4.31 a) Sketch showing the physical location of the stress relaxation profiles and b) the figure compares the stress relaxation profiles between the full inelastic (dashed lines) and infinite compliance analysis (solid lines) in the TZM Molybdenum clad/800 base system for the isothermal load. . . . . . . . . . . . . . . . .

4.32 Design chart illustrating the difference in the average creep damage, $\left\{\bar{D}_{\mathrm{c}}\right\}_{\text {infinite compliance }}-$ $\left\{\bar{D}_{\text {c }}\right\}_{\text {full inelastic }}$, in the base region during the hold of the last cycle (a) and the minimum difference of ASME equivalent strain range, $\{\Delta \varepsilon\}_{\text {infinite compliance }}-\{\Delta \varepsilon\}_{\text {full inelastic }}$, in the ID and OD clad regions over the last cycle (b) as a function of $E$ and $\sigma$ in the clad $/ 316 \mathrm{H}$ base system for the gradient load case. . . . . . . . . . . 
4.33 Design chart illustrating the difference in the average creep damage, $\left\{\bar{D}_{\mathrm{c}}\right\}_{\text {infinite compliance }}-$ $\left\{\bar{D}_{\text {c }}\right\}_{\text {full inelastic }}$, in the base region during the hold of the last cycle (a) and the minimum difference of ASME equivalent strain range, $\{\Delta \varepsilon\}_{\text {infinite compliance }}-\{\Delta \varepsilon\}_{\text {full inelastic }}$, in the ID and OD clad regions over the last cycle (b) as a function of $E$ and $\alpha$ in the clad $/ 316 \mathrm{H}$ base system for the gradient load case. . . . . . . . . . . . . . . . 44

4.34 Design chart illustrating the difference in the average creep damage, $\left\{\bar{D}_{\mathrm{c}}\right\}_{\text {infinite compliance }}-$ $\left\{\bar{D}_{\mathrm{c}}\right\}_{\text {full inelastic }}$, in the base region during the hold of the last cycle (a) and the minimum difference of ASME equivalent strain range, $\{\Delta \varepsilon\}_{\text {infinite compliance }}-\{\Delta \varepsilon\}_{\text {full inelastic }}$, in the ID and OD clad regions over the last cycle (b) as a function of $E$ and $\dot{\varepsilon}$ in the clad $/ 316 \mathrm{H}$ base system for the gradient load case. . . . . . . . . . . . . . . . 44

4.35 Design chart illustrating the difference in the average creep damage, $\left\{\bar{D}_{\mathrm{c}}\right\}_{\text {infinite compliance }}-$ $\left\{\bar{D}_{\text {c }}\right\}_{\text {full inelastic }}$, in the base region during the hold of the last cycle (a) and the minimum difference of ASME equivalent strain range, $\{\Delta \varepsilon\}_{\text {infinite compliance }}-\{\Delta \varepsilon\}_{\text {full inelastic }}$, in the ID and OD clad regions over the last cycle (b) as a function of $\sigma$ and $\alpha$ in the clad/316H base system for the gradient load case. . . . . . . . . . . . . 45

4.36 Design chart illustrating the difference in the average creep damage, $\left\{\bar{D}_{\mathrm{c}}\right\}_{\text {infinite compliance }}-$ $\left\{\bar{D}_{\mathrm{c}}\right\}_{\text {full inelastic }}$, in the base region during the hold of the last cycle (a) and the minimum difference of ASME equivalent strain range, $\{\Delta \varepsilon\}_{\text {infinite compliance }}-\{\Delta \varepsilon\}_{\text {full inelastic }}$, in the ID and OD clad regions over the last cycle (b) as a function of $\sigma$ and $\dot{\varepsilon}$ in the clad $/ 316 \mathrm{H}$ base system for the gradient load case. . . . . . . . . . . . . . . 45

4.37 Design chart illustration the difference in the average creep damage, $\left\{\bar{D}_{\mathrm{c}}\right\}_{\text {infinite compliance }}-$ $\left\{\bar{D}_{\mathrm{c}}\right\}_{\text {full inelastic }}$, in the base region during the hold of the last cycle (a) and minimum difference of ASME equivalent strain range, $\{\Delta \varepsilon\}_{\text {infinite compliance }}-\{\Delta \varepsilon\}_{\text {full inelastic }}$, in the ID and OD clad regions over the last cycle (b) as a function of $\alpha$ and $\dot{\varepsilon}$ in the clad $/ 316 \mathrm{H}$ base system for the gradient load case. . . . . . . . . . . . .

4.38 Design chart plotting the difference in the average creep damage, $\left\{\bar{D}_{\mathrm{c}}\right\}_{\text {infinite compliance }}-$ $\left\{\bar{D}_{\mathrm{c}}\right\}_{\text {full inelastic }}$, in the base region during the hold of the last cycle (a) and the minimum difference of ASME equivalent strain range, $\{\Delta \varepsilon\}_{\text {infinite compliance }}-\{\Delta \varepsilon\}_{\text {full inelastic }}$, in the ID and OD clad regions over the last cycle as a function of $E$ in the Nickel $\mathrm{clad} / 316 \mathrm{H}$ base system for the gradient load case. . . . . . . . . . . . . . .

4.39 Design chart plotting the difference in the average creep damage, $\left\{\bar{D}_{\mathrm{c}}\right\}_{\text {infinite compliance }}-$ $\left\{\bar{D}_{\mathrm{c}}\right\}_{\text {full inelastic }}$, in the base region during the hold of the last cycle (a) and the minimum difference of ASME equivalent strain range, $\{\Delta \varepsilon\}_{\text {infinite compliance }}-\{\Delta \varepsilon\}_{\text {full inelastic }}$, in the ID and OD clad regions over the last cycle as a function of $E$ and $\alpha$ in the Nickel clad/316H base system for the gradient load case. . . . . . . . . . . . . . 47

4.40 Design chart plotting the difference in the average creep damage, $\left\{\bar{D}_{\mathrm{c}}\right\}_{\text {infinite compliance }}-$ $\left\{\bar{D}_{\mathrm{c}}\right\}_{\text {full inelastic }}$, in the base region during the hold of the last cycle (a) and the minimum difference of ASME equivalent strain range, $\{\Delta \varepsilon\}_{\text {infinite compliance }}-\{\Delta \varepsilon\}_{\text {full inelastic }}$, in the ID and OD clad regions over the last ycle as a function of $E$ and $\dot{\varepsilon}$ in the Nickel clad $/ 316 \mathrm{H}$ base system for the gradient load case. . . . . . . . . . . . . .

4.41 Design chart plotting the difference in the average creep damage, $\left\{\bar{D}_{\mathrm{c}}\right\}_{\text {infinite compliance }}-$ $\left\{\bar{D}_{\text {c }}\right\}_{\text {full inelastic }}$, in the base region during the hold of the last cycle (a) and the minimum difference of ASME equivalent strain range, $\{\Delta \varepsilon\}_{\text {infinite compliance }}-\{\Delta \varepsilon\}_{\text {full inelastic }}$, in the ID and OD clad regions over the last cycle as a function of $\sigma$ and $\alpha$ in the Nickel clad $/ 316 \mathrm{H}$ base system for the gradient load case. . . . . . . . . . . 
4.42 Design chart plotting the difference in the average creep damage, $\left\{\bar{D}_{\mathrm{c}}\right\}_{\text {infinite compliance }}-$ $\left\{\bar{D}_{\text {c }}\right\}_{\text {full inelastic }}$, in the base region during the hold of the last cycle (a) and the minimum difference of ASME equivalent strain range, $\{\Delta \varepsilon\}_{\text {infinite compliance }}-\{\Delta \varepsilon\}_{\text {full inelastic }}$, in the ID and OD clad regions over the last cycle as a function of $\sigma$ and $\dot{\varepsilon}$ in the Nickel clad $/ 316 \mathrm{H}$ base system for the gradient load case. . . . . . . . . . . . . .

4.43 Design chart plotting the difference the average creep damage, $\left\{\bar{D}_{\mathrm{c}}\right\}_{\text {infinite compliance }}{ }^{-}$ $\left\{\bar{D}_{\mathrm{c}}\right\}_{\text {full inelastic }}$, in the base region during the hold of the last cycle (a) and the minimum difference of ASME equivalent strain range, $\{\Delta \varepsilon\}_{\text {infinite compliance }}-\{\Delta \varepsilon\}_{\text {full inelastic }}$, in the ID and OD clad regions over the last cycle as a function of $\alpha$ and $\dot{\varepsilon}$ in the Nickel clad/316H base system for the gradient load case. . . . . . . . . . . . . .

4.44 Design chart illustrating the difference in the average creep damage, $\left\{\bar{D}_{\mathrm{c}}\right\}_{\text {elastic cladding }}-$ $\left\{\bar{D}_{\text {c }}\right\}_{\text {full inelastic }}$, in the base region during the hold of the last cycle (a) and the minimum difference of ASME equivalent strain range, $\{\Delta \varepsilon\}_{\text {elastic cladding }}-\{\Delta \varepsilon\}_{\text {full inelastic }}$, in the ID and OD clad regions over the last cycle (b) as a function of $E$ and $\sigma$ in the clad $/ 316 \mathrm{H}$ base for the gradient load case. . . . . . . . . . . . . .

4.45 Design chart illustrating the difference in the average creep damage, $\left\{\bar{D}_{\mathrm{c}}\right\}_{\text {elastic cladding }}-$ $\left\{\bar{D}_{\mathrm{c}}\right\}_{\text {full inelastic }}$, in the base region during the hold of the last cycle (a) and the minimum difference of ASME equivalent strain range, $\{\Delta \varepsilon\}_{\text {elastic cladding }}-\{\Delta \varepsilon\}_{\text {full inelastic }}$, in the ID and OD clad regions over the last cycle (b) as a function of $E$ and $\alpha$ in the clad $/ 316 \mathrm{H}$ base system for the gradient load case. . . . . . . . . . . . .

4.46 Design chart illustrating the difference in the average creep damage, $\left\{\bar{D}_{\mathrm{c}}\right\}_{\text {elastic cladding }}-$ $\left\{\bar{D}_{\mathrm{c}}\right\}_{\text {full inelastic }}$, in the base region during the hold of the last cycle (a) and the minimum difference of ASME equivalent strain range, $\{\Delta \varepsilon\}_{\text {elastic cladding }}-\{\Delta \varepsilon\}_{\text {full inelastic }}$, in the ID and OD clad regions over the last cycle (b) as a function of $E$ and $\dot{\varepsilon}$ in the clad $/ 316 \mathrm{H}$ base sytem for the gradient load case. . . . . . . . . . . . . .

4.47 Design chart illustrating the difference in the average creep damage, $\left\{\bar{D}_{\mathrm{c}}\right\}_{\text {elastic cladding }}-$ $\left\{\bar{D}_{\mathrm{c}}\right\}_{\text {full inelastic }}$, in the base region during the hold of the last cycle (a) and the minimum difference of ASME equivalent strain range, $\{\Delta \varepsilon\}_{\text {elastic cladding }}-\{\Delta \varepsilon\}_{\text {full inelastic }}$, in the ID and OD clad regions over the last cycle (b) as a function of $\sigma$ and $\alpha$ in the clad $/ 316 \mathrm{H}$ base sytem for the gradient load case. . . . . . . . . . . . .

4.48 Design chart illustrating the difference in the average creep damage, $\left\{\bar{D}_{\mathrm{c}}\right\}_{\text {elastic cladding }}-$ $\left\{\bar{D}_{\mathrm{c}}\right\}_{\text {full inelastic }}$, in the base region during the hold of the last cycle (a) and the minimum difference of ASME equivalent strain range, $\{\Delta \varepsilon\}_{\text {elastic cladding }}-\{\Delta \varepsilon\}_{\text {full inelastic }}$, in the clad ID and OD regions over the last cycle (b) as a function of $\sigma$ and $\dot{\varepsilon}$ in the clad $/ 316 \mathrm{H}$ base sytem for the gradient load case. . . . . . . . . . . . .

4.49 Design chart illustration the difference in the average creep damage, $\left\{\bar{D}_{\text {c }}\right\}_{\text {elastic cladding }}-$ $\left\{\bar{D}_{\mathrm{c}}\right\}_{\text {full inelastic }}$, in the base region during the hold of the last cycle (a) and the minimum difference of ASME equivalent strain range, $\{\Delta \varepsilon\}_{\text {elastic cladding }}-\{\Delta \varepsilon\}_{\text {full inelastic }}$, in the ID and OD clad regions over the last cycle (b) as a function of $\alpha$ and $\dot{\varepsilon}$ in the clad $/ 316 \mathrm{H}$ base sytem for the gradient load case. . . . . . . . . . . . .

4.50 Design chart plotting the difference in the average creep damage, $\left\{\bar{D}_{\mathrm{c}}\right\}_{\text {elastic cladding }}-$ $\left\{\bar{D}_{\text {c }}\right\}_{\text {full inelastic }}$, in the base region during the hold of the last cycle (a) and the minimum difference of ASME equivalent strain range, $\{\Delta \varepsilon\}_{\text {elastic cladding }}-\{\Delta \varepsilon\}_{\text {full inelastic }}$, in the ID and OD clad regions over the last cycle as a function of $E$ and $\sigma$ in the TZM Molybdenum clad $/ 316 \mathrm{H}$ base sytem for the gradient load case. . . . . . . . 
4.51 Design chart plotting the difference in the average creep damage, $\left\{\bar{D}_{\mathrm{c}}\right\}_{\text {elastic cladding }}-$ $\left\{\bar{D}_{\mathrm{c}}\right\}_{\text {full inelastic }}$, in the base region during the hold of the last cycle (a) and the minimum difference of ASME equivalent strain range, $\{\Delta \varepsilon\}_{\text {elastic cladding }}-\{\Delta \varepsilon\}_{\text {full inelastic }}$, in the ID and OD clad regions over the last cycle as a function of $E$ and $\alpha$ in the TZM Molybdenum clad/316H base sytem for the gradient load case. . . . . . . .

4.52 Design chart plotting the difference in the average creep damage, $\left\{\bar{D}_{\mathrm{c}}\right\}_{\text {elastic cladding }}-$ $\left\{\bar{D}_{\mathrm{c}}\right\}_{\text {full inelastic }}$, in the base region during the hold of the last cycle (a) and the minimum difference of ASME equivalent strain range, $\{\Delta \varepsilon\}_{\text {elastic cladding }}-\{\Delta \varepsilon\}_{\text {full inelastic }}$, in the ID and OD clad regions over the last cycle as a function of $E$ and $\dot{\varepsilon}$ in the TZM Molybdenum clad $/ 316 \mathrm{H}$ base sytem for the gradient load case. . . . . . . .

4.53 Design chart plotting the difference in the average creep damage, $\left\{\bar{D}_{\text {c }}\right\}_{\text {elastic cladding }}-$ $\left\{\bar{D}_{\mathrm{c}}\right\}_{\text {full inelastic }}$, in the base region during the hold of the last cycle (a) and the minimum difference of ASME equivalent strain range, $\{\Delta \varepsilon\}_{\text {elastic cladding }}-\{\Delta \varepsilon\}_{\text {full inelastic }}$, in the ID and OD clad regions over the last cycle as a function of $\sigma$ and $\alpha$ in the TZM Molybdenum clad/316H base sytem for the gradient load case. . . . . . . .

4.54 Design chart plotting the difference in the average creep damage, $\left\{\bar{D}_{\text {c }}\right\}_{\text {elastic cladding }}-$ $\left\{\bar{D}_{\mathrm{c}}\right\}_{\text {full inelastic }}$, in the base region during the hold of the last cycle (a) and the minimum difference of ASME equivalent strain range, $\{\Delta \varepsilon\}_{\text {elastic cladding }}-\{\Delta \varepsilon\}_{\text {full inelastic }}$, in the ID and OD clad regions over the last cycle as a function of $\sigma$ and $\dot{\varepsilon}$ in the TZM Molybdenum clad $/ 316 \mathrm{H}$ base sytem for the gradient load case. . . . . . . .

4.55 Design chart plotting the difference in the average creep damage, $\left\{\bar{D}_{\mathrm{c}}\right\}_{\text {elastic cladding }}-$ $\left\{\bar{D}_{\mathrm{c}}\right\}_{\text {full inelastic }}$, in the base region during the hold of the last cycle (a) and difference of ASME equivalent strain range, $\{\Delta \varepsilon\}_{\text {elastic cladding }}-\{\Delta \varepsilon\}_{\text {full inelastic }}$, in the ID and OD clad regions over the last cycle as a function of $\alpha$ and $\dot{\varepsilon}$ in the TZM Molybdenum clad/316H base sytem for the gradient load case. . . . . . . . . . . . .

5.1 Sample problem used in this section: an axisymmetric representation of a single tube/tubesheet interface. The tube and tubesheet are cladded on both the inside and outside surfaces, representing a intermediate heat exchanger in a MSR.

5.2 Figure plotting the equivalent strain at the tube/tube-sheet interface for the full inelastic simulation of $316 \mathrm{H}$ cladded with $\mathrm{Ni}$ (solid) versus a compliant clad analysis (dashed). . . . . . . . . . . . . . .

5.3 The equivalent strain distribution in the full and compliant clad analysis at the end of the final hold at temperature. . . . . . . . . . . . .

5.4 The equivalent stress distribution in the full and compliant clad analysis at the end of the final hold at temperature. . . . . . . . . . . . . .

5.5 Figure plotting the equivalent strain at the tube/tube-sheet interface for the full inelastic simulation of $316 \mathrm{H}$ cladded with Mo (solid) versus an elastic clad analysis (dashed). . . . . . . . . . . . . . .

5.6 The equivalent strain distribution in the full and compliant clad analysis at the end of the final hold at temperature. . . . . . . . . . . . .

5.7 The equivalent stress distribution in the full and compliant clad analysis at the end of the final hold at temperature. . . . . . . . . . . . . 
5.8 (a) Geometry of the bent heat exchanger tube, (b) thermal loading profile, (c) symmetric FE model of the tube, and (d) temperature contour at a typical instant. The tube is cladded on both the inside and outside surfaces. Simulation results are analyzed for location-1 and location- 2 as indicated in c.

5.9 Von Mises stress contours after heat up in 12th load cycle. Results are from (a) a full inelastic simulation of $316 \mathrm{H}$ cladded with $\mathrm{Ni}$ and (b) a compliant clad analysis. . . . . . . . . . . . . . . . . .

5.10 Stress components, after (a) heat up, (b) hold, and (c) cool down in 12th load cycle, across the thickness in location-1 (see Figure 5.8c). Results are from a full inelastic simulation of $316 \mathrm{H}$ cladded with $\mathrm{Ni}$ and a compliant clad analysis. 64

5.11 Stress components, after (a) heat up, (b) hold, and (c) cool down in 12th load cycle, across the thickness in location-2 (see Figure 5.8c). Results are from a full inelastic simulation of $316 \mathrm{H}$ cladded with $\mathrm{Ni}$ and a compliant clad analysis. 65

5.12 Stress relaxation profiles at different locations of clad and in (a) location-1 and (b) location-2 (see Figure 5.8c), during hold in 12th load cycle. Results are from a full inelastic simulation of $316 \mathrm{H}$ cladded with $\mathrm{Ni}$ and a compliant

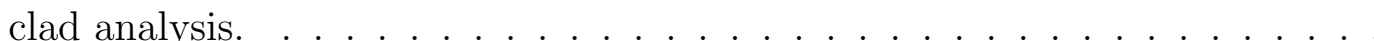

5.13 Mechanical strain components, after (a) heat up, (b) hold, and (c) cool down in 12th load cycle, across the thickness in location-1 (see Figure 5.8c). Results are from a full inela . . . . . . . . . . . . . . . .

5.14 Mechanical strain components, after (a) heat up, (b) hold, and (c) cool down in 12th load cycle, across the thickness in location-2 (see Figure 5.8c). Results are from a full inelastic simulation of $316 \mathrm{H}$ cladded with $\mathrm{Ni}$ and a compliant clad analysis.

5.15 ASME equivalent strain range, plotted over thickness in (a) location-1 and (b) location-2, for the 12 th load cycle. Results are from a full inelastic simulation of $316 \mathrm{H}$ cladded with $\mathrm{Ni}$ and a compliant clad analysis. . . . . . . . . . .

5.16 Creep damage in the base, plotted over thickness in (a) location-1 and (b) location-2, for the 12th load cycle. Results are from a full inelastic simulation of $316 \mathrm{H}$ cladded with $\mathrm{Ni}$ and a compliant clad analysis. . . . . . . . . . .

5.17 Von Mises stress contours after heat up in 30th load cycle. Results are from (a) a full inelastic simulation of $316 \mathrm{H}$ cladded with Mo and (b) an elastic clad analysis. . . . . . . . . . . . . . . . . .

5.18 Stress components, after (a) heat up, (b) hold, and (c) cool down in 30th load cycle, across the thickness in location-1 (see Figure 5.8c). Results are from a full inelastic simulation of $316 \mathrm{H}$ cladded with Mo and an elastic clad analysis.

5.19 Stress components, after (a) heat up, (b) hold, and (c) cool down in 30th load cycle, across the thickness in location-2 (see Figure 5.8c). Results are from a full inelastic simulation of $316 \mathrm{H}$ cladded with Mo and an elastic clad analysis.

5.20 Stress relaxation profiles at different locations of clad and base, in (a) location1 and (b) location-2 (see Figure 5.8c), during hold in 30th load cycle. Results are from a full inelastic simulation of $316 \mathrm{H}$ cladded with $\mathrm{Ni}$ and an elastic clad analysis. 
5.21 Mechanical strain components, after (a) heat up, (b) hold, and (c) cool down in 30th load cycle, across the thickness in location-1 (see Figure 5.8c). Results are from a full inelastic simulation of $316 \mathrm{H}$ cladded with Mo and an elastic clad analysis. . . . . . . . . . . . . . . . . .

5.22 Mechanical strain components, after (a) heat up, (b) hold, and (c) cool down in 30th load cycle, across the thickness in location-2 (see Figure 5.8c). Results are from a full inelastic simulation of $316 \mathrm{H}$ cladded with Mo and an elastic clad analysis. . . . . . . . . . . . . . . . . . .

5.23 ASME equivalent strain range, plotted over thickness in (a) location-1 and (b) location-2, for the 30th load cycle. Results are from a full inelastic simulation of $316 \mathrm{H}$ cladded with Mo and an elastic clad analysis. . . . . . . . . . .

5.24 Creep damage in the base, plotted over thickness in (a) location-1 and (b) location-2, for the 30th load cycle. Results are from a full inelastic simulation of $316 \mathrm{H}$ cladded with Mo and an elastic clad analysis. . . . . . . . . . . . 



\section{List of Tables}

2.1 Advantages and disadvantages of various creep-fatigue design approaches for compliant clads. The HBB-T column refers to the existing HBB Nonmandatory Appendix-T rules for either design by elastic or design by inelastic analysis 11

3.1 Table comparing the computational cost of the reference model using full axisymmetric analysis, the simplified 1D analysis with a full LU decomposition linear solver, and the simplified method with the specialized arrowhead solve. 21

4.1 Materials properties of base at $700^{\circ} \mathrm{C} \ldots \ldots . \ldots 24$

4.2 Materials properties of clad and their variation in reactor vessel simulations. . . . 25

4.3 Material properties of Nickel at $700^{\circ} \mathrm{C} \ldots \ldots . . \ldots 25$

4.4 Material properties of TZM Molybdenum at $700^{\circ} \mathrm{C} \ldots \ldots$. . . . . . . . . 37

4.5 Materials properties of $316 \mathrm{H}$ base at $700^{\circ} \mathrm{C} \ldots \ldots$. . . . . . . . . . . . . 42

4.6 Materials properties of clad and their variation in IHX tube simulations . . . . . 43

A.1 Nominal mechanical and thermal properties at room temperature . . . . . . . . 87

A.2 Strength properties at room temperature. UTS = Ultimate Tensile Strength . . 87

A.3 Fracture properties at room temperature . . . . . . . . . . . . . 88

A.4 Nominal mechanical and thermal properties at $700^{\circ} \mathrm{C} \ldots \ldots$. . . . . . . . 88

A.5 Strength properties at $700^{\circ} \mathrm{C}$. UTS $=$ Ultimate Tensile Strength . . . . . . . . 88

A.6 Fracture properties at $700^{0} \mathrm{C} \ldots \ldots \ldots$. . . . . . . . . . . 89

A.7 Reactivity properties . . . . . . . . . . . . . . . . . . 89 



\section{Introduction}

\subsection{Cladded components for high temperature nuclear service}

Molten salt reactors (MSRs) use corrosive salt coolant and fuel chemistries [18, 29, 41]. These coolants and fuels will necessarily be in contact with structural components which must maintain the integrity of the reactor pressure boundary under the high operating temperatures of around $700^{\circ} \mathrm{C}$. Most likely, as U.S.-based MSR would be designed to the ASME Section III, Division 5 rules for high temperature nuclear reactors [5]. The Code currently has five material qualified for Class A pressure retaining components: austenitic stainless steels $304 \mathrm{H}$ and $316 \mathrm{H}$, ferritic steel $2.25 \mathrm{Cr}-1 \mathrm{Mo}$, ferritic-martensitic steel 9Cr-1Mo (Grade 91), and austenitic high-alloy steel 800H. An in-progress Code Case will add the nickel-based Alloy 617 to the list of allowable Class A materials.

However, none of these materials are ideal for resisting corrosion when exposed to MSR salt. As such, corrosion will be a major constraint on long-life MSR designs if limited to the current Class A alloys. One option for overcoming this limitation would be to Code-qualify new, corrosion-resistant materials for Class A service. However, the process of Code qualifying a new material is lengthy and expensive, requiring long-term creep and creep-rupture test data. MSR designers have a near-term need for corrosion resistant, high temperature nuclear components. This near-term need would preclude qualifying new Class A materials.

An alternative would be to allow designers to clad an existing Class A base material with some corrosion resistant clad material. The idea would be the Class A material would resist the elevated-temperature structural loads while the clad only serves to protect the base material from the corrosive coolant. Because the clad does not carry the structural load, this approach could avoid the long-term testing required to Code qualify a new material.

The nuclear industry has experience with cladded vessels for light water reactors (LWRs). LWR reactor vessels are typically made from carbon steel clad with a stainless steel layer in contact with the reactor coolant water. Additional information can be gleaned from the practices of the high-temperature petro-chemical industry. However, there is no set of design rules currently suitable for designing cladded components for elevated temperature nuclear service. This report begins to address this deficiency.

The goal for a set of design rules is to be as independent as possible as to the selection of a clad material. This would allow designers full flexibility in choosing a material suitable for their coolant or fuel chemistries and the structural details of their reactor system. However, both practical design considerations and the available salt chemistries tend to limit the types of clad materials. Chapter 2 discusses this in further detail, but this report focuses on two types of clads: elastic clads, exemplified by refractory metals and refractory metal alloys and compliant clads, exemplified by nickel or high nickel alloys.

\subsection{Existing rules in Section III, Division 5}

There are existing rules for rule temperature nuclear cladded components in Section III, Division 5 of the ASME Boiler and Pressure Vessel Code [5]. HBB-2121(c) allows the use of materials that do not meet the HBB material specifications if they are used as clads with thicknesses less than $10 \%$ of the vessel wall. This provision allows the approach described above, which avoids the long term testing required to Code qualify a material for Class 
A components. The HBB stress classification tables provide guidance on classifying thermal stresses arises through differential thermal expansion. Specifically, the table suggests classifying such stresses as peak. Finally, HBB-3227.8 contains three relevant provisions:

1. When designing a cladded component for primary load ignore the clad material - do not attribute any material strength to it.

2. Similarly, ignore the clad in buckling design.

3. However, the designer must consider the clad and the interaction of the clad and base materials when designing the vessel to meet the Division 5 deformation controlled quantity limits - creep-fatigue damage and ratcheting strain accumulation.

The third provision is the most significant. It requires designing the clad/base system to meet the Code creep-fatigue and ratcheting strain limits. However, it provides no design rules. This report begins to address this gap. The goal is then to develop a set of design rules that ensure both clad and base material integrity under long term, high temperature service, with the added constraint of not requiring long-term testing.

This report addresses a portion of the challenge of developing design rules for cladded elevated temperature nuclear components by assessing the mechanical interaction of the base and clad materials in prototypical reactor components. The goal is to assess the impact of adding a clad on the base material system to determine if the clad could negatively affect the mechanical integrity of the base. Additionally, we aim to develop design analysis methods that reasonably represent or bound the mechanical response of the base and the clad materials without requiring long term test data to establish a constitutive model for the clad.

\subsection{Report Overview}

As described in Chapter 2, we divide clads into three categories: elastic, compliant, and neither. For the first two this report develops simplified analysis rules that bound the structural response of the system without requiring long-term creep constitutive properties for prospective clads. Chapter 2 also discusses potential routes towards full design rules leveraging existing Section III, Division 5 methods [3-5].

To determine the effectiveness of these analysis methods and to determine the range of applicability for the elastic and compliant design strategies, Chapter 3 develops a simplified, 1D model of a cladded cylindrical vessel or pipe section. Chapter 4 then uses this simplified model to run high-throughput simulations of thousands of combinations of base/clad material properties and structural loading to determine the range of validity of the elastic and compliant analysis approximations. Chapter 5 further verifies the proposed analysis strategies by running full-scale axisymmetric and 3D analyses of representative cladded reactor components. Finally, Chapter 6 summarizes the conclusions of this report and discusses future work on developing design rules for cladded, high temperature, nuclear components. An appendix to the report summarizes material properties of several prospective clad materials to assess the suitability from the mechanical point of view only, i.e. not considering chemical interaction with the MSR salts. 


\subsection{Bonding methods}

Several bonding or deposition methods are feasible for joining the clad and base materials. This section is not intended to be a comprehensive review of available options, but rather to note the feasibility of bonding potential materials of interest. There are two general categories of materials of interest for high temperature MSR clads: pure, ductile materials like nickel and refractory metals and refractory metal alloys.

Weld overlay clads are formed by depositing weld material through relatively standard fusion welding processes on top of the base layer. This method is widely used in the petrochemical industry and has been demonstrated for stainless steel [53] and nickel [17] clads. Welding refractories, like molybdenum [57], is notoriously challenging so the weld overlay process may not be well suited for these materials.

Coextrusion/roll bonding processes use hot work to bond two materials. The process has been demonstrated cladding stainless steel on carbon steel [32] and aluminium and other pure materials, including nickel, on stainless steel [49]. Corolled plates are commercially available with nickel cladding. Coextrusion processes have been demonstrated with refractory and refractory alloy metals, particularly focusing on thin clad canning applications [10, 26].

Explosion bonding using a controlled high-explosive detonation to bond two materials, essentially by flowing the materials into one another by jetting mechanisms at the shock front $[9,14]$. The process has been demonstrated for a wide variety of materials, including refractory metals [58].

Cold spray processes jet a powder of a metallic material onto the surface of another material using a supersonic gas to carry the metal powder [37]. The process has been demonstrated for many materials, from pure metals, including refractory and reactive metals, to complex alloys [51].

This section did not attempt to sample the full variety of available technologies, which include many novel advanced manufacturing techniques in addition to the more established methods $[34,40,52]$. The point is to demonstrate that available commercial technologies can produce cladded components using the clad materials of interest for high temperature, MSR applications. The strength and reliability of the interfaces produced by these technologies remains to be evaluated, particularly for high temperature service. This report focuses instead on the integrity and mechanical interaction of the base and clad materials assuming a perfect interface. 



\section{Bounding analysis strategies and conceptual design methods for cladded components}

The introduction describes a near-term need for design rules for elevated temperature cladded nuclear components. A design method for cladded components to be embedded in the ASME Section III, Division 5 rules should guard against the six failure modes considered by the Code:

1. Time-independent plastic instability

2. Time-dependent creep-rupture

3. Creep-fatigue damage

4. Time-dependent cyclic excessive deformation (ratcheting)

5. Time-independent buckling

6. Time-dependent buckling.

A potential design method should guard against these failure modes in both the base and clad material and should account for the mechanical interaction of the base and clad in the composite system.

Additionally, in the clad there are additional potential failure modes not fully considered in the existing rules

1. Failure of the clad/base interface

2. Brittle failure of non-ductile clad materials.

The goal of this work is to develop a design method to prevent these potential failure modes without requiring long term testing on clad materials. A complete design method has two components: a method of analysis and design checks on the analysis results to guard against each potential failure mode. In principal a design method might "mix and match" using different combinations of analysis methods and design checks to guard against each individual failure mode. However, in general existing design methods use a common analysis approach and then individual design checks.

In the context of cladded components the analysis method must account for the mechanical interaction of the base and clad materials - how the clad material affects the structural response of the base material without clad and vice-versa. The development of such an analysis method is the primary focus of this report. For design checks and rules the report is limited to a general evaluation of the merits of different approaches.

\subsection{Analysis methods}

A general goal for a design analysis method is simplicity. A designer will need to analyze many structural components for many combinations of loading conditions. The second objective for a clad analysis method set out here is to avoid long term testing of clad materials. 
This requirement limits the type of analysis that could be done for the clad material, as constitutive models for creep cannot be calibrated without long-term test data.

The general analysis strategies described here are independent to the particular, final design analysis approach. Section III, Division 5 and associated nuclear Code Cases describe three potential methods of analysis:

1. Design by elastic analysis

2. Design by elastic perfectly plastic (EPP) analysis

3. Design by inelastic analysis.

The analysis strategies developed here could be used for any three of these options. The key question addressed in this subsection is how to treat the clad material in the general sense if long term clad material properties are unavailable.

The subsequent subsections describe three types of clad/base systems: elastic clads, compliant clads, and intermediate cases which do not fall into either of the first two categories. These general categories are expanded into particular ranges of clad/base material property mismatches in subsequent chapters. Each subsection describes the types of clad/base materials that might fall into the category and a general method of analyzing the particular type of material system that could, conceptually, be put into practice in any of the three existing Division 5 design methods.

\subsubsection{Elastic clads}

In general, an elastic clad has a higher yield stress and generally plastically deforms at higher flow stresses than the base material and creeps slower than the base material. Examples of these types of clad materials, relative to the HBB Class A materials, might refractory metals including tungsten and its alloys, molybdenum and its alloys, and potentially some reactive metals.

The method we propose to analyze these types of systems is to treat the clad material as linear elastic. The base material constitutive response would be the standard representation for the underlying design method: elastic for design by elastic analysis, elastic perfectly plastic for EPP, and inelastic for design by inelastic analysis.

Clearly, this proposed analysis method does not require long term material properties. The only properties required to conduct the analysis are the clad elastic and thermalmechanical properties at temperature, measured through standard short term tests. The accuracy of this method will depend on linear elasticity representing the actual material response of the clad material, hence the requirement that the clad material have a higher yield stress and lower creep rate than the base material. Subsequent chapters assess the accuracy of this design approach for generic base/clad material systems and for particular materials of interest.

In additional to the traditional elevated temperature modes, elastic clad design must also consider the possibility of brittle failure in the clad. A subsequent subsection discusses this failure mode. 

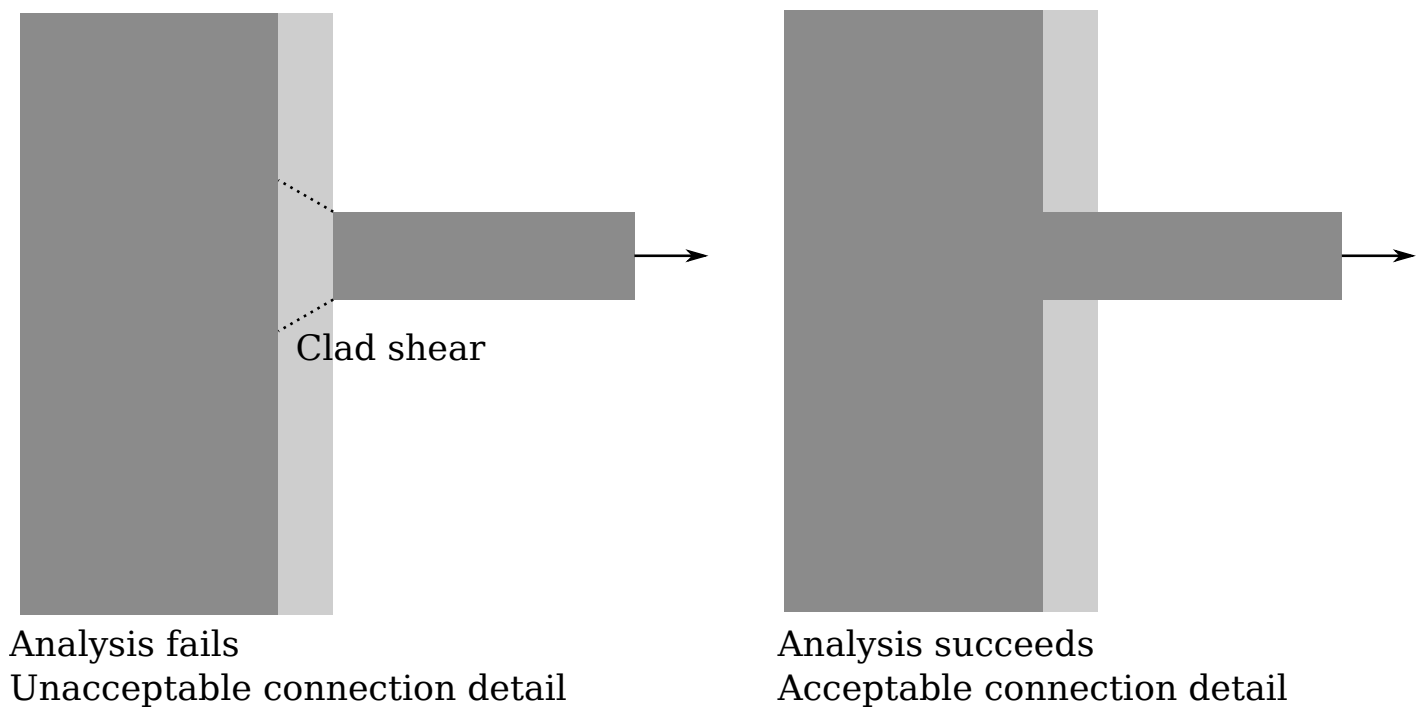

Figure 2.1: Example of a connection detail that would fail the compliant clad analysis and a corresponding design fix. The connection on the left requires the clad material to bear shear to transmit the load from the two base material sections. A compliant analysis of this system would fail as it would predict infinite deformation in the clad. The connection detail on the right resolves the issue by transmitting the force directly into the base material. The compliant analysis method prevents designers from making an actual design mistake: relying on the clad material strength.

\subsubsection{Compliant clads}

A compliant clad is essentially the opposite of an elastic clad. Relative to the base material the clad has a lower yield stress, flow stress and creeps faster. Examples of these types of clads include pure materials like nickel as well as alloys with relatively low creep resistance.

Additionally, compliance depends on the thickness of the clad. Very thin clads, even if relatively rigid, will be compliant relative to the effective stiffness of the base material. The analysis in this report does not consider this effect. Instead it focuses on the bounding case of a $10 \%$ thick clad, the upper limit currently implemented in Section III, Division 5. With the clad thickness fixed the compliance of the clad depends only material properties. However, a complete set of design rules should also allow designers to use the compliant rules for very thin clads.

To analyze these types of clad materials we propose to entirely neglect the strength of the material. The effect of this approximation is to treat clad material as a compressible inviscid fluid. The only material property required to define this constitutive model is the actual material bulk modulus - available without long term testing.

This approximation has a significant consequence: the clad can only transmit pressure loads. If the design requires the clad to carry shear stresses the analysis will predict infinite deformation at that location. This is a positive feature of the proposed method as it actively prevents a designer from relying on the strength of the clad. Figure 2.1 shows a design example of the consequences of this approximation. 
While the compliant clad cannot transmit shear it can transmit pressure from the surface of the clad to the surface of the base. Depending on the position of the clad (i.e. inside or outside diameter of a vessel or pipe) this may either increase or decrease the effective pressure on the base material, essentially accounting for the difference in pressure bearing surface area caused by the clad thickness.

This compliant clad approximation can also be used as a bookkeeping method for tracking the strain range in the clad material. The clad model should include the effects of thermal expansion in the clad. The induced thermal strains and stresses are volumetric and so the fluid/compliant clad can withstand and transmit them. Tracking these strains will be important for clad creep-fatigue design, as described below. Defining the thermal strains in the clad requires the clad coefficient of thermal expansion, available from short term testing.

Designers have several options for implementing the compliant clad/fluid approach in an analysis:

1. Remove the clad entirely from the structural model and adjust the applied pressures on the base to account for the differences in load resisting surface area. Manually track the thermal strain in the clad. This approach is only suitable for hand calculations and requires extensive bookkeeping to track thermal expansion.

2. Use a special finite element formulation to model the clad as an inviscid, compressible fluid and the base as a standard solid.

3. Use a standard solid element method and model the clad as an elastic perfectly-plastic material with a very small, near zero yield stress and the actual clad material elastic and thermal properties.

All of these approaches are approximately equivalent. This report adopts the third approach in all the simulations presented here. Standard plasticity implementations cannot accommodate a true zero yield stress so the designer must select some small, non-zero value. Additional work may be required to set guidelines on selecting this fictitious yield stress.

As with the elastic clad approach the base material constitutive response in the analysis will conform to the underlying design method: elastic, EPP, or inelastic.

No material is in actuality perfectly compliant. Therefore, this analysis method relies on bounding the response of the actual material, rather than accurately representing its response in service. Subsequent chapters evaluate this bounding analysis approach for various types of clad/base systems. Overall, it produces conservative analysis results, particularly for strain ranges used in computing creep-fatigue damage. Fundamentally, the more compliant the clad material the more accurate the assumption of treating it as if it has zero strength. However, underestimating the strength of the compliant clad material tends to overestimate the strains in the clad material, which produces conservative analysis results for design calculations. Similarly, actual clad materials will have some effect on the base material even if the clad has very low strength. Therefore, the compliant analysis neglects some interaction between the base and clad system. Again, the compliant approximation tends to overestimate the design quantities of interest in the base material by entirely neglecting any resistance to deformation provided by the clad. As such, the compliant analysis method tends to produce conservative design predictions. 


\subsubsection{Intermediate cases}

The remaining types of clad/base systems are those that do not fall into either the elastic or compliant categories. Examples of these types of systems might be a Class A material cladded with a different Class A material. It would be difficult to develop a method of analysis or design for these types of intermediate cases that does not require long term material testing. Because the creep and plastic flow characteristics of the two materials will be relatively similar there are no obvious approximate ways to analyze the clad material, like for the elastic and compliant clads. As such, for these types of systems long term material testing and properties will be required.

\subsection{Conceptual design methods}

The previous section describes methods of analysis that, for two particular types of cladded systems, avoid requiring long term material properties and corresponding long term test programs. The rest of this report justifies these analysis approaches through comparative simulations. In addition to these analysis methods a complete design method would require design checks to guard against the failure modes described above. Of course ideally these design checks would also not require long term material properties or long term testing. The following section describes potential approaches for elastic and compliant clad systems relative to both the existing ASME design approaches and a new approach based on Simplified Model Tests (SMT), described in more detail in other publications and DOE reports $[42,54-56]$.

\subsubsection{Primary load design and buckling}

\subsubsection{Elastic clads}

In primary load and buckling design the elastic clad analysis approach assumes the clad remains linear elastic and can fail only under short-term failure modes, namely time-independent plastic instability and time-independent buckling. The material properties required to evaluate these design checks from the analysis results are short-term properties that can be determined from standard tension tests, notably the material yield stress. The underlying assumption here is that the clad material does not creep and therefore cannot undergo creep-rupture.

One potential concern is stress redistribution over time from the base to the clad. If the clad material truly does not creep, over time stress will redistribute from the base into the clad. The analysis method will need to determine the amount of this stress redistribution. This may be challenging for design by elastic analysis, which uses stress classification to approximate the stationary stress state. The classical stress classification methods were not developed to account for multimaterial components. The other two design methods - EPP and inelastic analysis - have mechanisms for accounting for this stress redistribution. However, it is an open question if the bounding theories used in constructing the proposed EPP method for primary load design, currently under discussion in the ASME Code Committees, will adequately account for or bound the redistribution. 
Even assuming that the analysis method can account for the redistribution, analyzing elastic clad systems will require a subtle change from the existing primary load and buckling design checks. The designer will need to evaluate the clad for time-independent failure modes using both the time-independent, initial stress distribution and the long-term redistributed, stationary stress distribution. That is, the clad could undergo some nominally time-independent failure mechanisms later in time as the stress state changes. Rules will needed to guard against this potential failure mode.

\subsubsection{Compliant clads}

For primary load design for compliant clads the effect of the compliant analysis approach is to neglect the clad when conducting the primary load analysis and design. As discussed in the introduction, this approach is essentially what the existing HBB design rules require. For the base material primary load design this approximation is always conservative - it entirely neglects the strength of the clad. It is also conservative for buckling design provided the clad remains fully bonded to the base material.

This leaves the question of how to address long term creep rupture in the clad itself. The compliant analysis method will not produce a realistic or bounding stress distribution in the clad material, as the clad deviatoric stress will be zero. Therefore, the only approach is to not check for long-term creep rupture in the clad. This is reasonable provided the clad does in fact creep much faster than the base. If the clad creep faster than the base it will quickly redistribute whatever stress it develops due to pressure and thermal loads onto the base material. Because it is then at a low stress level for most of the component life it should not creep rupture. Fundamentally this approach is reasonable but further work is required to determine its adequacy for designing high temperature components.

\subsubsection{Creep-fatigue and ratcheting limits}

\subsubsection{Elastic clads}

A priori elastic clad materials do not creep and therefore will not undergo creep-fatigue failure. Any of the general analysis approaches will produce a reasonable design strain range for an elastic clad. The design information required to evaluate the clad for fatigue damage is a fatigue curve. These can be generated for clad material relatively rapidly with high frequency strain controlled experiments at operating temperatures.

Similarly, ratcheting strain accumulation in the clad itself will not be a concern. The elastic clad may significantly slow ratcheting in the base/clad system as the rigid elastic clad will tend to restrain the amount of ratcheting deformation that can accumulate in the creeping base material. Evaluating the base material for ratcheting is then basically a problem of structural analysis, addressed in the previous section.

\subsubsection{Compliant clads}

Any of the existing creep-fatigue methods - HBB design by elastic analysis, HBB design by inelastic analysis, the EPP Code Case, or the in-development SMT method - could be used to analyze the base material for creep-fatigue damage. The compliant clad itself creeps and 


\begin{tabular}{|c|c|c|c|}
\hline & HBB-T & EPP & SMT \\
\hline Advantages & $\begin{array}{l}\text { - Incremental devel- } \\
\text { opment of existing } \\
\text { rules }\end{array}$ & $\begin{array}{l}\text { - Incremental devel- } \\
\text { opment of existing } \\
\text { rules }\end{array}$ & $\begin{array}{l}\text { - No creep rupture } \\
\text { tests } \\
\text { - Only uses strain } \\
\text { ranges }\end{array}$ \\
\hline Disadvantages & $\begin{array}{l}\text { - Requires fatigue } \\
\text { curves } \\
\text { - Requires short- } \\
\text { term rupture } \\
\text { - Requires creep- } \\
\text { fatigue tests }\end{array}$ & $\begin{array}{l}\text { - Requires fatigue } \\
\text { curves } \\
\text { - Requires short- } \\
\text { term rupture } \\
\text { - Requires creep- } \\
\text { fatigue tests }\end{array}$ & $\begin{array}{l}\text { - Requires creep- } \\
\text { fatigue-type } \\
\text { (SMT) tests } \\
\text { - Entirely new } \\
\text { method }\end{array}$ \\
\hline
\end{tabular}

Table 2.1: Advantages and disadvantages of various creep-fatigue design approaches for compliant clads. The HBB-T column refers to the existing HBB Nonmandatory Appendix$\mathrm{T}$ rules for either design by elastic or design by inelastic analysis

could therefore fail due to creep-fatigue damage. Therefore, the final design approach will require an explicit evaluation of creep-fatigue damage in the clad material, using the results of the compliant analysis. Table 2.1 describes the advantages and disadvantages of the four methods, focusing on long-term testing requirements. All of the methods require some form of creep rupture and/or creep-fatigue testing The key point is that the duration of these tests can be limited to a single design cycle period. None of the methods requires long term rupture data extending to the full design life of the component. Overall, the SMT approach may be the most advantageous for compliant clad systems as it only requires creep-fatiguetype tests, not rupture data, and only strain ranges analysis results which, as the subsequent chapters show, are conservatively bounded by the compliant analysis method.

Evaluating ratcheting strains in the base/clad system is again essentially a problem of structural analysis, addressed above. The compliant clad assumption is likely conservative for this design check as it neglects entirely the creep resistance of the compliant clad.

\subsubsection{Clad failure modes}

\subsubsection{Interface failure}

Interface failure is a concern for both elastic and compliant clads. Design by analysis of some kind is a possibility in assessing the reliability of the interface. The analysis approaches described here could give realistic estimates of the interface tractions that would lead to potential delamination. However, evaluating the strength of the interface will be challenging as it will depend on the details of the bonding method. The introduction surveyed a variety of potential joining methods and noted the goal of this work is a design method that is 
independent to both the choice of the clad material and the method of bonding base and clad. As such, it may be difficult to develop a design by analysis method for assessing the reliability of the clad/base interface.

Acceptance testing could be an alternative approach. This would be a standard test or series of tests on cladded specimens. The objective would be to design some test protocol for accelerated loading conditions, compared to operating conditions, so that if the bound between the base and clad materials remained intact throughout the accelerated loading it would be reliable under the lower, service loading conditions for the full component design life. The idea of this testing would be to assess only the bonding method - failure in the bulk of the base or clad material would be covered by the design methods described above. Developing such a test protocol will require a research and testing program in its own right, separate from work on design methods.

\subsubsection{Brittle failure modes}

Brittle failure is only a concern for elastic clad materials, in particular pure refractory metals. Alloys of tungsten, notably W-Re [36], and alloys of molybdenum, notably TZM [12, 44], have relatively low ductile-to-brittle transition temperatures, well below expected reactor operating conditions. Pure $\mathrm{W}[36]$ and Mo $[27,50]$ have relatively high transitions temperatures, and so brittle failure under design conditions could be a concern for these materials. The final design procedure should either ensure that the clad material selection excludes materials with high transition temperature or provide rules for evaluating brittle failure. Section III, Division 5, HBB-3241 already requires a fracture analysis for certain Class A materials. That section references Section III Nonmandatory Appendix G for guidance on how to carry out the fracture analysis. It may be sufficient to apply these design provisions to elastic clads. However, more research is required to make this determination or to provide new design guidance specific to elastic cladding. 


\section{Simplified modeling methods}

Developing design methods for cladded systems requires running a large number of numerical simulations to evaluate the response of different clad/base material combinations, structural components, and load histories. Full 3D or axisymmetric finite element simulations are too slow to evaluate hundreds or thousands of different combinations of clad/base material properties. This chapter develops a simplified, 1D analysis method for a representative cladded component that can be used to rapidly evaluate different clad/base systems.

\subsection{Developing the simplified model}

Figure 3.1 shows the representative cladded component: a cylindrical pressure vessel under internal pressure and some through-wall thermal gradient. Both the pressure and the temperature history may be time dependent and cyclic. This full problem is axisymmetric. However, away from the geometric discontinuity of the connection between the cylindrical vessel and the head the problem can be simplified to $1 \mathrm{D}$.

\subsubsection{Simplified kinematics}

Figure 3.1 also shows the kinematic simplifications made to simplify the problem to a 1D model. The essential simplification is the assumption that all the gradients with respect to $z$ become zero away from discontinuities.

The mathematical $1 \mathrm{D}$ domain is the region $r \in\left[r_{i}, r_{o}\right]$. We can divide this domain into any number of subregions, each representing a different material. We will use the notation $\left[r_{i}, r_{1}, r_{2}, \ldots, r_{n-1}, r_{n}, r_{o}\right]$ to define these subregions with subregion 1 defined by $\left[r_{i}, r_{1}\right]$, subregion 2 by $\left[r_{1}, r_{2}\right]$, etc.

To form the simplified model start with the axisymmetric strain-compatibility equations

$$
\begin{array}{llr}
\varepsilon_{r r} & = & \frac{\partial u_{r}}{\partial r} \\
\varepsilon_{\theta \theta}= & \frac{u_{r}}{r} \\
\varepsilon_{z z}= & \frac{\partial u_{z}}{\partial z} \\
\varepsilon_{r z}=\frac{1}{2}\left(\frac{\partial u_{r}}{\partial z}+\frac{\partial u_{z}}{\partial r}\right)
\end{array}
$$

and equilibrium conditions

$$
\begin{aligned}
\frac{1}{r} \frac{\partial}{\partial r}\left(r \sigma_{r r}\right)+\frac{\partial}{\partial z} \sigma_{r z}-\frac{\sigma_{\theta \theta}}{r} & =0 \\
\frac{1}{r} \frac{\partial}{\partial r}\left(r \sigma_{z r}\right)+\frac{\partial}{\partial z} \sigma_{z z} & =0
\end{aligned}
$$

The boundary conditions are the applied pressure $p$ on the inside surface

$$
\left.\sigma_{r r}\right|_{r=r_{i}}=-p,
$$




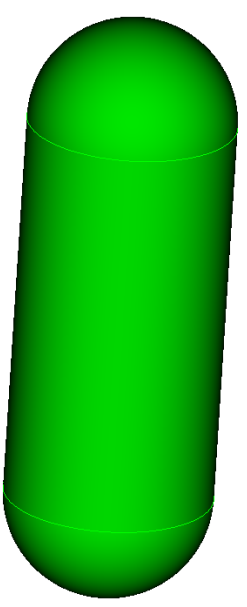

$3 \mathrm{D}$

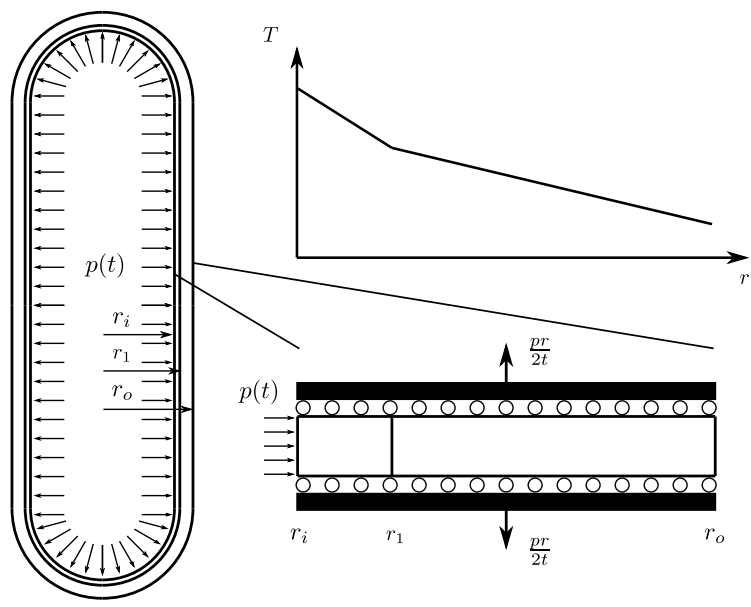

$1 \mathrm{D}$

Figure 3.1: Schematic drawing showing the model simplifications from a closed cylindrical vessel, to an axisymmetric representation, to the 1D simplified model developed here.

zero shear on the inside surface, and zero tractions on the outside surface. Additionally, the 1D axisymmetric section of the vessel must be in equilibrium with the end-cap reaction caused by the internal pressure. We will not specify axial stress distribution, but instead simply require equilibrium of net forces

$$
\frac{1}{t} \int_{r_{i}}^{r_{o}} \sigma_{z z} d r=\frac{p r_{i}}{2 t}
$$

with $t=r_{o}-r_{i}$. This integral condition allows a non-uniform axial stress distribution in the 1D section provided that the reaction force equilibrates the end-cap reaction.

Additionally, at each interface between subregions there are strain compatibility

$$
\begin{aligned}
& \left.\varepsilon_{\theta \theta}\right|_{+}=\left.\varepsilon_{\theta \theta}\right|_{-} \\
& \left.\varepsilon_{z z}\right|_{+}=\left.\varepsilon_{z z}\right|_{-}
\end{aligned}
$$

and jump-equilibrium conditions

$$
\begin{aligned}
& \left.\sigma_{r z}\right|_{+}=\left.\sigma_{r z}\right|_{-} \\
& \left.\sigma_{r r}\right|_{+}=\left.\sigma_{r r}\right|_{-} .
\end{aligned}
$$

The problem, as defined by these continuum equations, is a mixed integral-differential equation for the unknown displacement field $\mathbf{u}=\left[\begin{array}{ll}u_{r} & u_{z}\end{array}\right]$.

To simplify the axisymmetric equations, note that away from the structural discontinuity of the vessel end caps derivatives of the fields with respect to $z$ become zero

$$
\frac{\partial \sigma_{r r}}{\partial z}=\frac{\partial \sigma_{\theta \theta}}{\partial z}=\frac{\partial \sigma_{z z}}{\partial z}=\frac{\partial \sigma_{r z}}{\partial z}=0
$$




$$
\frac{\partial \varepsilon_{r r}}{\partial z}=\frac{\partial \varepsilon_{\theta \theta}}{\partial z}=\frac{\partial \varepsilon_{z z}}{\partial z}=\frac{\partial \varepsilon_{r z}}{\partial z}=0
$$

Combining equations 3.8 and 3.1

$$
\frac{\partial \varepsilon_{\theta \theta}}{\partial z}=\frac{\partial}{\partial z}\left(\frac{u_{r}}{r}\right)=0 \Longrightarrow \frac{\partial u_{r}}{\partial z}=0 .
$$

A similar simplification reduces the equilibrium equations (Eq. 3.2)

$$
\begin{aligned}
\frac{\partial \sigma_{r r}}{\partial r}+\frac{1}{r}\left(\sigma_{r r}-\sigma_{\theta \theta}\right) & =0 \\
\frac{\partial \sigma_{z r}}{\partial r}+\frac{1}{r} \sigma_{z r} & =0 .
\end{aligned}
$$

The second equilibrium equation can be solved for the shear stress distribution

$$
\sigma_{z r}=\frac{c}{r}
$$

for some constant $c$. Because the boundary conditions are zero shear tractions on both the inner and outer vessel walls the only solution to this boundary value problem is

$$
\sigma_{z r}=0 .
$$

Therefore, the shear stresses will be zero in the simplified model. The field equations themselves do not force the shear strain to zero. However, for an isotropic material if the shear stress is zero so is the shear strain. So in the simplified model

$$
\varepsilon_{z r}=0
$$

Combining equations $3.1,3.13$, and 3.9 shows that the derivative of the axial displacement in the radial direction is zero

$$
\frac{\partial u_{z}}{\partial r}=0
$$

Similarly for the gradient of the axial strain

$$
\frac{\partial \varepsilon_{z z}}{\partial r}=\frac{\partial^{2} u_{z}}{\partial z \partial r}=\frac{\partial}{\partial z}\left(\frac{\partial u_{z}}{\partial r}\right)=0
$$

Therefore, the axial strain is constant over the 1D section

$$
\varepsilon_{z z}(r)=\bar{\varepsilon}_{z z} .
$$

In Fig. 3.1 this is shown as a rigid block connecting the $z$-displacements through the 1D section.

These simplifications produce the integral-differential boundary value problem

$$
\begin{aligned}
\frac{\partial \sigma_{r r}}{\partial r}+\frac{1}{r}\left(\sigma_{r r}-\sigma_{\theta \theta}\right) & =0 \\
\left.\sigma_{r r}\right|_{r_{i}} & =-p \\
\int_{r_{i}}^{r_{o}} \sigma_{z z} d r & =\frac{p r_{i}}{2}
\end{aligned}
$$


with

$$
\begin{aligned}
\boldsymbol{\sigma} & =\left[\begin{array}{lll}
\sigma_{r r} & \sigma_{\theta \theta} & \sigma_{z z}
\end{array}\right] \\
\boldsymbol{\varepsilon} & =\left[\begin{array}{lll}
\frac{\partial u_{r}}{\partial r} & \frac{u_{r}}{r} & \bar{\varepsilon}_{z z}
\end{array}\right] .
\end{aligned}
$$

The stress is a function of the strain, as determined by some general material constitutive model. Any material model can be used. Subsequent examples use elastic, elastic-plastic, and elastic-plastic-creep material models. The unknowns to solve for are the generalized displacements

$$
\mathbf{u}=\left[\begin{array}{ll}
u_{r} & \bar{\varepsilon}_{z z}
\end{array}\right]
$$

describing the radial displacement as a function of $r$ and the constant axial strain. These equations, supplemented with the jump conditions in Eqs. 3.5 and 3.6, represent a 1D simplification of the axisymmetric cladded cylinder boundary value problem.

\subsubsection{Discretizing the problem}

To solve this problem numerically represent the continuous radial displacement field $u_{r}(r)$ with a nodal interpolation:

$$
u_{r}=\boldsymbol{N}(r) \cdot \boldsymbol{U}_{r}
$$

Select interpolation functions $N$ with compact support so that we can implement this interpolation as a 1D finite element method. The mesh is a division of the domain $r$ into a collection of regions. There is no restriction on how to divide the problem into a mesh except that material subregion boundaries (e.g. a base/clad interface) should fall at node points, not inside an element. The constant value of the axial strain, $\bar{\varepsilon}_{z z}$, supplements these nodal degrees of freedom in the discretized vector of generalized displacements $\mathbf{U}=\left[\begin{array}{ll}\mathbf{U}_{r} & \bar{\varepsilon}_{z z}\end{array}\right]$.

The discrete strain-displacement relation is

$$
\boldsymbol{\varepsilon}=\boldsymbol{B} \cdot \boldsymbol{U}_{r}+\left[\begin{array}{c}
0 \\
0 \\
\bar{\varepsilon}_{z z}
\end{array}\right]=\left[\begin{array}{c}
\boldsymbol{N}^{\prime} \\
\boldsymbol{N} / r \\
\mathbf{0}
\end{array}\right] \cdot \boldsymbol{U}_{r}+\left[\begin{array}{c}
0 \\
0 \\
\bar{\varepsilon}_{z z}
\end{array}\right]
$$

Standard 1D finite element shape functions are often defined over over a reference domain $\xi=[-1,1]$. The element strain-displacement relation is then

$$
\boldsymbol{\varepsilon}=\left[\begin{array}{c}
2 \boldsymbol{N}^{\prime} / l_{e} \\
\boldsymbol{N} / r \\
\mathbf{0}
\end{array}\right] \cdot \boldsymbol{U}_{r}+\left[\begin{array}{c}
0 \\
0 \\
\bar{\varepsilon}_{z z}
\end{array}\right]
$$

with $l_{e}$ the length of element $e$.

Use the Galerkin method to solve the differential part of the integral-differential boundary value problem. Applying integration by parts to the weak form of the 1D equilibrium equation produces

$$
\begin{array}{rlr}
\int_{r}\left[\frac{\partial \sigma_{r r}}{\partial r}+\frac{1}{r}\left(\sigma_{r r}-\sigma_{\theta \theta}\right)\right] \bar{u} d r & = & 0 \\
\int_{r}\left[\sigma_{r r} \frac{\partial \bar{u}}{\partial r}+\frac{1}{r}\left(\sigma_{\theta \theta}-\sigma_{r r}\right) \bar{u}\right] d r & = & \left.\sigma_{r r} \bar{u}\right|_{r i} ^{r o} .
\end{array}
$$


For a Galerkin method

$$
\bar{u}_{r}=\boldsymbol{N}(r) \cdot \overline{\boldsymbol{U}}_{r} .
$$

Substitute these test functions into the equilibrium equation:

$$
\int_{r}\left[\sigma_{r r} \boldsymbol{N}^{\prime}+\frac{1}{r}\left(\sigma_{\theta \theta}-\sigma_{r r}\right) \boldsymbol{N}\right] \cdot \overline{\boldsymbol{U}}_{r} d r=\left.\sigma_{r r} \boldsymbol{N} \cdot \overline{\boldsymbol{U}}_{r}\right|_{r i} ^{r o} .
$$

Applying the fundamental theorem of the calculus of variations and combining the resulting integral equation with the integral equation for the axial strains gives the discrete variational equations to solve

$$
\begin{aligned}
\int_{r}\left[\sigma_{r r} \boldsymbol{N}^{\prime}+\frac{1}{r}\left(\sigma_{\theta \theta}-\sigma_{r r}\right) \boldsymbol{N}\right] d r & = & \left.\sigma_{r r} \boldsymbol{N}\right|_{r i} ^{r_{0}} \\
\int_{r_{i}}^{r_{o}} \sigma_{z z} d r & = & \frac{p r_{i}}{2} .
\end{aligned}
$$

Because we chose interpolation functions with compact support we can write these equations as element-by-element assemblies, now using numerical quadrature to replace the continuum integrals

$$
\begin{gathered}
\sum_{e=1}^{n_{\text {elem }}} \sum_{i=1}^{n_{\text {integration }}} w_{i}\left[\sigma_{r r}\left(\boldsymbol{\varepsilon}_{i}\right) \boldsymbol{N}^{\prime}\left(\xi_{i}\right) \frac{2}{l_{e}}+\right. \\
\left.\frac{1}{r_{i}}\left(\sigma_{\theta \theta}\left(\boldsymbol{\varepsilon}_{i}\right)-\sigma_{r r}\left(\boldsymbol{\varepsilon}_{i}\right)\right) \boldsymbol{N}\left(\xi_{i}\right)\right]=\left[\begin{array}{llll}
-p & 0 & \cdots & 0
\end{array}\right] \\
\sum_{e=1}^{n_{\text {elem }}} \sum_{i=1}^{n_{\text {weight }}} w_{i} \sigma_{z z}\left(\boldsymbol{\varepsilon}_{i}\right)=\frac{p r_{i}}{2}
\end{gathered}
$$

Here $n_{\text {elem }}$ is the number of elements in the mesh, $n_{\text {integration }}$ is the number of Gauss points per finite element, $w_{i}$ are the quadrature weights, $\xi_{i}$ are the quadrature points, and $r_{i}$ is the corresponding point in global coordinates. The strains in this expression are the mechanical strains, which can be computed from the total strains using the known temperature history $T_{i}$, reference temperature $T_{0}$, and element coefficient of thermal expansion $\alpha_{i}$

$$
\boldsymbol{\varepsilon}_{i}=\left[\begin{array}{c}
2 \boldsymbol{N}^{\prime}\left(\xi_{i}\right) / l_{e} \\
\boldsymbol{N}\left(\xi_{i}\right) / r \\
\mathbf{0}
\end{array}\right] \cdot \boldsymbol{U}_{r}+\left[\begin{array}{c}
0 \\
0 \\
\bar{\varepsilon}_{z z}
\end{array}\right]-\alpha_{i}\left(T-T_{0}\right)\left[\begin{array}{l}
1 \\
1 \\
1
\end{array}\right] .
$$

In general, the constitutive model $\boldsymbol{\sigma}(\boldsymbol{\varepsilon})$ will be nonlinear. The discrete equations will then likewise be nonlinear and must be solved incrementally. From a known pressure history $p(t)$ and temperature history $T(r, t)$ divide the simulation time $t$ into discrete time steps $t_{n}$. Define the pressure and temperature profile at each time step as $p_{n+1}=p\left(t_{n+1}\right)$ and $T_{n+1}(r)=T\left(r, t_{n+1}\right)$. These time-discrete pressures and temperatures replace $p$ and $T_{i}$ in the previous equations. 
The goal of the time integration scheme is to advance the simulation from time step $t_{n}$ to time step $t_{n+1}$. We do this with a backward Euler integration scheme by solving the nonlinear residual equation

$$
\begin{gathered}
\boldsymbol{R}_{1}=\sum_{e=1}^{n_{\text {elem }}} \sum_{i=1}^{n_{\text {weight }}} w_{i} \frac{l_{e}}{2}\left[\sigma_{r r}\left(\boldsymbol{\varepsilon}_{i}\right) \boldsymbol{N}^{\prime}\left(\xi_{i}\right) \frac{2}{l_{e}}+\frac{1}{r_{i}}\left(\sigma_{\theta \theta}\left(\boldsymbol{\varepsilon}_{i}\right)\right.\right. \\
\left.\left.-\sigma_{r r}\left(\boldsymbol{\varepsilon}_{i}\right)\right) \boldsymbol{N}\left(\xi_{i}\right)\right]-\left[\begin{array}{llll}
-p_{n+1} & 0 & \cdots & 0
\end{array}\right]=\mathbf{0} \\
R_{2}=\frac{1}{t} \sum_{e=1}^{n_{\text {elem }}} \sum_{i=1}^{n_{\text {weight }}} \frac{l_{e}}{2} w_{i} \sigma_{z z}\left(\varepsilon_{i}\right)-\frac{p_{n+1} r}{2 t}=0 .
\end{gathered}
$$

using Newton's method. Define the residual vector as

$$
\boldsymbol{R}=\left[\begin{array}{ll}
\boldsymbol{R}_{1} & R_{2}
\end{array}\right]
$$

where the vector equation $\boldsymbol{R}(\mathbf{U})=\mathbf{0}$ describes the nonlinear equations to solve. Using Newton's method requires the Jacobian of this nonlinear vector equations, the derivative of the residual with respect to the generalized displacement vector. This Jacobian can be defined as the block matrix

$$
\boldsymbol{J}=\frac{\partial \boldsymbol{R}}{\partial \boldsymbol{x}}=\left[\begin{array}{ll}
\boldsymbol{J}_{11} & \boldsymbol{J}_{12} \\
\boldsymbol{J}_{21} & J_{22}
\end{array}\right] .
$$

Each block is

$$
\begin{gathered}
\boldsymbol{J}_{11}=\sum_{e=1}^{n_{\text {elem }}} \sum_{i=1}^{n_{\text {weight }}} w_{i} \frac{l_{e}}{2}\left[\frac{2}{l_{e}}\left(\boldsymbol{N}_{i}^{\prime} \otimes\left[\begin{array}{ll}
A_{r r} & A_{r \theta}
\end{array}\right]\right)+\right. \\
\left.\frac{1}{r_{i}}\left(\boldsymbol{N}_{i} \otimes\left[\begin{array}{ll}
A_{\theta r}-A_{r r} & A_{\theta \theta}-A_{r \theta}
\end{array}\right]\right)\right] \cdot \boldsymbol{B} \\
\boldsymbol{J}_{12}=\sum_{e=1}^{n_{\text {elem }}} \sum_{i=1}^{n_{\text {weight }}} w_{i} \frac{l_{e}}{2}\left[A_{r z} \boldsymbol{N}_{i}^{\prime} \frac{2}{l_{e}}+\frac{A_{\theta z}-A_{r z}}{r_{i}} \boldsymbol{N}_{i}\right] \\
\boldsymbol{J}_{21}=\sum_{e=1}^{n_{\text {elem }}} \sum_{i=1}^{n_{\text {weight }}} \frac{w_{i} l_{e}}{2 t}\left(\left[\begin{array}{ll}
A_{z r} & A_{z \theta}
\end{array}\right] \cdot \boldsymbol{B}\right) \\
J_{22}=\sum_{e=1}^{n_{\text {elem }}} \sum_{i=1}^{n_{\text {weight }}} \frac{w_{i} l_{e}}{2 t}\left[A_{z z}\right] .
\end{gathered}
$$

The matrix $\mathbf{A}$ is the material model algorithmic tangent, i.e. the derivative $\mathbf{A}=\frac{\partial \boldsymbol{\sigma}}{\partial \varepsilon}$. The subscript notation then represents components of that derivative, i.e. $A_{z z}$ is the derivative of the axial stress with respect to the axial strain. 


\subsubsection{Efficient solution methods}

Applying Newton's method requires solving a series of linear equations of the form

$$
-\mathbf{R}=\mathbf{J} \cdot \mathbf{U} .
$$

The form of the Jacobian matrix admits a special solution algorithm that is much faster than standard techniques like LU decomposition. The key observation is that block $\mathbf{J}_{11}$ of the Jacobian is tridiagonal. Existing algorithms for solving tridiagonal equations can take advantage of the structure of the matrix to vastly reduce the amount of time required to solve the system. The Jacobian overall, including the 12, 21, and 22 blocks, has a tridiagonal arrowhead structure:

$$
\left[\begin{array}{cccccc}
a_{1} & u_{2} & & & & d_{1 n} \\
l_{2} & a_{2} & u_{3} & & & d_{2 n} \\
& l_{3} & \ddots & \ddots & & \vdots \\
& & \ddots & a_{n-1} & u_{n} & d_{n-2 n} \\
& & & l_{n} & a_{n} & d_{n-1 n} \\
d_{n 1} & d_{n 2} & \cdots & d_{n n-2} & d_{n n-1} & d_{n n}
\end{array}\right]\left[\begin{array}{c}
x_{1} \\
x_{2} \\
\vdots \\
x_{n-2} \\
x_{n-1} \\
x_{n}
\end{array}\right]=\left[\begin{array}{c}
y_{1} \\
y_{2} \\
\vdots \\
y_{n-2} \\
y_{n-1} \\
y_{n}
\end{array}\right] .
$$

Write the equations in block form as

$$
\left[\begin{array}{ll}
\boldsymbol{J}_{11} & \boldsymbol{J}_{12} \\
\boldsymbol{J}_{21} & J_{22}
\end{array}\right] \cdot\left[\begin{array}{l}
\boldsymbol{x}_{1} \\
x_{2}
\end{array}\right]=\left[\begin{array}{l}
\boldsymbol{y}_{1} \\
y_{2}
\end{array}\right]
$$

Rearranging produces

$$
x_{2}=\frac{y_{2}-\boldsymbol{J}_{21} \cdot \boldsymbol{x}_{1}}{J_{22}}
$$

and

$$
\boldsymbol{y}_{1}=\boldsymbol{J}_{11} \cdot \boldsymbol{x}_{1}+\boldsymbol{J}_{12} \frac{y_{2}-\boldsymbol{J}_{21} \cdot \boldsymbol{x}_{1}}{J_{22}}
$$

or

$$
\boldsymbol{y}_{1}-\boldsymbol{J}_{12} y_{2}=\left[\boldsymbol{J}_{11}-\frac{1}{J_{22}}\left(\boldsymbol{J}_{12} \otimes \boldsymbol{J}_{21}\right)\right] \cdot \boldsymbol{x}_{1} .
$$

The Sherman-Morrison formula for a rank 1 update of a matrix $\mathbf{B}$ will be useful for solving this system:

$$
(\boldsymbol{B}+\boldsymbol{u} \otimes \boldsymbol{v})^{-1}=\boldsymbol{B}^{-1} \boldsymbol{c}-\frac{\boldsymbol{B}^{-1} \cdot(\boldsymbol{u} \otimes \boldsymbol{v}) \cdot \boldsymbol{B}^{-1}}{1+\boldsymbol{v} \cdot \boldsymbol{B}^{-1} \cdot \boldsymbol{u}}
$$

Let

$$
\begin{array}{ll}
\mathrm{B} \cdot \boldsymbol{x}^{\prime}= & \mathrm{c} \\
\mathrm{B} \cdot \boldsymbol{y}^{\prime}= & \mathrm{u}
\end{array}
$$

then

$$
(\boldsymbol{B}+\boldsymbol{u} \otimes \boldsymbol{v}) \boldsymbol{x}=\boldsymbol{c}
$$


with

$$
\begin{gathered}
\boldsymbol{x}=\boldsymbol{B}^{-1} \boldsymbol{c}-\frac{\boldsymbol{B}^{-1} \cdot(\boldsymbol{u} \otimes \boldsymbol{v}) \cdot \boldsymbol{B}^{-1} \boldsymbol{c}}{1+\boldsymbol{v} \cdot \boldsymbol{B}^{-1} \cdot \boldsymbol{u}} \\
\boldsymbol{x}=\boldsymbol{x}^{\prime}-\frac{\boldsymbol{v} \cdot \boldsymbol{x}^{\prime}}{1+\boldsymbol{v} \cdot \boldsymbol{y}^{\prime}} \boldsymbol{y}^{\prime} .
\end{gathered}
$$

For our system of equations $\boldsymbol{B}=\boldsymbol{J}_{11}, \boldsymbol{u}=-\frac{1}{J_{22}} \boldsymbol{J}_{12}, \boldsymbol{v}=\boldsymbol{J}_{21}$, and $\boldsymbol{c}=\boldsymbol{y}_{1}-\boldsymbol{J}_{12} \frac{y_{2}}{J_{22}}$. Then

$$
\begin{aligned}
\boldsymbol{J}_{11} \cdot \boldsymbol{z}_{1} & = & \boldsymbol{y}_{1}-\boldsymbol{J}_{12} \frac{y_{2}}{J_{22}} \\
\boldsymbol{J}_{11} \cdot \boldsymbol{z}_{2} & = & -\frac{1}{J_{22}} \boldsymbol{J}_{12} \\
{\left[\boldsymbol{J}_{11}-\frac{1}{J_{22}}\left(\boldsymbol{J}_{12} \otimes \boldsymbol{J}_{21}\right)\right] \cdot \boldsymbol{x}_{1} } & = & \boldsymbol{y}_{1}-\boldsymbol{J}_{12} \frac{y_{2}}{J_{22}}
\end{aligned}
$$

which implies

$$
\begin{array}{rr}
\boldsymbol{x}_{1}= & \boldsymbol{z}_{1}-\frac{\boldsymbol{J}_{21} \cdot \boldsymbol{x}^{\prime}}{1+\boldsymbol{J}_{21} \cdot \boldsymbol{y}^{\prime}} \boldsymbol{y}^{\prime} \\
x_{2}= & \frac{y_{2}-\boldsymbol{J}_{21} \cdot \boldsymbol{x}_{1}}{J_{22}}
\end{array}
$$

Using this method reduces solving each linear system to solving two triagonal systems of equations. The tridiagonal factorization can be reused for the two solves, which makes solving the system of equations very numerically efficient. The next section demonstrates the advantages of this approach.

\subsection{Verification}

Figure 3.2 shows a sample problem used to compare a full axisymmetric simulation of the reference problem to the simplified model. There are two comparisons of interest: verifying that the simplified model reproduces the results of the full model away from structural discontinuities and evaluating the merits of using the simplified approach by comparing the numerical cost of solving a full simulation by each of the two methods.

The figure defines a pressure and temperature load cycle with a period of 10,002 hours. The outer wall temperature, $T_{o}$, remains fixed. The inner wall temperature cycles as shown in the figure. In between these two points both models apply a linear, through-wall temperature gradient. In addition, the vessel is under a constant pressure ramped over an initial time of 1 hour.

The vessel has a wall thickness of $50 \mathrm{~mm}$ and a clad on the inside and outside diameters of $5 \mathrm{~mm}$. The vessel base material is $316 \mathrm{H}$ stainless steel and the clad is pure nickel, both represented by inelastic material models.

Figure 3.3 compares the stress and mechanical strain profiles for two methods of analysis: the full axisymmetric simulation described in Figure 3.2 and the simplified 1D model derived in this chapter. The discretizations for the two methods are similar: both have the same number of finite elements through the thickness of the vessel. This plot shows the quantities 

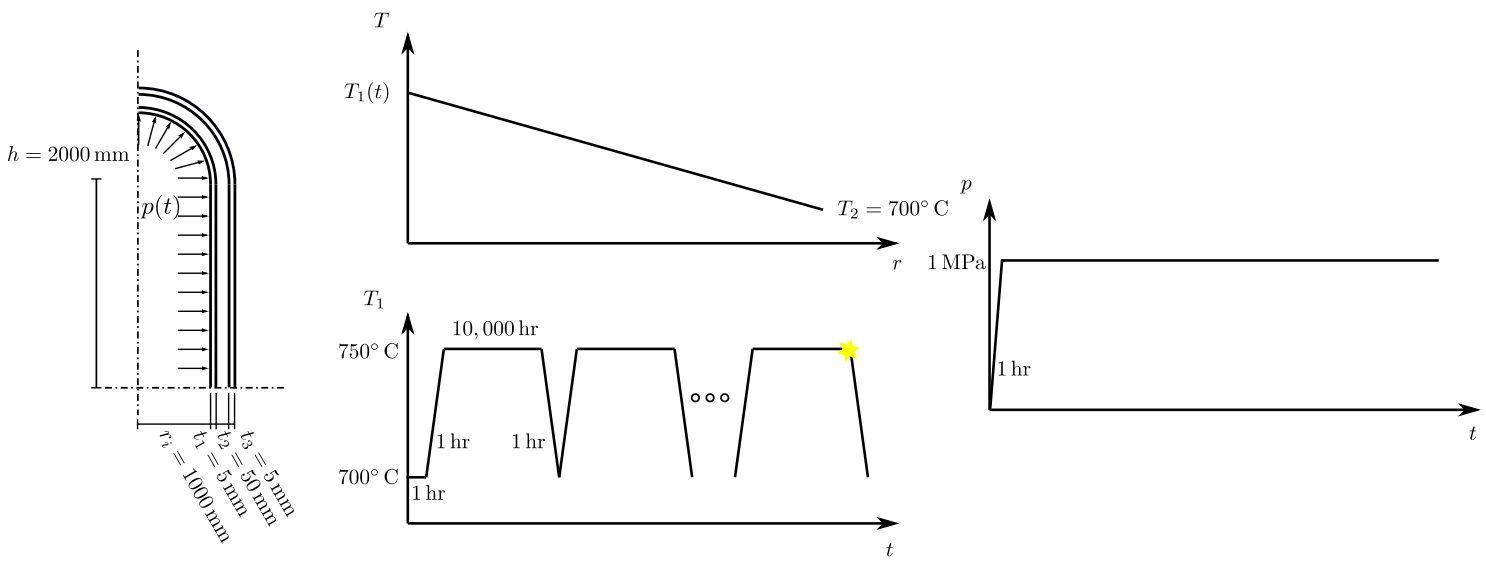

Figure 3.2: Example problem used to compare full axisymmetric analysis to the simplified analysis method

\begin{tabular}{ll}
\hline Method & Time \\
\hline Axisymmetric & $17360 \mathrm{~s}$ \\
Simplified, with full LU & $123 \mathrm{~s}$ \\
Simplified, with arrowhead & $115 \mathrm{~s}$ \\
\hline
\end{tabular}

Table 3.1: Table comparing the computational cost of the reference model using full axisymmetric analysis, the simplified 1D analysis with a full LU decomposition linear solver, and the simplified method with the specialized arrowhead solve.

through the thickness of the vessel for a point, in the axisymmetric simulation, though the center of the vessel in between the end caps and at the time indicated in Figure 3.2 during the 20th loading cycle. The figure shows that the two solutions are essentially identical, verifying the simplified analysis method.

Table 3.1 compares the cost of solving 20 cycles of the load history using the full axisymmetric model, the simplified model using an LU decomposition algorithm to solve the Newton iteration linear equations, and the simple model using the specialized arrowhead solution scheme described above. The finite element method used in the axisymmetric model uses Newton's method and an LU decomposition scheme to solve the axisymmetric finite element so the comparison between the first two solution methods essentially probes only the kinematic simplifications. The comparison between the second and third methods probes the effectiveness of the specialized linear solution method.

The results show that the kinematic simplifications greatly reduce the computational effort required to solve the problem. The simplified model runs 150 times faster than the full axisymmetric simulation. The gain from employing the specialized arrowhead solution produce is much less. However, the advantage of the specialized linear solution method increases as the size of the problem increases.

Overall this simplified method of analyzing cladded vessels vastly reduces the computational expense of simulating a particular combination of structural dimensions, clad/base material properties, and loading conditions. This simulation method will be used in the subsequent chapters to probe the effectiveness of the approximate analysis methods described in 
Finite element analysis of compliant cladding and base metal systems

July 2018

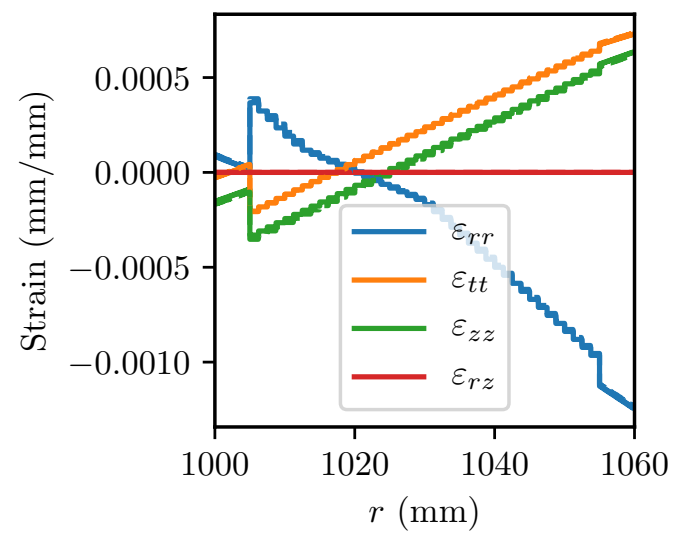

(a) Mechanical strains

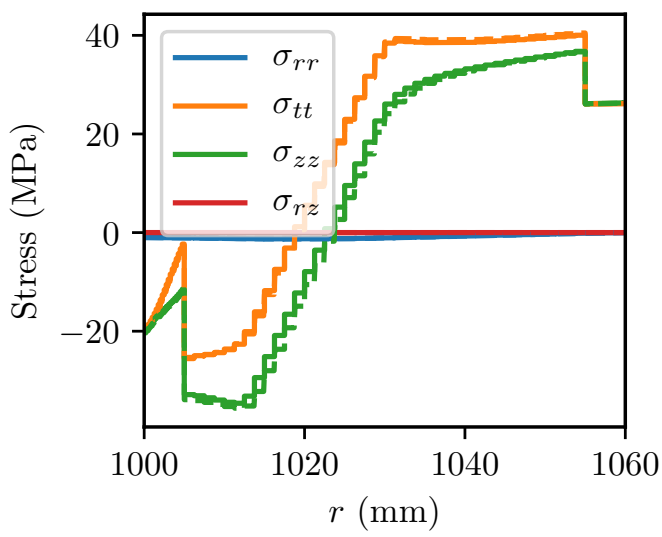

(b) Stresses

Figure 3.3: Comparison between the simplified model (solid lines) and the full axisymmetric analysis (dashed lines) for the problem described by Fig. 3.2. The corresponding dashed/solid lines are essentially identical, meaning the two modeling methods are producing nearly identical results. These results are plotted at the end of the hold during the final load cycle.

Chapter 2 using high throughput simulation of many different clad/base material systems. 


\section{Simple representative models}

This chapter describes results of simulations using the simplified model as introduced in Chapter 3. The simplified model reduces very significantly the simulation time and enable high-throughput calculations to examine the effect of different clad/base material combinations vessel sections away from structural discontinuities. This chapter considers four combinations of structural geometry and load. The two prototypical vessel sections represent a cladded vessel, where the clad material is applied only on the inside diameter of the cylinder, and a tube cladded on both the inside and outside diameters, representative, for example, of a intermediate heat exchanger (IHX) tube in a MSR. The two load cases both subject the vessel to a constant pressure and a cyclic thermal load. For the gradient load case the vessel wall cycles between an isothermal cold temperature and a linear through-wall thermal gradient with a hot inner wall and a cold outer wall. The load cycle holds the vessel in the thermal gradient conditions for an extended period of time before returning to isothermal conditions and repeating. The second load case has an isothermal hold. Here the vessel cycles between a linear, through-wall thermal gradient and an isothermal hot condition. There is an extended hold in the hot condition before the load cycle repeats.

In addition, the simplified method is then used to examine two types of clad/base systems - compliant clads, where the clad material creeps much faster and sheds load onto the base material, and elastic clads, where the cladding material is essentially linear elastic. As described above, the purpose of the simulations described in this chapter is to assess the reliability of approximate analysis methods. For the compliant systems the design analysis assumes the clad has zero strength. For the elastic systems the design analysis assumes the clad is linear elastic. The comparisons here then are between two simulations at the same loading conditions and structural geometries: one where the base and clad materials are modeled with an elastic perfectly-plastic power law creep inelastic model and one where the base material uses the same inelastic model but the clad constitutive response is approximated either as perfectly compliant or perfectly elastic. Each analysis compares two simulation results:

1. The difference in the average creep damage over the last cycle, computed using the ASME Section III, Division 5 procedure

2. The minimum difference over the vessel wall thickness between the stable ASME Section III, Division 5 stable strain range over the last load cycle

The first metric assess the impact of the approximate design analysis on stress relaxation in the base material. The second metric assess the conservatism of bounding the strain range in the structure with the design analysis method. Both comparison metrics are scalars and so they can be plotted as a function of the material property mismatch to determine the limits, in terms of relative property mismatches, of the proposed design analysis methods. Note that as constructed for both comparison metrics positive numbers represent positive results - the approximate analysis conservatively bounds the full inelastic calculations and negative numbers represent negative, nonconservative results.

This chapter presents results using design charts. These charts vary a particular property mismatch on the $\mathrm{x}$ - and $\mathrm{y}$-axes. The contour colors show the results of the comparison metrics described in the previous paragraph. By looking at a design chart, or rather a collection of 
design charts, we can determine approximate ranges of validity for the two design methods for various structural configurations, loading conditions, and property mismatch ratios.

To save space the chapter only shows design charts for the thermal gradient load case. However, the conclusions developed in this Chapter apply to both the thermal gradient and isothermal temperature histories.

\subsection{Clad on inner diameter only}

For the analyses described in this section the vessel base material is Alloy $800 \mathrm{H}$ with a total wall thickness of $60 \mathrm{~mm}$ and an inner radius of $1690 \mathrm{~mm}$ cladded by a $10 \%$ vessel-thickness layer of different clad materials $(6 \mathrm{~mm})$. Figure $4.1 \mathrm{a}-\mathrm{b}$ shows the two load cases described at the start of the section. Both load cases apply a constant pressure of $0.2 \mathrm{MPa}$ on the interior of the vessel and cycle the temperature. The hold in the hot condition is 10,000 hours The material properties of the $800 \mathrm{H}$ base determined at $700^{\circ} \mathrm{C}$ are listed in Table 4.1. This analysis varies the clad Young's modulus, yield, thermal coefficient and creep rate relative to the base material to determine the effectiveness of the two design analysis methods for various material property ratios. Table 4.2 lists the discrete material properties considered in this study. The Poisson ratio $\nu$ and the creep rate exponent $n$ of clad are assumed to match the $800 \mathrm{H}$ base.

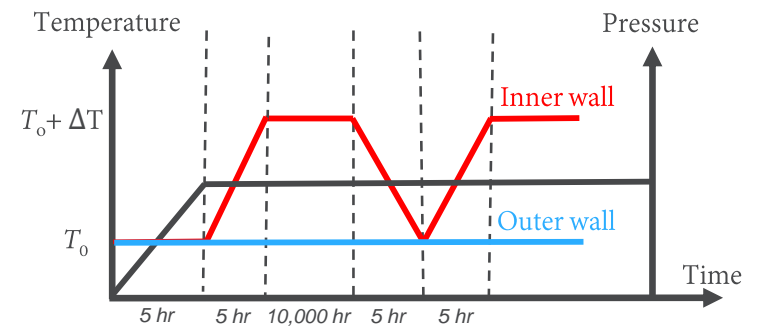

(a)

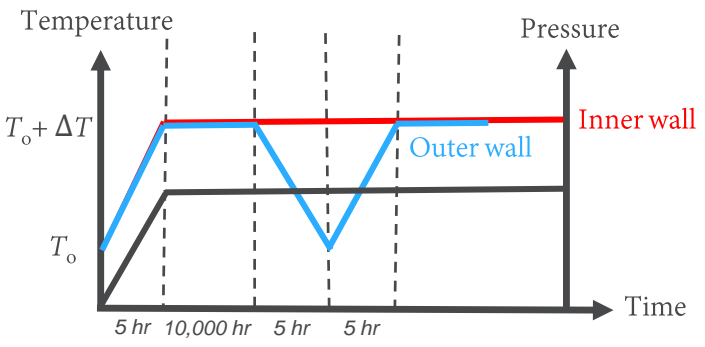

Figure 4.1: The times for the isothermal case are similar except the load is applied simultaneously with the initial temperature ramp. For both cases $T_{0}=700^{\circ} \mathrm{C}$ and $\Delta T=70^{\circ} \mathrm{C}$

\begin{tabular}{llll}
\hline Property & Symbols & $800 \mathrm{H}$ & Units \\
\hline Young's modulus & $E_{800 H}$ & 156000 & $\mathrm{MPa}$ \\
Poisson ratio & $\nu_{800 H}$ & 0.31 & - \\
Yield stress & $\sigma_{800 H}$ & 102 & $\mathrm{MPa}$ \\
Thermal coefficient & $\alpha_{800 H}$ & $19.9 \times 10^{-06}$ & $\mathrm{~mm} /\left(\mathrm{mm} \times{ }^{0} \mathrm{C}\right)^{-1}$ \\
Creep prefactor & $A_{800 H}$ & $6.94 \times 10^{-22}$ & $(\mathrm{MPa}-n / \mathrm{h})$ \\
Creep rate exponent & $n_{800 H}$ & 6 & - \\
Creep rate & $\dot{\varepsilon}_{800 H}$ & $7.816 \times 10^{-10}$ & $\mathrm{~h}^{-1}$ \\
\hline
\end{tabular}

Table 4.1: Materials properties of base at $700^{\circ} \mathrm{C}$ 
Finite element analysis of compliant cladding and base metal systems

July 2018

\begin{tabular}{llll}
\hline Property & Symbols & Units & Varied values \\
\hline Young's modulus & $E_{\text {clad }}$ & $\mathrm{MPa}$ & {$[0.8,1.0,1.2,1.41,1.6,2.0]^{*} E_{1}$} \\
Yield stress & $\sigma_{\text {clad }}$ & $\mathrm{MPa}$ & {$[0.2,0.42,0.8,1.0,3.0,6.15]^{*} \sigma_{1}$} \\
Thermal coefficient & $\alpha_{\text {clad }}$ & $\mathrm{mm} /\left(\mathrm{mm} \times{ }^{0} \mathrm{C}\right)^{-1}$ & {$[0.2,0.3,0.55,0.79,0.85,1.0]^{*} \alpha_{1}$} \\
Creep rate & $\dot{\varepsilon}_{\text {clad }}$ & $\mathrm{h}^{-1}$ & {$[0.0002,0.0015,0.02,0.11,1.0,100.0]^{*} \dot{\varepsilon}_{1}$} \\
\hline
\end{tabular}

Table 4.2: Materials properties of clad and their variation in reactor vessel simulations.

\subsubsection{Comparison to compliant clad analysis}

Figures 4.2 to 4.7 show design charts where the reference clad material as the same material properties as the base. That is, except for the two material properties varied in the diagram, the remaining clad material properties are the same as the base material. Figures 4.8 to 4.13 then show charts where the reference clad material properties are those of pure nickel, as described in Table 4.3. These figures mark the location of the pure nickel clad on each design chart.

Summarizing the results of these design charts, the following set of criteria describe the situations where the compliant analysis adequate represents the full inelastic results:

$$
\begin{array}{rll}
\text { Young's modulus } & : & E_{\text {clad }}<E_{800 H} \\
\text { Yield stress } & : & \sigma_{\text {clad }}<0.6 \sigma_{800 H} \\
\text { Thermal coefficient } & : & \alpha_{\text {clad }}>0.4 \alpha_{800 H} \\
\text { Creep rate } & : & \text { No constraint }
\end{array}
$$

Note that a compliant clad - a clad that can be analyzed with the compliant concept does not need to meet all criteria simultaneously. Instead these guidelines provide "rules of thumb" for clad materials that tend to meet the compliant criteria. Furthermore, we expect there to be a corresponding upper bound on the mismatch in the clad/base coefficient of thermal expansion, complementing the lower bound found here. This work focuses on clad materials with lower thermal expansion coefficients than the base materials because most likely clad materials do in fact have a lower coefficient of thermal expansion than the Class A metallic materials.

\begin{tabular}{llll}
\hline Property & Symbols & Nickel & Units \\
\hline Young's modulus & $E$ & 174000 & $\mathrm{MPa}$ \\
Yield stress & $\sigma$ & 43.0 & $\mathrm{MPa}$ \\
Thermal coefficient & $\alpha$ & $15.8 \times 10^{-06}$ & $\mathrm{~mm} /\left(\mathrm{mm} \times{ }^{\circ} \mathrm{C}\right)^{-1}$ \\
Creep prefactor & $A$ & $4.66 \times 10^{-19}$ & $\left(\mathrm{MPa}^{-n} / \mathrm{h}\right)$ \\
Creep rate exponent & $n$ & 6.0 & - \\
Creep rate & $\dot{\varepsilon}$ & $2.95 \times 10^{-09}$ & $\mathrm{~h}^{-1}$ \\
\hline
\end{tabular}

Table 4.3: Material properties of Nickel at $700^{\circ} \mathrm{C}$

Figure 4.14 plots the ASME equivalent strain ranges in corresponding full and compliant 
Finite element analysis of compliant cladding and base metal systems

July 2018

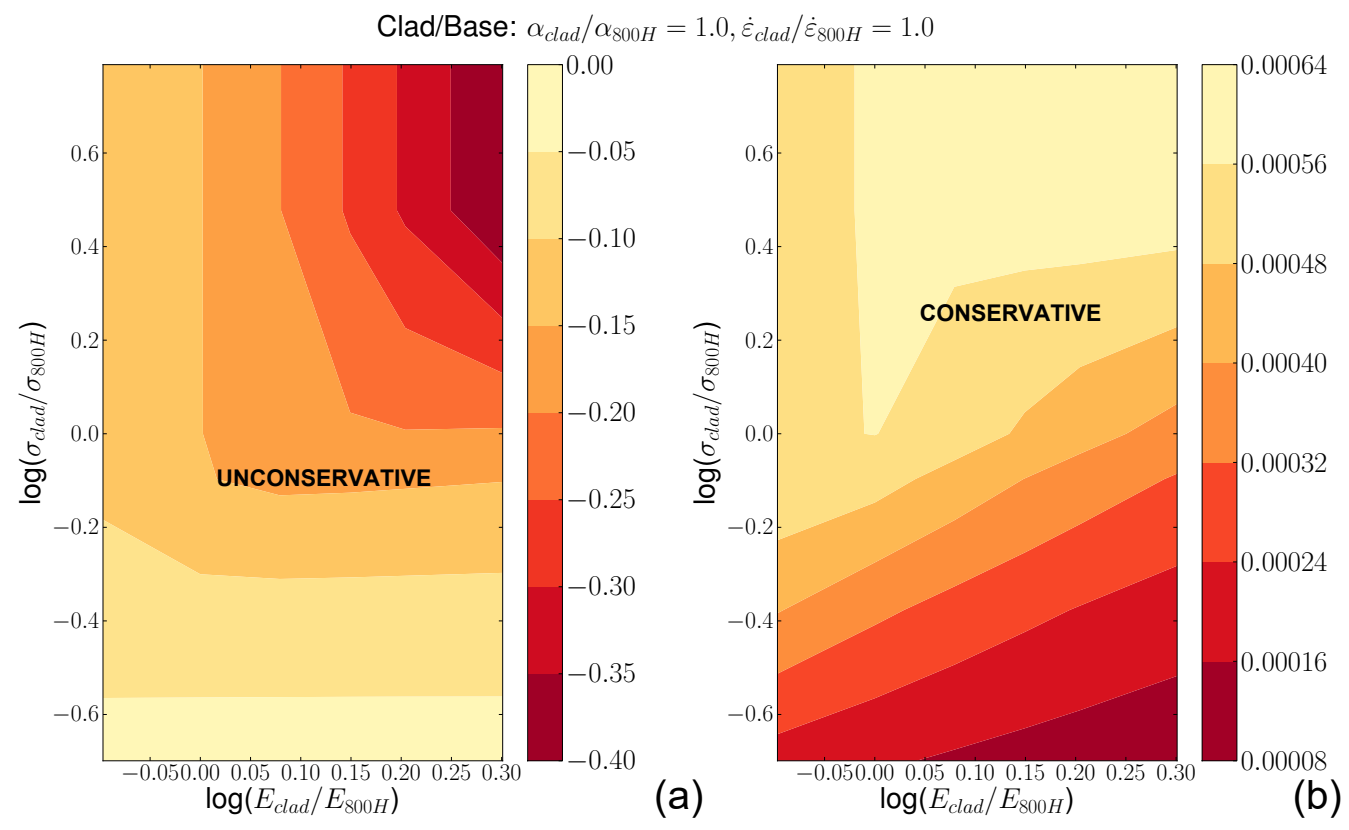

Figure 4.2: Design chart illustrating the difference in the average creep damage, $\left\{\bar{D}_{\text {c }}\right\}_{\text {infinite compliance }}-\left\{\bar{D}_{\text {c }}\right\}_{\text {full inelastic }}$, in the base region during the hold of the last cycle (a) and the minimum difference of ASME equivalent strain range, $\{\Delta \varepsilon\}_{\text {infinite compliance }}-\{\Delta \varepsilon\}_{\text {full inelastic }}$, in the clad region over the last cycle (b) as a function of $E$ and $\sigma$ in the clad/800H base system for the gradient load case.

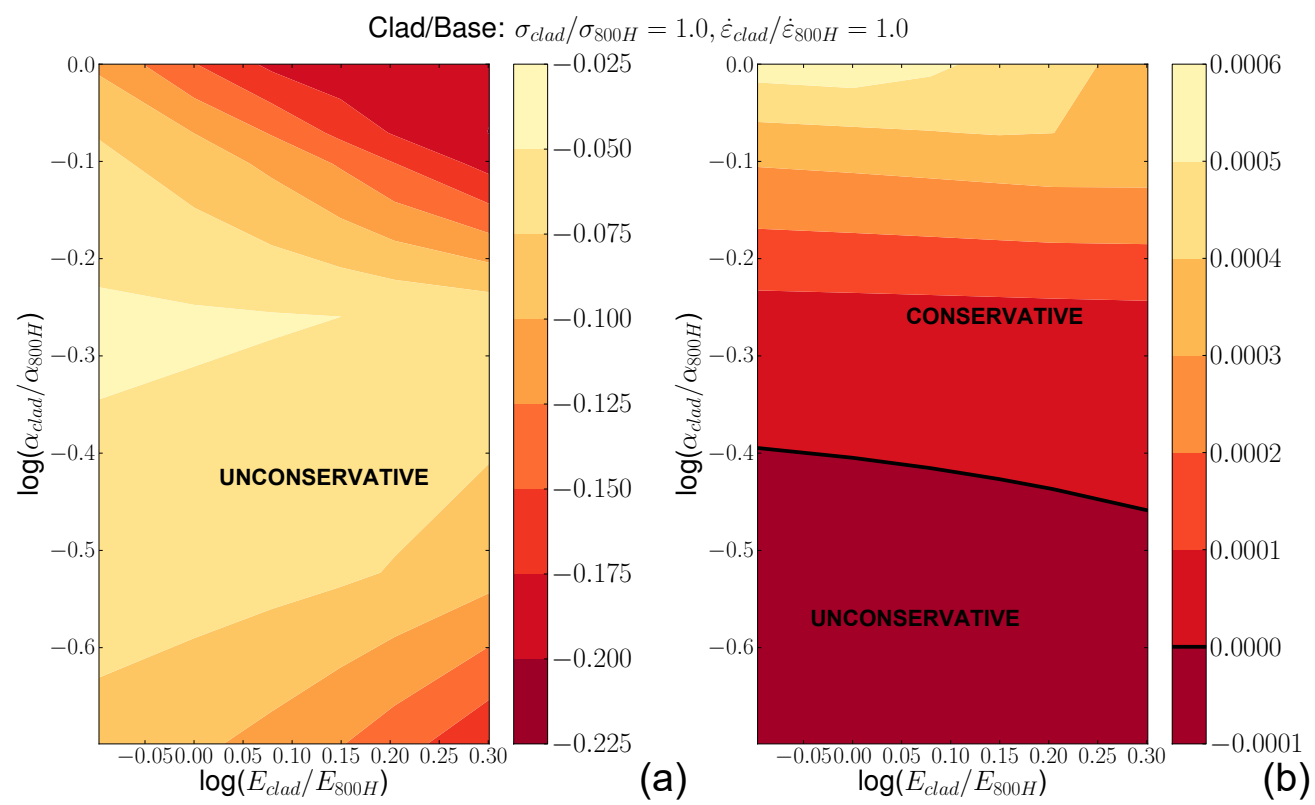

Figure 4.3: Design chart illustrating the difference in the average creep damage, $\left\{\bar{D}_{\mathrm{c}}\right\}_{\text {infinite compliance }}-\left\{\bar{D}_{\mathrm{c}}\right\}_{\text {full inelastic }}$, in the base region during the hold of the last cycle (a) and the minimum difference of ASME equivalent strain range, $\{\Delta \varepsilon\}_{\text {infinite compliance }}-\{\Delta \varepsilon\}_{\text {full inelastic }}$, in the clad region over the last cycle (b) as a function of $E$ and $\alpha$ in the clad/800H base system for the gradient load case. 
Finite element analysis of compliant cladding and base metal systems

July 2018

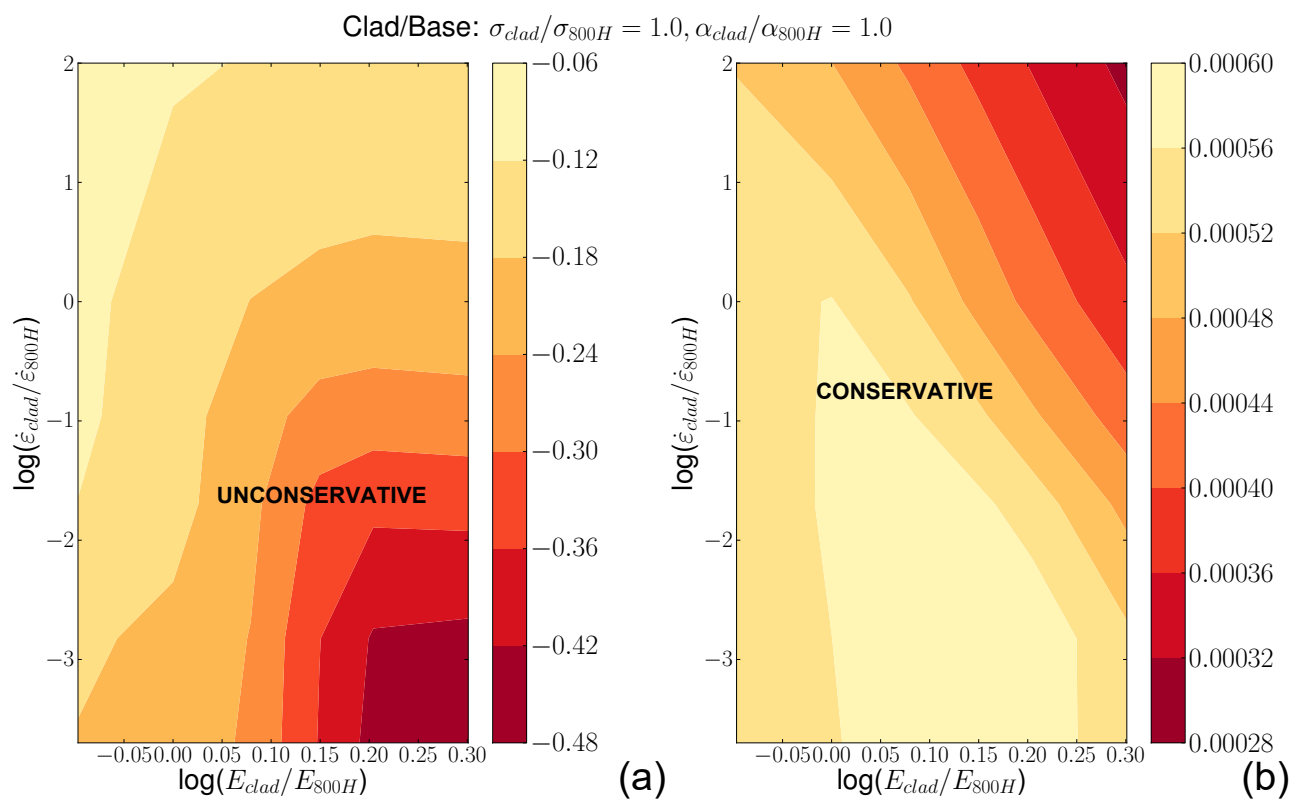

Figure 4.4: Design chart illustrating the difference in the average creep damage, $\left\{\bar{D}_{\text {c }}\right\}_{\text {infinite compliance }}-\left\{\bar{D}_{\text {c }}\right\}_{\text {full inelastic }}$, in the base region during the hold of the last cycle (a) and the minimum difference of ASME equivalent strain range, $\{\Delta \varepsilon\}_{\text {infinite compliance }}-\{\Delta \varepsilon\}_{\text {full inelastic }}$, in the clad region over the last cycle (b) as a function of $E$ and $\dot{\varepsilon}$ in the clad/800H base system for the gradient load case.

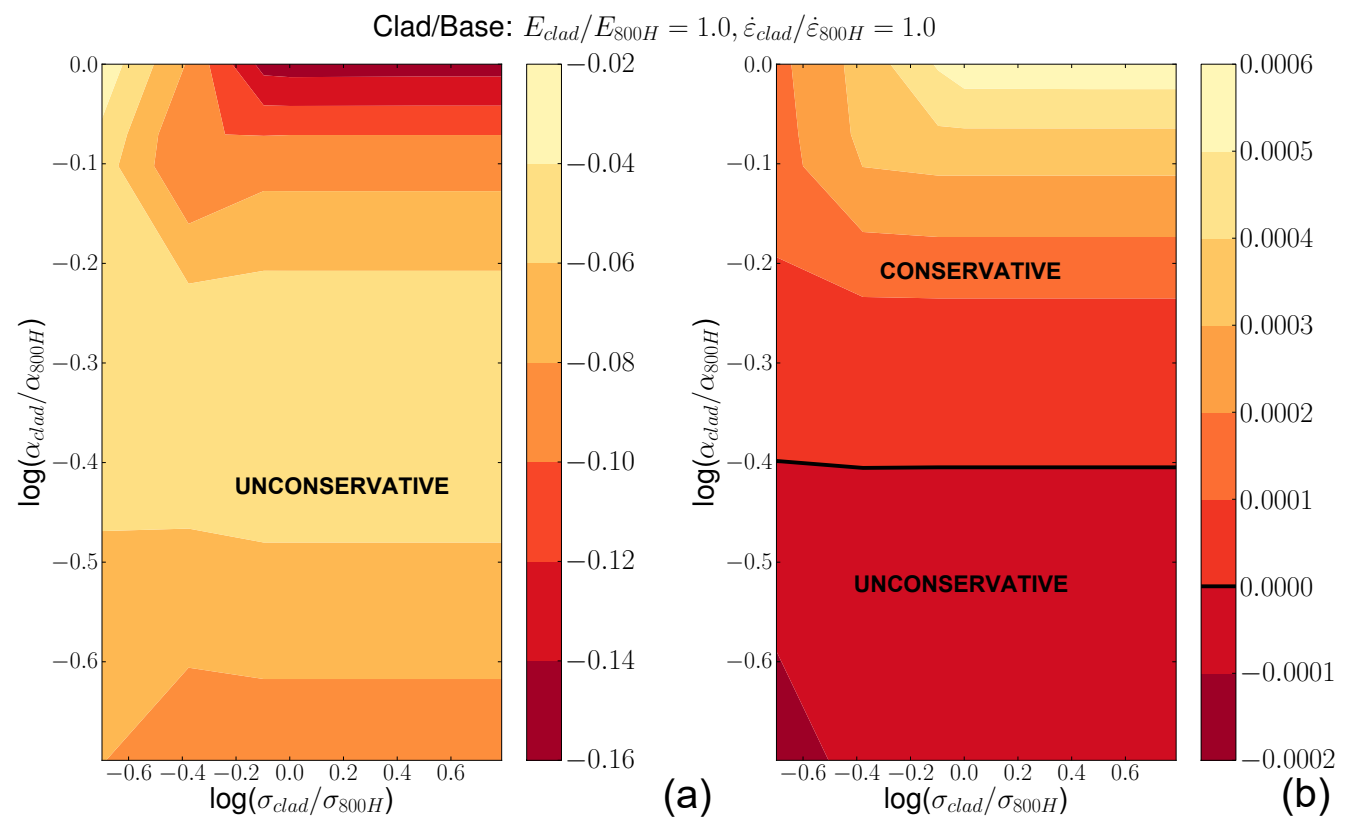

Figure 4.5: Design chart illustrating the difference in the average creep damage, $\left\{\bar{D}_{\mathrm{c}}\right\}_{\text {infinite compliance }}-\left\{\bar{D}_{\mathrm{c}}\right\}_{\text {full inelastic }}$, in the base region during the hold of the last cycle (a) and the minimum difference of ASME equivalent strain range, $\{\Delta \varepsilon\}_{\text {infinite compliance }}-\{\Delta \varepsilon\}_{\text {full inelastic }}$, in the clad region over the last cycle (b) as a function of $\sigma$ and $\alpha$ in the clad/800H base system for the gradient load case. 
Finite element analysis of compliant cladding and base metal systems

July 2018

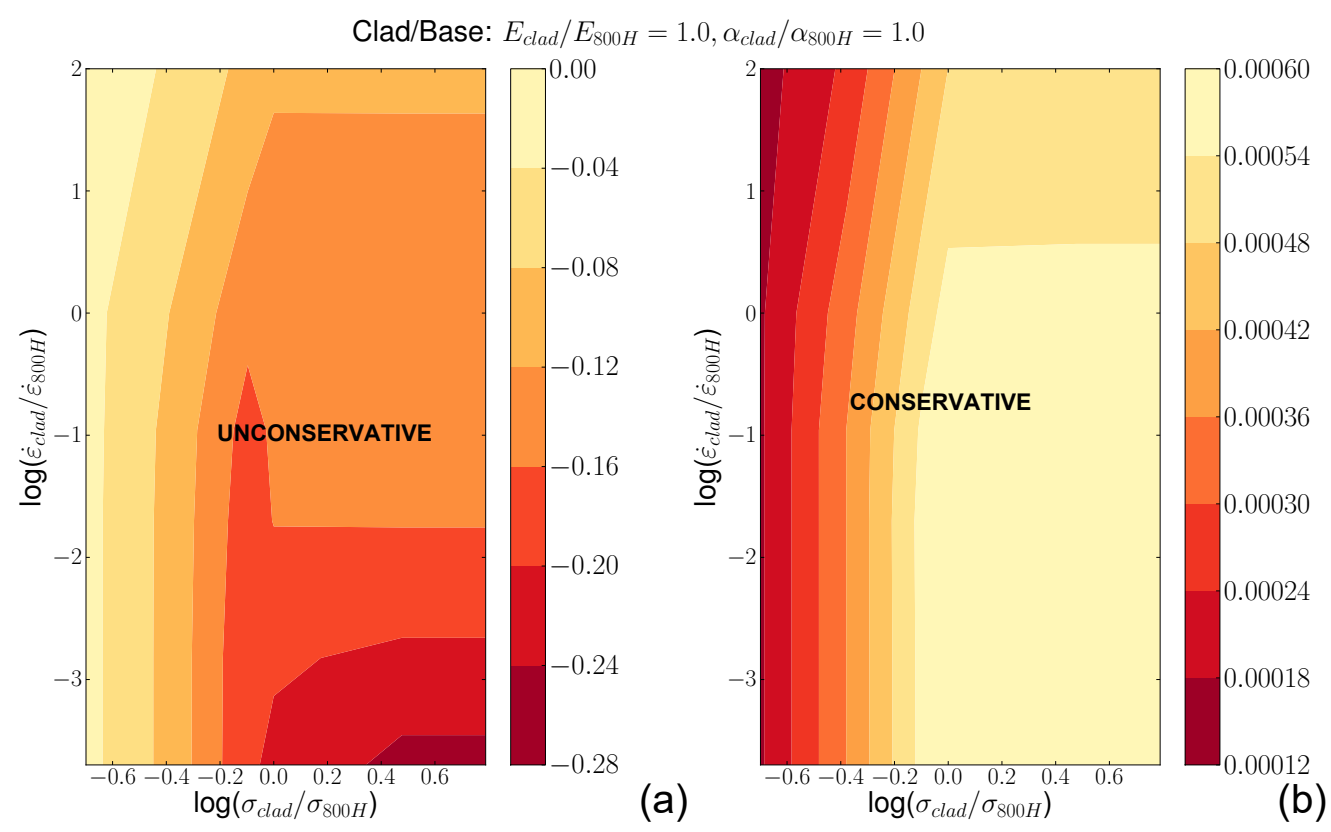

Figure 4.6: Design chart illustrating the difference in the average creep damage, $\left\{\bar{D}_{\text {c }}\right\}_{\text {infinite compliance }}-\left\{\bar{D}_{\text {c }}\right\}_{\text {full inelastic }}$, in the base region during the hold of the last cycle (a) and the minimum difference of ASME equivalent strain range, $\{\Delta \varepsilon\}_{\text {infinite compliance }}-\{\Delta \varepsilon\}_{\text {full inelastic }}$, in the clad region over the last cycle (b) as a function of $\sigma$ and $\dot{\varepsilon}$ in the clad/800H base system for the gradient load case.

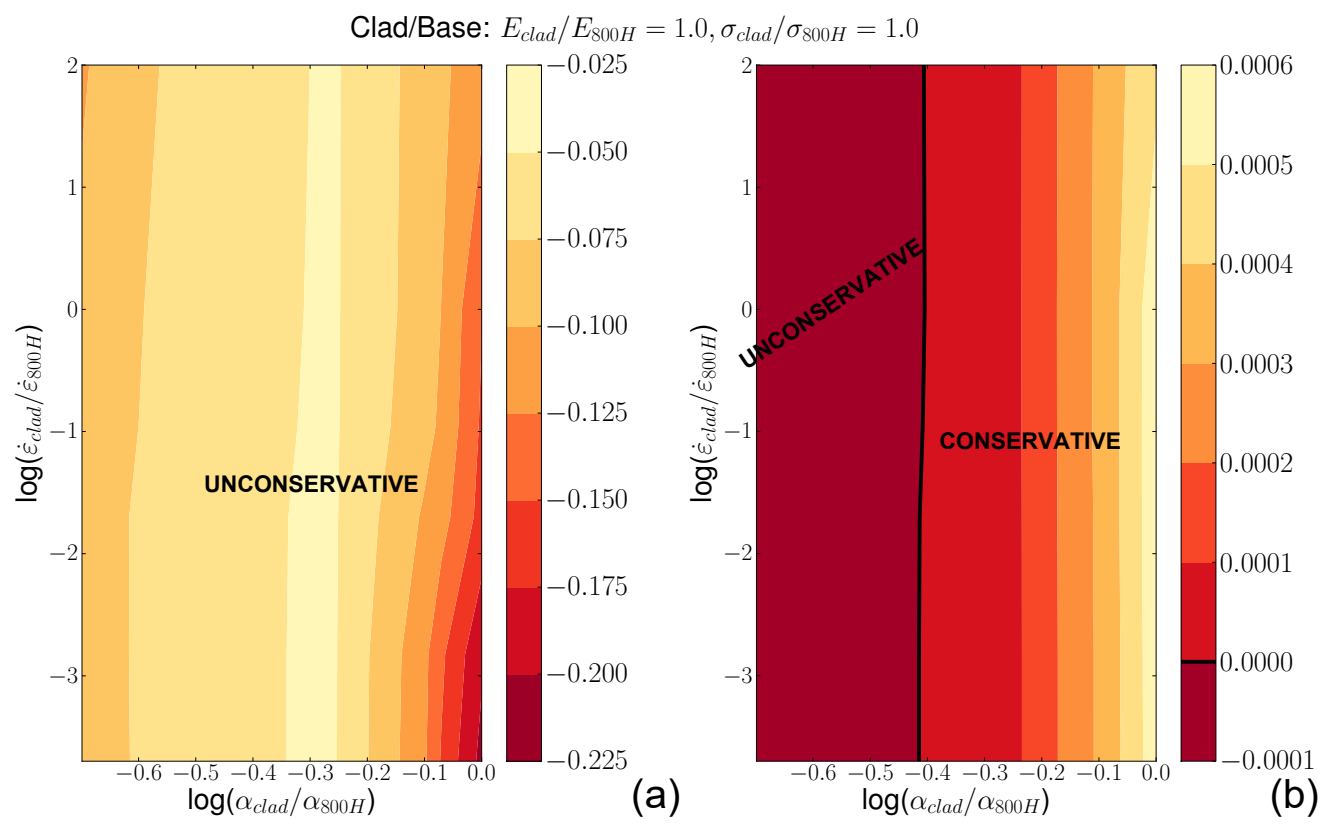

Figure 4.7: Design chart illustration the difference in the average creep damage, $\left\{\bar{D}_{\mathrm{c}}\right\}_{\text {infinite compliance }}-\left\{\bar{D}_{\mathrm{c}}\right\}_{\text {full inelastic }}$, in the base region during the hold of the last cycle (a) and the minimum difference of ASME equivalent strain range, $\{\Delta \varepsilon\}_{\text {infinite compliance }}-\{\Delta \varepsilon\}_{\text {full inelastic }}$, in the clad region over the last cycle (b) as a function of $\alpha$ and $\dot{\varepsilon}$ in the clad/800H base system for the gradient load case. 
simulations. The plot shows that the compliant analysis bounds, pointwise, the equivalent strain range in the full inelastic analysis.

Figures 4.15 and 4.16 show the von Mises equivalent stress in the vessel as a function of time during the hold of the 5th load cycle for the gradient and isothermal load cases, respectively. The figures show the stress relaxation profile at three locations in the base material, as indicated by the diagram. In the half of base material near the clad material, the stress relaxation profiles for the full inelastic is bounded completely by the infinite compliance analysis at the points $\mathrm{C}$ and $\mathrm{D}$. However, the stress relaxation profile is not bounded at the outer surface. The profiles are very different in the clad material - by definition the clad material does not undergo stress relaxation because it has zero strength. In practice, the clad stress relaxation profile could be bounded by considering the stress relaxation profile in the extreme fiber of the base material.

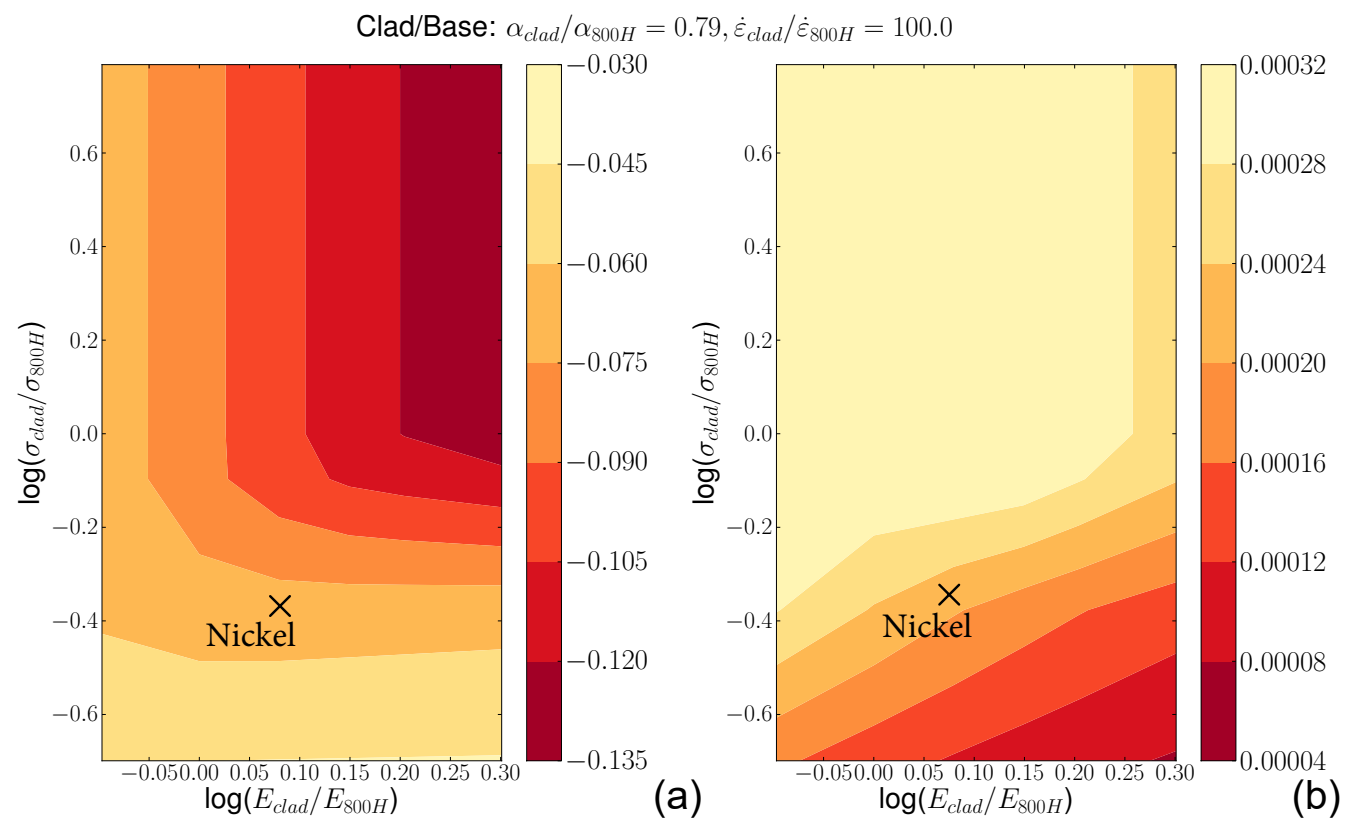

Figure 4.8: Design chart plotting the difference in the average creep damage, $\left\{\bar{D}_{\mathrm{c}}\right\}_{\text {infinite compliance }}-$ $\left\{\bar{D}_{\mathrm{c}}\right\}_{\text {full inelastic }}$, in the base region during the hold of the last cycle (a) and the minimum difference of ASME equivalent strain range, $\{\Delta \varepsilon\}_{\text {infinite compliance }}-\{\Delta \varepsilon\}_{\text {full inelastic }}$, in the clad region over the last cycle as a function of $E$ and $\sigma$ in the Nickel clad/800H base system for the gradient load case.

\subsubsection{Elastic cladding}

This subsection now applies the elastic analysis concept to the inner-diameter-clad vessel. Again, there are two analysis cases. In the first the reference clad material properties match the base material. Each property is varied to make design charts using the scheme summarized in Table 4.2. Figures 4.17-4.22 are the corresponding design charts for the thermal gradient load.

The second set of calculations uses TZM molybdenum alloy as the reference clad. Table 4.4 summarizes the material properties used for TZM. Figures 4.23 to 4.28 show the diagrams for this case. 
Finite element analysis of compliant cladding and base metal systems

July 2018

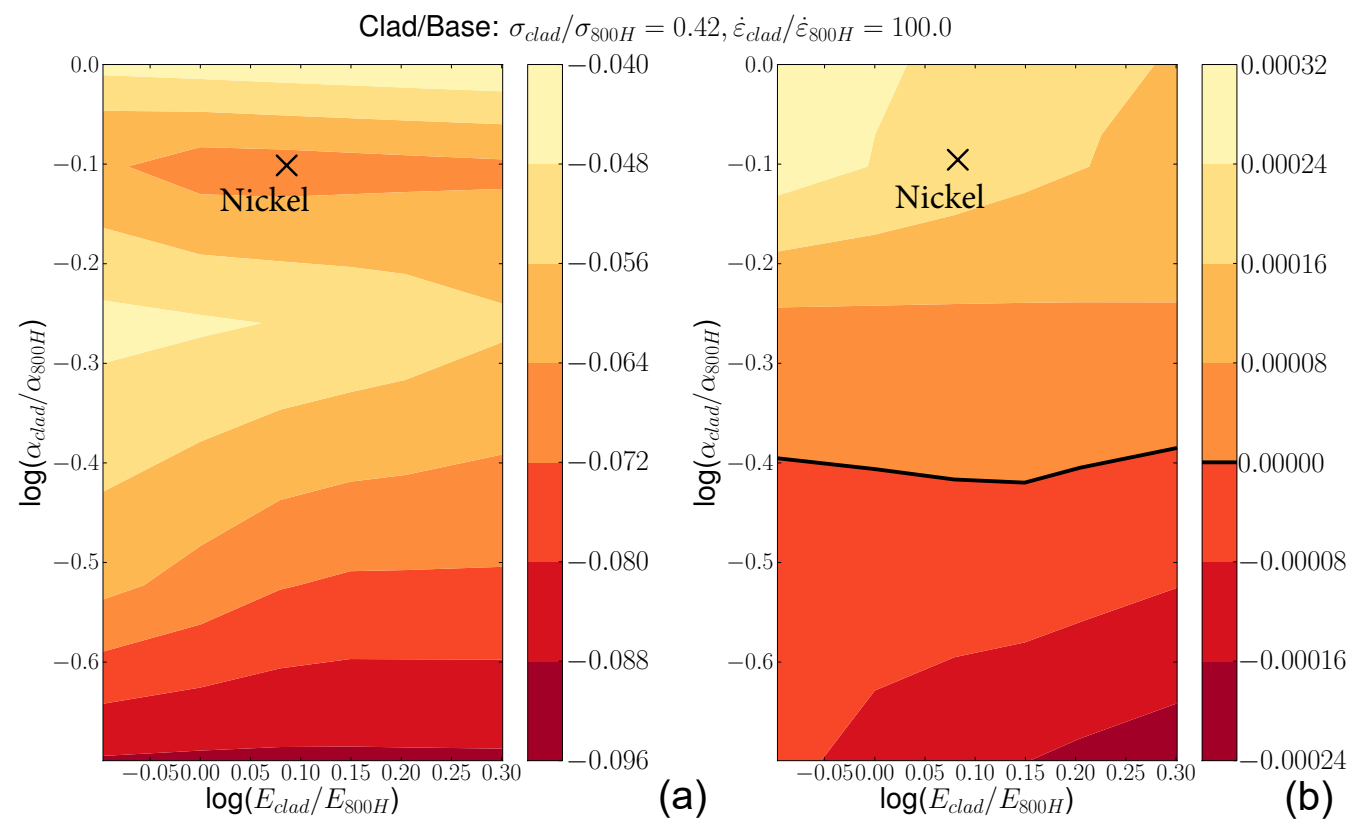

Figure 4.9: Design chart plotting the difference in the average creep damage, $\left\{\bar{D}_{\text {c }}\right\}_{\text {infinite compliance }}-$ $\left\{\bar{D}_{\text {c }}\right\}_{\text {full inelastic }}$, in the base region during the hold of the last cycle (a) and the minimum difference of ASME equivalent strain range, $\{\Delta \varepsilon\}_{\text {infinite compliance }}-\{\Delta \varepsilon\}_{\text {full inelastic }}$, in the clad region over the last cycle as a function of $E$ and $\alpha$ in the Nickel clad/800H base system for the gradient load case.

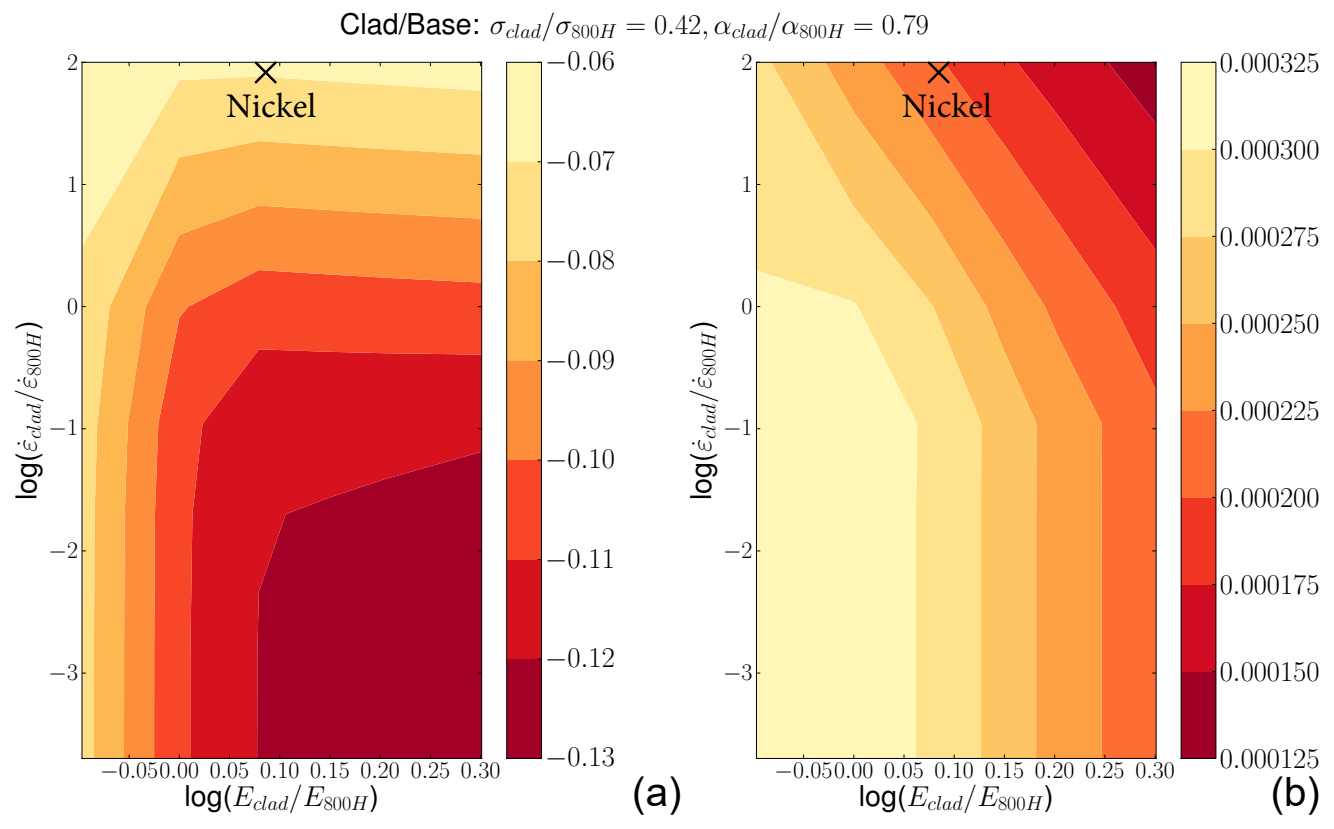

Figure 4.10: Design chart plotting the difference in the average creep damage, $\left\{\bar{D}_{\mathrm{c}}\right\}_{\text {infinite compliance }}-\left\{\bar{D}_{\mathrm{c}}\right\}_{\text {full inelastic }}$, in the base region during the hold of the last cycle (a) and minimum difference of ASME equivalent strain range, $\{\Delta \varepsilon\}_{\text {infinite compliance }}-\{\Delta \varepsilon\}_{\text {full inelastic }}$, in the clad region over the last cycle as a function of $E$ and $\dot{\varepsilon}$ in the Nickel clad/800H base system for the gradient load case. 
Finite element analysis of compliant cladding and base metal systems

July 2018

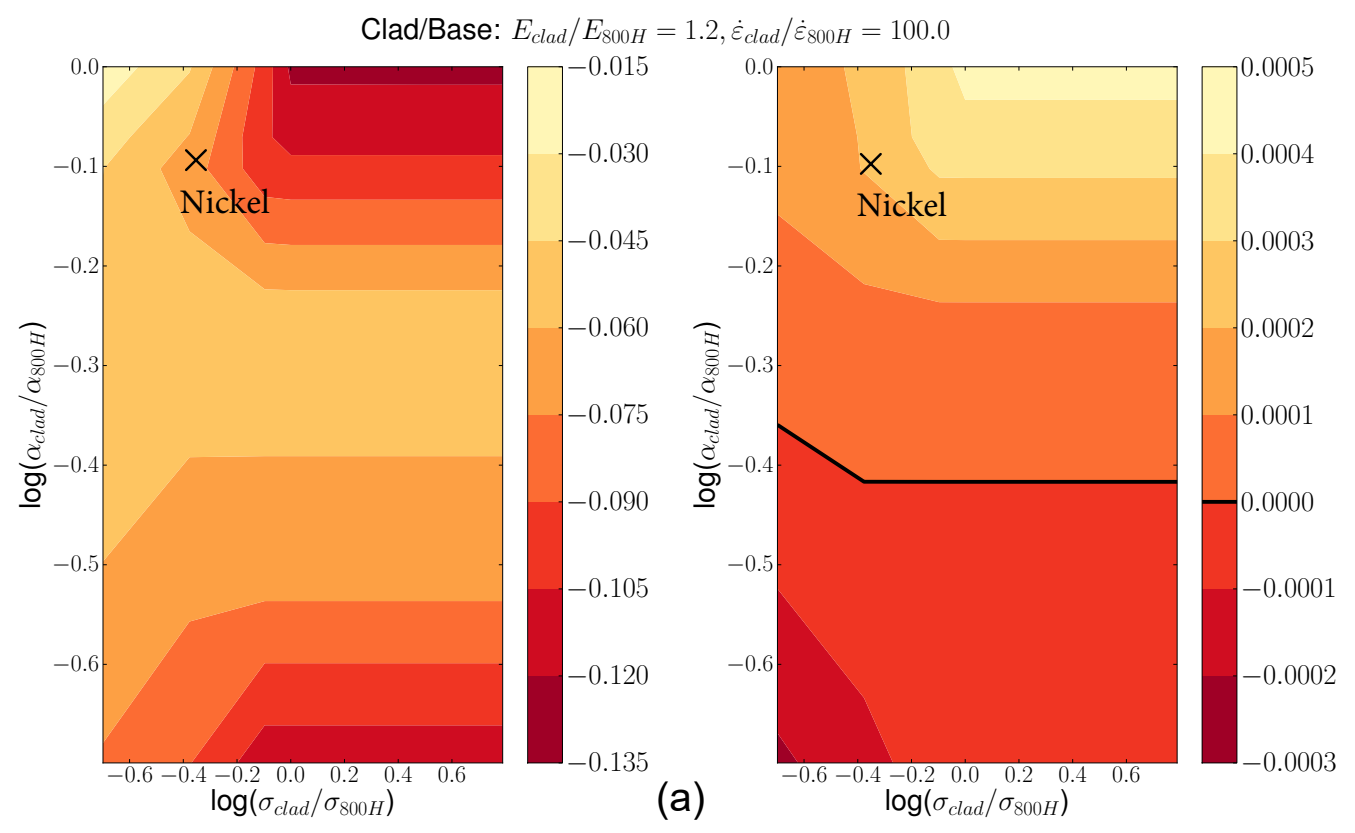

Figure 4.11: Design chart plotting the difference in the average creep damage, $\left\{\bar{D}_{\text {c }}\right\}_{\text {infinite compliance }}-\left\{\bar{D}_{\text {c }}\right\}_{\text {full inelastic }}$, in the base region during the hold of the last cycle (a) and the minimum difference of ASME equivalent strain range, $\{\Delta \varepsilon\}_{\text {infinite compliance }}-\{\Delta \varepsilon\}_{\text {full inelastic }}$, in the clad region over the last cycle as a function of $\sigma$ and $\alpha$ in the Nickel clad/800H base system for the gradient load case.

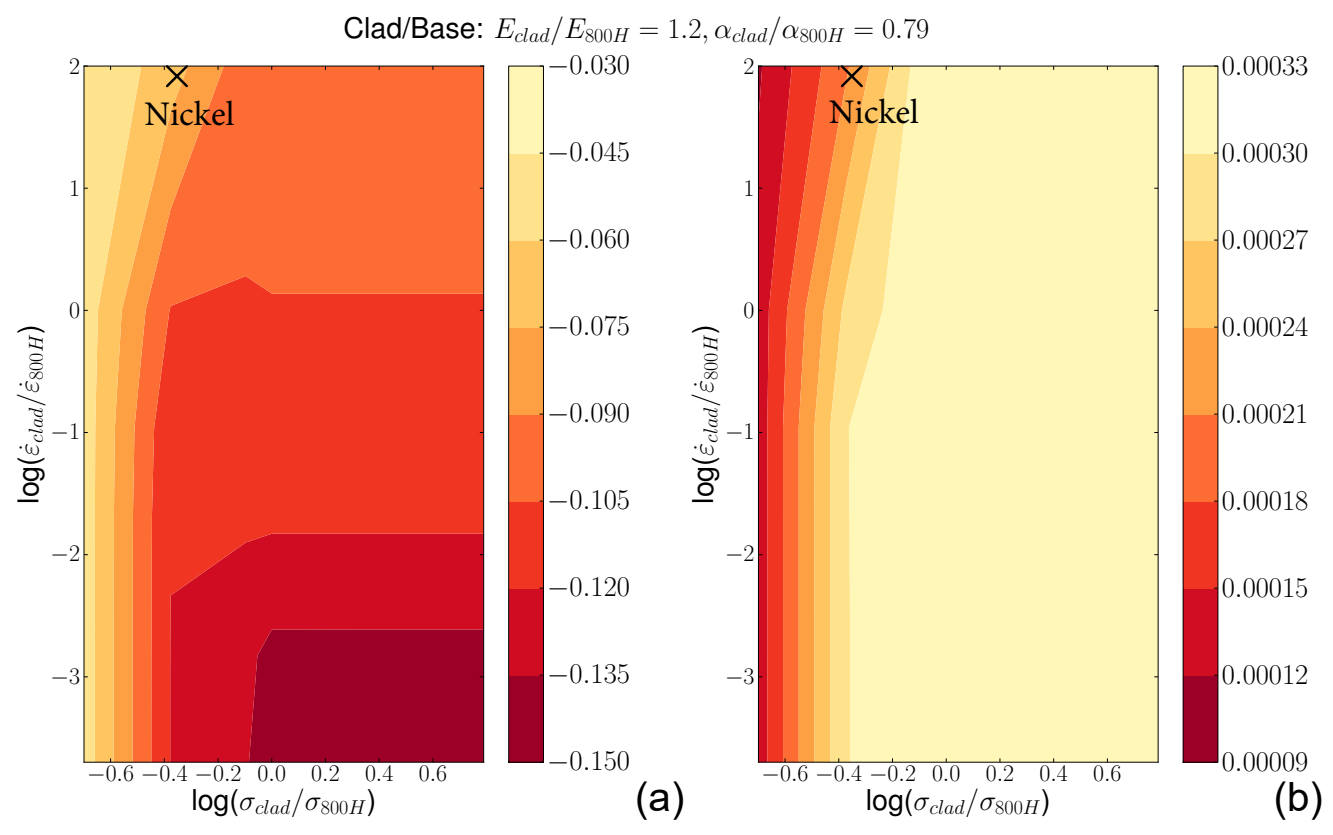

Figure 4.12: Design chart plotting the difference in the average creep damage, $\left\{\bar{D}_{\mathrm{c}}\right\}_{\text {infinite compliance }}-\left\{\bar{D}_{\mathrm{c}}\right\}_{\text {full inelastic }}$, in the base region during the hold of the last cycle (a) and the minimum difference of ASME equivalent strain range, $\{\Delta \varepsilon\}_{\text {infinite compliance }}-\{\Delta \varepsilon\}_{\text {full inelastic }}$, in the clad region over the last cycle as a function of $\sigma$ and $\dot{\varepsilon}$ in the Nickel clad/800H base system for the gradient load case. 
Finite element analysis of compliant cladding and base metal systems

July 2018

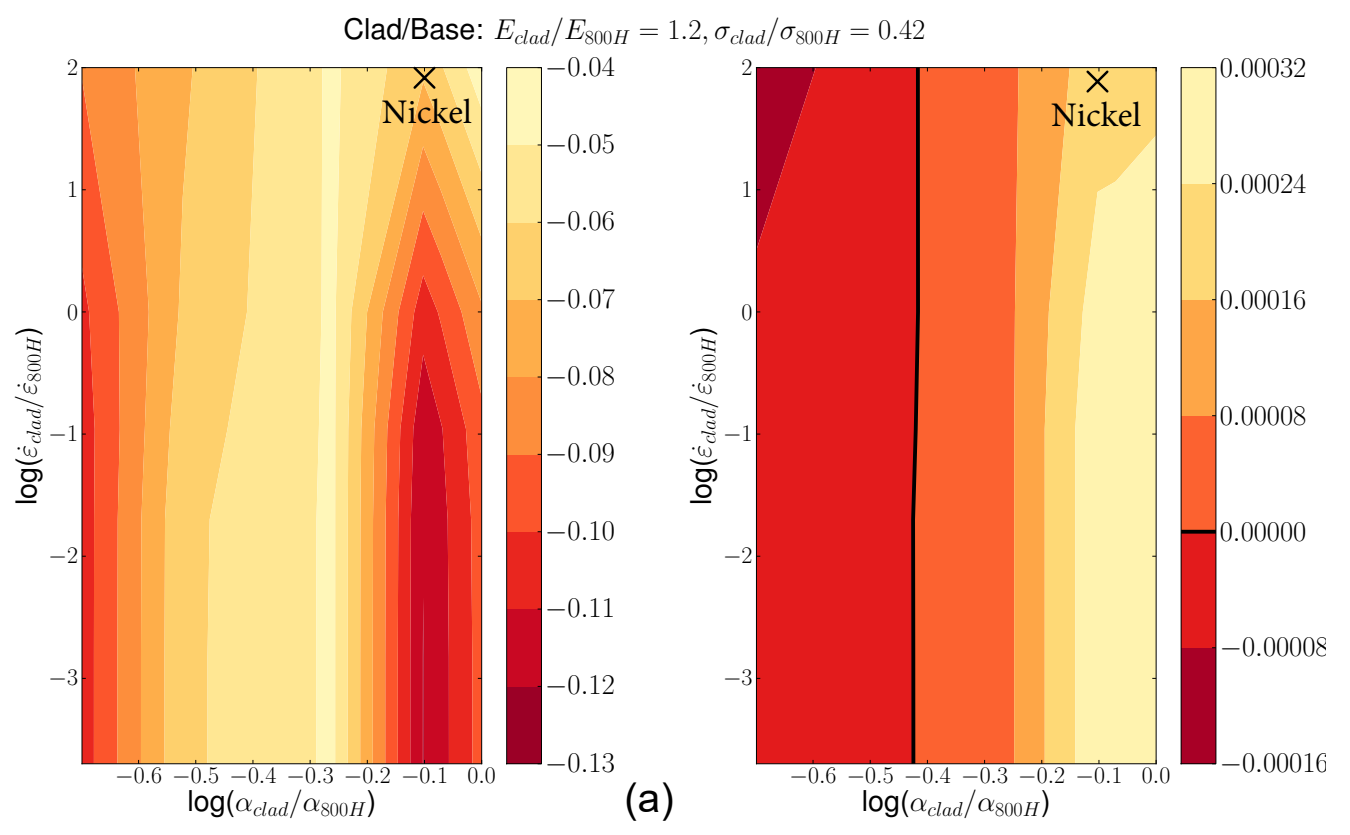

Figure 4.13: Design chart plotting the difference in the average creep damage, $\left\{\bar{D}_{\mathrm{c}}\right\}_{\text {infinite compliance }}-\left\{\bar{D}_{\mathrm{c}}\right\}_{\text {full inelastic }}$, in the base region during the hold of the last cycle (a) and the minimum difference of ASME equivalent strain range, $\{\Delta \varepsilon\}_{\text {infinite compliance }}-\{\Delta \varepsilon\}_{\text {full inelastic }}$, in the clad region over the last cycle as a function of $\alpha$ and $\dot{\varepsilon}$ in the Nickel clad/800H base system for the gradient load case.

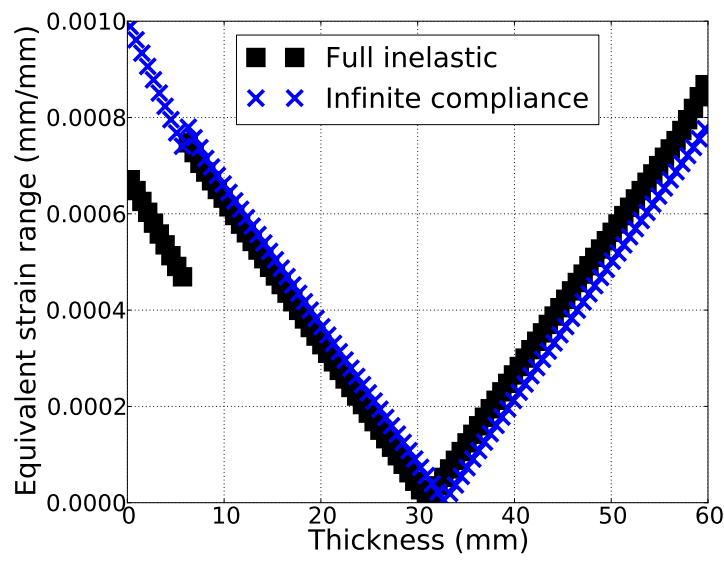

(a)

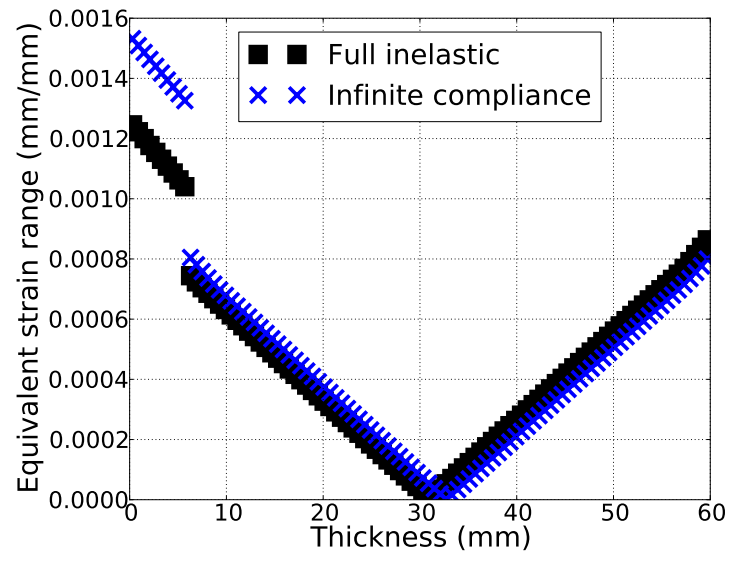

Figure 4.14: ASME equivalent strain range, plotted over the vessel thickness, over the last cycle for the gradient load case (a) and the isothermal load case (b). The figure compares the full inelastic analysis with the bounding, infinite compliance analysis in the Nickel clad/800H base system. 


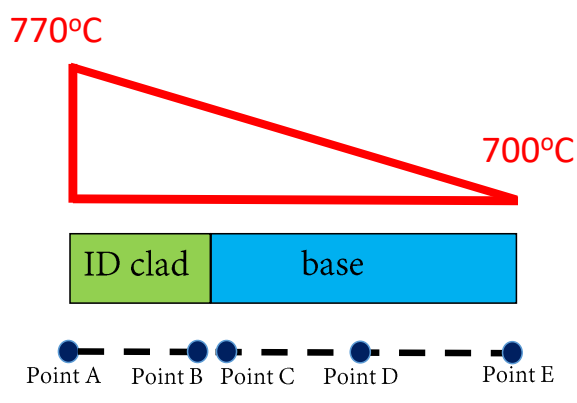

(a)

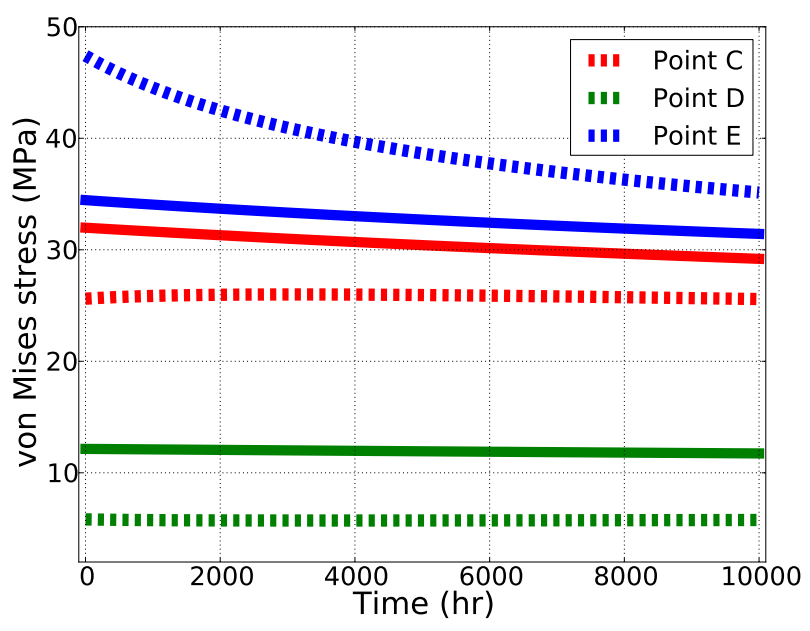

(b)

Figure 4.15: (a) Sketch showing the physical location of the stress relaxation profiles and (b) the figure compares the stress relaxation profiles between the full inelastic (dashed lines) and infinite compliance analysis (solid lines) for the thermal gradient load in the Nickel clad/800H base system.

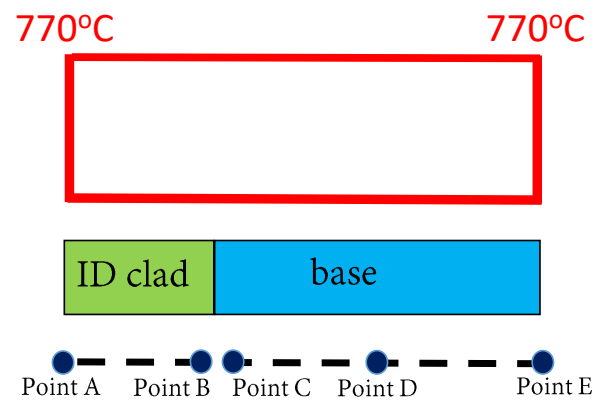

(a)

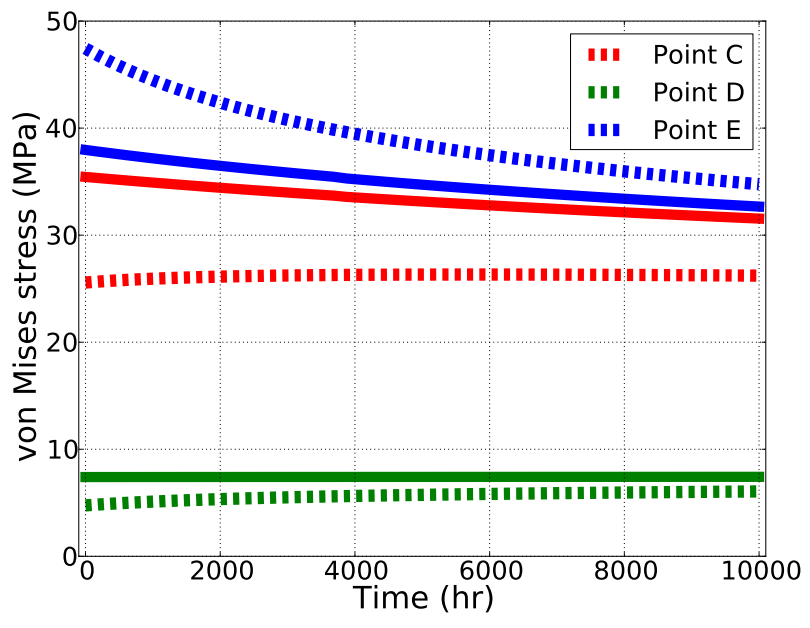

(b)

Figure 4.16: (a) Sketch showing the physical location of the stress relaxation profiles and (b) the figure compares the stress relaxation profiles between the full inelastic (dashed lines) and infinite compliance analysis (solid lines) for the isothermal load in the Nickel clad/800H base system. 
The elastic cladding analysis bounds conservatively the creep damage in the full inelastic analysis in the base region if a relative ratio of thermal coefficient $\alpha_{\text {clad }} / \alpha_{800 \mathrm{H}}>0.5$ is used. As described above, there is likely also an upper bound on the thermal expansion mismatch ratio. In the clad material, the strain ranges from the elastic cladding are quite similar to the strain range in the full inelastic analysis if the clad yield is higher and the clad creep rate is smaller than the ones of base. Rules of thumb summarizing the results are:

$$
\begin{array}{rll}
\text { Young's modulus } & : & E_{\text {clad }}<1.25 E_{800 \mathrm{H}} \\
\text { Yield stress } & : & \sigma_{800 \mathrm{H}}<\sigma_{\text {clad }}<2.5 \sigma_{800 \mathrm{H}} \\
\text { Thermal coefficient } & : & \alpha_{\text {clad }}>0.5 \alpha_{800 \mathrm{H}} \\
\text { Creep rate } & : & \dot{\varepsilon}_{\text {clad }}<\dot{\varepsilon}_{800 \mathrm{H}} .
\end{array}
$$

Again, a material does not need to meet all of these criteria simultaneously. There is also likely an upper bound on the mismatch of thermal expansion coefficients, as described above.

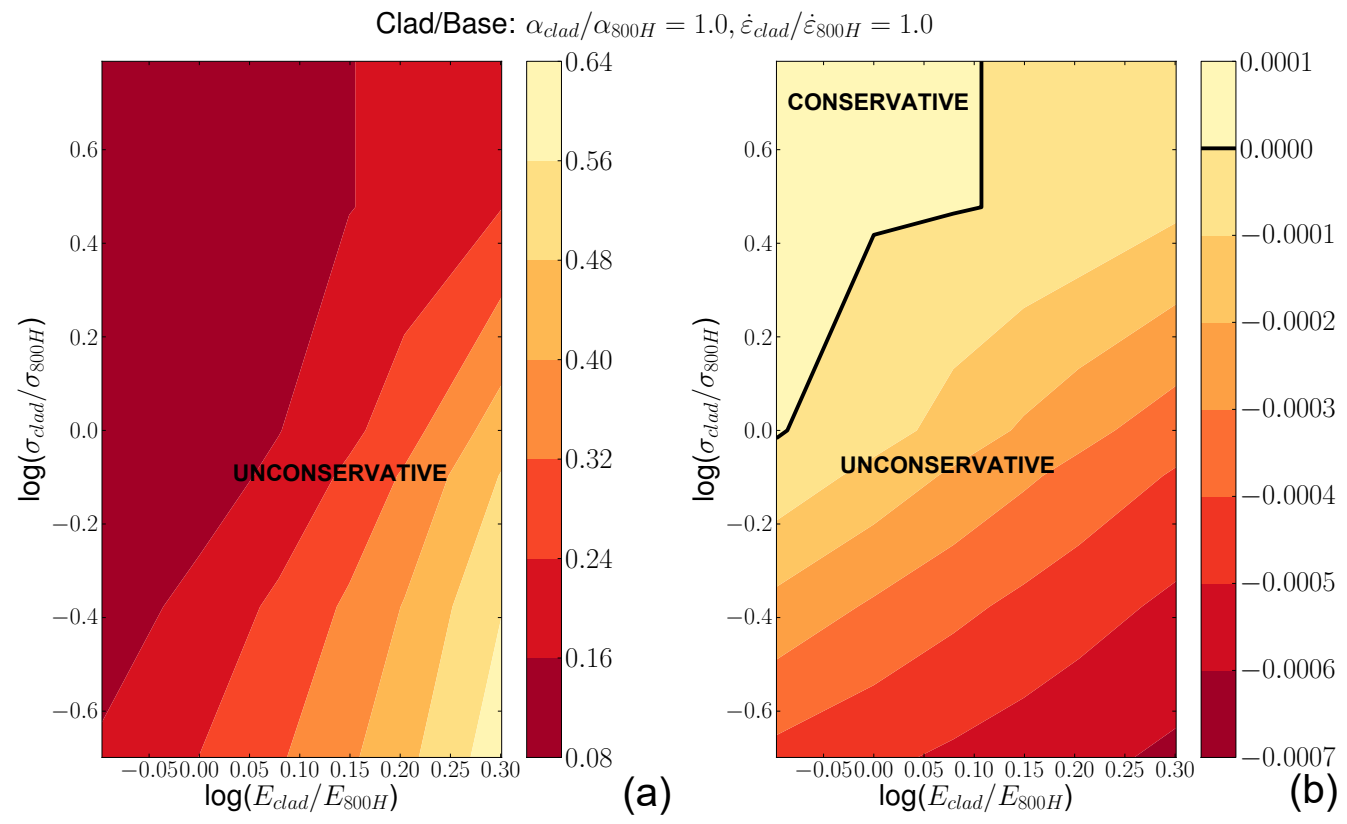

Figure 4.17: Design chart illustrating the difference in the average creep damage, $\left\{\bar{D}_{\text {c }}\right\}_{\text {elastic cladding }}-\left\{\bar{D}_{\text {c }}\right\}_{\text {full inelastic }}$, in the base region during the hold of the last cycle (a) and the minimum difference of ASME equivalent strain range, $\{\Delta \varepsilon\}_{\text {elastic cladding }}-\{\Delta \varepsilon\}_{\text {full inelastic }}$, in the clad region over the last cycle (b) as a function of $E$ and $\sigma$ in the clad/800H base system for the gradient load case.

Figures 4.29-4.31 show a good match between the full inelastic and elastic cladding analysis for both the ASME strain range and the stress relaxation profiles with two different types of thermal loading for a particular material property mismatch in the conservative region. 
Finite element analysis of compliant cladding and base metal systems

July 2018

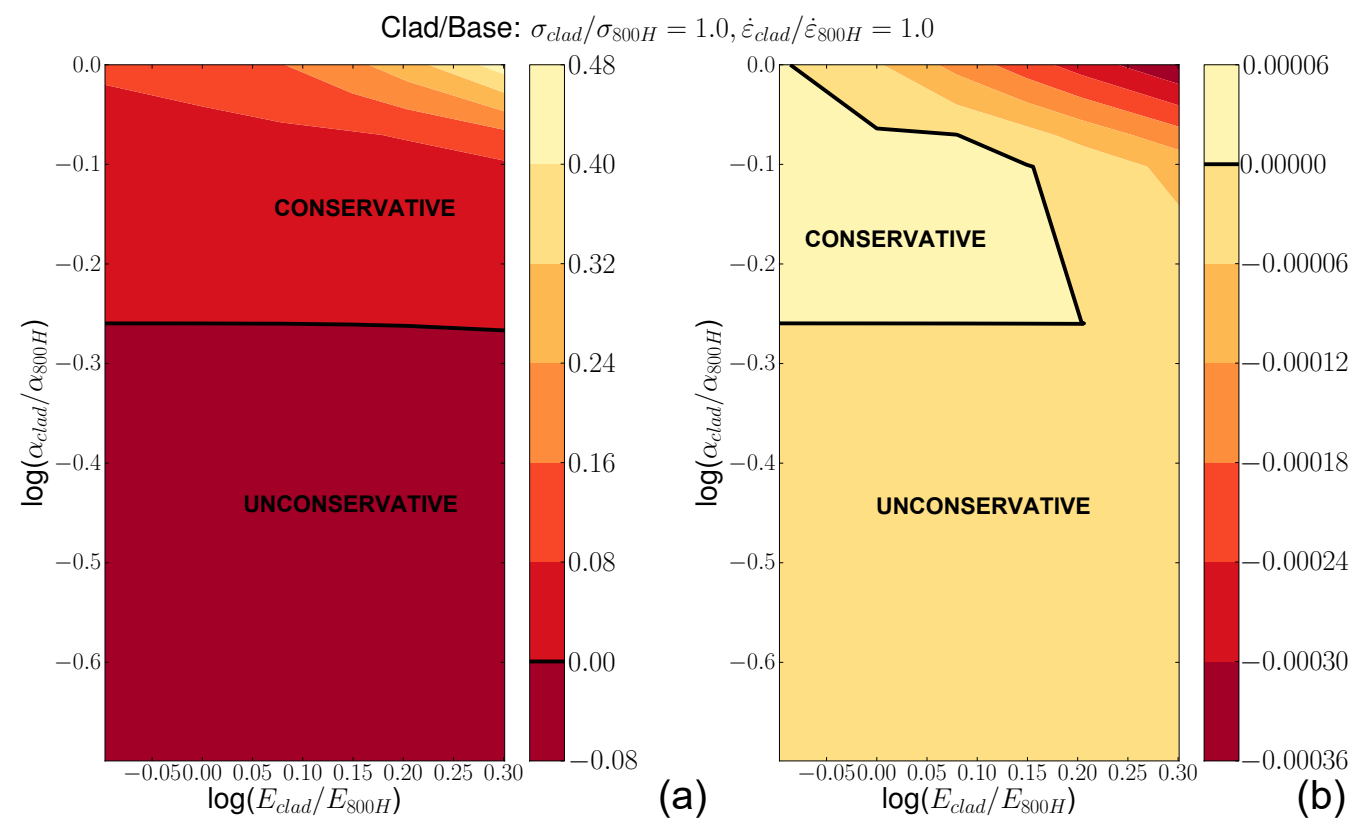

Figure 4.18: Design chart illustrating the difference in the average creep damage, $\left\{\bar{D}_{\text {c }}\right\}_{\text {elastic cladding }}-\left\{\bar{D}_{\text {c }}\right\}_{\text {full inelastic }}$, in the base region during the hold of the last cycle (a) and the minimum difference of ASME equivalent strain range, $\{\Delta \varepsilon\}_{\text {elastic cladding }}-\{\Delta \varepsilon\}_{\text {full inelastic }}$, in the clad region over the last cycle (b) as a function of $E$ and $\alpha$ in the clad/800H base system for the gradient load case.

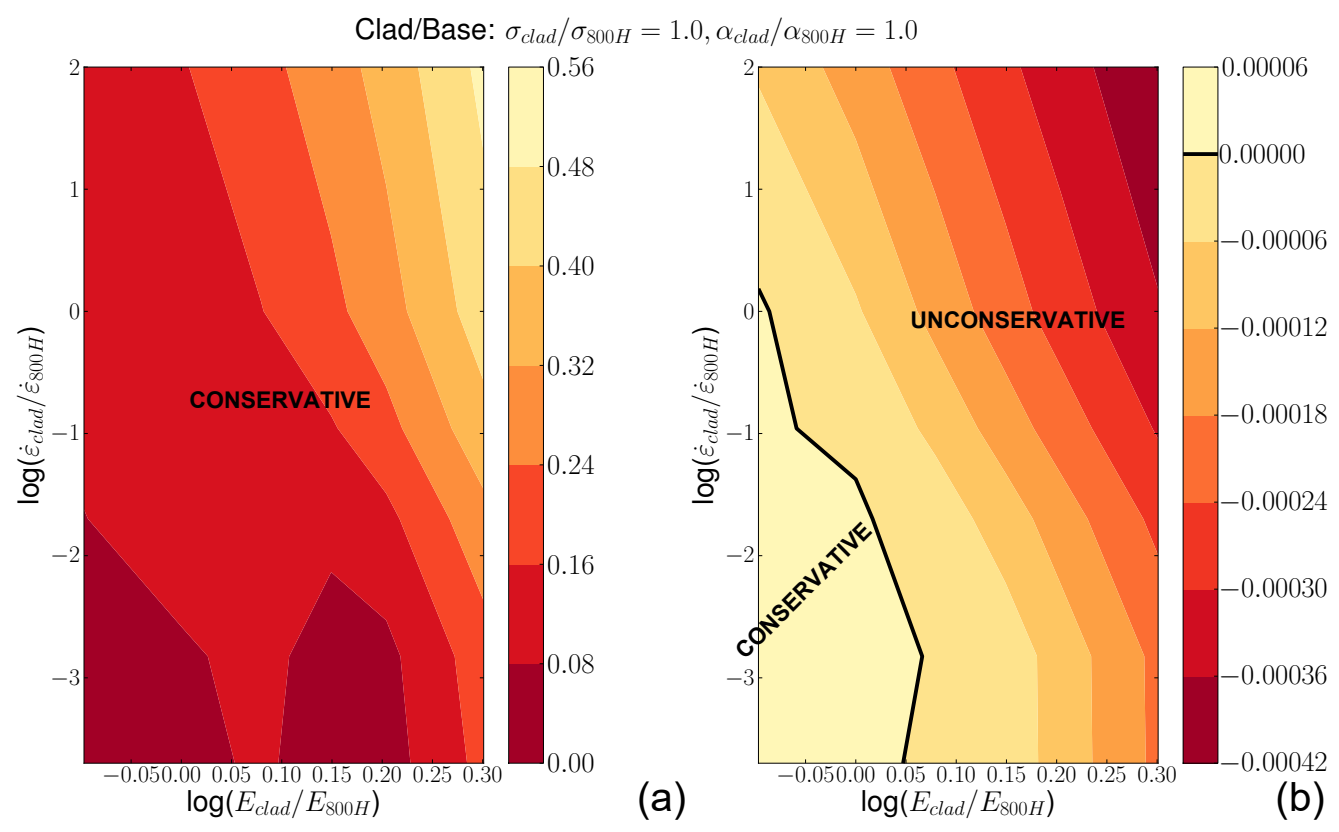

Figure 4.19: Design chart illustrating the difference in the average creep damage, $\left\{\bar{D}_{\text {c }}\right\}_{\text {elastic cladding }}-\left\{\bar{D}_{\mathrm{c}}\right\}_{\text {full inelastic }}$, in the base region during the hold of the last cycle (a) and the minimum difference of ASME equivalent strain range, $\{\Delta \varepsilon\}_{\text {elastic cladding }}-\{\Delta \varepsilon\}_{\text {full inelastic }}$, in the clad region over the last cycle (b) as a function of $E$ and $\dot{\varepsilon}$ in the clad/800H base system for the gradient load case. 
Finite element analysis of compliant cladding and base metal systems

July 2018

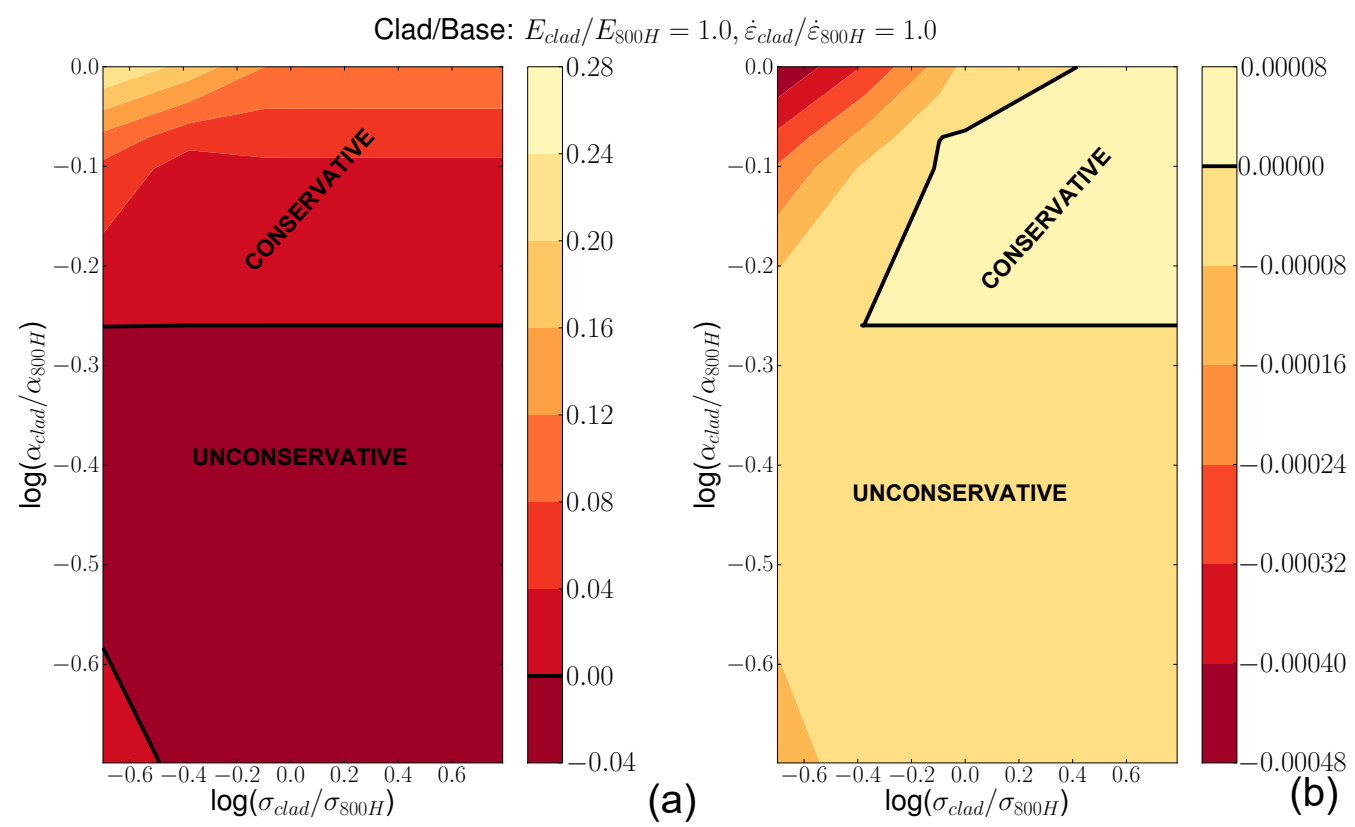

Figure 4.20: Design chart illustrating the difference in the average creep damage, $\left\{\bar{D}_{\text {c }}\right\}_{\text {elastic cladding }}-\left\{\bar{D}_{\text {c }}\right\}_{\text {full inelastic }}$, in the base region during the hold of the last cycle (a) and the minimum difference of ASME equivalent strain range, $\{\Delta \varepsilon\}_{\text {elastic cladding }}-\{\Delta \varepsilon\}_{\text {full inelastic }}$, in the clad region over the last cycle (b) as a function of $\sigma$ and $\alpha$ in the clad/800H base system for the gradient load case.

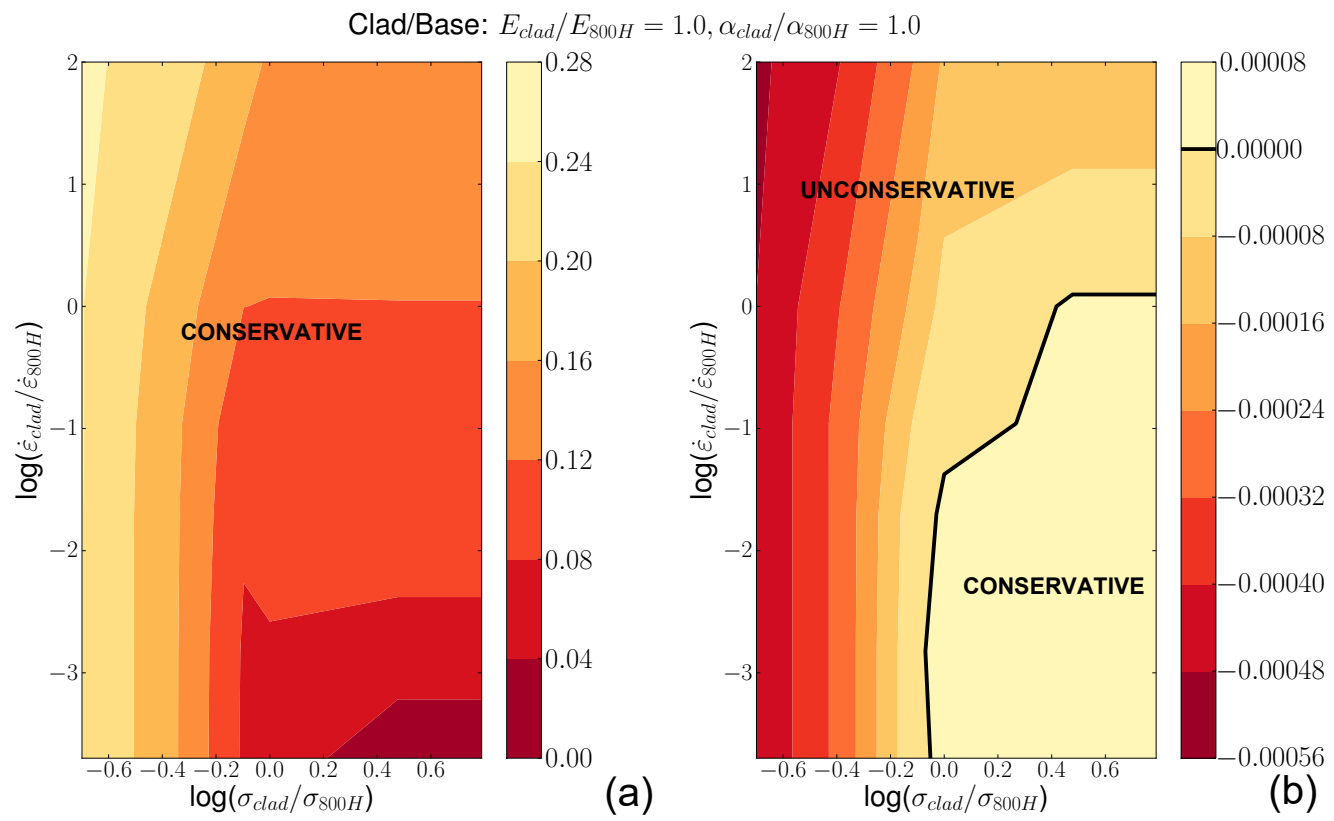

Figure 4.21: Design chart illustrating the difference in the average creep damage, $\left\{\bar{D}_{\text {c }}\right\}_{\text {elastic cladding }}-\left\{\bar{D}_{\mathrm{c}}\right\}_{\text {full inelastic }}$, in the base region during the hold of the last cycle (a) and the minimum difference of ASME equivalent strain range, $\{\Delta \varepsilon\}_{\text {elastic cladding }}-\{\Delta \varepsilon\}_{\text {full inelastic }}$, in the clad region over the last cycle (b) as a function of $\sigma$ and $\dot{\varepsilon}$ in the clad/800H base system for the gradient load case. 
Finite element analysis of compliant cladding and base metal systems

July 2018

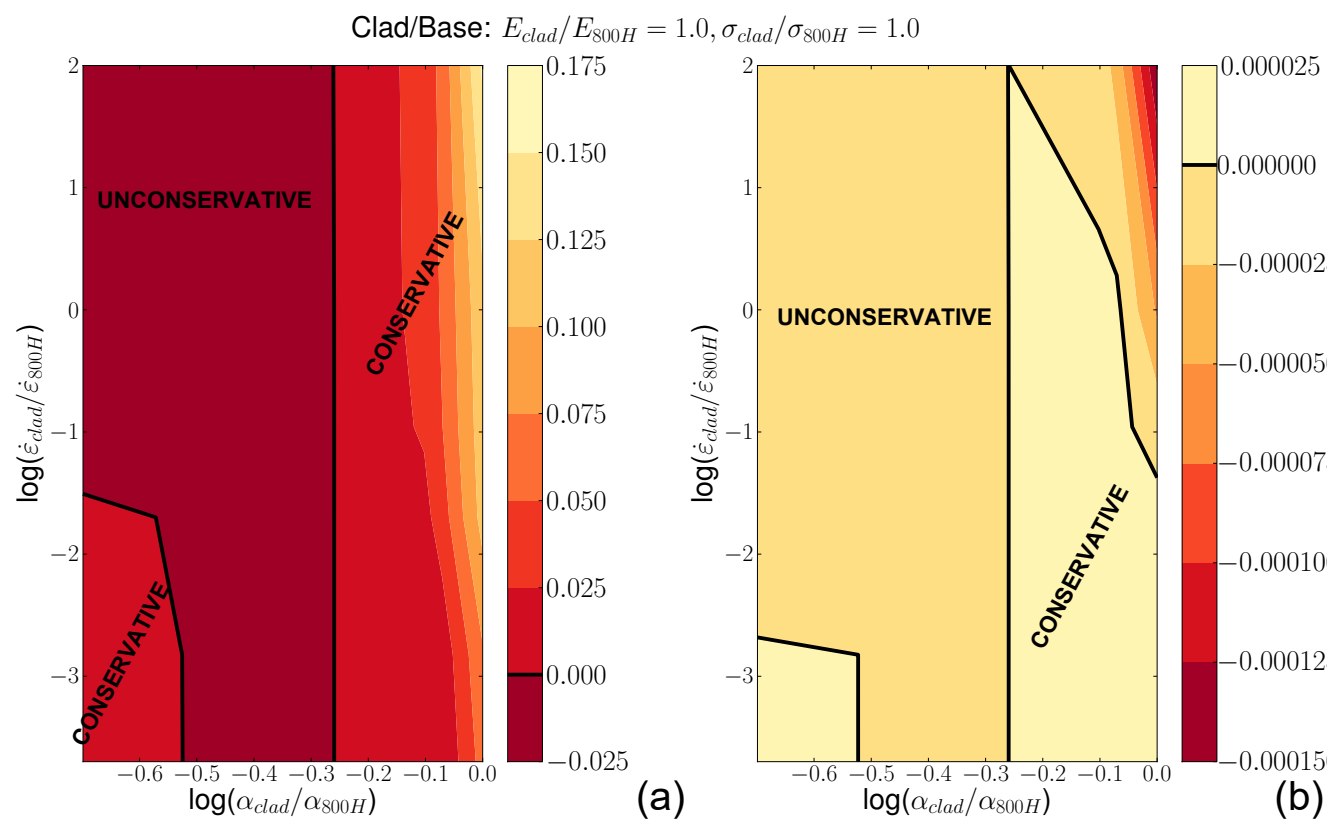

Figure 4.22: Design chart illustration the difference in the average creep damage, $\left\{\bar{D}_{\text {c }}\right\}_{\text {elastic cladding }}-\left\{\bar{D}_{\text {c }}\right\}_{\text {full inelastic }}$, in the base region during the hold of the last cycle (a) and the minimum difference of ASME equivalent strain range, $\{\Delta \varepsilon\}_{\text {elastic cladding }}-\{\Delta \varepsilon\}_{\text {full inelastic }}$, in the clad region over the last cycle (b) as a function of $\alpha$ and $\dot{\varepsilon}$ in the clad/800H base system for the gradient load case.

\begin{tabular}{llll}
\hline Property & Symbols & TZM Molybdenum & Units \\
\hline Young's modulus & $E$ & 220000 & $\mathrm{MPa}$ \\
Yield stress & $\sigma$ & 627.0 & $\mathrm{MPa}$ \\
Thermal coefficient & $\alpha$ & $5.5 \times 10^{-06}$ & $\mathrm{~mm} /\left(\mathrm{mm} \times{ }^{\circ} \mathrm{C}\right)^{-1}$ \\
Creep prefactor & $A$ & $5.33 \times 10^{-27}$ & $(\mathrm{MPa}-\mathrm{h})$ \\
Creep rate exponent & $n$ & 4.85 & - \\
Creep rate & $\dot{\varepsilon}$ & $1.97 \times 10^{-13}$ & $\mathrm{~h}^{-1}$ \\
\hline
\end{tabular}

Table 4.4: Material properties of TZM Molybdenum at $700^{\circ} \mathrm{C}$ 
Finite element analysis of compliant cladding and base metal systems

July 2018

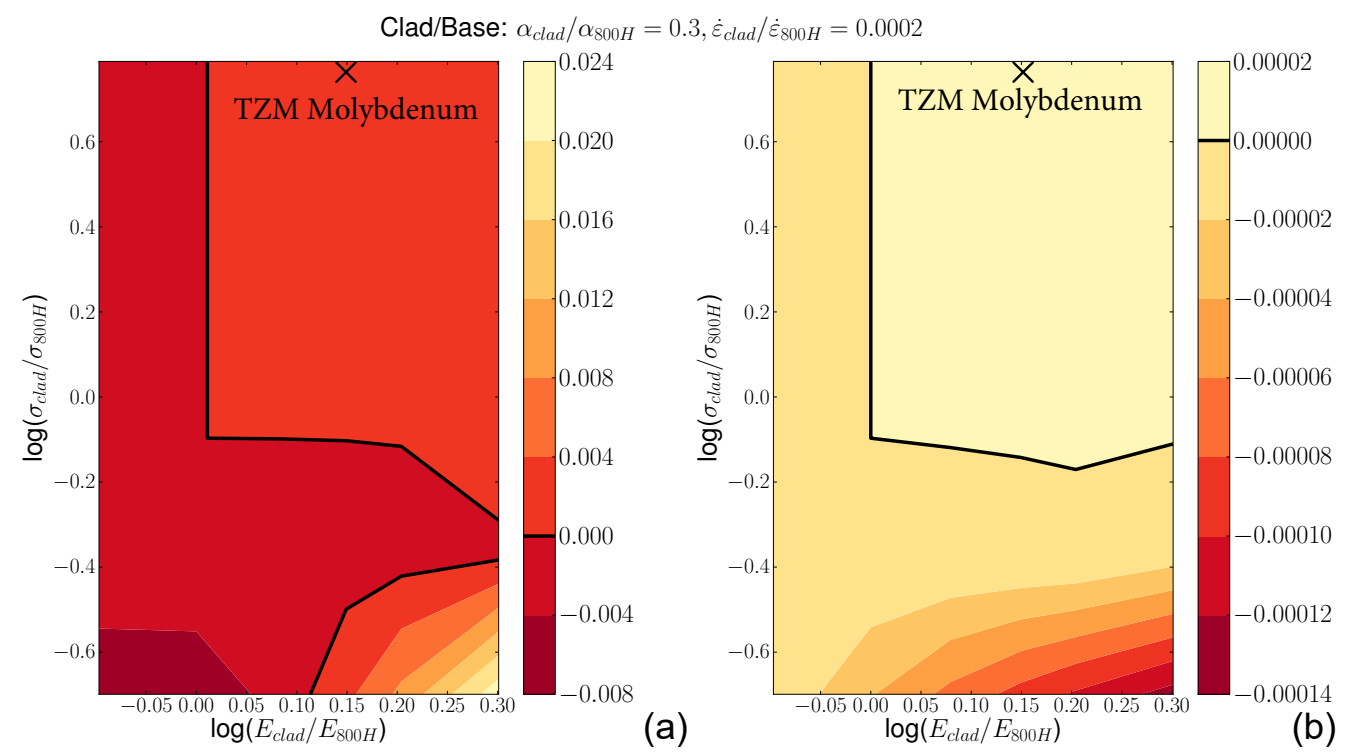

Figure 4.23: Design chart plotting the difference in the average creep damage, $\left\{\bar{D}_{\mathrm{c}}\right\}_{\text {elastic cladding }}-$ $\left\{\bar{D}_{\mathrm{c}}\right\}_{\text {full inelastic }}$, in the base region during the hold of the last cycle (a) and the minimum difference of ASME equivalent strain range, $\{\Delta \varepsilon\}_{\text {elastic cladding }}-\{\Delta \varepsilon\}_{\text {full inelastic }}$, in the clad region over the last cycle as a function of $E$ and $\sigma$ in the TZM Molybdenum clad/800H base system for the gradient load case.

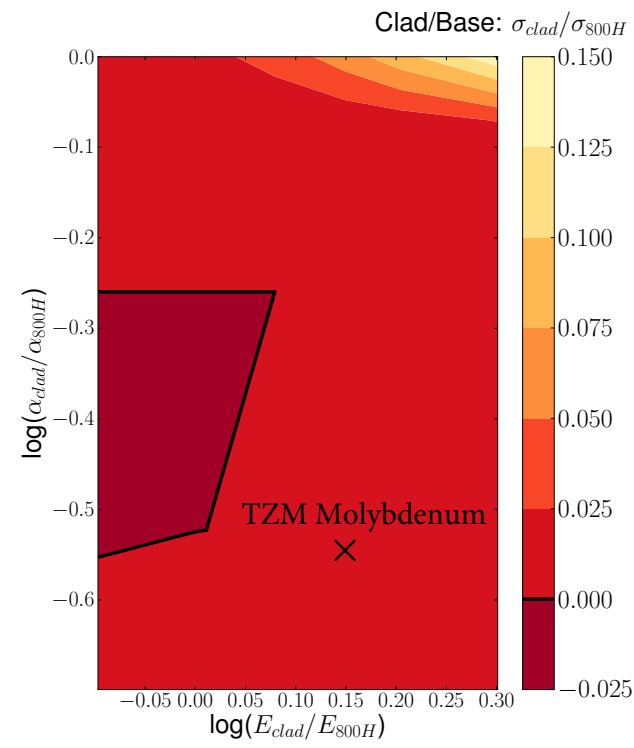

(a)

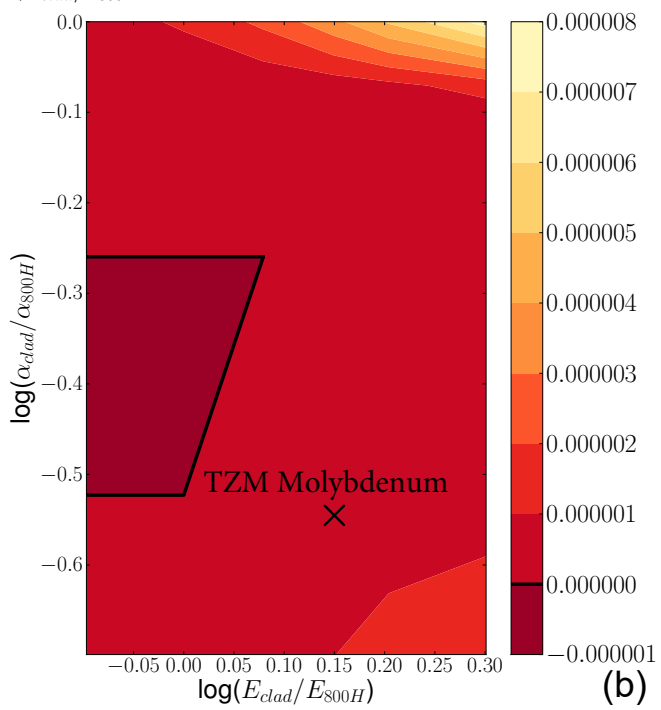

Figure 4.24: Design chart plotting the difference in the average creep damage, $\left\{\bar{D}_{\mathrm{c}}\right\}_{\text {elastic cladding }}-$ $\left\{\bar{D}_{\mathrm{c}}\right\}_{\text {full inelastic }}$, in the base region during the hold of the last cycle (a) and the minimum difference of ASME equivalent strain range, $\{\Delta \varepsilon\}_{\text {elastic cladding }}-\{\Delta \varepsilon\}_{\text {full inelastic }}$, in the clad region over the last cycle as a function of $E$ and $\alpha$ in the TZM Molybdenum clad/800H base system for the gradient load case. 
Finite element analysis of compliant cladding and base metal systems

July 2018

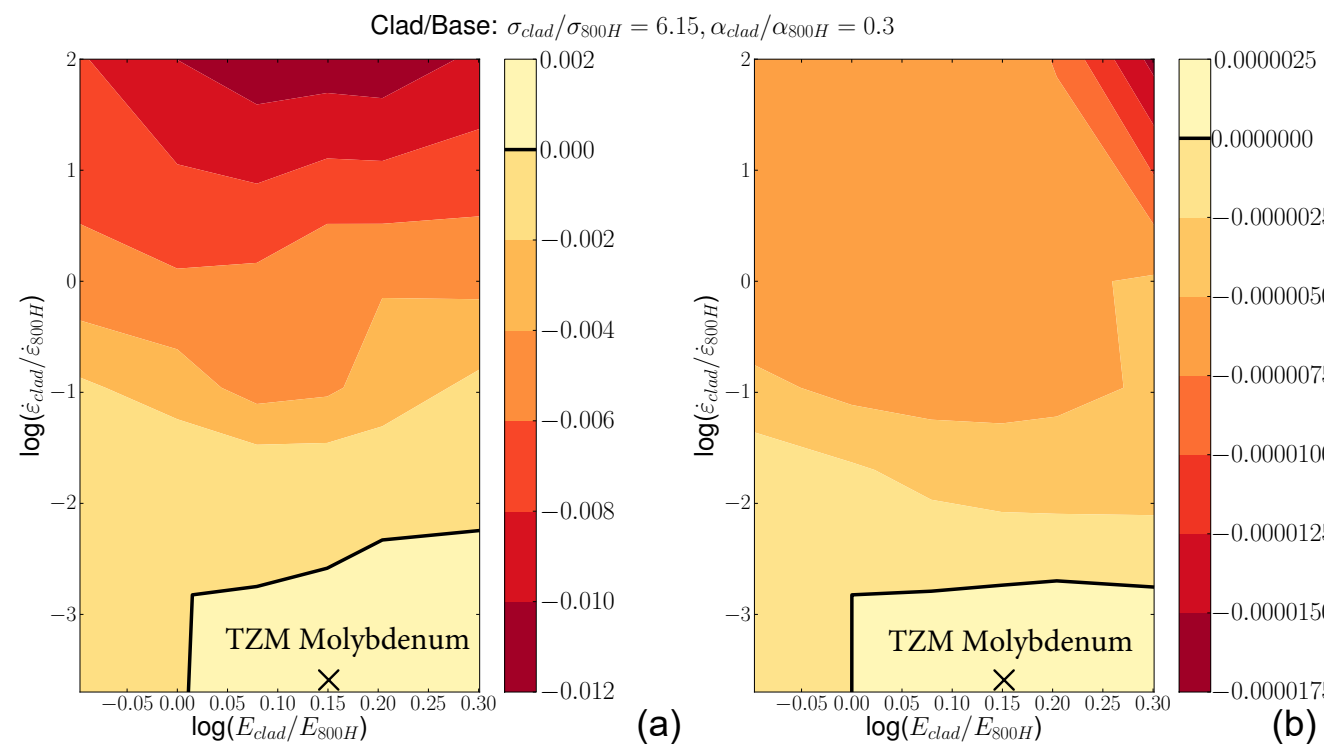

Figure 4.25: Design chart plotting the difference in the average creep damage, $\left\{\bar{D}_{\mathrm{c}}\right\}_{\text {elastic cladding }}-$ $\left\{\bar{D}_{\mathrm{c}}\right\}_{\text {full inelastic }}$, in the base region during the hold of the last cycle (a) and the minimum difference of ASME equivalent strain range, $\{\Delta \varepsilon\}_{\text {elastic cladding }}-\{\Delta \varepsilon\}_{\text {full inelastic }}$, in the clad region over the last cycle as a function of $E$ and $\dot{\varepsilon}$ in the TZM Molybdenum clad/800H base system for the gradient load case.

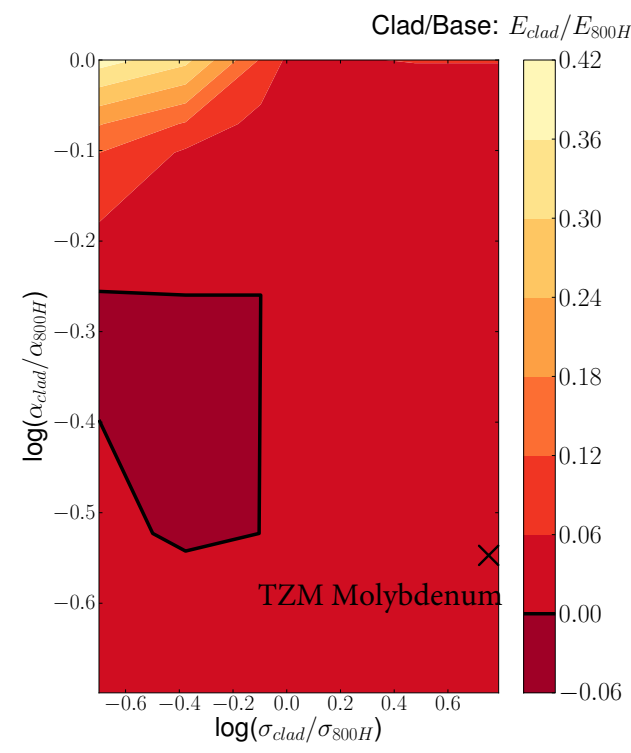

(a)

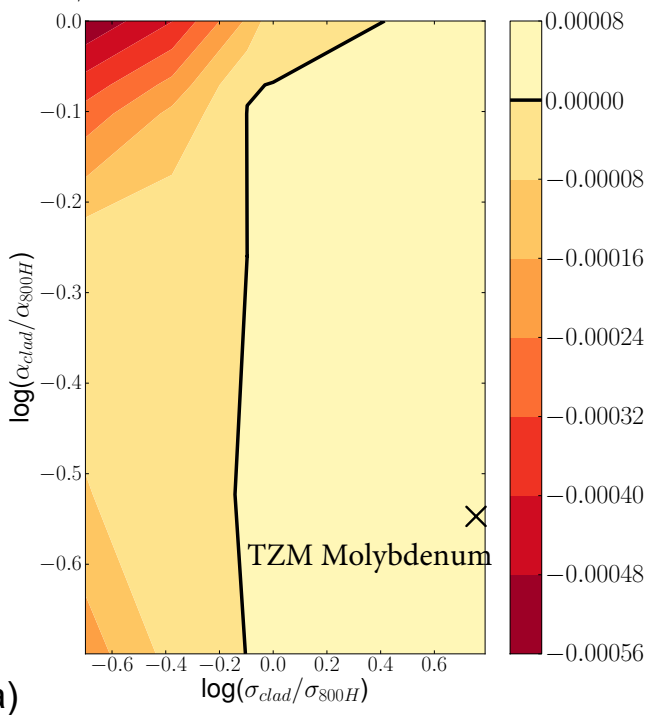

Figure 4.26: Design chart plotting the difference in the average creep damage, $\left\{\bar{D}_{\text {c }}\right\}_{\text {elastic cladding }}-$ $\left\{\bar{D}_{\mathrm{c}}\right\}_{\text {full inelastic }}$, in the base region during the hold of the last cycle (a) and difference of ASME equivalent strain range, $\{\Delta \varepsilon\}_{\text {elastic cladding }}-\{\Delta \varepsilon\}_{\text {full inelastic }}$, in the clad region over the last cycle as a function of $\sigma$ and $\alpha$ in the TZM Molybdenum clad/800H base system for the gradient load case. 
Finite element analysis of compliant cladding and base metal systems

July 2018

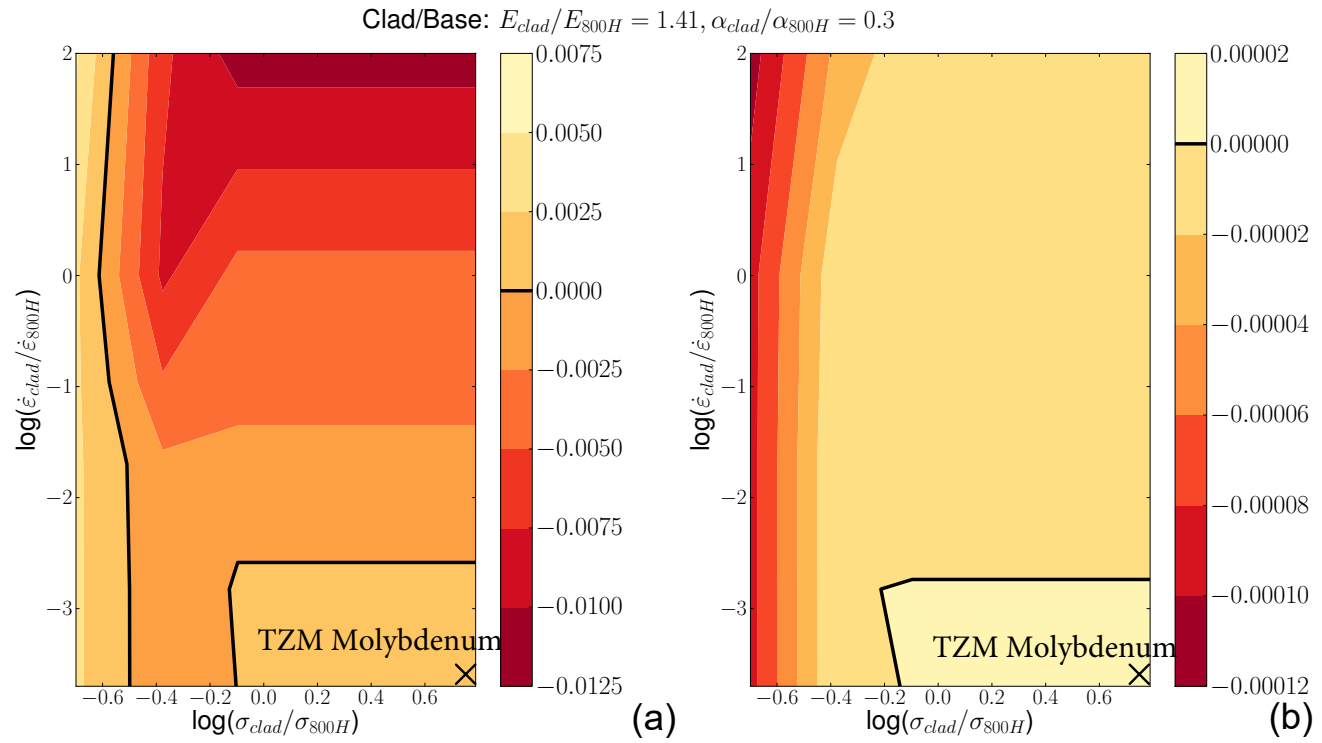

Figure 4.27: Design chart plotting the difference in the average creep damage, $\left\{\bar{D}_{\text {c }}\right\}_{\text {elastic cladding }}-$ $\left\{\bar{D}_{\mathrm{c}}\right\}_{\text {full inelastic }}$, in the base region during the hold of the last cycle (a) and the minimum difference of ASME equivalent strain range, $\{\Delta \varepsilon\}_{\text {elastic cladding }}-\{\Delta \varepsilon\}_{\text {full inelastic }}$, in the clad region over the last cycle as a function of $\sigma$ and $\dot{\varepsilon}$ in the TZM Molybdenum clad/800H base system for the gradient load case.

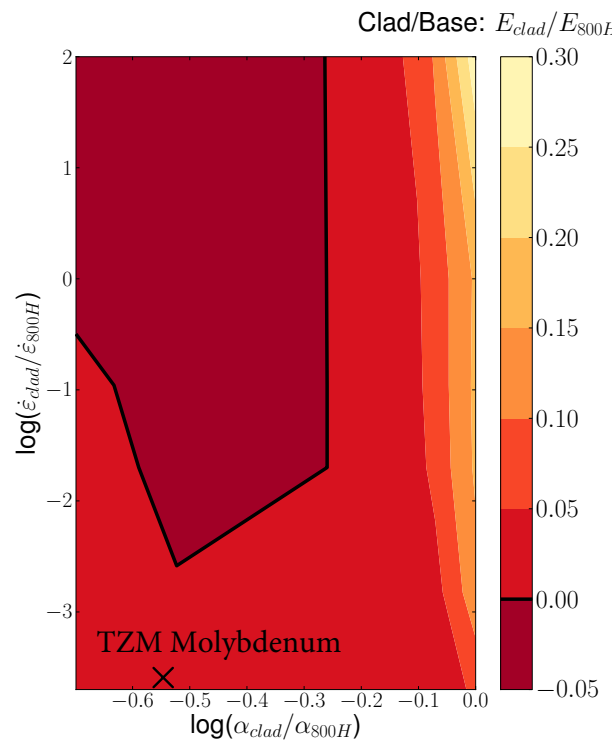

(a)

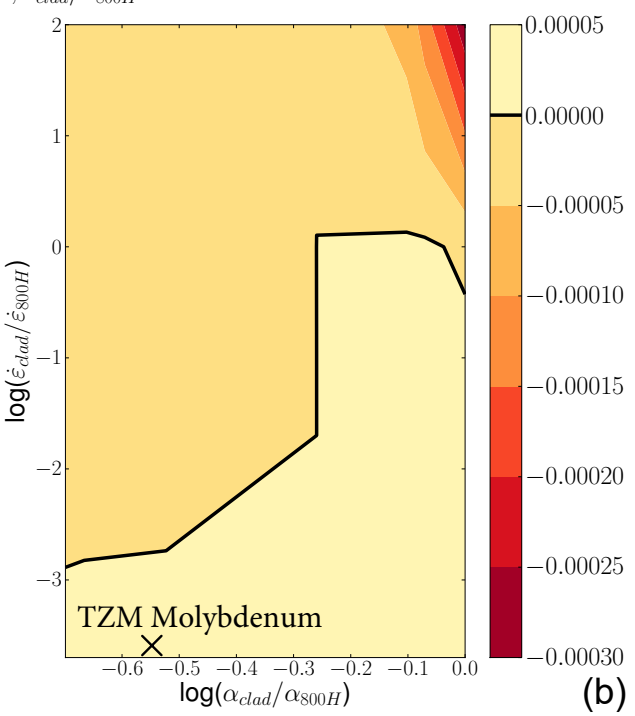

Figure 4.28: Design chart plotting the difference in the average reep damage, $\left\{\bar{D}_{\mathrm{c}}\right\}_{\text {elastic cladding }}-$ $\left\{\bar{D}_{c}\right\}_{\text {full inelastic }}$, in the base region during the hold of the last cycle (a) and the minimum difference of ASME equivalent strain range, $\{\Delta \varepsilon\}_{\text {elastic cladding }}-\{\Delta \varepsilon\}_{\text {full inelastic }}$, in the clad region over the last cycle as a function of $\alpha$ and $\dot{\varepsilon}$ in the TZM Molybdenum clad/800H base system for the gradient load case. 
Finite element analysis of compliant cladding and base metal systems

July 2018

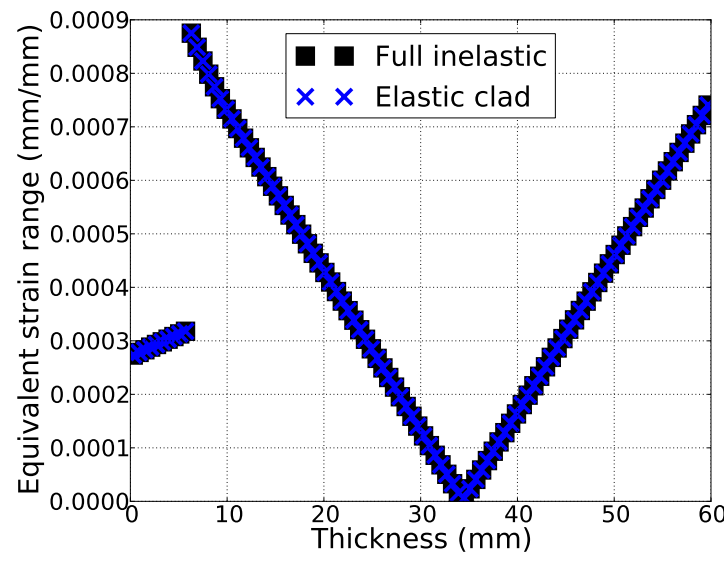

(a)

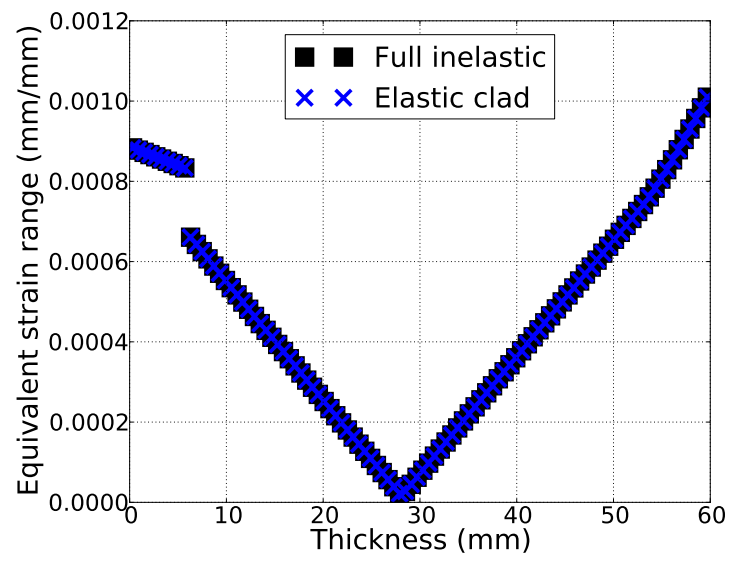

(b)

Figure 4.29: ASME equivalent strain range, plotted over the vessel thickness, over the last cycle in the TZM Molybdenum clad/800H base system for the gradient load case (a) and the isothermal load case (b). The figure compares the full inelastic analysis with the bounding, elastic cladding analysis.
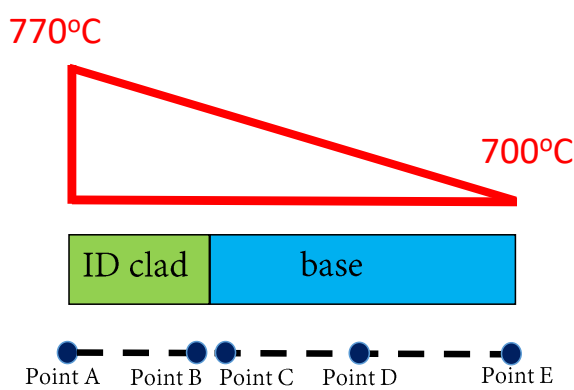

(a)

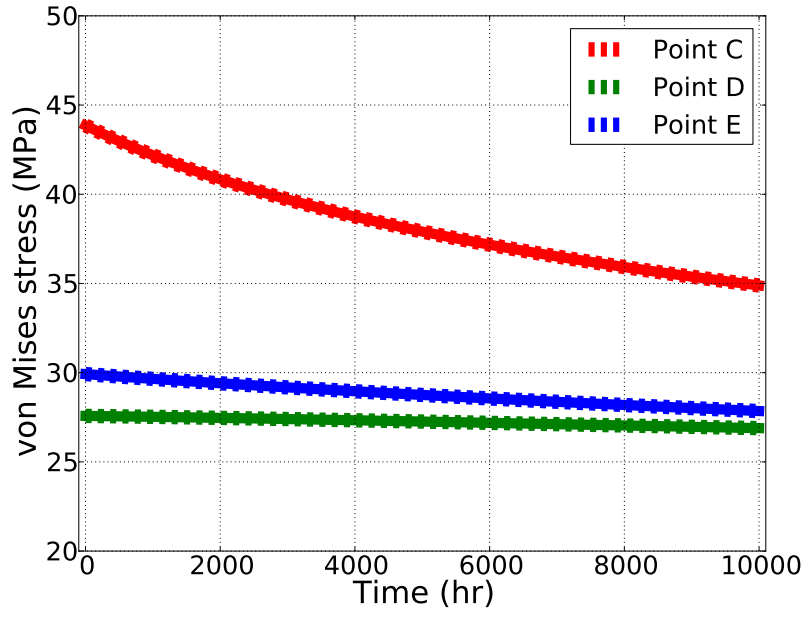

(b)

Figure 4.30: a) Sketch showing the physical location of the stress relaxation profiles and b) the figure compares the stress relaxation profiles between the full inelastic (dashed lines) and infinite compliance analysis (solid lines) in the TZM Molybdenum clad/800H base system for the thermal gradient load. 

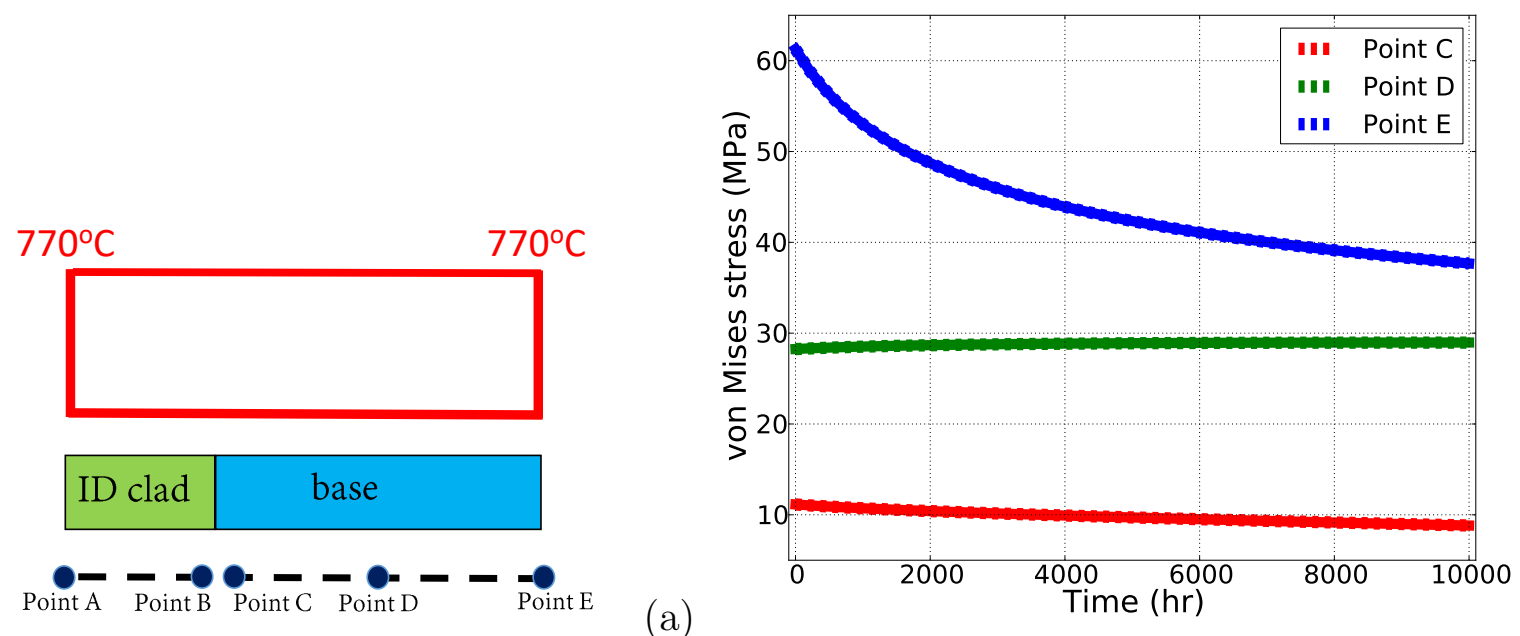

Figure 4.31: a) Sketch showing the physical location of the stress relaxation profiles and b) the figure compares the stress relaxation profiles between the full inelastic (dashed lines) and infinite compliance analysis (solid lines) in the TZM Molybdenum clad/800 base system for the isothermal load.

\subsection{Cladded IHX tube}

This section repeats similar analyses to those described above but now for a configuration representative an IHX tube cladded on both the inner and outer diameters. The base material is stainless steel $316 \mathrm{H}$ with total wall thickness of $0.2 \mathrm{~mm}$ with an inner of radius of $2 \mathrm{~mm}$, cladded by a $10 \%$ thickness layer $(0.02 \mathrm{~mm})$ for both inner (ID clad) and outer (OD clad) surfaces. Again, the tube is under a constant pressure and two different thermal cycles, described in Fig. $4.1 \mathrm{a}-\mathrm{b}$ with $\Delta T=60^{\circ} \mathrm{C}$. The tube is held for 100 hours at the peak thermal load. Material properties of the $316 \mathrm{H}$ base at $700^{\circ} \mathrm{C}$ are summarized in Table 4.5 and the ranges of material properties of the clad components are given in Table 4.6. For simplicity the Poisson ratio $\nu$ and the creep rate exponent $n$ of inner and outer clad components are assumed to match the $316 \mathrm{H}$ base material.

\begin{tabular}{llll}
\hline Property & Symbols & $316 \mathrm{H}$ & Units \\
\hline Young's modulus & $E_{316 H}$ & 140000 & $\mathrm{MPa}$ \\
Poisson ratio & $\nu_{316 H}$ & 0.27 & - \\
Yield stress & $\sigma_{316 H}$ & 103.0 & $\mathrm{MPa}$ \\
Thermal coefficient & $\alpha_{316 H}$ & $18.6 \times 10^{-06}$ & $\mathrm{~mm} /\left(\mathrm{mm} \times{ }^{0} \mathrm{C}\right)^{-1}$ \\
Creep prefactor & $A_{316 H}$ & $1.72 \times 10^{-26}$ & $\left(\mathrm{MPa}^{-n} / \mathrm{h}\right)$ \\
Creep rate exponent & $n_{316 H}$ & 7.9 & - \\
Creep rate & $\dot{\varepsilon}_{316 H}$ & $1.37 \times 10^{-10}$ & $\mathrm{~h}^{-1}$ \\
\hline
\end{tabular}

Table 4.5: Materials properties of $316 \mathrm{H}$ base at $700^{\circ} \mathrm{C}$ 
Finite element analysis of compliant cladding and base metal systems

July 2018

\begin{tabular}{llll}
\hline Property & Symbols & Units & Varied values \\
\hline Young's modulus & $E_{\text {clad }}$ & $\mathrm{MPa}$ & {$[0.8,1.0,1.2,1.6,2.0]^{*} E_{3}$} \\
Yield stress & $\sigma_{\text {clad }}$ & $\mathrm{MPa}$ & {$[0.2,0.42,1.0,3.0,6.15]^{*} \sigma_{3}$} \\
Thermal coefficient & $\alpha_{\text {clad }}$ & $\mathrm{mm} /\left(\mathrm{mm} \times{ }^{0} \mathrm{C}\right)^{-1}$ & {$[0.1,0.3,0.85,1.0,2.0]^{*} \alpha_{3}$} \\
Creep rate & $\dot{\varepsilon}_{\text {clad }}$ & $\mathrm{h}^{-1}$ & {$[0.0002,0.02,1.0,10.0,100.0]^{*} \dot{\varepsilon}_{3}$} \\
\hline
\end{tabular}

Table 4.6: Materials properties of clad and their variation in IHX tube simulations

\subsubsection{Creep compliant cladding}

Figures 4.32-4.37 plot design charts for the thermal gradient load case with the clad reference material matching the base material properties. Figures 4.38-4.43 are corresponding plots where the reference clad is nickel. Suggested limits on the clad properties $\left(E_{4}, \sigma_{\text {clad }}, \alpha_{\text {clad }}, \dot{\varepsilon}_{\text {clad }}\right)$ relative to the $316 \mathrm{H}$ base properties $\left(E_{316 H}, \sigma_{316 H}, \alpha_{316 H}, \dot{\varepsilon}_{316 H}\right)$ are

$$
\begin{aligned}
\text { Young's modulus } & : \text { No constraint } \\
\text { Yield stress } & : 0.6 \sigma_{316 H}<\sigma_{\text {clad }}<2.0 \sigma_{316 H} \\
\text { Thermal coefficient } & : \alpha_{\text {clad }}>0.3 \alpha_{316 H} \\
\text { Creep rate } & : \dot{\varepsilon}_{\text {clad }}>0.1 \dot{\varepsilon}_{316 H}
\end{aligned}
$$

with the same caveats described above.

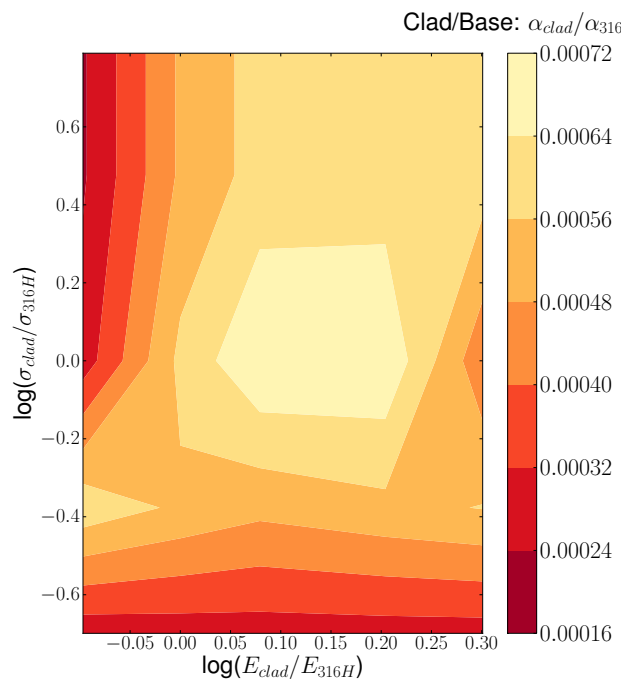

(a)

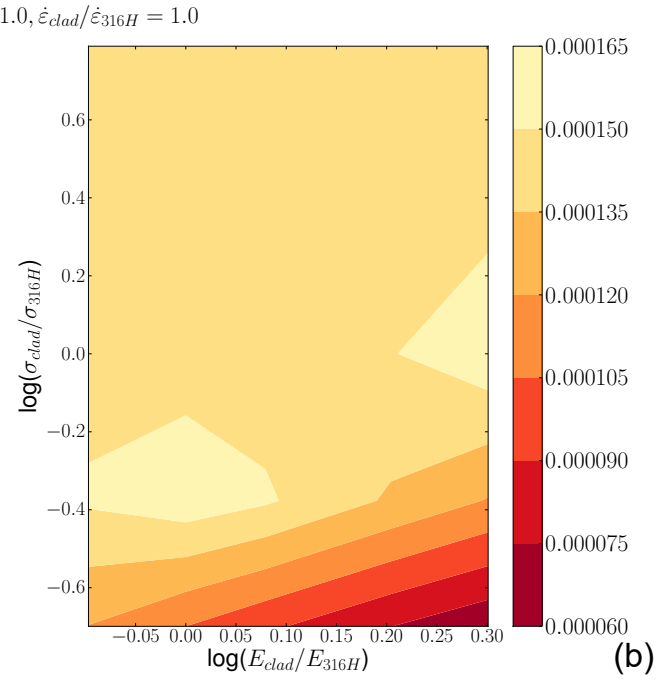

Figure 4.32: Design chart illustrating the difference in the average creep damage, $\left\{\bar{D}_{\text {c }}\right\}_{\text {infinite compliance }}-\left\{\bar{D}_{\text {c }}\right\}_{\text {full inelastic }}$, in the base region during the hold of the last cycle (a) and the minimum difference of ASME equivalent strain range, $\{\Delta \varepsilon\}_{\text {infinite compliance }}-\{\Delta \varepsilon\}_{\text {full inelastic }}$, in the ID and OD clad regions over the last cycle (b) as a function of $E$ and $\sigma$ in the clad/316H base system for the gradient load case. 
Finite element analysis of compliant cladding and base metal systems

July 2018

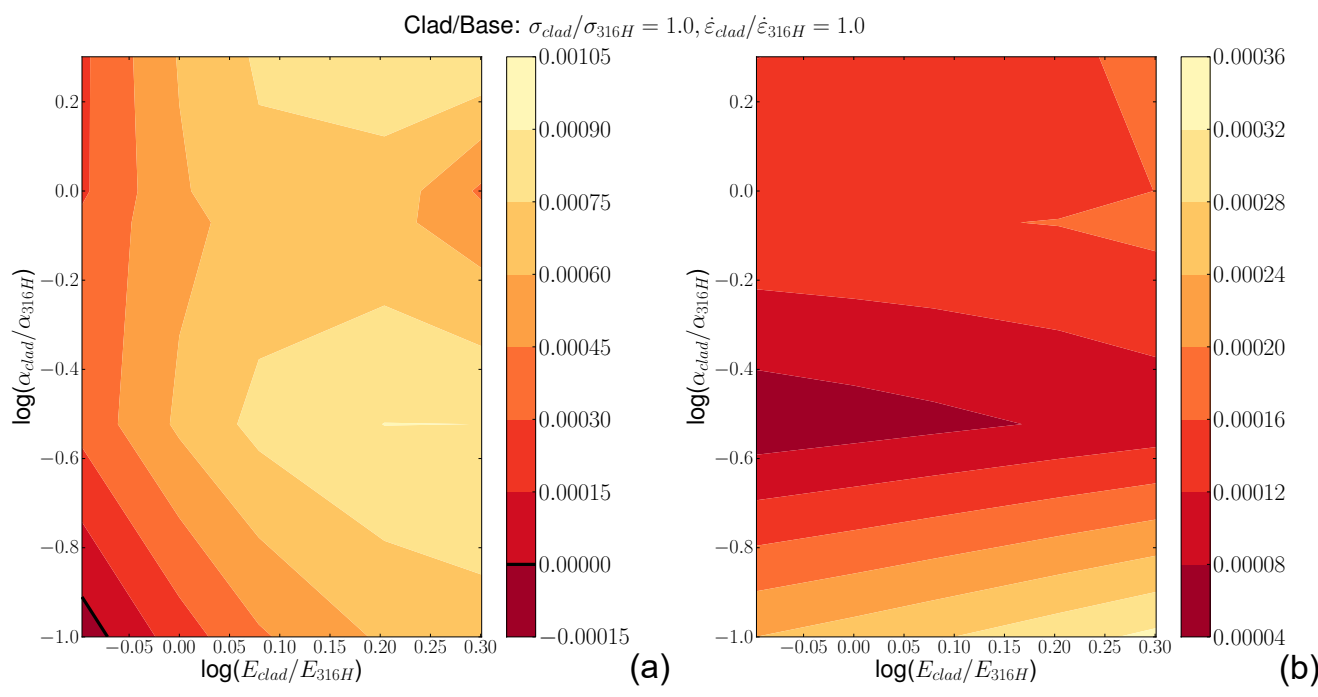

Figure 4.33: Design chart illustrating the difference in the average creep damage, $\left\{\bar{D}_{\mathrm{c}}\right\}_{\text {infinite compliance }}-\left\{\bar{D}_{\mathrm{c}}\right\}_{\text {full inelastic }}$, in the base region during the hold of the last cycle (a) and the minimum difference of ASME equivalent strain range, $\{\Delta \varepsilon\}_{\text {infinite compliance }}-\{\Delta \varepsilon\}_{\text {full inelastic }}$, in the ID and OD clad regions over the last cycle (b) as a function of $E$ and $\alpha$ in the clad/316H base system for the gradient load case.

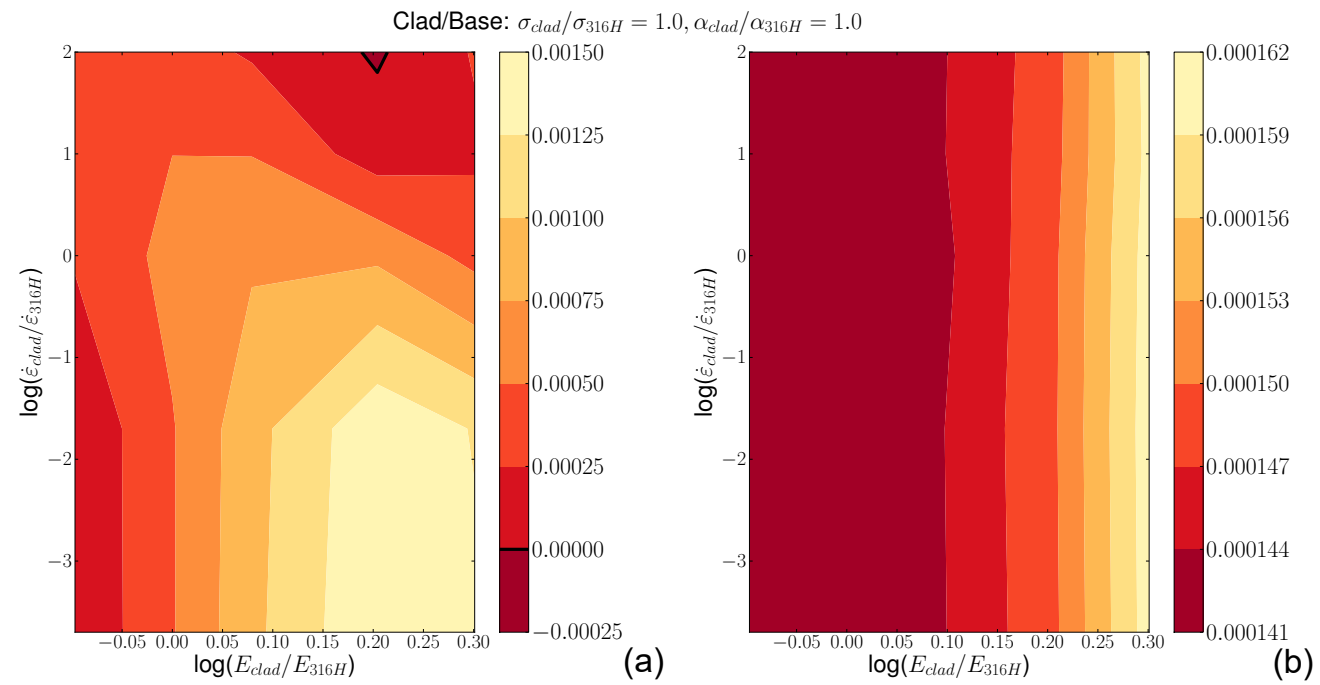

Figure 4.34: Design chart illustrating the difference in the average creep damage, $\left\{\bar{D}_{\mathrm{c}}\right\}_{\text {infinite compliance }}-\left\{\bar{D}_{\mathrm{c}}\right\}_{\text {full inelastic }}$, in the base region during the hold of the last cycle (a) and the minimum difference of ASME equivalent strain range, $\{\Delta \varepsilon\}_{\text {infinite compliance }}-\{\Delta \varepsilon\}_{\text {full inelastic }}$, in the ID and OD clad regions over the last cycle (b) as a function of $E$ and $\dot{\varepsilon}$ in the clad/316H base system for the gradient load case. 
Finite element analysis of compliant cladding and base metal systems

July 2018

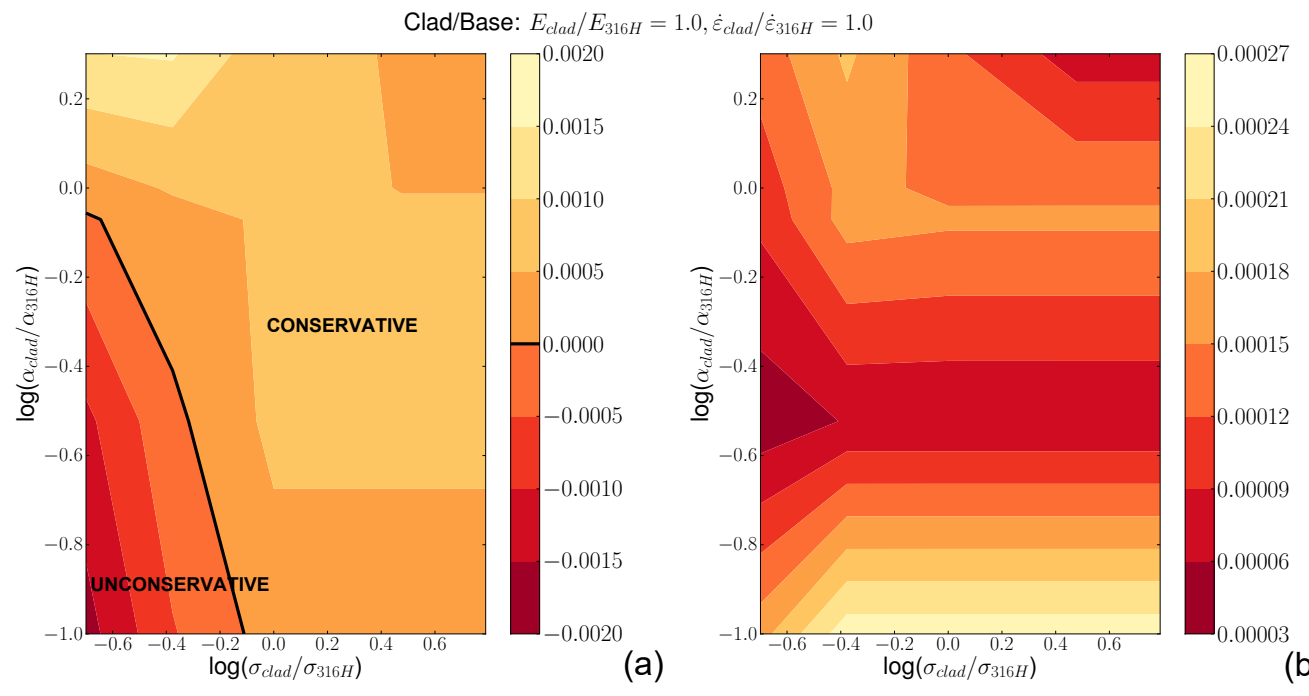

Figure 4.35: Design chart illustrating the difference in the average creep damage, $\left\{\bar{D}_{\mathrm{c}}\right\}_{\text {infinite compliance }}-\left\{\bar{D}_{\mathrm{c}}\right\}_{\text {full inelastic }}$, in the base region during the hold of the last cycle (a) and the minimum difference of ASME equivalent strain range, $\{\Delta \varepsilon\}_{\text {infinite compliance }}-\{\Delta \varepsilon\}_{\text {full inelastic }}$, in the ID and OD clad regions over the last cycle (b) as a function of $\sigma$ and $\alpha$ in the clad/316H base system for the gradient load case.

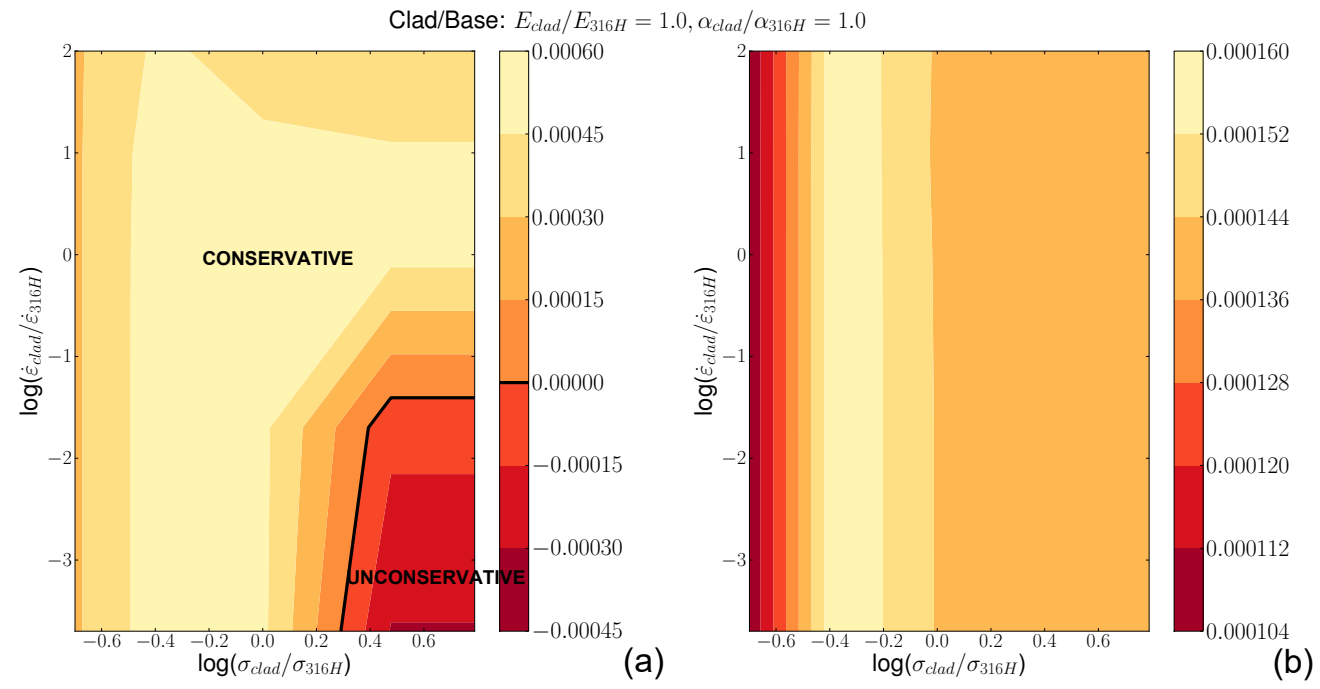

Figure 4.36: Design chart illustrating the difference in the average creep damage, $\left\{\bar{D}_{\mathrm{c}}\right\}_{\text {infinite compliance }}-\left\{\bar{D}_{\mathrm{c}}\right\}_{\text {full inelastic }}$, in the base region during the hold of the last cycle (a) and the minimum difference of ASME equivalent strain range, $\{\Delta \varepsilon\}_{\text {infinite compliance }}-\{\Delta \varepsilon\}_{\text {full inelastic }}$, in the ID and OD clad regions over the last cycle (b) as a function of $\sigma$ and $\dot{\varepsilon}$ in the clad/316H base system for the gradient load case. 


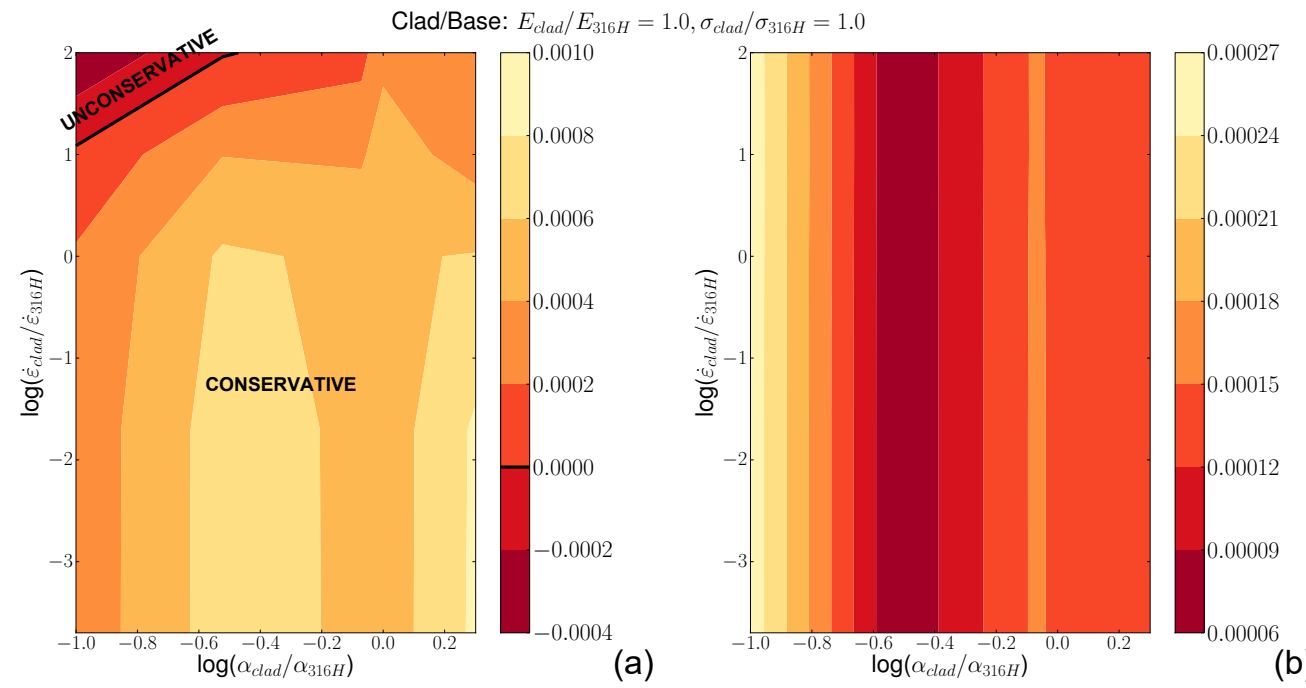

Figure 4.37: Design chart illustration the difference in the average creep damage, $\left\{\bar{D}_{\mathrm{c}}\right\}_{\text {infinite compliance }}-\left\{\bar{D}_{\mathrm{c}}\right\}_{\text {full inelastic }}$, in the base region during the hold of the last cycle (a) and minimum difference of ASME equivalent strain range, $\{\Delta \varepsilon\}_{\text {infinite compliance }}-\{\Delta \varepsilon\}_{\text {full inelastic }}$, in the ID and OD clad regions over the last cycle (b) as a function of $\alpha$ and $\dot{\varepsilon}$ in the clad/316H base system for the gradient load case.

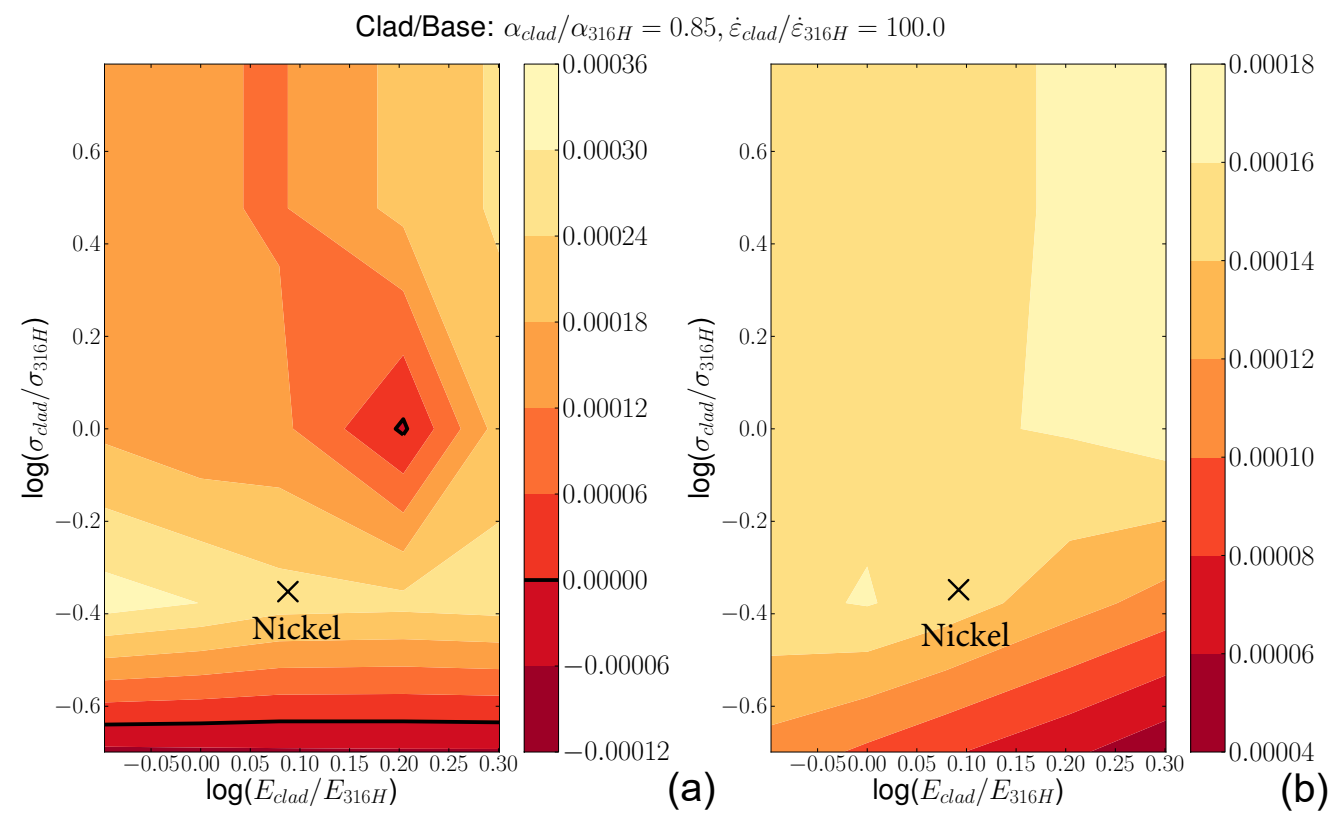

Figure 4.38: Design chart plotting the difference in the average creep damage, $\left\{\bar{D}_{\text {c }}\right\}_{\text {infinite compliance }}-\left\{\bar{D}_{\text {c }}\right\}_{\text {full inelastic }}$, in the base region during the hold of the last cycle (a) and the minimum difference of ASME equivalent strain range, $\{\Delta \varepsilon\}_{\text {infinite compliance }}-\{\Delta \varepsilon\}_{\text {full inelastic }}$, in the ID and OD clad regions over the last cycle as a function of $E$ in the Nickel clad/316H base system for the gradient load case. 
Finite element analysis of compliant cladding and base metal systems

July 2018

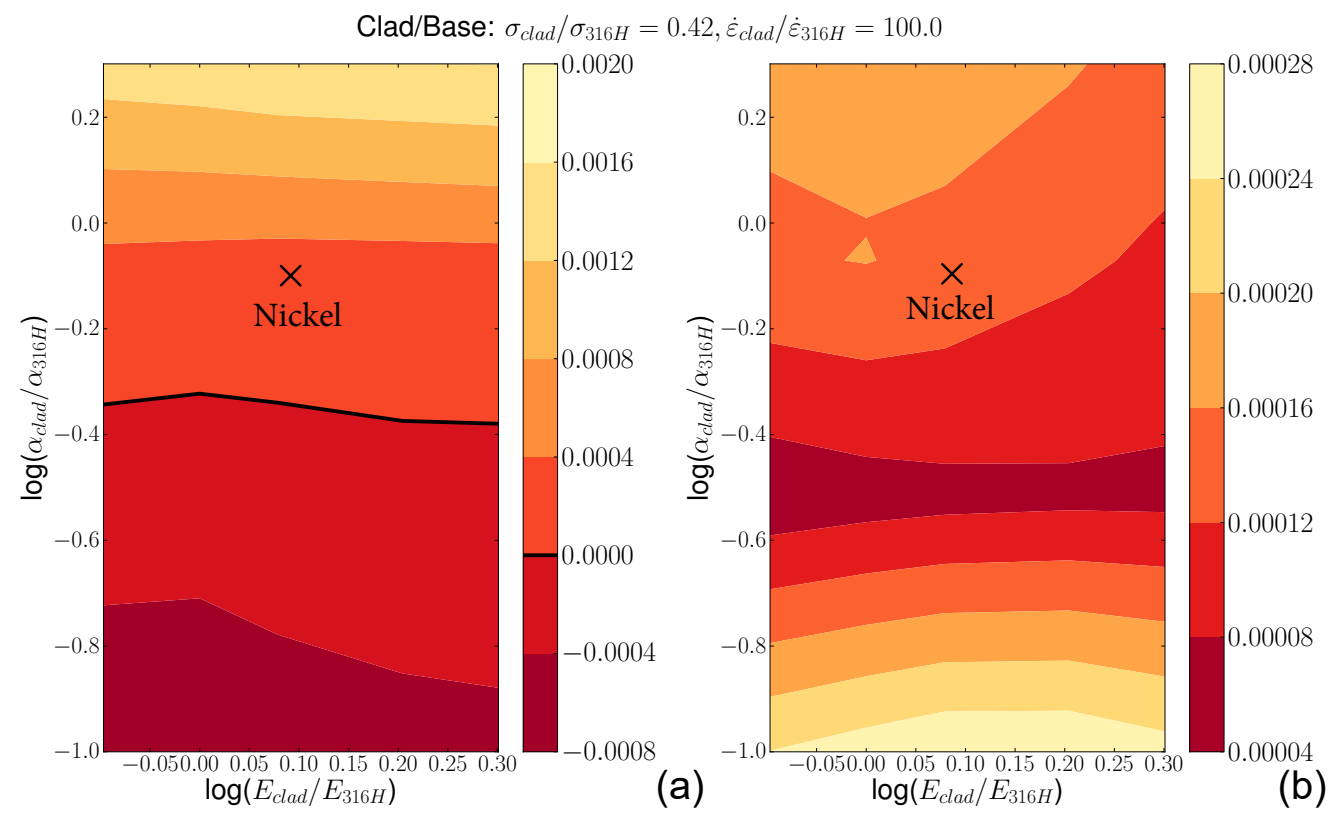

Figure 4.39: Design chart plotting the difference in the average creep damage, $\left\{\bar{D}_{\mathrm{c}}\right\}_{\text {infinite compliance }}-\left\{\bar{D}_{\mathrm{c}}\right\}_{\text {full inelastic }}$, in the base region during the hold of the last cycle (a) and the minimum difference of ASME equivalent strain range, $\{\Delta \varepsilon\}_{\text {infinite compliance }}-\{\Delta \varepsilon\}_{\text {full inelastic }}$, in the ID and OD clad regions over the last cycle as a function of $E$ and $\alpha$ in the Nickel clad/316H base system for the gradient load case.

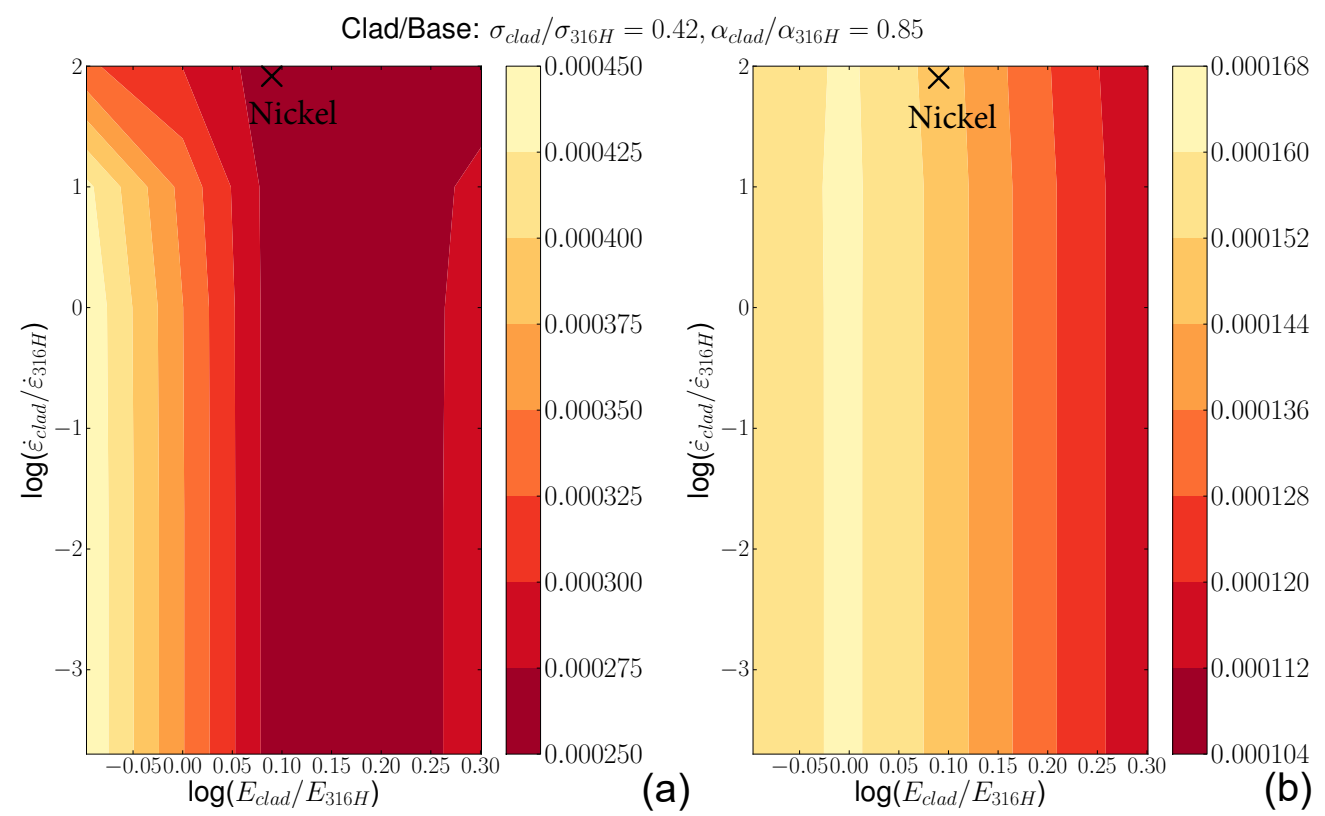

Figure 4.40: Design chart plotting the difference in the average creep damage, $\left\{\bar{D}_{\mathrm{c}}\right\}_{\text {infinite compliance }}-\left\{\bar{D}_{\mathrm{c}}\right\}_{\text {full inelastic }}$, in the base region during the hold of the last cycle (a) and the minimum difference of ASME equivalent strain range, $\{\Delta \varepsilon\}_{\text {infinite compliance }}-\{\Delta \varepsilon\}_{\text {full inelastic }}$, in the ID and OD clad regions over the last ycle as a function of $E$ and $\dot{\varepsilon}$ in the Nickel clad/316H base system for the gradient load case. 
Finite element analysis of compliant cladding and base metal systems

July 2018

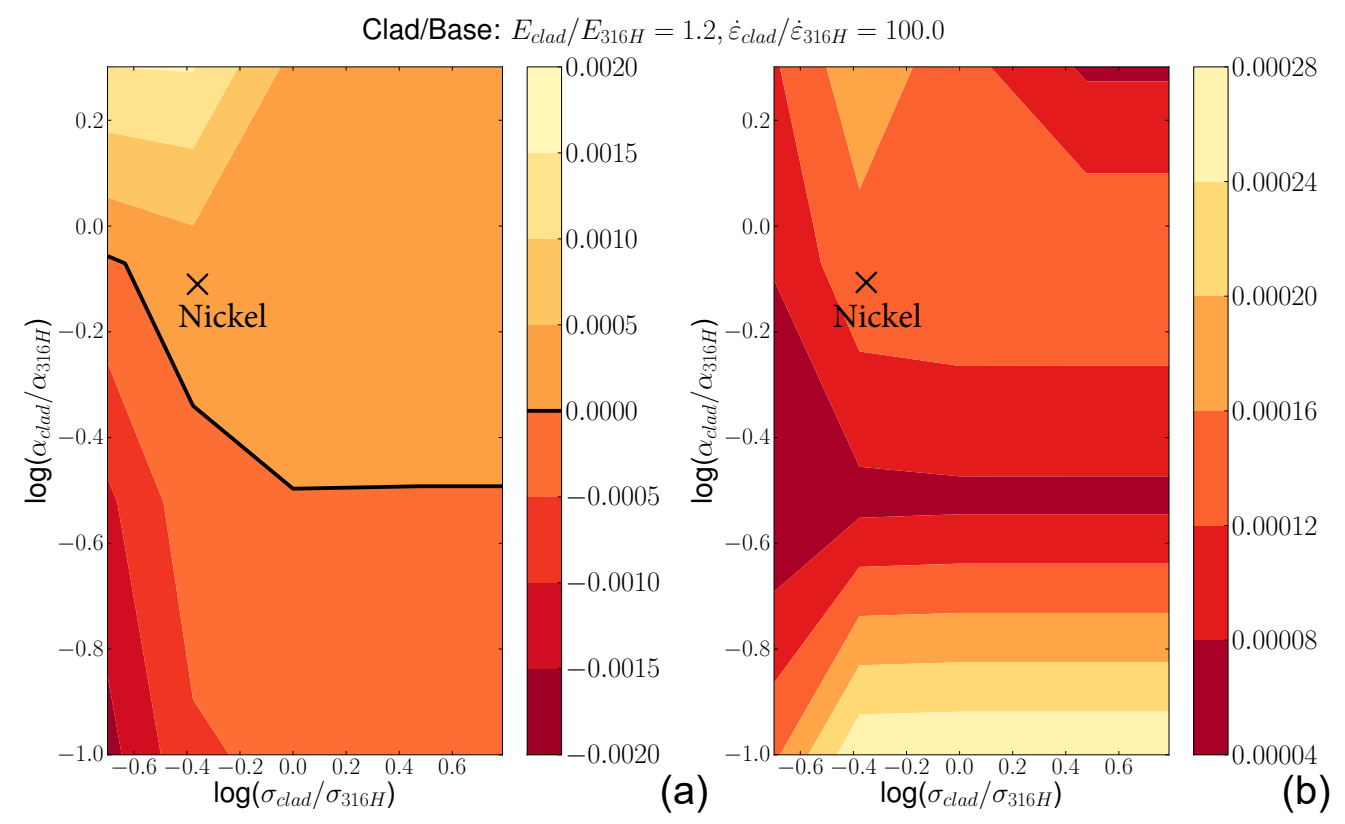

Figure 4.41: Design chart plotting the difference in the average creep damage, $\left\{\bar{D}_{\mathrm{c}}\right\}_{\text {infinite compliance }}-\left\{\bar{D}_{\mathrm{c}}\right\}_{\text {full inelastic }}$, in the base region during the hold of the last cycle (a) and the minimum difference of ASME equivalent strain range, $\{\Delta \varepsilon\}_{\text {infinite compliance }}-\{\Delta \varepsilon\}_{\text {full inelastic }}$, in the ID and OD clad regions over the last cycle as a function of $\sigma$ and $\alpha$ in the Nickel clad/316H base system for the gradient load case.

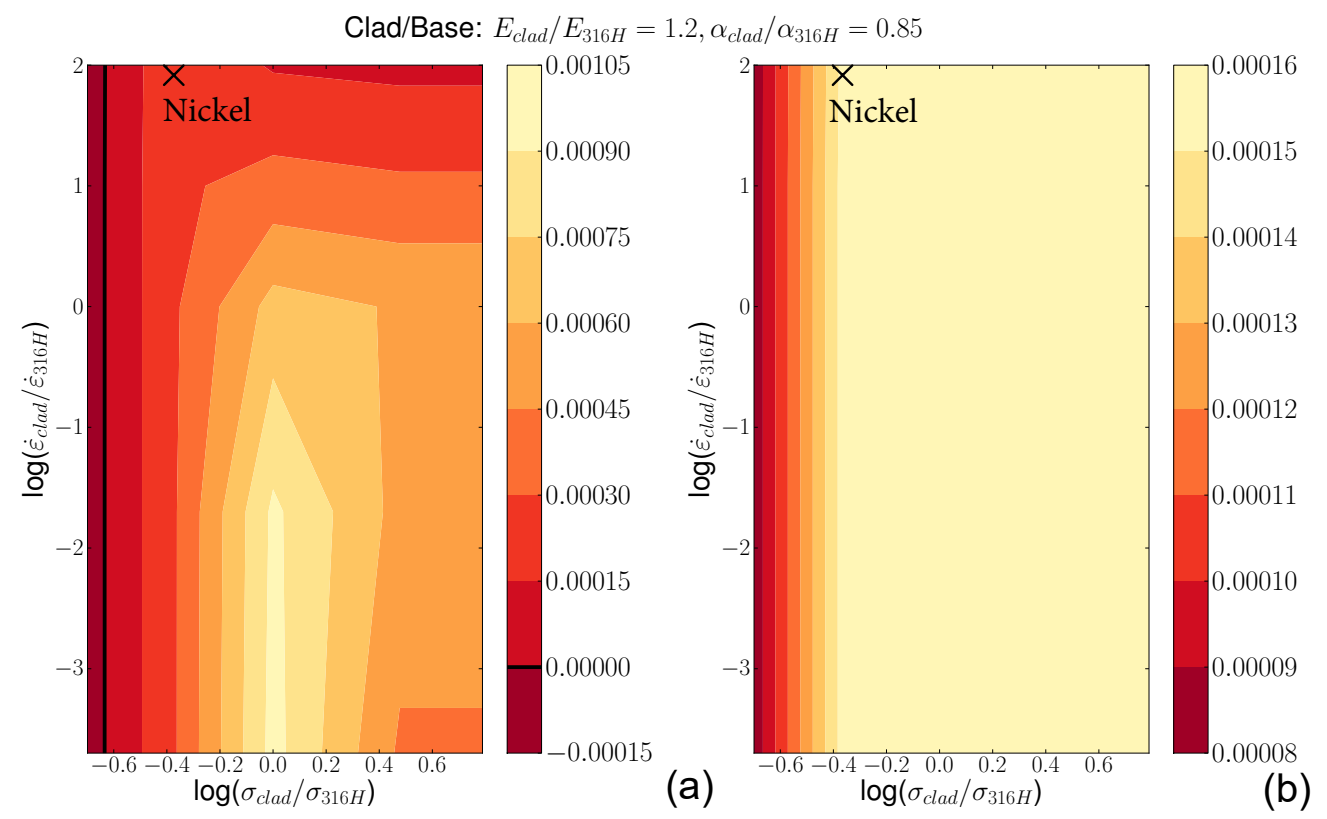

Figure 4.42: Design chart plotting the difference in the average creep damage, $\left\{\bar{D}_{\mathrm{c}}\right\}_{\text {infinite compliance }}-\left\{\bar{D}_{\mathrm{c}}\right\}_{\text {full inelastic }}$, in the base region during the hold of the last cycle (a) and the minimum difference of ASME equivalent strain range, $\{\Delta \varepsilon\}_{\text {infinite compliance }}-\{\Delta \varepsilon\}_{\text {full inelastic }}$, in the ID and OD clad regions over the last cycle as a function of $\sigma$ and $\dot{\varepsilon}$ in the Nickel clad/316H base system for the gradient load case. 


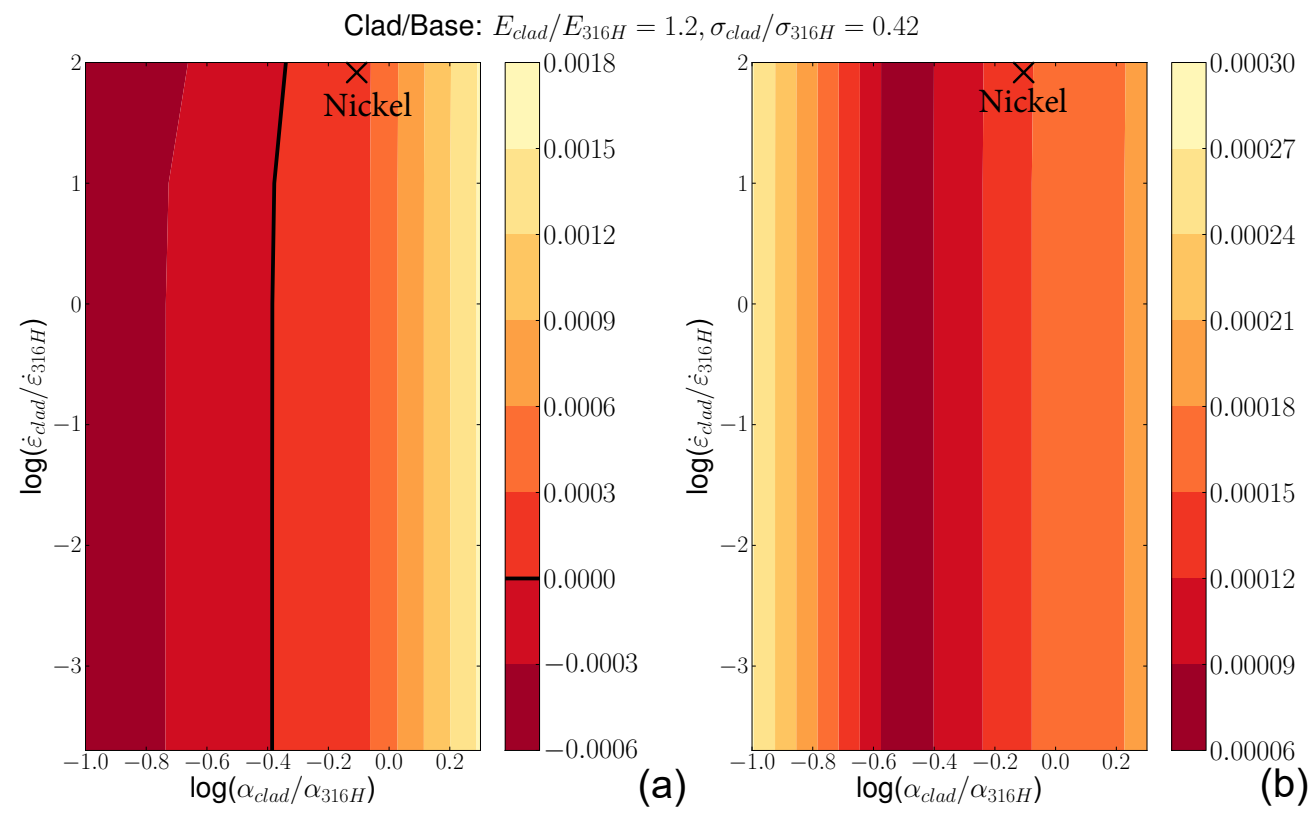

Figure 4.43: Design chart plotting the difference the average creep damage, $\left\{\bar{D}_{\mathrm{c}}\right\}_{\text {infinite compliance }}-$ $\left\{\bar{D}_{\text {c }}\right\}_{\text {full inelastic }}$, in the base region during the hold of the last cycle (a) and the minimum difference of ASME equivalent strain range, $\{\Delta \varepsilon\}_{\text {infinite compliance }}-\{\Delta \varepsilon\}_{\text {full inelastic, }}$, in the ID and OD clad regions over the last cycle as a function of $\alpha$ and $\dot{\varepsilon}$ in the Nickel clad/316H base system for the gradient load case.

\subsubsection{Elastic cladding}

Finally then the IHX tube analysis was repeated to assess the elastic analysis method using both a reference clad that matches the base (Figs. 4.44-4.49) and a reference TZM clad (4.50-4.55). Guidelines on the applicability of the elastic analysis method for this case are:

$$
\begin{aligned}
& \text { Young's modulus }: E_{\text {clad }}<1.25 E_{316 H} \\
& \text { Yield stress : } \sigma_{\text {clad }}>0.6 \sigma_{316 H} \\
& \text { Thermal coefficient : } \alpha_{\text {clad }}>0.32 \alpha_{316 H} \\
& \text { Creep rate }: \dot{\varepsilon}_{\text {clad }}<\dot{\varepsilon}_{316 H}
\end{aligned}
$$

with the same caveats mentioned for the other rules of thumb.

\subsection{Summary}

The simplified analysis results presented in this chapter demonstrate the feasibility of the elastic and compliant analysis methods, provided the material property mismatches between the clad and base materials fall into certain ranges. For both elastic and compliant analysis the clad thermal expansion coefficient should be relatively close to that of the base material. This restriction limits the thermal stress and strain induced by differential thermal expansion. For the elastic clad analysis the clad yield stress should be generally higher than the base material and the clad creep rate lower than the base material. For compliant analysis the 
Finite element analysis of compliant cladding and base metal systems

July 2018

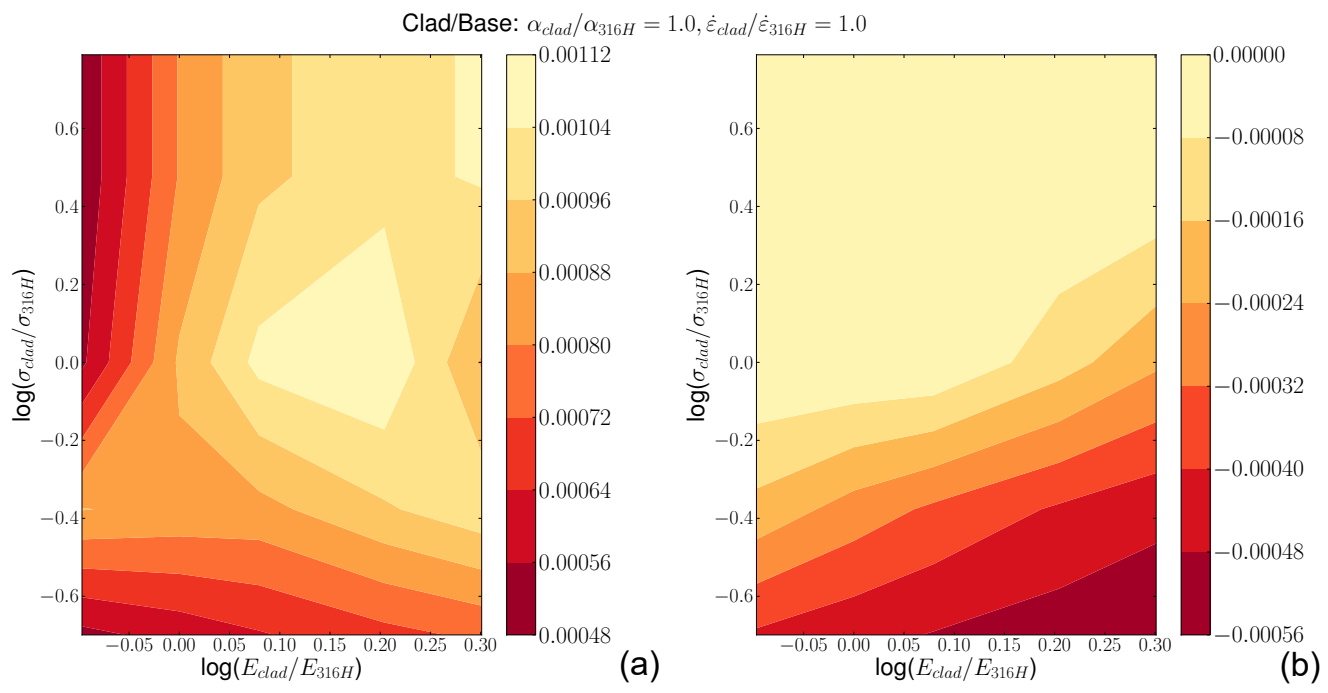

Figure 4.44: Design chart illustrating the difference in the average creep damage, $\left\{\bar{D}_{\mathrm{c}}\right\}_{\text {elastic cladding }}-\left\{\bar{D}_{\mathrm{c}}\right\}_{\text {full inelastic }}$, in the base region during the hold of the last cycle (a) and the minimum difference of ASME equivalent strain range, $\{\Delta \varepsilon\}_{\text {elastic cladding }}-\{\Delta \varepsilon\}_{\text {full inelastic }}$, in the ID and OD clad regions over the last cycle (b) as a function of $E$ and $\sigma$ in the clad/316H base for the gradient load case.

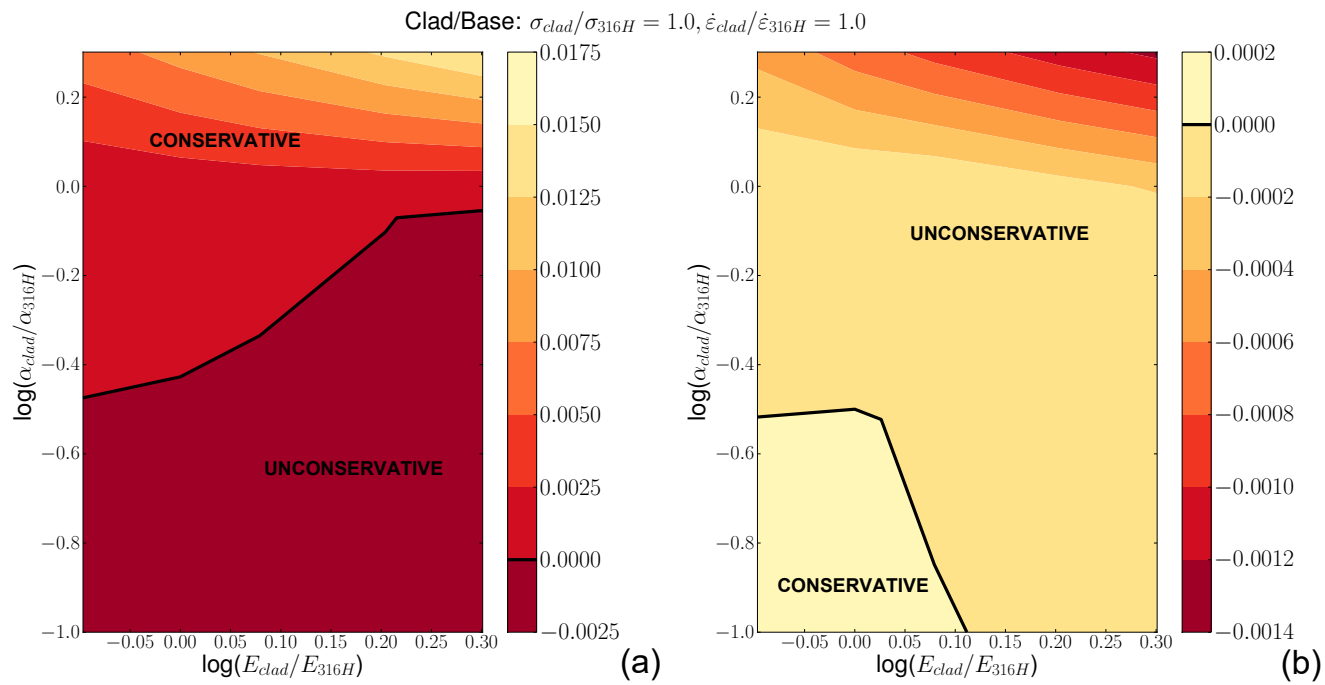

Figure 4.45: Design chart illustrating the difference in the average creep damage, $\left\{\bar{D}_{\mathrm{c}}\right\}_{\text {elastic cladding }}-\left\{\bar{D}_{\mathrm{c}}\right\}_{\text {full inelastic }}$, in the base region during the hold of the last cycle (a) and the minimum difference of ASME equivalent strain range, $\{\Delta \varepsilon\}_{\text {elastic cladding }}-\{\Delta \varepsilon\}_{\text {full inelastic }}$, in the ID and OD clad regions over the last cycle (b) as a function of $E$ and $\alpha$ in the clad/316H base system for the gradient load case. 
Finite element analysis of compliant cladding and base metal systems

July 2018

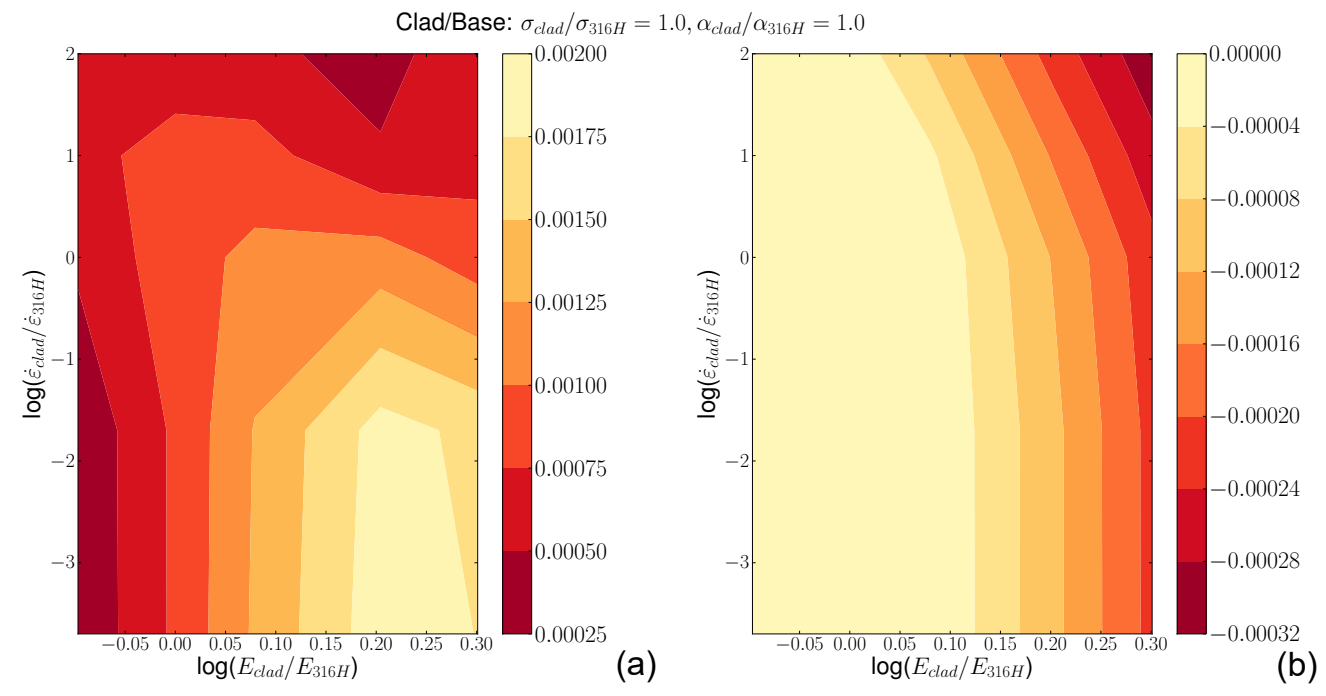

Figure 4.46: Design chart illustrating the difference in the average creep damage, $\left\{\bar{D}_{\mathrm{c}}\right\}_{\text {elastic cladding }}-\left\{\bar{D}_{\mathrm{c}}\right\}_{\text {full inelastic }}$, in the base region during the hold of the last cycle (a) and the minimum difference of ASME equivalent strain range, $\{\Delta \varepsilon\}_{\text {elastic cladding }}-\{\Delta \varepsilon\}_{\text {full inelastic }}$, in the ID and OD clad regions over the last cycle (b) as a function of $E$ and $\dot{\varepsilon}$ in the clad/316H base sytem for the gradient load case.

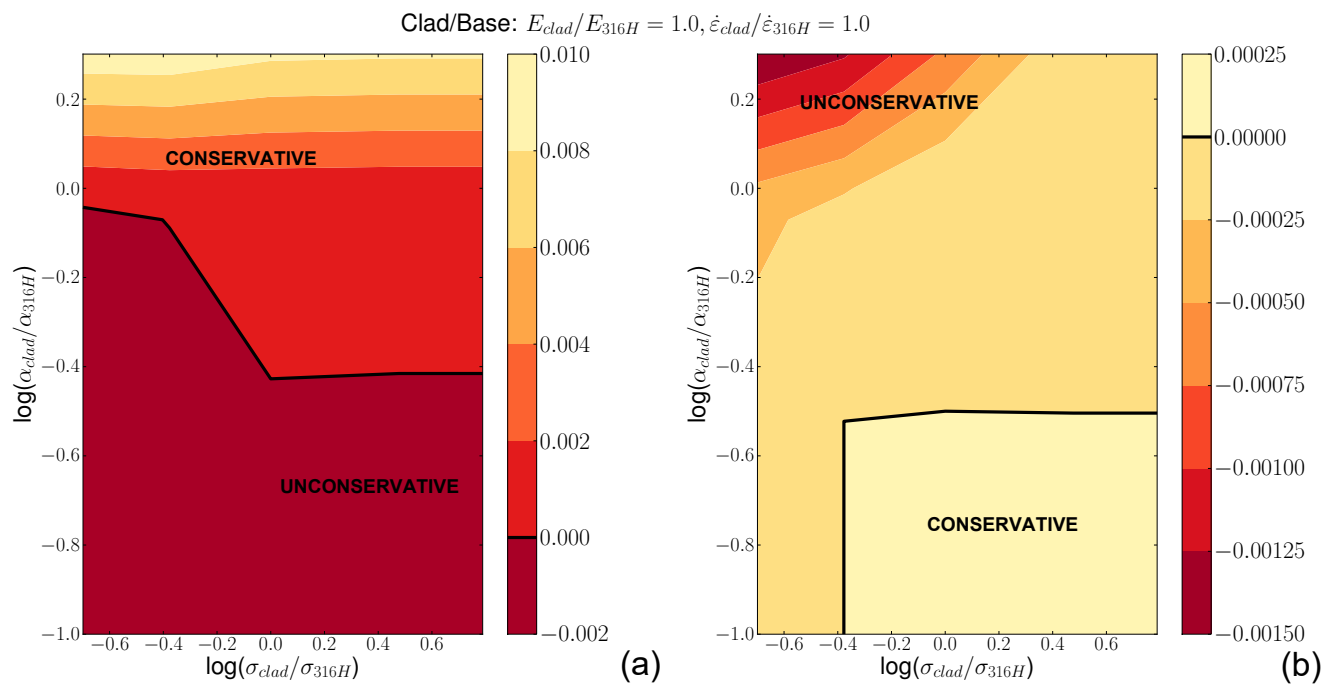

Figure 4.47: Design chart illustrating the difference in the average creep damage, $\left\{\bar{D}_{\mathrm{c}}\right\}_{\text {elastic cladding }}-\left\{\bar{D}_{\mathrm{c}}\right\}_{\text {full inelastic }}$, in the base region during the hold of the last cycle (a) and the minimum difference of ASME equivalent strain range, $\{\Delta \varepsilon\}_{\text {elastic cladding }}-\{\Delta \varepsilon\}_{\text {full inelastic }}$, in the ID and OD clad regions over the last cycle (b) as a function of $\sigma$ and $\alpha$ in the clad/316H base sytem for the gradient load case. 
Finite element analysis of compliant cladding and base metal systems

July 2018

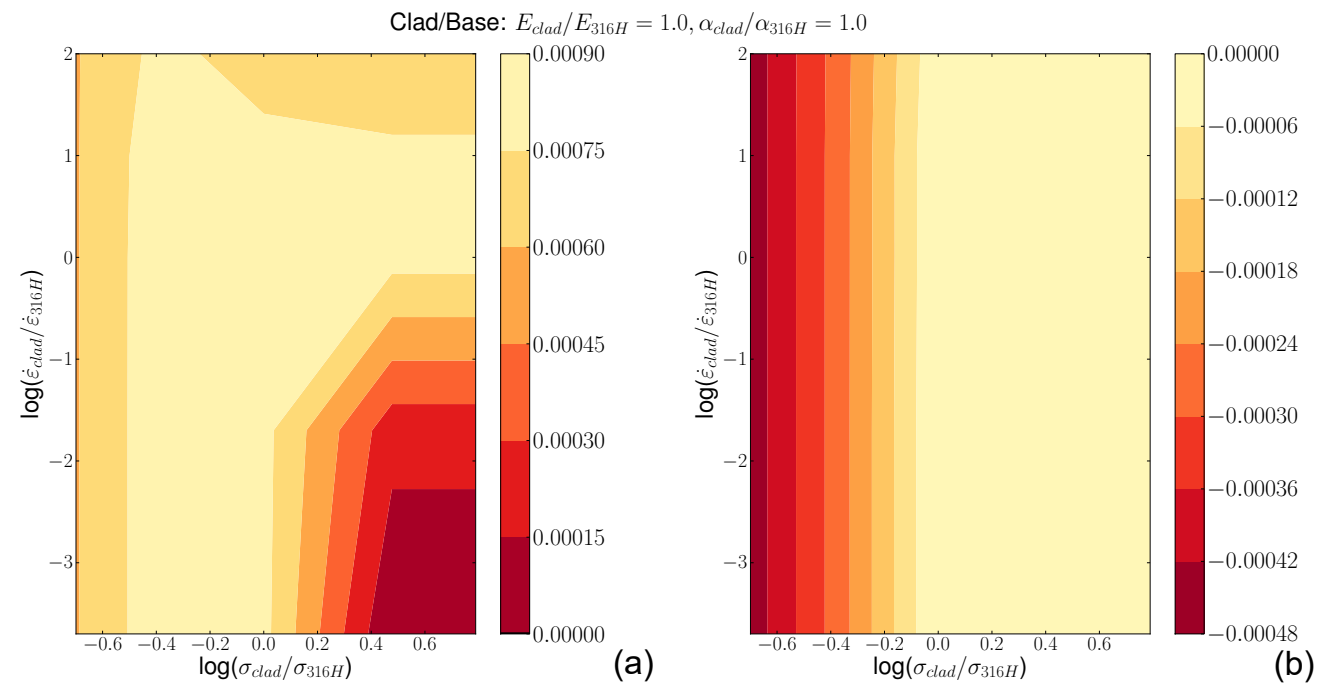

Figure 4.48: Design chart illustrating the difference in the average creep damage, $\left\{\bar{D}_{\mathrm{c}}\right\}_{\text {elastic cladding }}-\left\{\bar{D}_{\mathrm{c}}\right\}_{\text {full inelastic }}$, in the base region during the hold of the last cycle (a) and the minimum difference of ASME equivalent strain range, $\{\Delta \varepsilon\}_{\text {elastic cladding }}-\{\Delta \varepsilon\}_{\text {full inelastic }}$, in the clad ID and OD regions over the last cycle (b) as a function of $\sigma$ and $\dot{\varepsilon}$ in the clad/316H base sytem for the gradient load case.

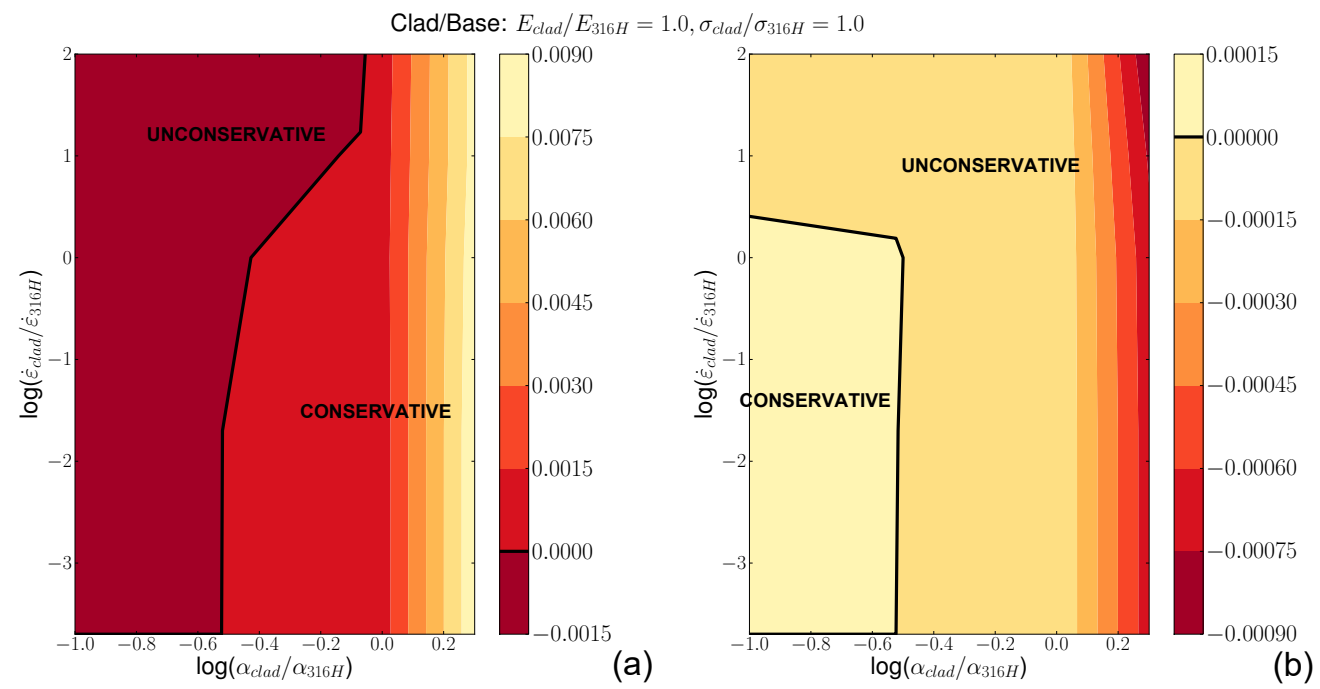

Figure 4.49: Design chart illustration the difference in the average creep damage, $\left\{\bar{D}_{\mathrm{c}}\right\}_{\text {elastic cladding }}-\left\{\bar{D}_{\mathrm{c}}\right\}_{\text {full inelastic }}$, in the base region during the hold of the last cycle (a) and the minimum difference of ASME equivalent strain range, $\{\Delta \varepsilon\}_{\text {elastic cladding }}-\{\Delta \varepsilon\}_{\text {full inelastic }}$, in the ID and OD clad regions over the last cycle (b) as a function of $\alpha$ and $\dot{\varepsilon}$ in the clad/316H base sytem for the gradient load case. 
Finite element analysis of compliant cladding and base metal systems

July 2018

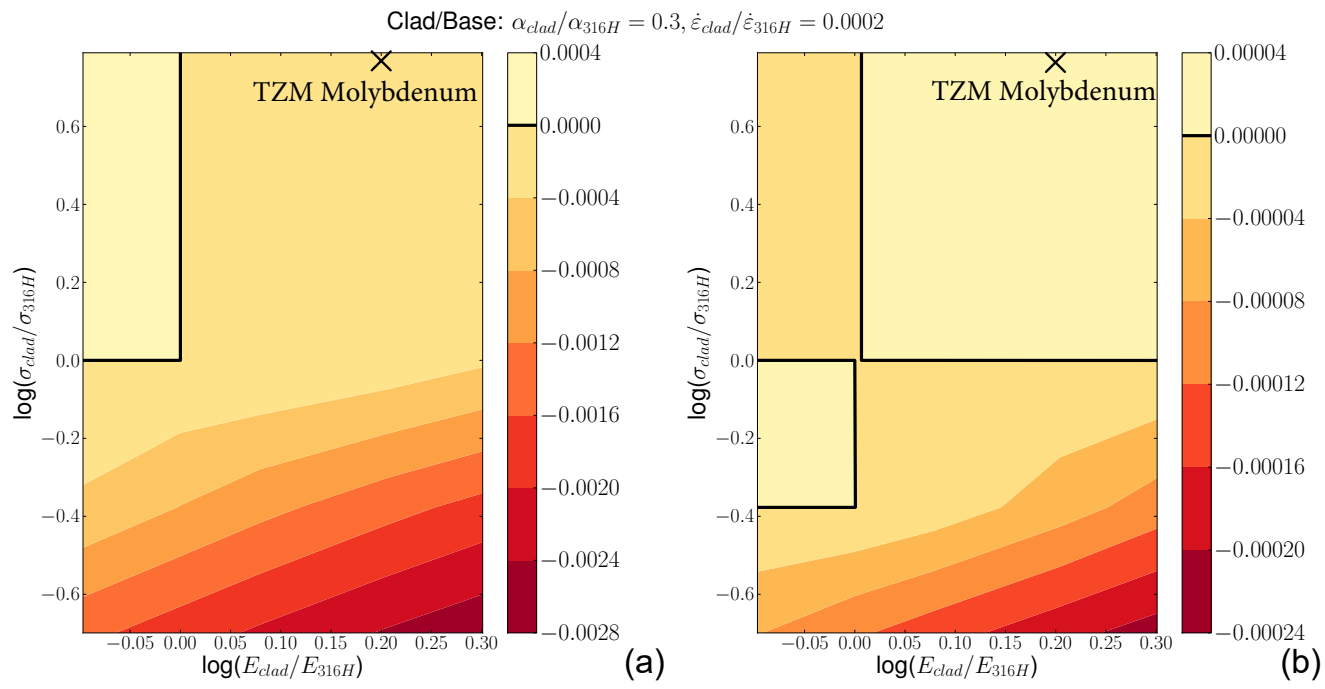

Figure 4.50: Design chart plotting the difference in the average creep damage, $\left\{\bar{D}_{\text {c }}\right\}_{\text {elastic cladding }}-$ $\left\{\bar{D}_{\mathrm{c}}\right\}_{\text {full inelastic }}$, in the base region during the hold of the last cycle (a) and the minimum difference of ASME equivalent strain range, $\{\Delta \varepsilon\}_{\text {elastic cladding }}-\{\Delta \varepsilon\}_{\text {full inelastic }}$, in the ID and OD clad regions over the last cycle as a function of $E$ and $\sigma$ in the TZM Molybdenum clad/316H base sytem for the gradient load case.

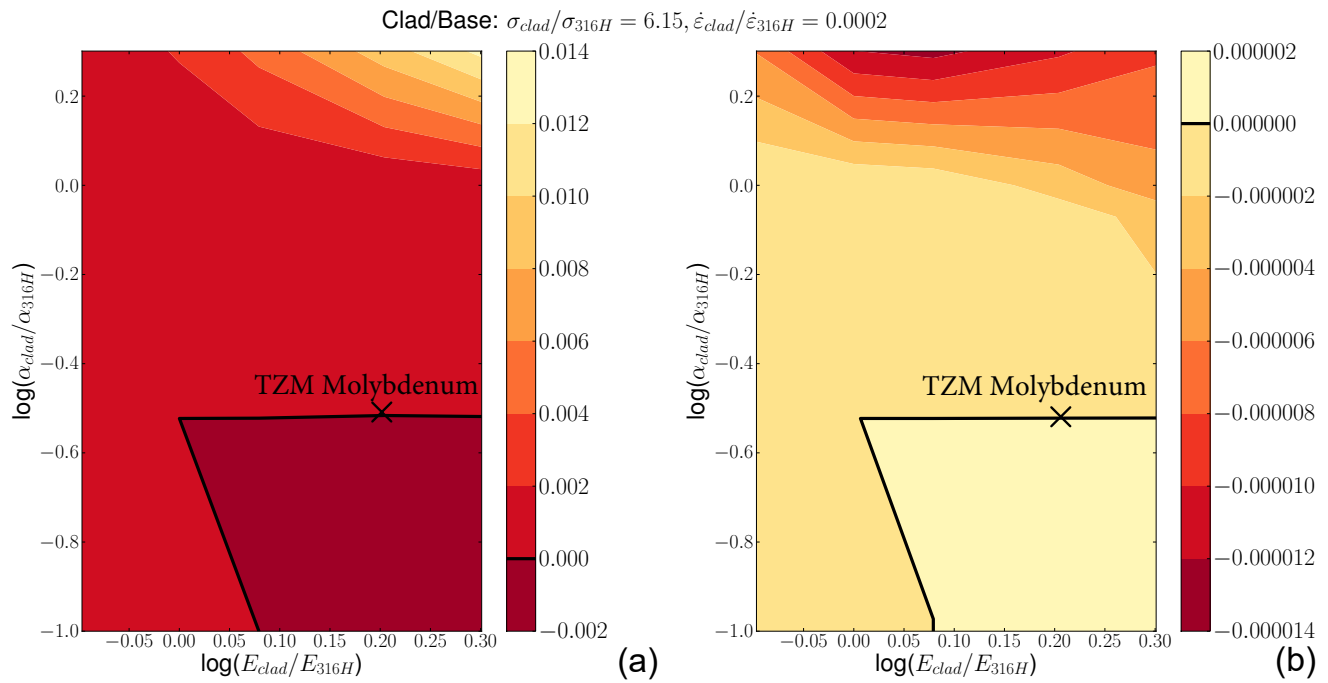

Figure 4.51: Design chart plotting the difference in the average creep damage, $\left\{\bar{D}_{\mathrm{c}}\right\}_{\text {elastic cladding }}-$ $\left\{\bar{D}_{\text {c }}\right\}_{\text {full inelastic }}$, in the base region during the hold of the last cycle (a) and the minimum difference of ASME equivalent strain range, $\{\Delta \varepsilon\}_{\text {elastic cladding }}-\{\Delta \varepsilon\}_{\text {full inelastic }}$, in the ID and OD clad regions over the last cycle as a function of $E$ and $\alpha$ in the TZM Molybdenum clad/316H base sytem for the gradient load case. 
Finite element analysis of compliant cladding and base metal systems

July 2018

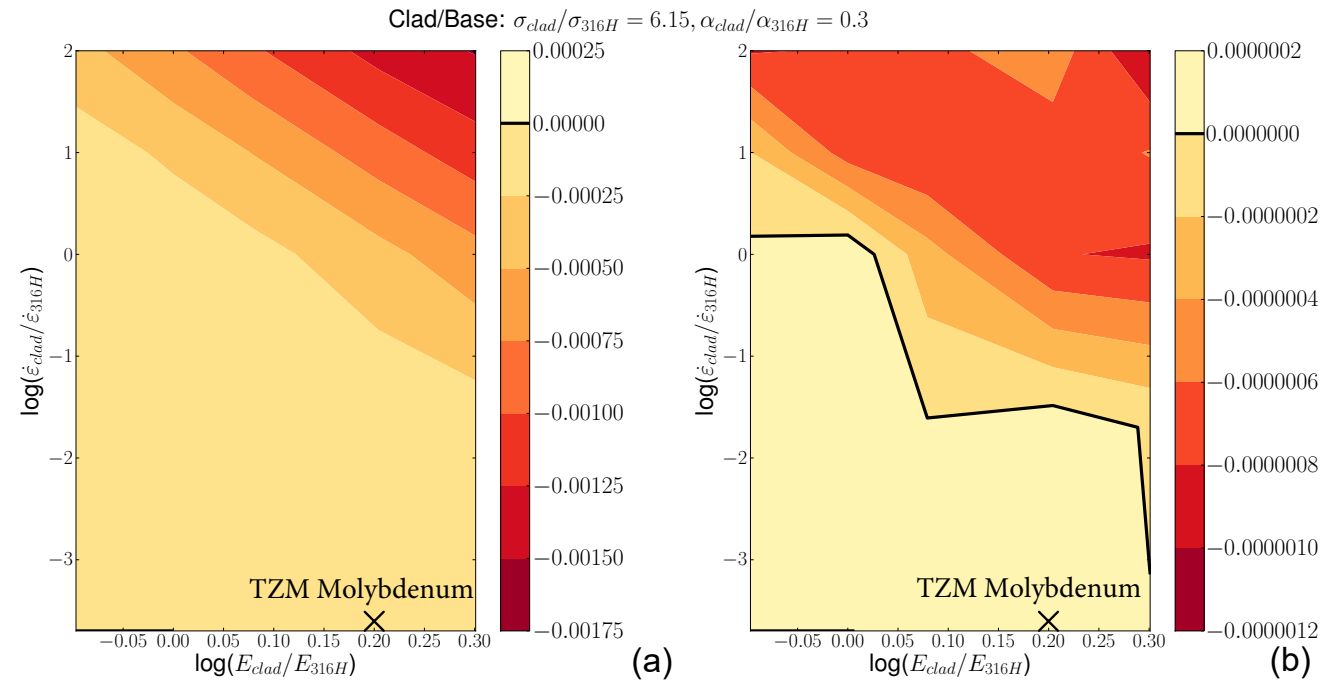

Figure 4.52: Design chart plotting the difference in the average creep damage, $\left\{\bar{D}_{\text {c }}\right\}_{\text {elastic cladding }}-$ $\left\{\bar{D}_{\mathrm{c}}\right\}_{\text {full inelastic }}$, in the base region during the hold of the last cycle (a) and the minimum difference of ASME equivalent strain range, $\{\Delta \varepsilon\}_{\text {elastic cladding }}-\{\Delta \varepsilon\}_{\text {full inelastic }}$, in the ID and OD clad regions over the last cycle as a function of $E$ and $\dot{\varepsilon}$ in the TZM Molybdenum clad/316H base sytem for the gradient load case.

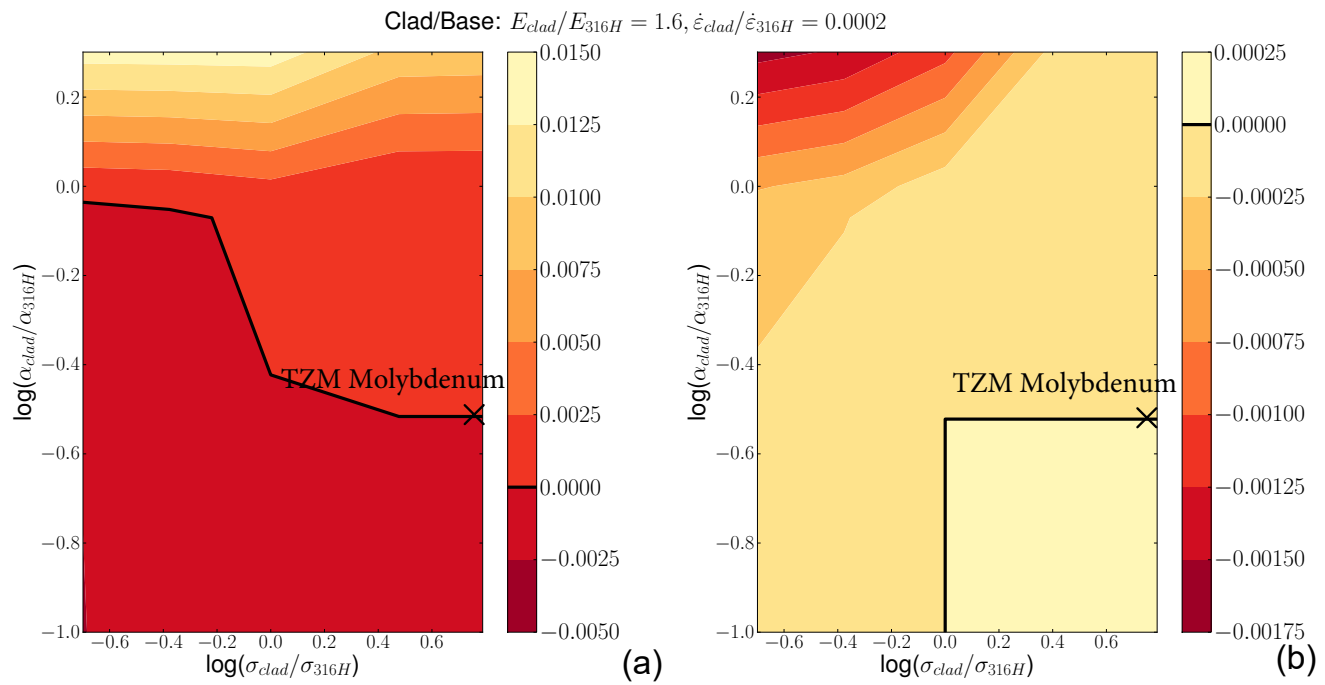

Figure 4.53: Design chart plotting the difference in the average creep damage, $\left\{\bar{D}_{\mathrm{c}}\right\}_{\text {elastic cladding }}-$ $\left\{\bar{D}_{\text {c }}\right\}_{\text {full inelastic }}$, in the base region during the hold of the last cycle (a) and the minimum difference of ASME equivalent strain range, $\{\Delta \varepsilon\}_{\text {elastic cladding }}-\{\Delta \varepsilon\}_{\text {full inelastic }}$, in the ID and OD clad regions over the last cycle as a function of $\sigma$ and $\alpha$ in the TZM Molybdenum clad/316H base sytem for the gradient load case. 
Finite element analysis of compliant cladding and base metal systems

July 2018

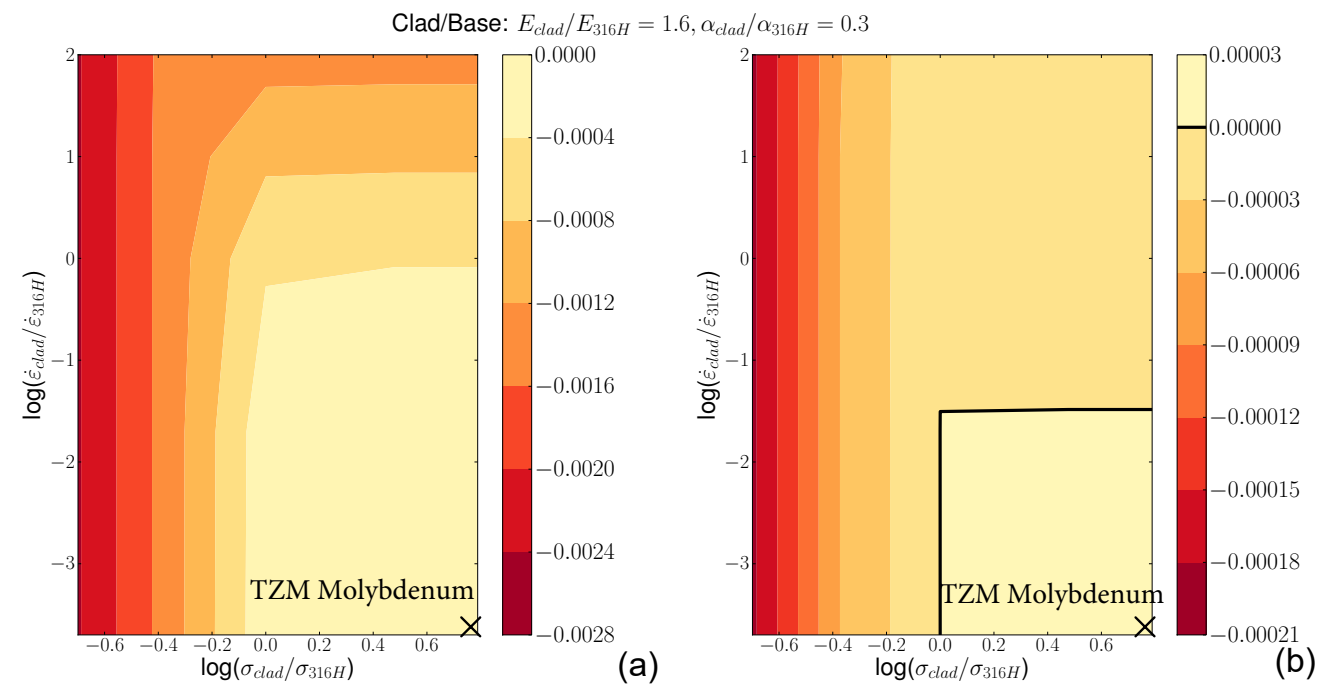

Figure 4.54: Design chart plotting the difference in the average creep damage, $\left\{\bar{D}_{\mathrm{c}}\right\}_{\text {elastic cladding }}-$ $\left\{\bar{D}_{\mathrm{c}}\right\}_{\text {full inelastic }}$, in the base region during the hold of the last cycle (a) and the minimum difference of ASME equivalent strain range, $\{\Delta \varepsilon\}_{\text {elastic cladding }}-\{\Delta \varepsilon\}_{\text {full inelastic }}$, in the ID and OD clad regions over the last cycle as a function of $\sigma$ and $\dot{\varepsilon}$ in the TZM Molybdenum clad/316H base sytem for the gradient load case.

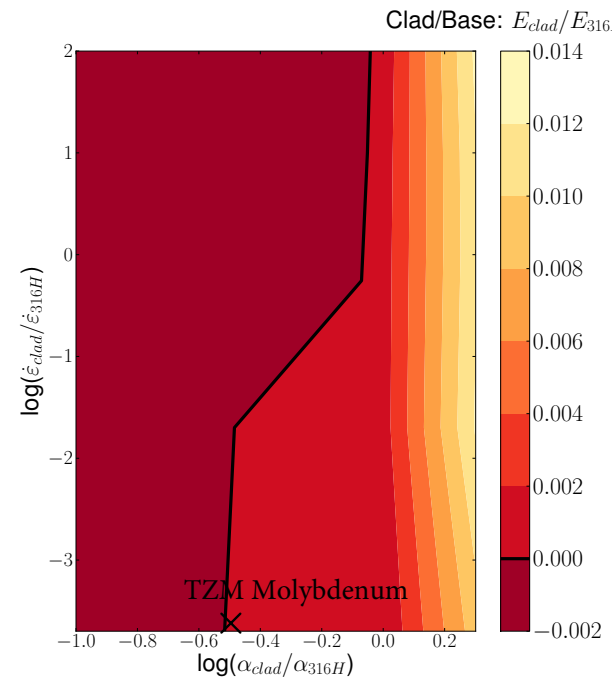

(a)

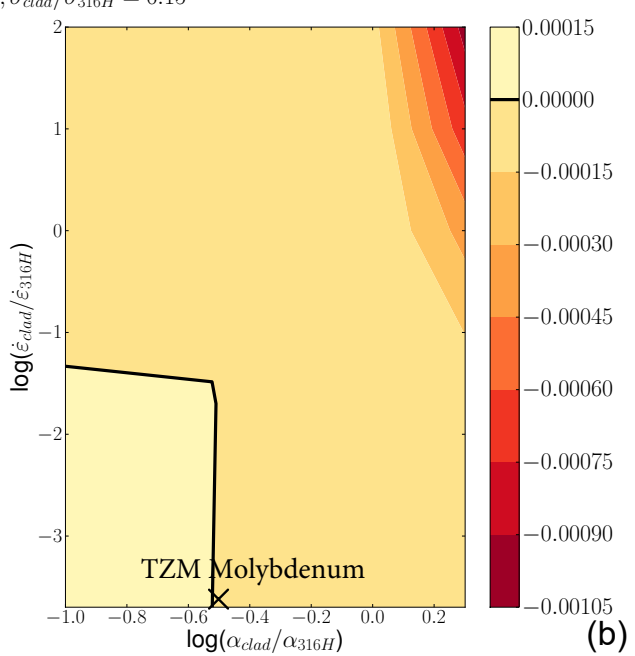

Figure 4.55: Design chart plotting the difference in the average creep damage, $\left\{\bar{D}_{\text {c }}\right\}_{\text {elastic cladding }}-$ $\left\{\bar{D}_{\mathrm{c}}\right\}_{\text {full inelastic }}$, in the base region during the hold of the last cycle (a) and difference of ASME equivalent strain range, $\{\Delta \varepsilon\}_{\text {elastic cladding }}-\{\Delta \varepsilon\}_{\text {full inelastic }}$, in the ID and OD clad regions over the last cycle as a function of $\alpha$ and $\dot{\varepsilon}$ in the TZM Molybdenum clad/316H base sytem for the gradient load case. 
clad yield stress should generally be lower than the base material and the clad should creep faster than the base.

These analyses also demonstrate that pure nickel is a viable material to analyze as compliant and TZM is a viable material to analyze as elastic. These two materials are likely candidates for high temperature MSR clads and so these results demonstrate the feasibility of the proposed analysis methods for realistic material selections. 


\section{Full component analysis}

Chapter 4 verified the elastic and compliant analysis methods and established approximate bounds on their use with high-throughput simulations of a simple cylindrical vessel. This chapter extends these verification simulations to axisymmetric and full 3D analyses of representative reactor components.

\subsection{Axisymmetric analysis of a tubesheet}

Figure 5.1 illustrates the analysis problem used in this section. The problem is an axisymmetric analysis of a single tube/tubesheet connection. This model represents the critical connection in the design of heat exchangers for elevated temperature service. The tubesheet plate and the tubes are $316 \mathrm{H}$ stainless steel represented with an inelastic material model. Both the tube and tubesheet and clad on both the inside and outside surfaces with pure $\mathrm{Ni}$. The tube is $4.5 \mathrm{~mm}$ thick, with an inner and outer $0.35 \mathrm{~mm}$ thick layer of $\mathrm{Ni}$ and the remaining $3.8 \mathrm{~mm} 316 \mathrm{H}$. The tube inner radius is $6.8 \mathrm{~mm}$. The tubesheet is $16.8 \mathrm{~mm}$ thick, with an inner and outer $1.4 \mathrm{~mm}$ thick layer of $\mathrm{Ni}$ and the remaining $14.0 \mathrm{~mm} 316 \mathrm{H}$. This structure could represent an intermediate heat exchanger in a MSR where both the shell and tube surfaces are exposed to some corrosive molten salt coolant.

As with the simplified analysis, this section considers two analyses using the same geometry and loading conditions: one where a full inelastic model is used to represent the deformation of the Ni clad and another using the compliant method of analysis, representing the clad with a material with zero flow strength.

The figure also shows the loading conditions used in the problem. The tubes are under a constant pressure of $1.38 \mathrm{MPa}$. The outer wall temperature of the tube and tubesheet remains constant at $700^{\circ} \mathrm{C}$. The inner wall temperature cycles between $700^{\circ} \mathrm{C}$ and $725^{\circ}$ $\mathrm{C}$ following the temperature cycle shown in the figure. The wall temperature is increased over 10 hours, held for 1000 hours, and then decreased over 10 hours. The simulation is a multiphysics, coupled structural and heat transfer calculation. The thermal properties of the nickel clad and $316 \mathrm{H}$ base material are those found in Section II of the ASME Code. Figure 5.1 shows a typical temperature profile during a hold.

In phase with the temperature loading the simulation imposes a fixed displacement on the bottom of the tube in the vertical direction, as shown in Figure 5.1. This represents the constrained axial thermal expansion of the tube bundle relative to the heat exchanger shell. The analysis repeats this load cycle ten times.

Figure 5.2 plots the mechanical strain components at the critical tubesheet/tube weld location, shown on Figure 5.1. Figure 5.2 plots results for both the full inelastic and compliant clad analyses. The simulation results show that the compliant analysis bounds the mechanical strains found in the full simulation - the absolute values of the strain components are always greater in the compliant simulation and therefore the strain range for each cycle in the compliant simulation is greater than in the full calculation. The compliant analysis results could then be safely used to design the tubesheet using one of the design strategies discussed in Chapter 2.

Figure 5.3 shows fringe plots of the equivalent strain distribution at the end of the hold during the final repetition of the load cycle. Again, the figure compares the full to the compliant analyses. The strain distribution in the compliant analysis reasonably represents 

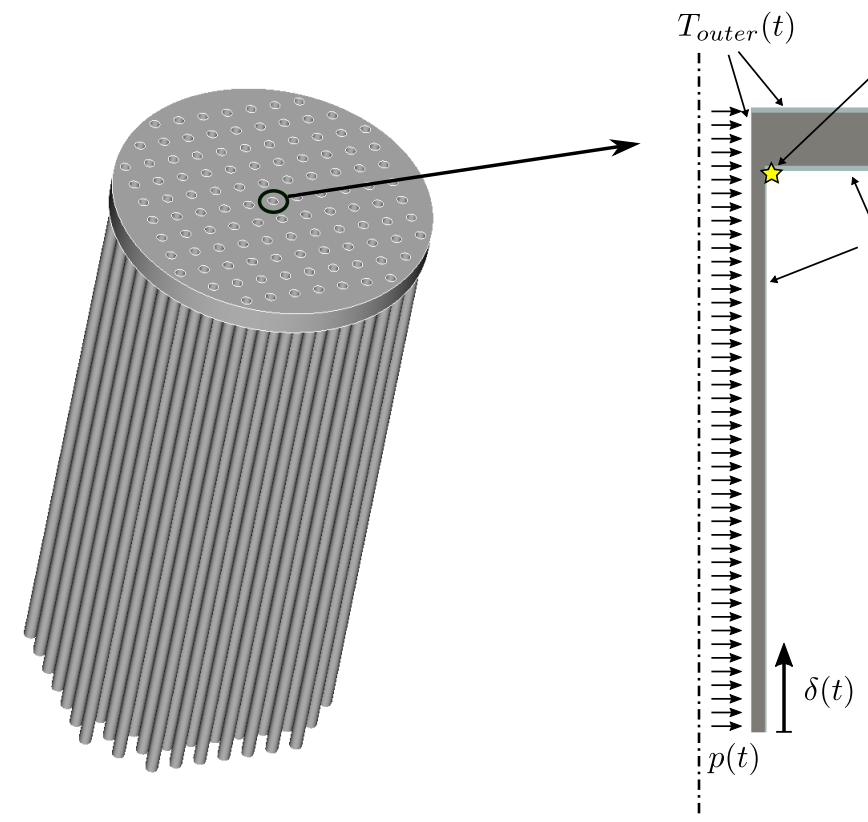

Component

Axisymmetric model
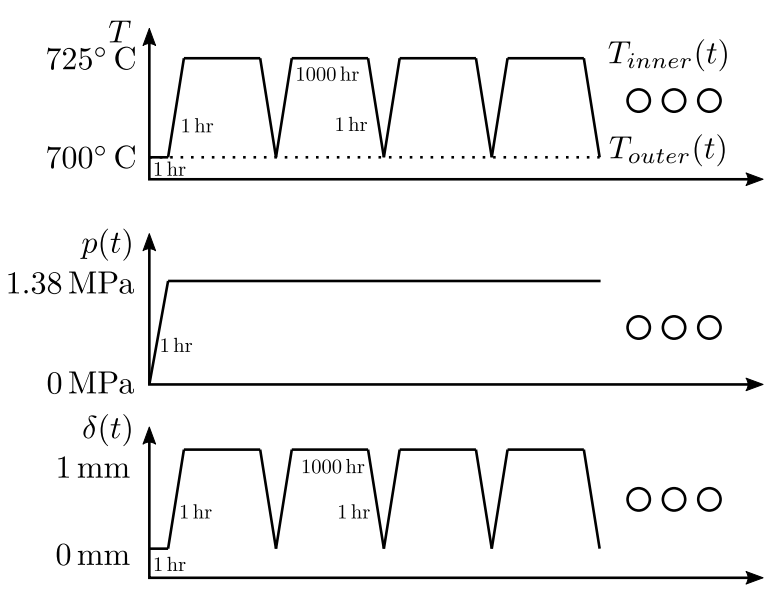

Loading conditions

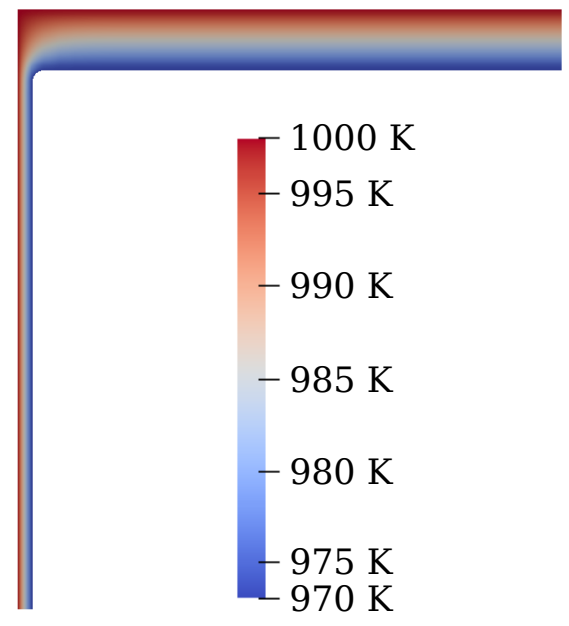

Typical temperature profile

Figure 5.1: Sample problem used in this section: an axisymmetric representation of a single tube/tubesheet interface. The tube and tubesheet are cladded on both the inside and outside surfaces, representing a intermediate heat exchanger in a MSR. 
Finite element analysis of compliant cladding and base metal systems

July 2018

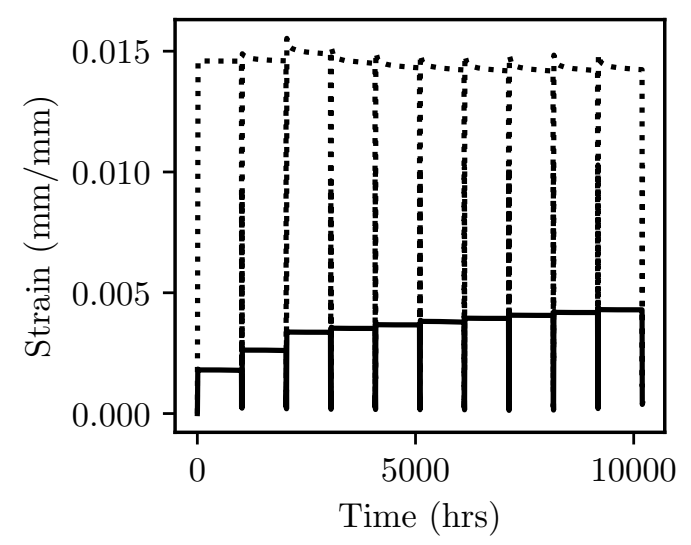

Figure 5.2: Figure plotting the equivalent strain at the tube/tube-sheet interface for the full inelastic simulation of $316 \mathrm{H}$ cladded with $\mathrm{Ni}$ (solid) versus a compliant clad analysis (dashed).
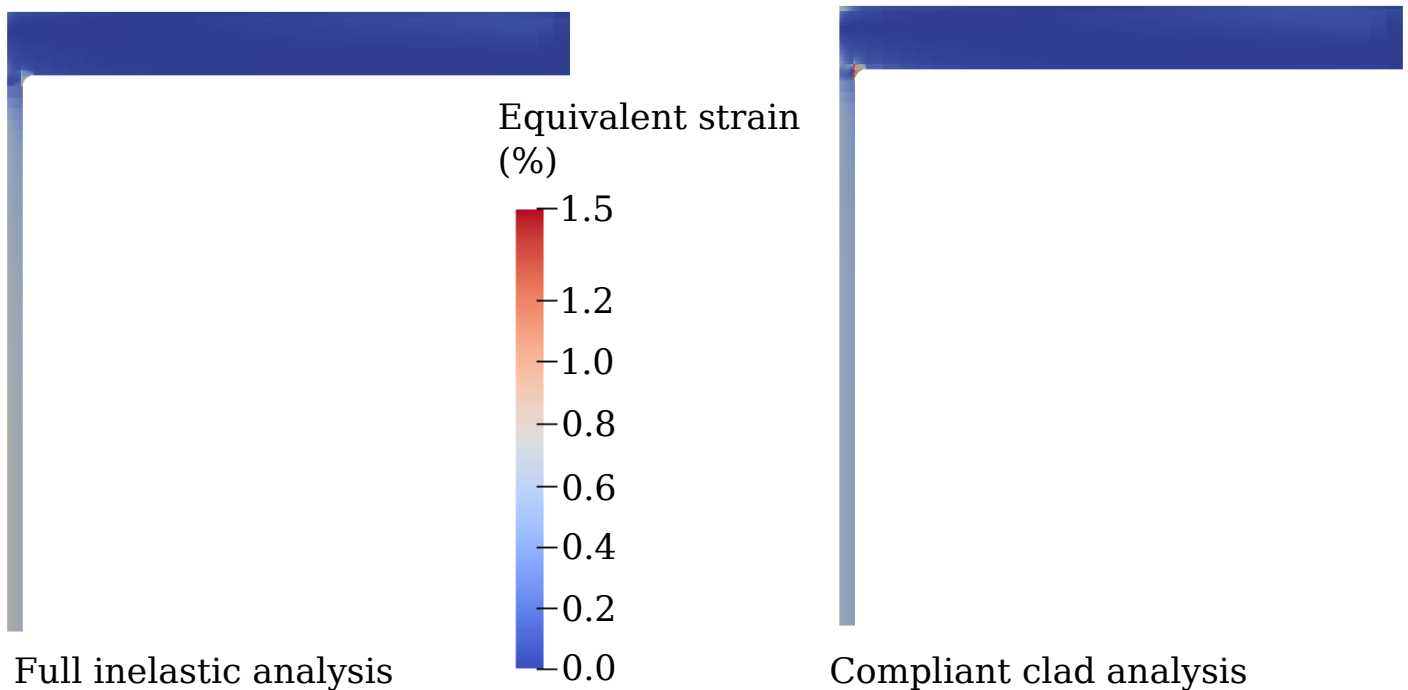

Compliant clad analysis

Figure 5.3: The equivalent strain distribution in the full and compliant clad analysis at the end of the final hold at temperature. 


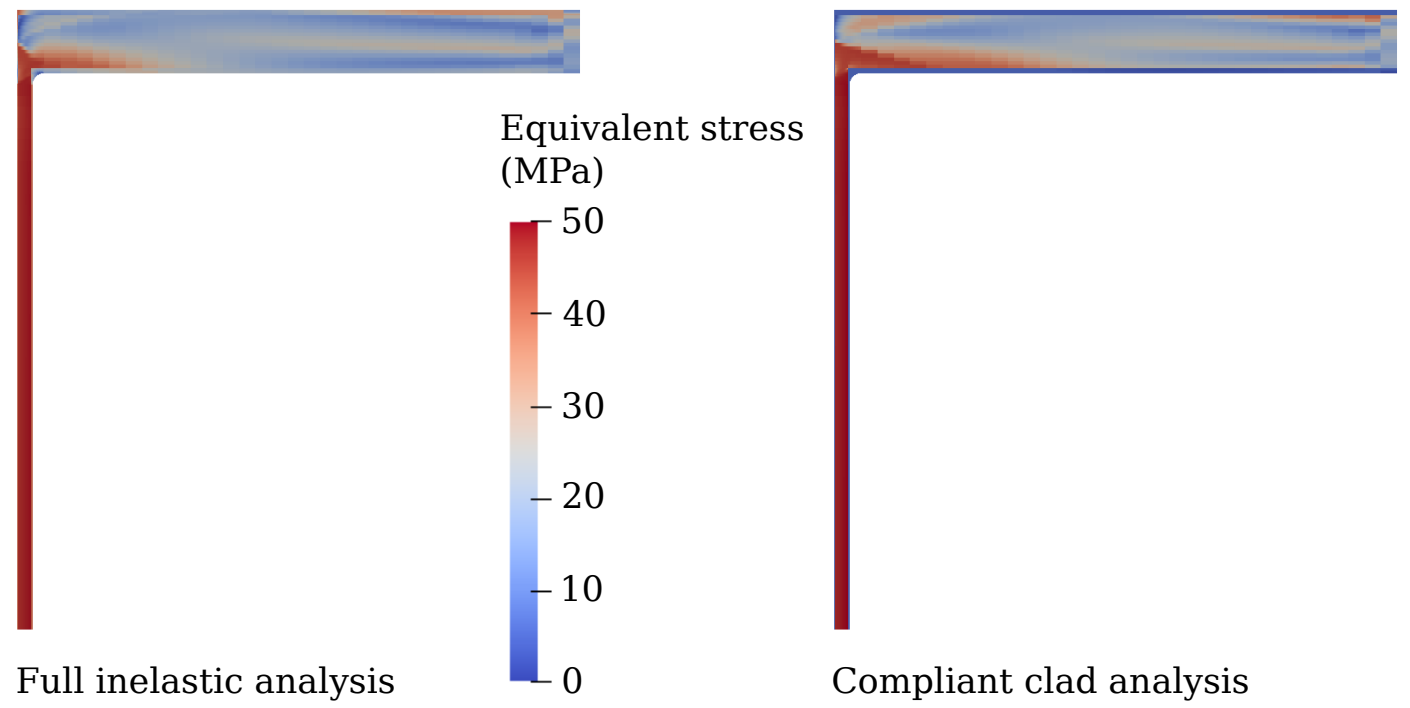

Figure 5.4: The equivalent stress distribution in the full and compliant clad analysis at the end of the final hold at temperature.

the spatial distribution of strain in the full analysis, in addition to bounding the pointwise values of the strain components. Figure 5.4 is a similar fringe plot showing the equivalent stress distribution at the same time. The stress distribution for the compliant analysis adequately represents the distribution from the full analysis. Overall then, this simulation demonstrates that the compliant analysis method is a reasonable approach for designing compliant clad systems.

Figures 5.5 - 5.7 show results for the same structural configuration and loading conditions but now changing the nickel clad to molybdenum. The comparison is now between full inelastic elastic and the elastic analysis approach. Figure 5.5 shows the mechanical strain results for the same location shown in Figure 5.1, Fig. 5.6 is a fringe plot of the equivalent strain at the end of the hold in the final load cycle, and Fig. 5.7 is a similar plot of the equivalent stress. The strain ranges, strain distributions, and stress distributions are very similar between the full inelastic and elastic analyses, implying that the elastic analysis approach is a reasonable approximation for this problem.

\subsection{Full 3D analysis of a bent heat exchanger tube}

Figure 5.8 illustrates the full 3D analysis problem used in this section. The model represents a single tube of a fuel salt primary heat exchanger in a MSR. Fuel salt flows through the tubes and the fission heat is transferred to the coolant salt flowing in the shells. The heat exchanger tubes are often bent to accommodate the differential thermal expansion between the inner and outer banks of tubes [39]. The heat exchanger tube considered for analysis is $60 \mathrm{~mm}$ long of which $20 \mathrm{~mm}$ is bent. The tube is $316 \mathrm{H}$ stainless steel, represented with an inelastic material model. It is cladded on both inner and outer surfaces as both are exposed to corrosive molten salt. The clad material is either Ni or Mo. The tube is $0.2 \mathrm{~mm}$ thick, with an inner and outer $0.02 \mathrm{~mm}$ thick layer of clad and the remaining $0.16 \mathrm{~mm}$ of $316 \mathrm{H}$ 
Finite element analysis of compliant cladding and base metal systems

July 2018

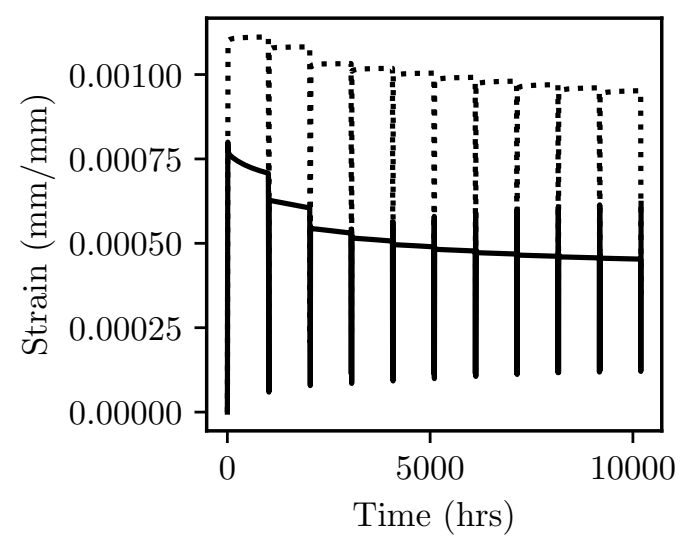

Figure 5.5: Figure plotting the equivalent strain at the tube/tube-sheet interface for the full inelastic simulation of $316 \mathrm{H}$ cladded with Mo (solid) versus an elastic clad analysis (dashed).

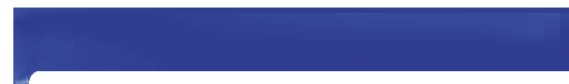

Equivalent strain

(\%)
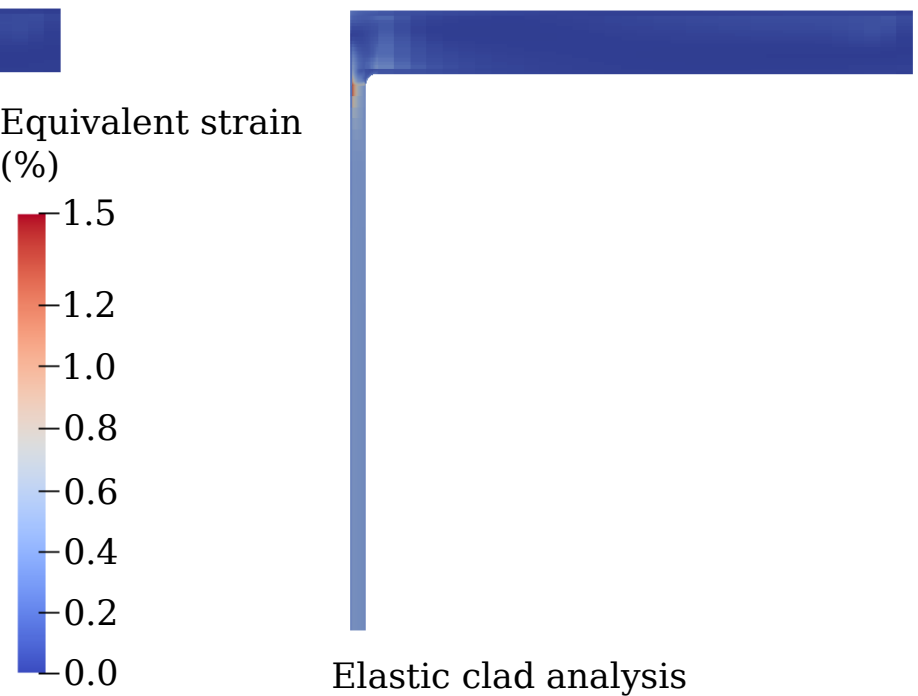

Full inelastic analysis

0.0

Elastic clad analysis

Figure 5.6: The equivalent strain distribution in the full and compliant clad analysis at the end of the final hold at temperature. 


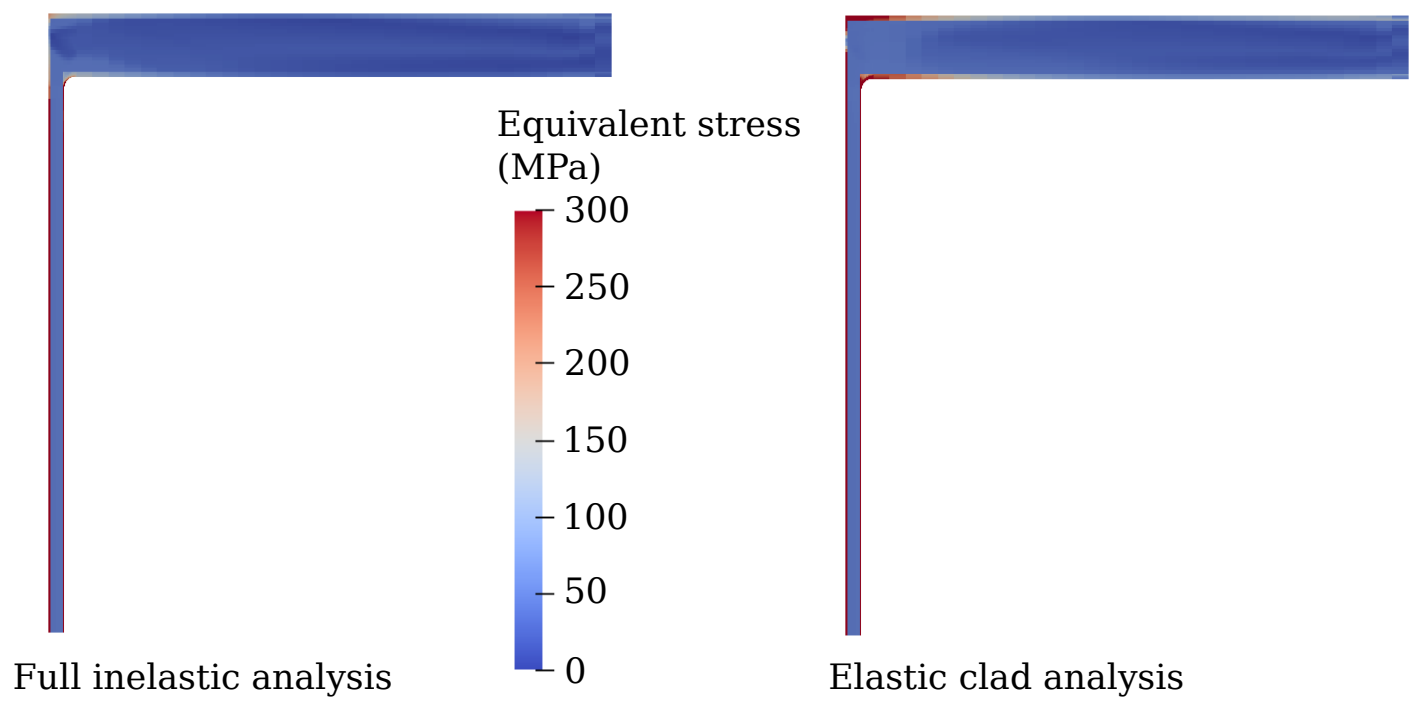

Figure 5.7: The equivalent stress distribution in the full and compliant clad analysis at the end of the final hold at temperature.

stainless steel. Figure 5.8 a shows half of the tube. The tube is symmetric about XY plane along $\mathrm{x}$-direction and about YZ plane at $x=30 \mathrm{~mm}$. The symmetric FE model of the tube is shown in Figure 5.8c. A fixed displacement boundary condition is applied at $x=0$ end of the tube. Figure 5.8b shows the loading condition used in this problem. The outer wall temperature remains constant at $670^{\circ} \mathrm{C}$, while the inner wall temperature cycles between $670^{\circ} \mathrm{C}$ and $730^{\circ} \mathrm{C}$. The inner wall temperature is increased from $670^{\circ} \mathrm{C}$ to $730^{\circ} \mathrm{C}$ over 1 hour, held for 100 hours, and then decreased to $670^{\circ} \mathrm{C}$ over 1 hour. A linear temperature gradient is considered between inner and outer wall. Figure 5.8d shows a typical temperature contour during hold.

Two sets of structural analyses are performed using the same geometry and loading conditions. In the first set, a full inelastic model is used to represent $\mathrm{Ni} / 316 \mathrm{H} / \mathrm{Ni}$ (clad/base/clad) system and compared with another using the compliant method of analysis representing the clad with a material with zero flow strength. The second set compares a full inelastic analysis of Mo/316H/Mo system with an elastic analysis. The thermal loading cycle is repeated 12 times for the first set of analysis and repeated for 30 times for the second set of analysis. Temperature independent material properties (at $700^{\circ} \mathrm{C}$ ) are used for the simulation. Material properties are listed in Tables 4.3, 4.4, and 4.5. The simulation results are analyzed at two locations: one at the middle of the straight section of the tube and another at the end of the bend, as indicated by location-1 and location-2, respectively, in Figure 5.8c.

Figure 5.9 compares the von Mises contours, after heat up at 12th load cycle, between the full inelastic simulation of $\mathrm{Ni} / 316 \mathrm{H} / \mathrm{Ni}$ system and the compliant clad analysis. As the clad material has zero flow strength there is no stress on clad in complaint clad analysis. Stress components, across tube thickness, from two analysis are compared in Figures 5.10 and 5.11. Figure 5.10 shows stress components for location-1, while Figure 5.11 shows for location-2. Stress profiles are shown for after heat up, after hold, and after cool down, all in 12 th load cycle. Von Mises stress relaxation profiles, during hold at 12 th load cycle, at 


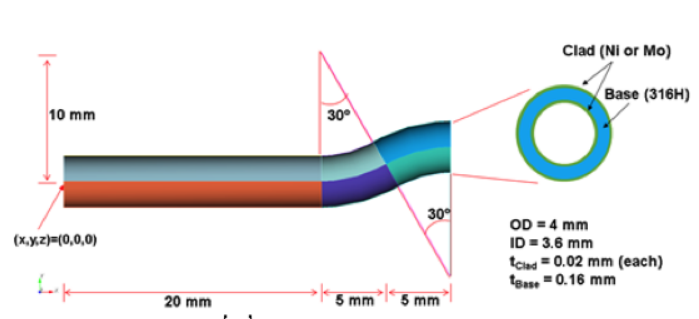

(a)

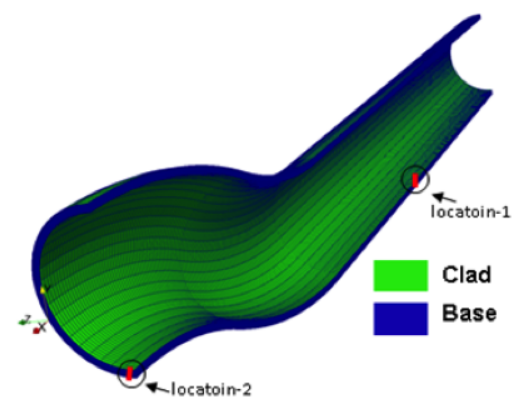

(c)

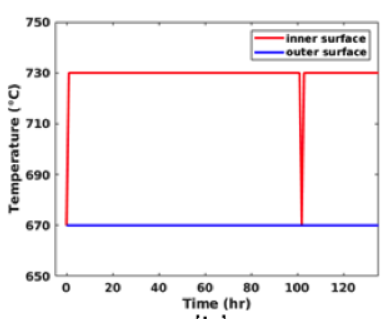

(b)

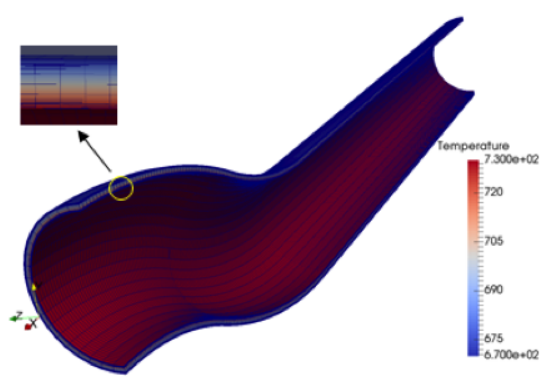

(d)

Figure 5.8: (a) Geometry of the bent heat exchanger tube, (b) thermal loading profile, (c) symmetric FE model of the tube, and (d) temperature contour at a typical instant. The tube is cladded on both the inside and outside surfaces. Simulation results are analyzed for location-1 and location-2 as indicated in c.
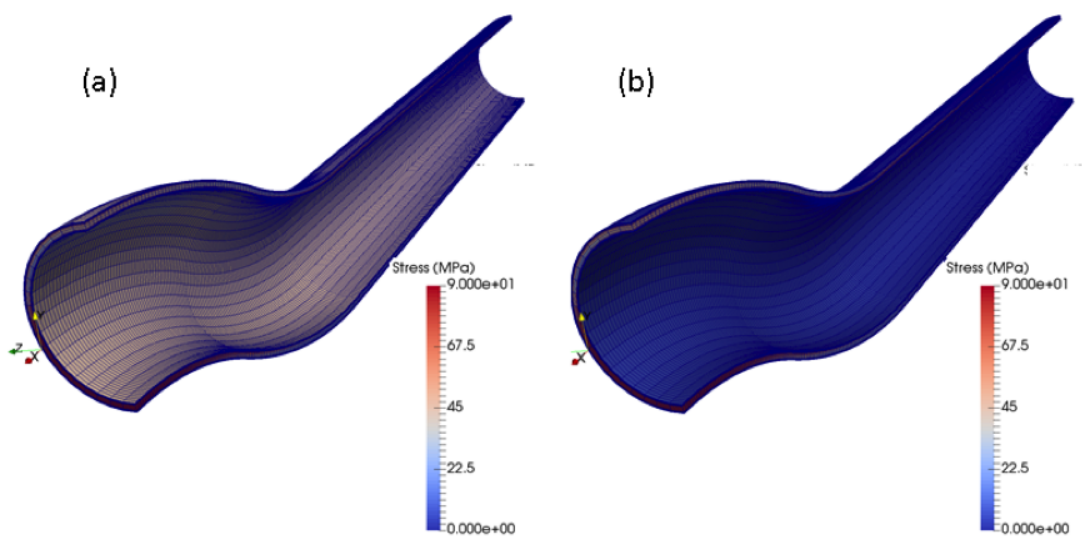

Figure 5.9: Von Mises stress contours after heat up in 12th load cycle. Results are from (a) a full inelastic simulation of $316 \mathrm{H}$ cladded with $\mathrm{Ni}$ and (b) a compliant clad analysis. 
Finite element analysis of compliant cladding and base metal systems

July 2018
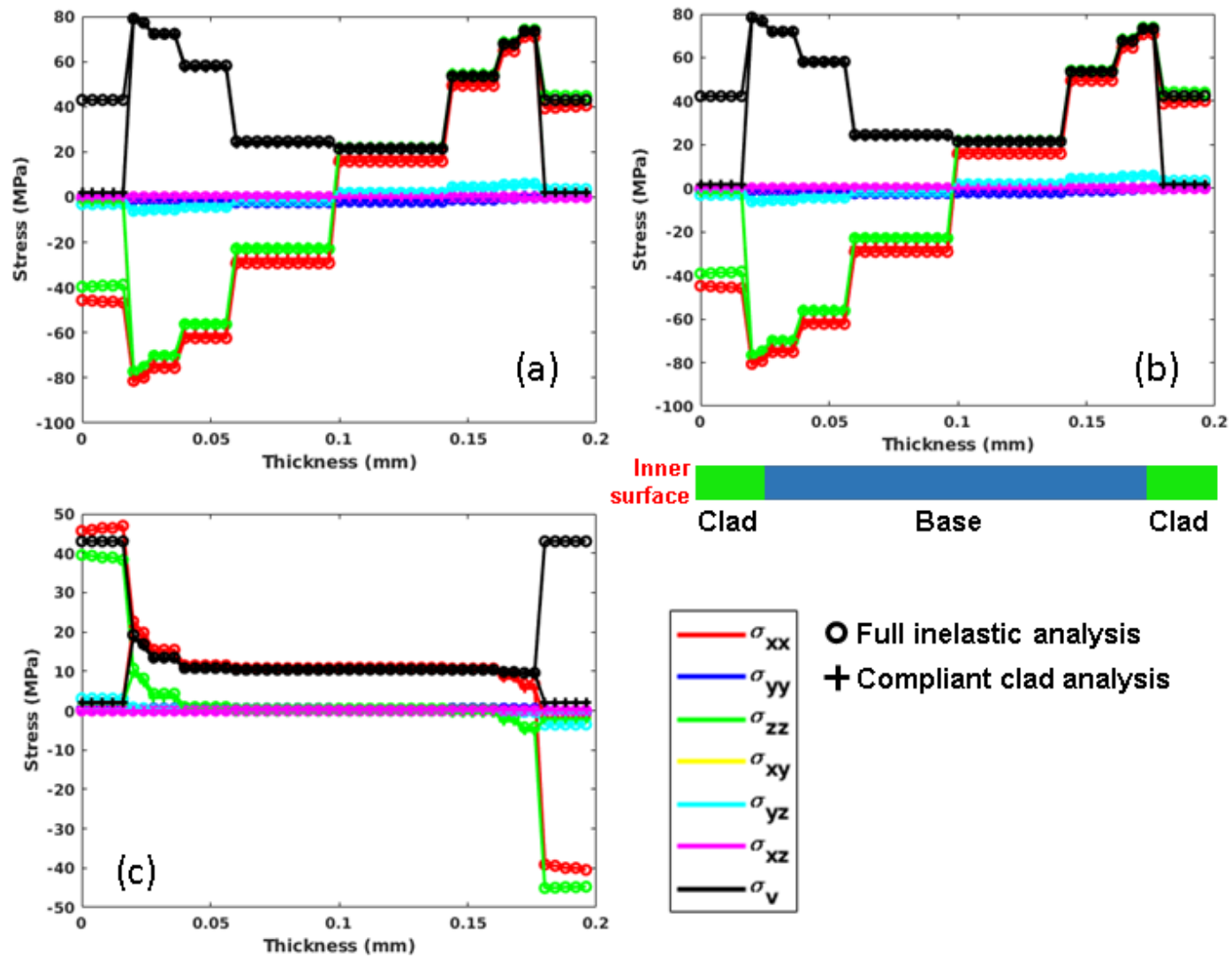

Figure 5.10: Stress components, after (a) heat up, (b) hold, and (c) cool down in 12th load cycle, across the thickness in location-1 (see Figure 5.8c). Results are from a full inelastic simulation of $316 \mathrm{H}$ cladded with $\mathrm{Ni}$ and a compliant clad analysis. 
Finite element analysis of compliant cladding and base metal systems
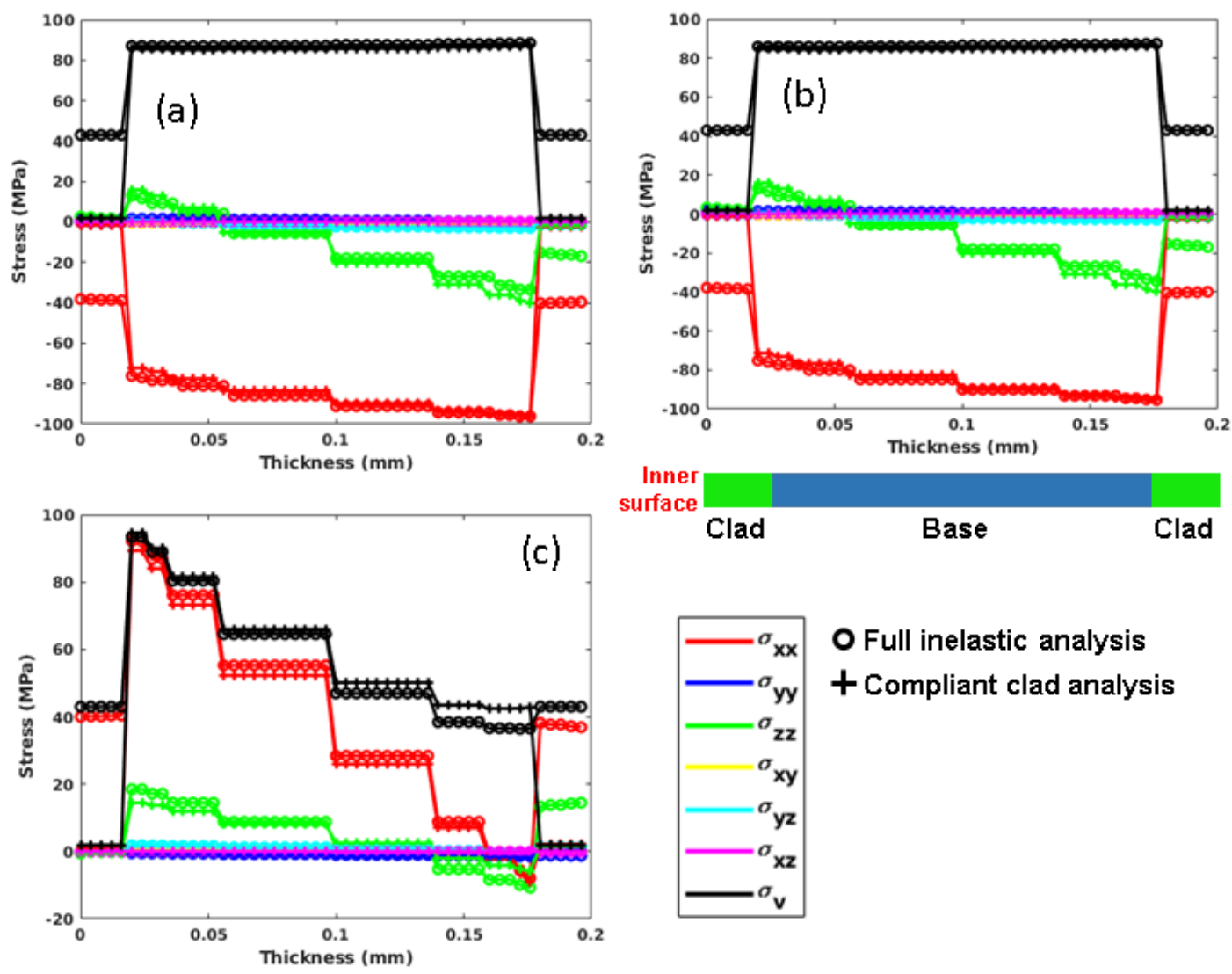

Figure 5.11: Stress components, after (a) heat up, (b) hold, and (c) cool down in 12th load cycle, across the thickness in location-2 (see Figure 5.8c). Results are from a full inelastic simulation of $316 \mathrm{H}$ cladded with $\mathrm{Ni}$ and a compliant clad analysis. 

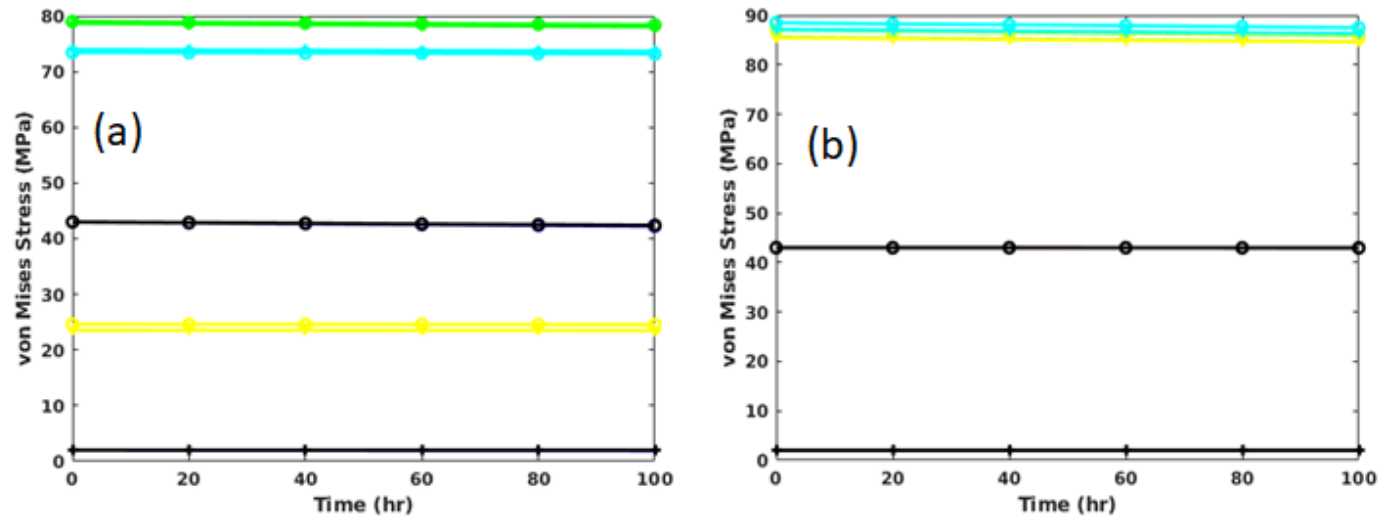

O Full inelastic analysis

+Compliant clad analysis
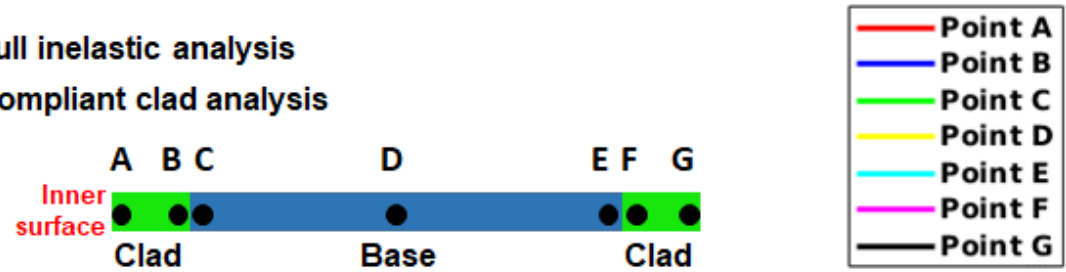

Figure 5.12: Stress relaxation profiles at different locations of clad and , in (a) location-1 and (b) location-2 (see Figure 5.8c), during hold in 12th load cycle. Results are from a full inelastic simulation of $316 \mathrm{H}$ cladded with $\mathrm{Ni}$ and a compliant clad analysis.

different points across tube thickness are plotted in Figure 5.12. Figure 5.12 also compares the stress relaxation profile between two analysis methods. In all the cases (Figures 5.10 to 5.12 ), both analysis methods provide similar stress profiles in the base.

Similarly, the mechanical strain components, across tube thickness, from two analysis are compared in Figures 5.13 and 5.14. As seen in the stress profiles, both analysis method provides similar results for mechanical strain profiles in the base. However, strain profiles in clad are significantly different from two analysis.

To examine whether the complaint clad analysis bounds the mechanical strains found in the full simulation, ASME equivalent strain range from two analysis methods are compared in Figure 5.15. As seen in the figure, the equivalent strain ranges from compliant clad analysis is greater than those from full simulation in clad and very close in the base. Creep damage in the base for 12th load cycle from two simulations are compared in Figure 5.16. Simulation results show that the compliant clad analysis bounds the full inelastic simulation results for location-1 (straight section). In location-2 (bent section) creep damage from compliant clad analysis is found to be little less than that from full inelastic analysis method, however, the difference is not very significant. Moreover, the creep damage values in location-2 are much lower than those in location-1, which means the creep damage values in location-1 bounds those in location-2. This also signifies the importance of analyzing simulation results both in straight (location-1) and bent (location-2) section of the tube. For example, von Mises stress and equivalent strain range are higher in location-1, while creep damage is higher is location-2. Note that, one would expect higher creep damage in location-2 due to higher von Mises stress. However, ASME uses the Huddleston equivalent stress for calculating creep damage (ASME BPVC.III.5-2017 HBB-T-1411). The equivalent stress in the bent section 
Finite element analysis of compliant cladding and base metal systems
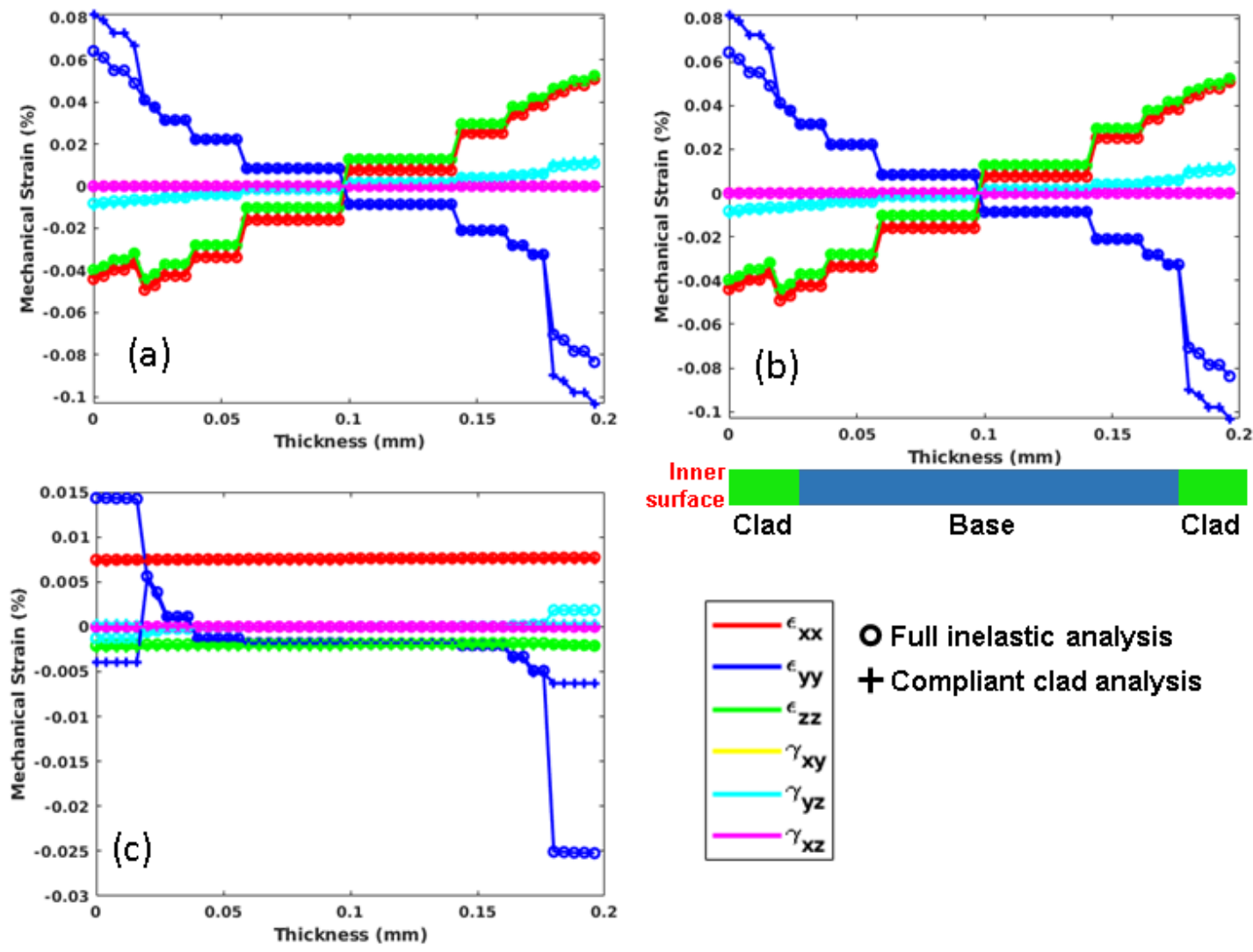

Figure 5.13: Mechanical strain components, after (a) heat up, (b) hold, and (c) cool down in 12th load cycle, across the thickness in location-1 (see Figure 5.8c). Results are from a full inela 
Finite element analysis of compliant cladding and base metal systems
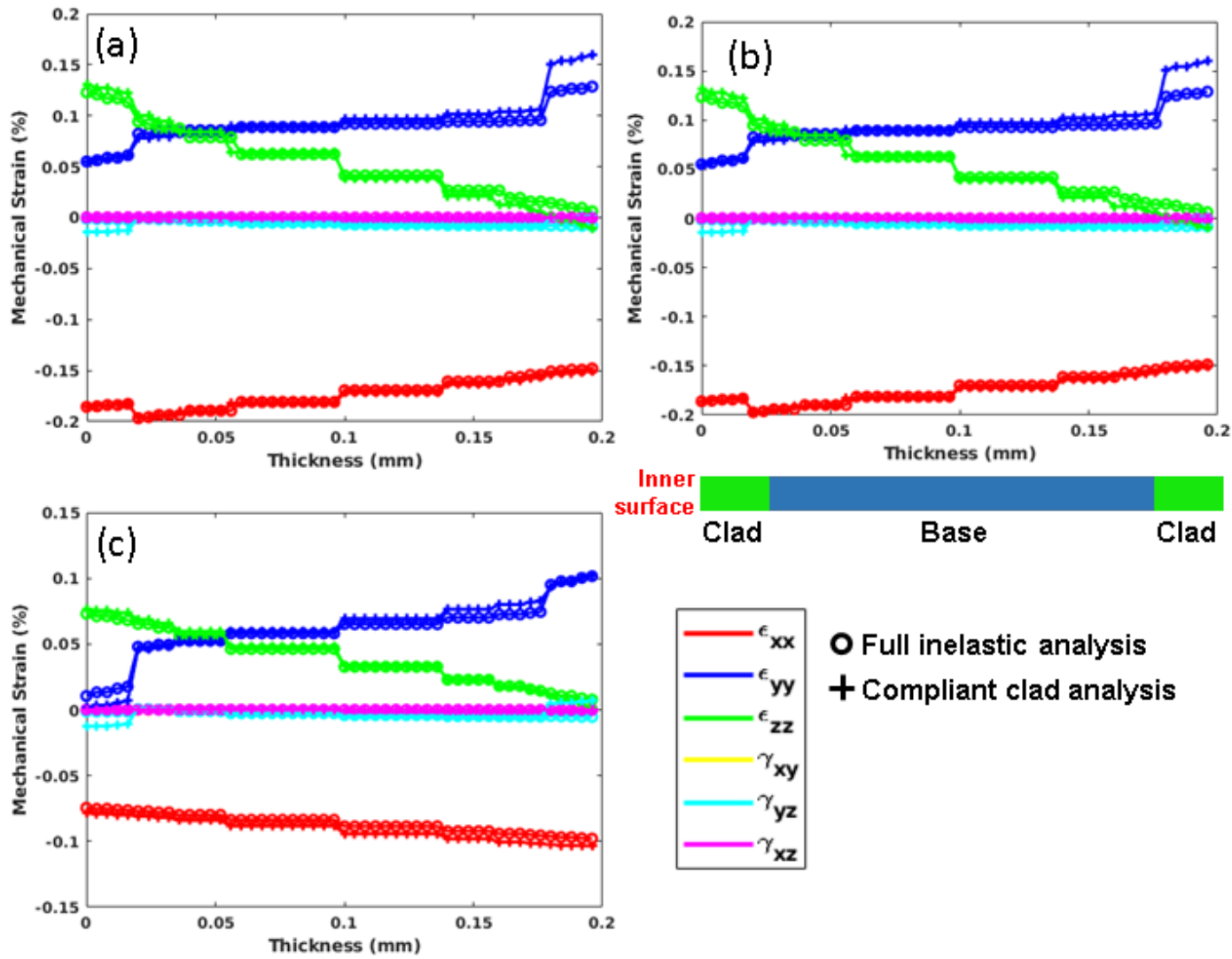

Clad

Base

Clad

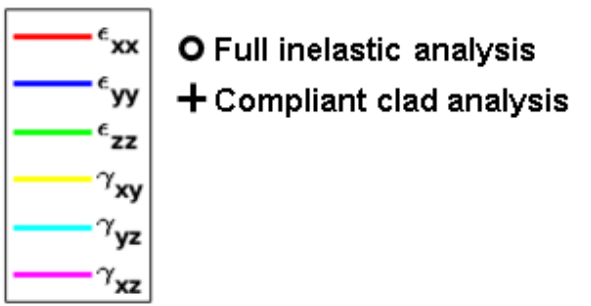

Figure 5.14: Mechanical strain components, after (a) heat up, (b) hold, and (c) cool down in 12th load cycle, across the thickness in location-2 (see Figure 5.8c). Results are from a full inelastic simulation of $316 \mathrm{H}$ cladded with $\mathrm{Ni}$ and a compliant clad analysis.
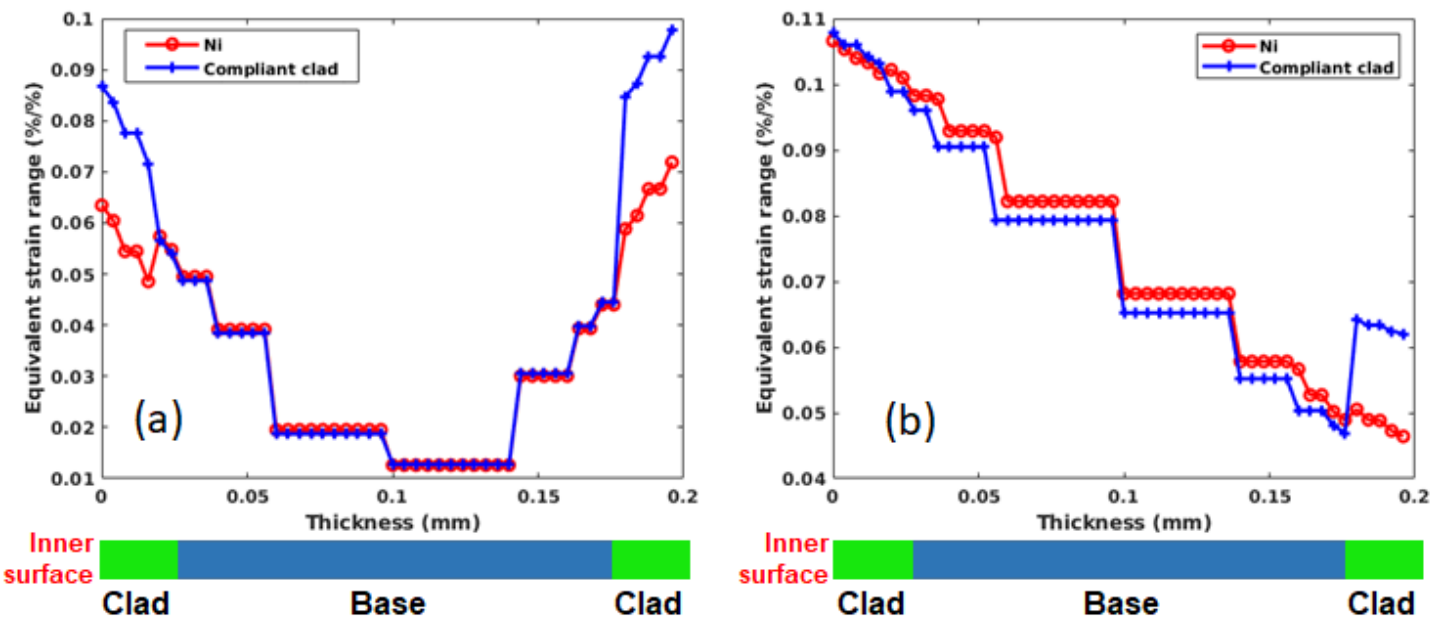

Figure 5.15: ASME equivalent strain range, plotted over thickness in (a) location-1 and (b) location-2, for the 12th load cycle. Results are from a full inelastic simulation of $316 \mathrm{H}$ cladded with $\mathrm{Ni}$ and a compliant clad analysis. 

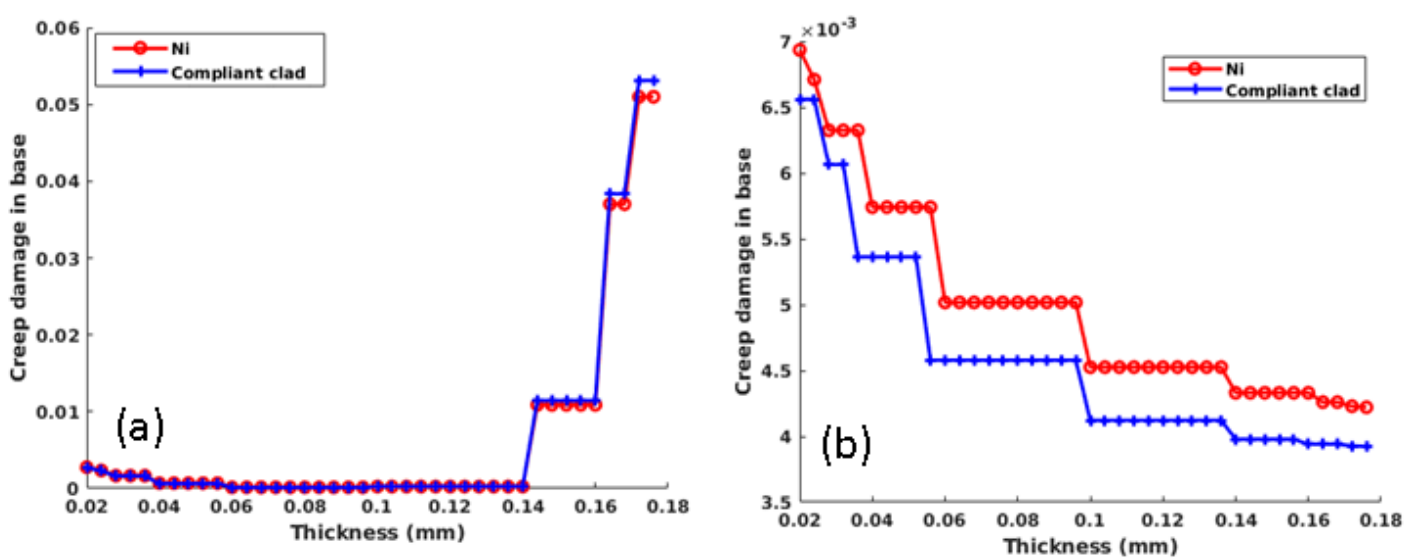

Figure 5.16: Creep damage in the base, plotted over thickness in (a) location-1 and (b) location-2, for the 12th load cycle. Results are from a full inelastic simulation of $316 \mathrm{H}$ cladded with $\mathrm{Ni}$ and a compliant clad analysis.
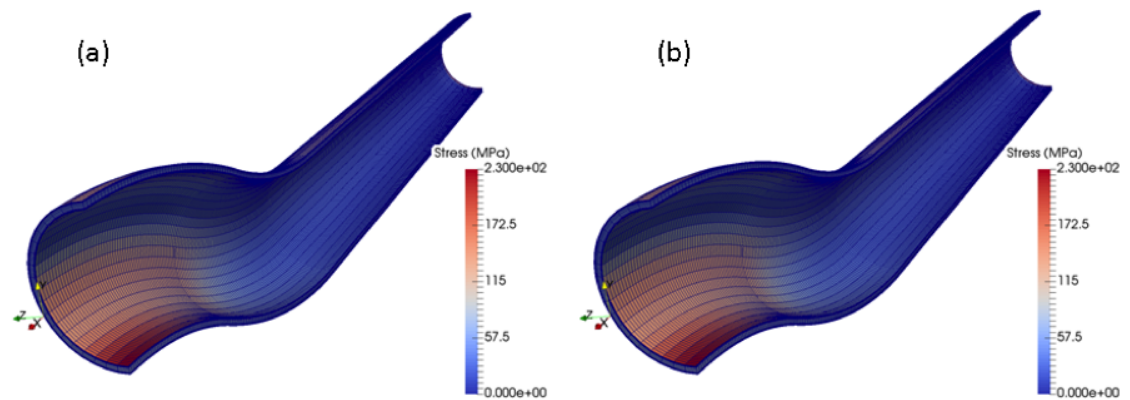

Figure 5.17: Von Mises stress contours after heat up in 30th load cycle. Results are from (a) a full inelastic simulation of $316 \mathrm{H}$ cladded with Mo and (b) an elastic clad analysis.

is lower than that in straight section.

The second set of comparisons is performed between results from the full inelastic simulation of Mo/316H/Mo system and the elastic clad analysis. Figure 5.17 shows von Mises stress contours after heat up at 30th cycle. Unlike the compliant clad analysis (Figure 5.9b), high stress in clad is observed in elastic clad analysis. Stress components, across tube thickness, from full inelastic simulation of $\mathrm{Mo} / 316 \mathrm{H} / \mathrm{Mo}$ and elastic clad analysis are plotted in Figure 5.18 and 5.19, respectively, for location-1 and location-2. Stress components are shown for after heat up, after hold, and after cool down, all in the 30th load cycle. As seen from the figures, stress from both simulation are similar. Similar observation can also be seen in stress relaxation profiles, shown in Figure 5.20, during hold in 30th load cycle. Strain components across the thickness are compared in Figures 5.21 and 5.22, for location-1 and location-2. Strain components are shown for after heat up, after hold, and after cool down, all in 30th load cycle. As seen in figures, strain profiles from both simulation are very similar. The ASME equivalent strain range and creep damage in the base are similar in both simulations, as shown in Figure 5.23 and 5.24. Therefore, the elastic clad analysis is a reasonable design analysis approach for this problem. 
Finite element analysis of compliant cladding and base metal systems

July 2018
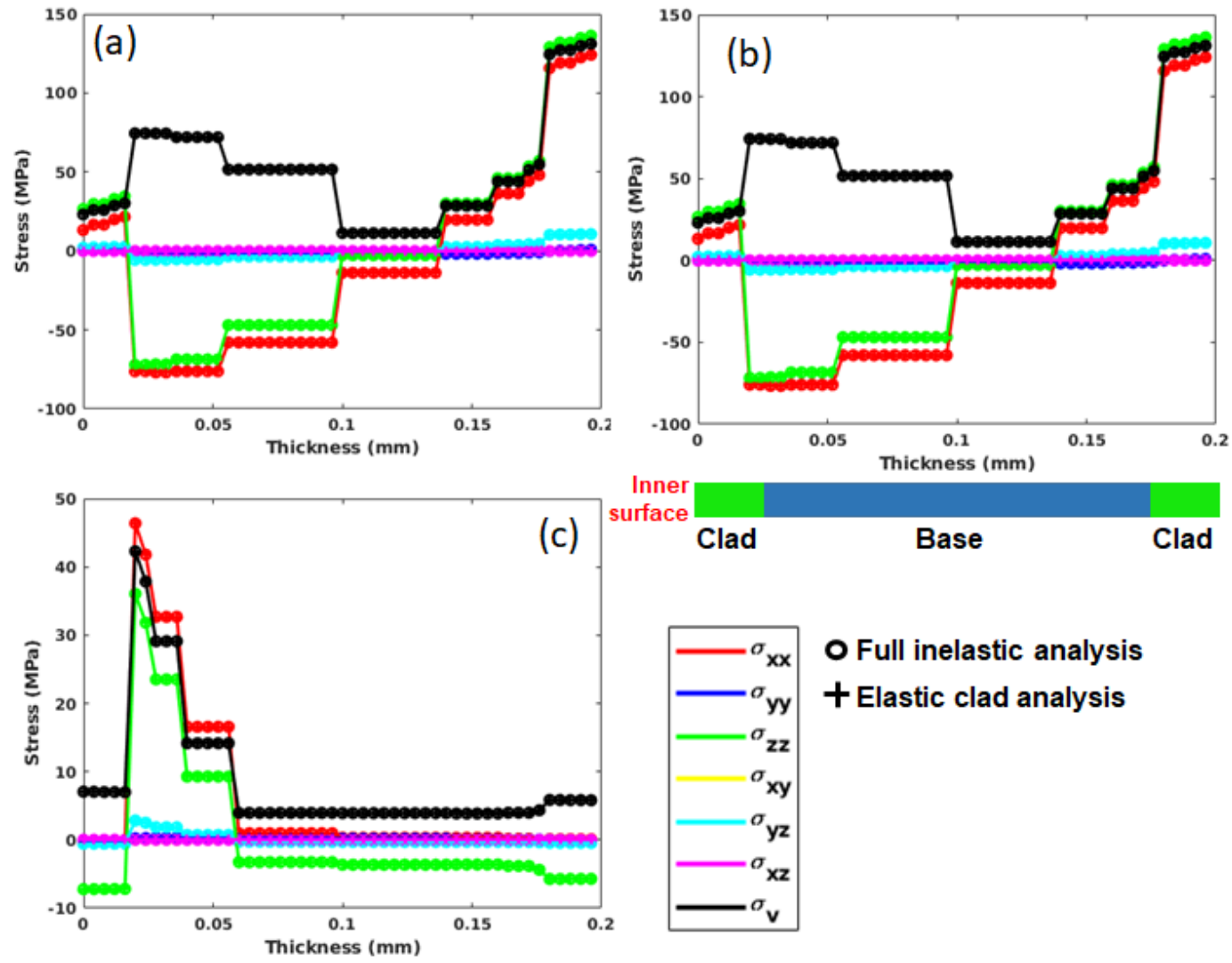

Figure 5.18: Stress components, after (a) heat up, (b) hold, and (c) cool down in 30th load cycle, across the thickness in location-1 (see Figure 5.8c). Results are from a full inelastic simulation of $316 \mathrm{H}$ cladded with Mo and an elastic clad analysis. 
Finite element analysis of compliant cladding and base metal systems

July 2018
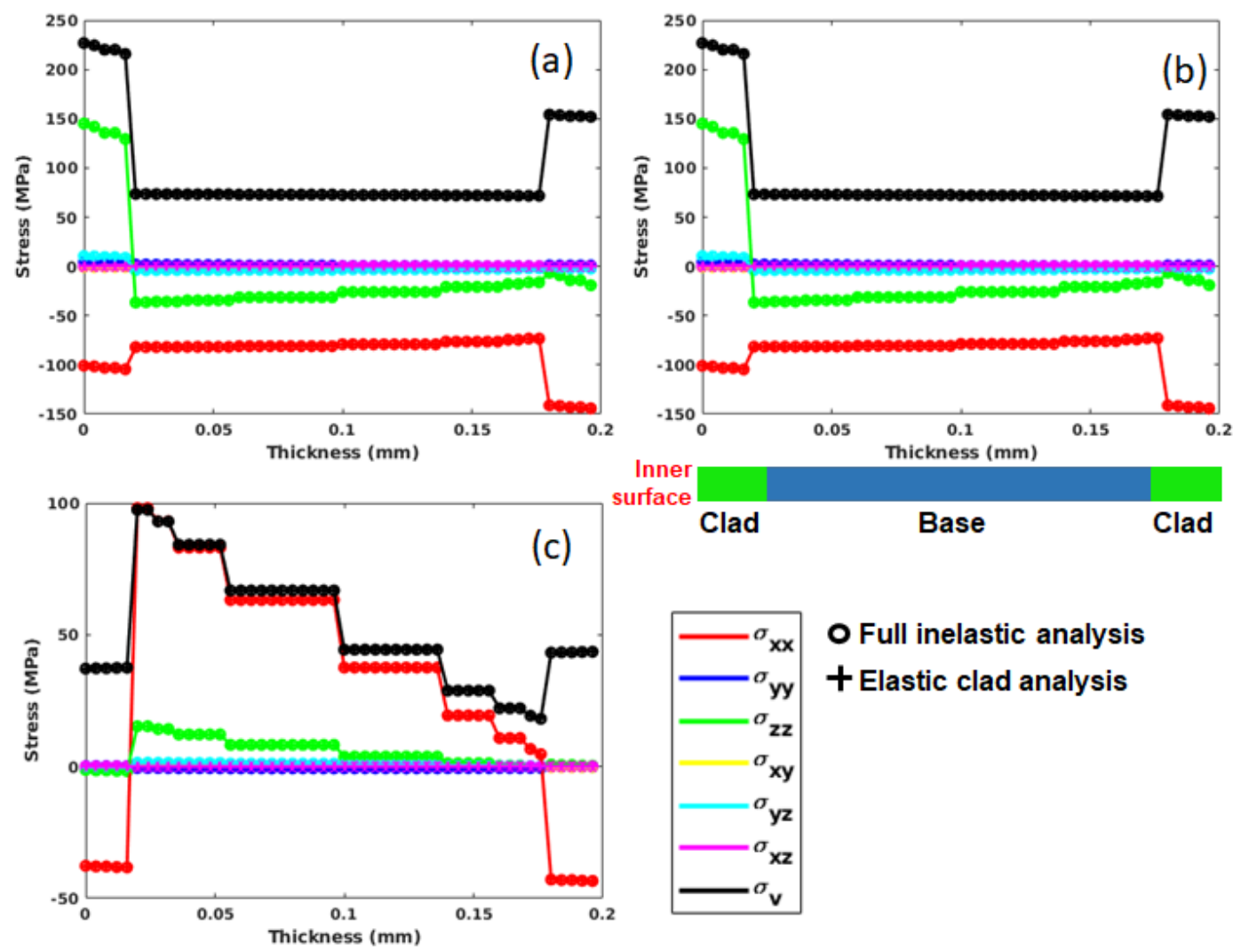

Figure 5.19: Stress components, after (a) heat up, (b) hold, and (c) cool down in 30th load cycle, across the thickness in location-2 (see Figure 5.8c). Results are from a full inelastic simulation of $316 \mathrm{H}$ cladded with Mo and an elastic clad analysis. 
Finite element analysis of compliant cladding and base metal systems

July 2018
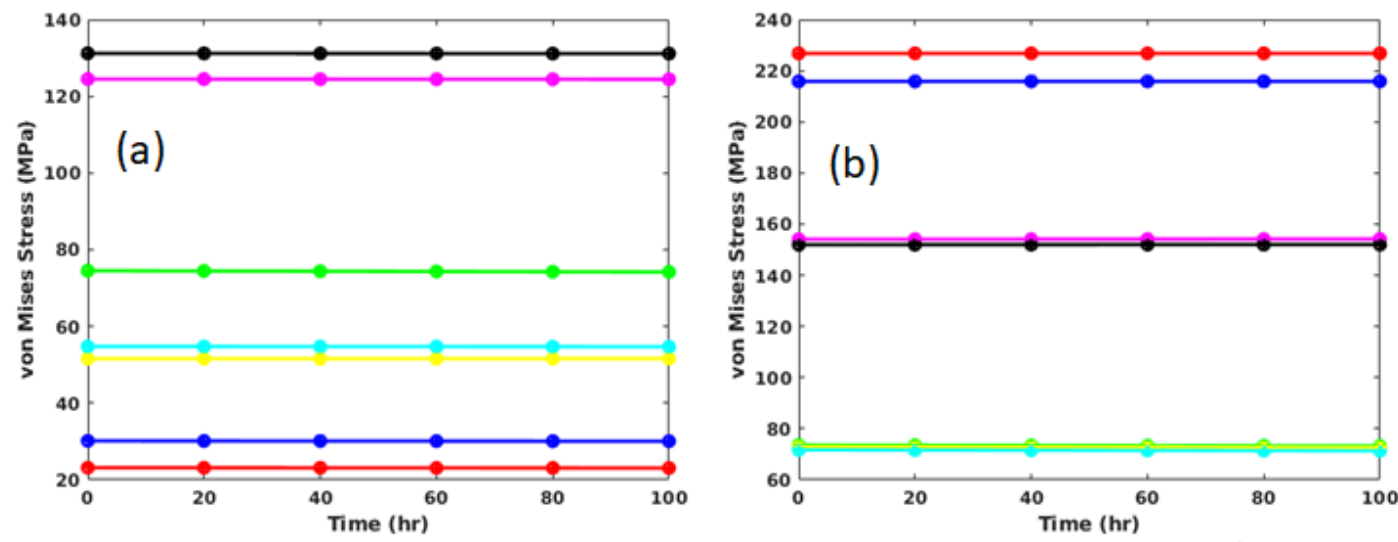

\section{O Full inelastic analysis \\ +Elastic clad analysis}
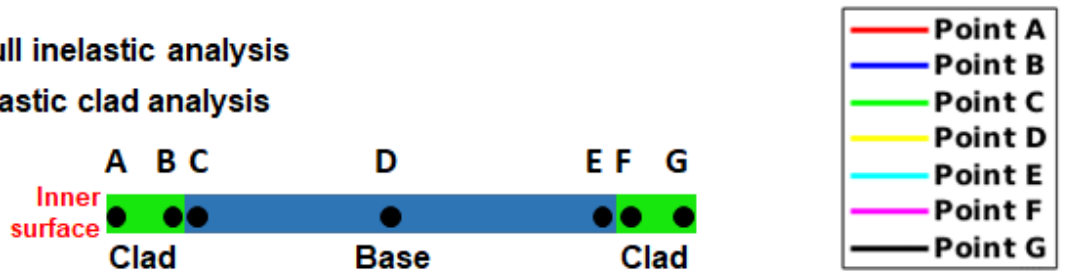

Figure 5.20: Stress relaxation profiles at different locations of clad and base, in (a) location-1 and (b) location-2 (see Figure 5.8c), during hold in 30th load cycle. Results are from a full inelastic simulation of $316 \mathrm{H}$ cladded with $\mathrm{Ni}$ and an elastic clad analysis. 
Finite element analysis of compliant cladding and base metal systems

July 2018
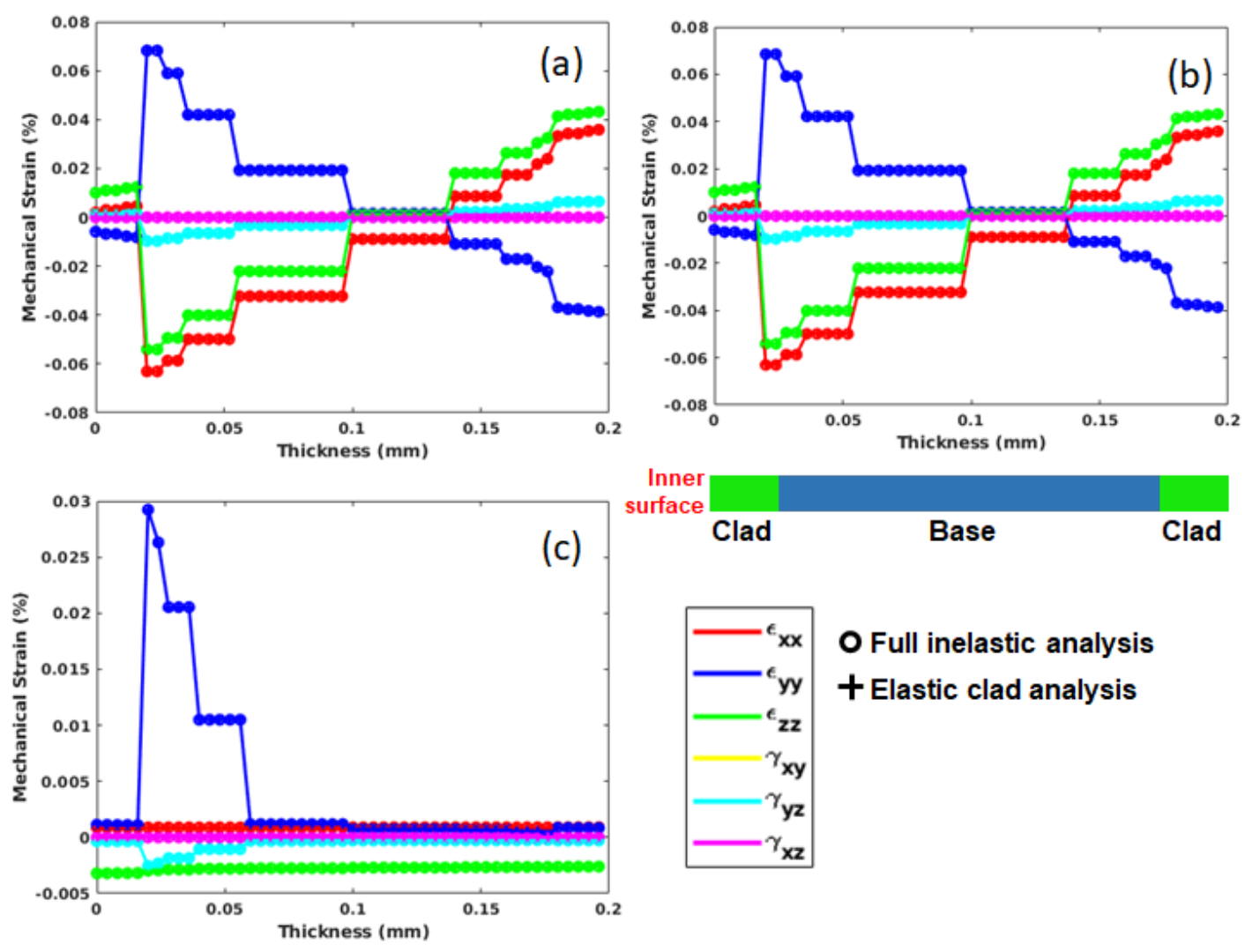

Figure 5.21: Mechanical strain components, after (a) heat up, (b) hold, and (c) cool down in 30th load cycle, across the thickness in location-1 (see Figure 5.8c). Results are from a full inelastic simulation of $316 \mathrm{H}$ cladded with Mo and an elastic clad analysis. 
Finite element analysis of compliant cladding and base metal systems
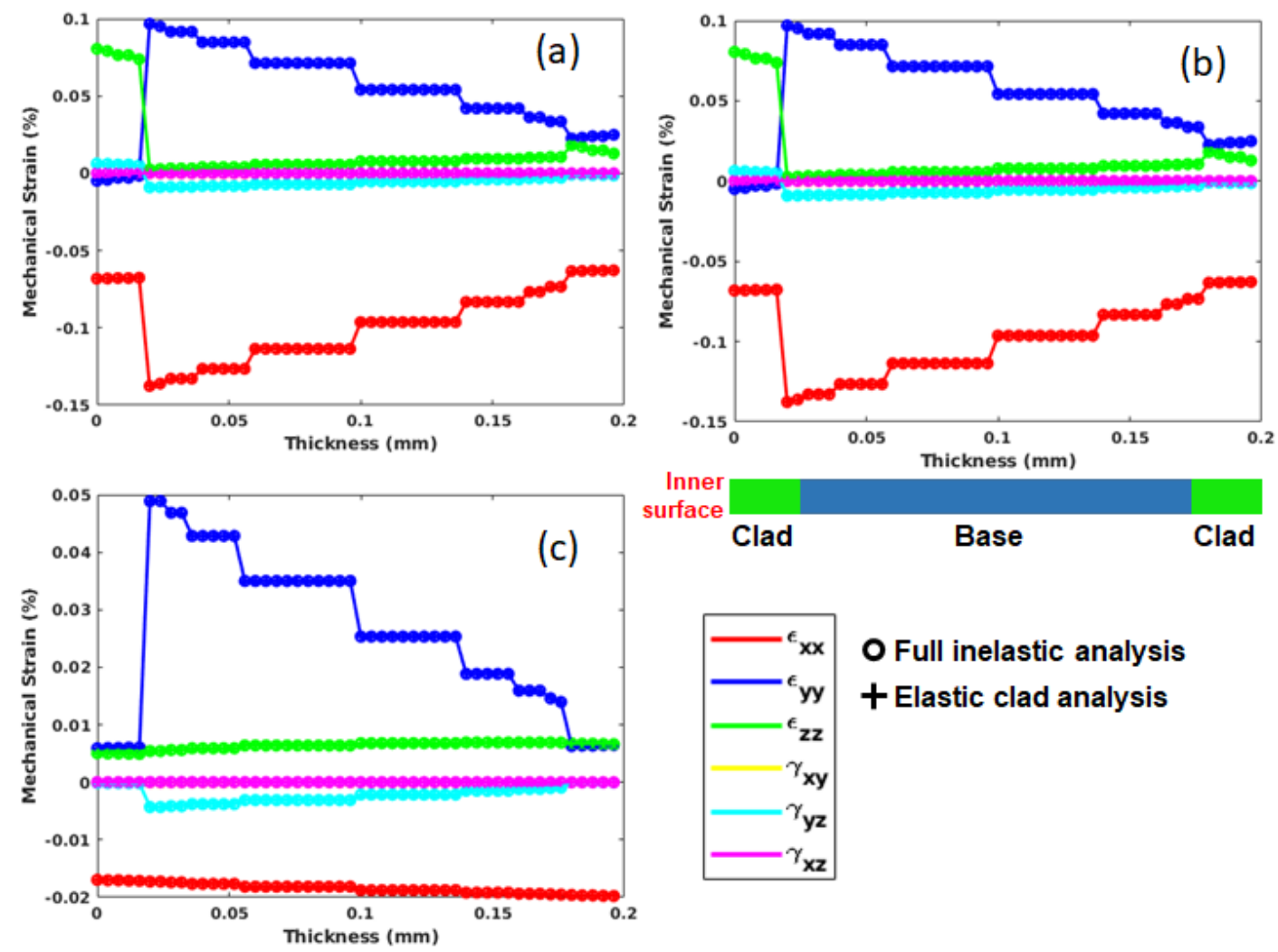

Figure 5.22: Mechanical strain components, after (a) heat up, (b) hold, and (c) cool down in 30th load cycle, across the thickness in location-2 (see Figure 5.8c). Results are from a full inelastic simulation of $316 \mathrm{H}$ cladded with Mo and an elastic clad analysis.
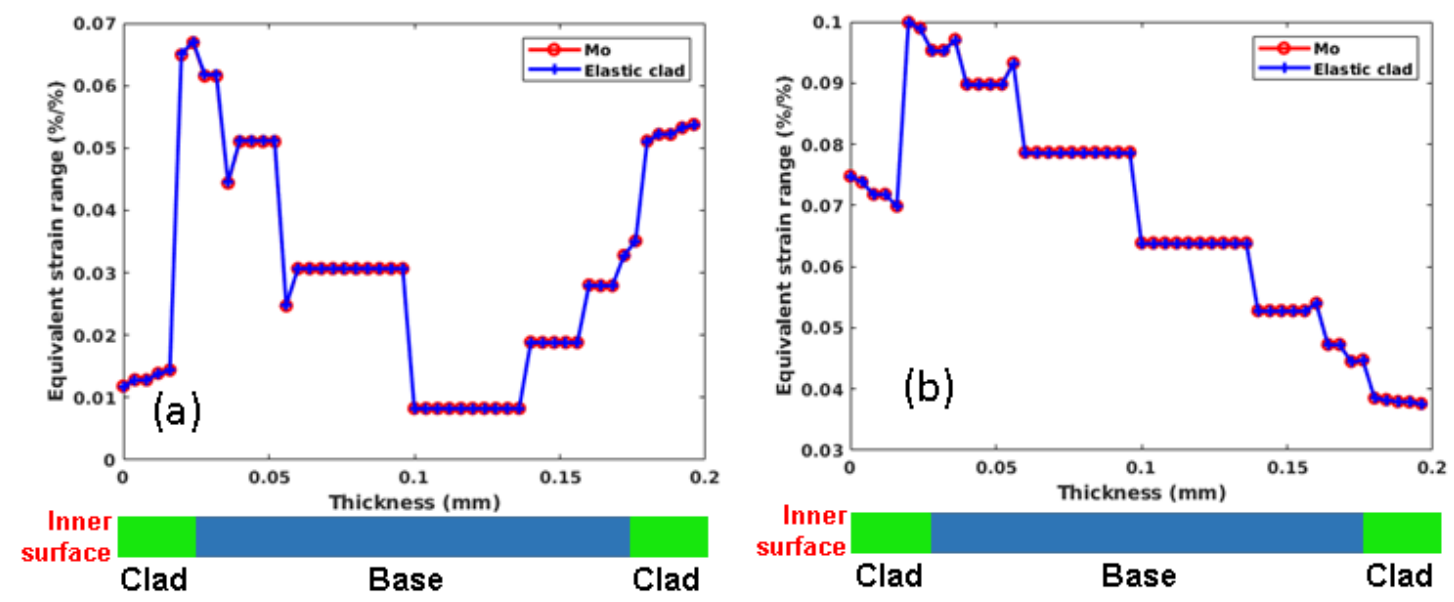

Figure 5.23: ASME equivalent strain range, plotted over thickness in (a) location-1 and (b) location-2, for the 30th load cycle. Results are from a full inelastic simulation of $316 \mathrm{H}$ cladded with Mo and an elastic clad analysis. 
Finite element analysis of compliant cladding and base metal systems

July 2018
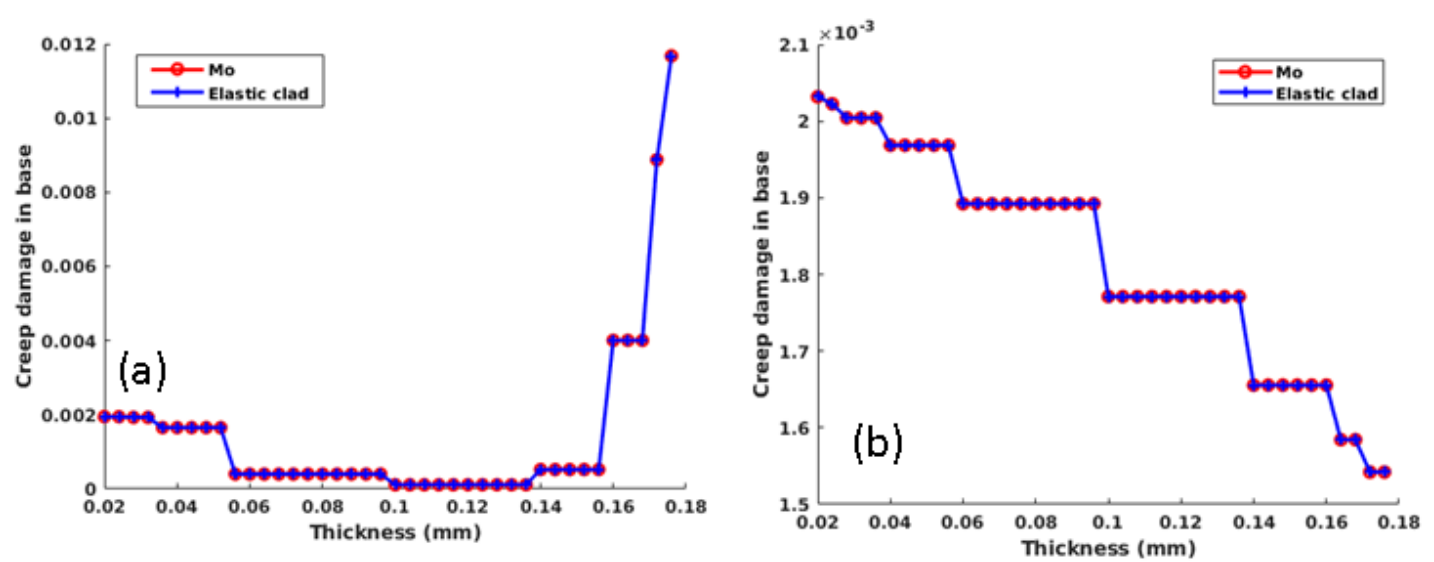

Figure 5.24: Creep damage in the base, plotted over thickness in (a) location-1 and (b) location-2, for the 30th load cycle. Results are from a full inelastic simulation of $316 \mathrm{H}$ cladded with Mo and an elastic clad analysis. 



\section{Conclusions}

This report establishes a path towards developing design rules for cladded, high temperature nuclear components that does not require long-term test data for potential clad materials. The objective is to enable MSR developers to use cladding to protect existing Class A metallic materials from corrosion. This approach avoids code qualifying new corrosion resistant materials and should shorten the path towards designing and putting into service MSRs with long service lives.

The approach developed here relies on categorizing clad/base combinations into either elastic or compliant systems. This report proposes analysis and potential design strategies that avoid long term testing for clad/base material combinations that fall into these categories. Chapter 4 develops tentative bounds on which types of material systems can be accurately represented with each of the two approaches based on high throughput simulations using a simplified mechanical representation of a cladded vessel, developed in Chapter 3. Chapter 2 describes path towards full design methods using these elastic and compliant analysis strategies and Chapter 5 verifies aspects of the methods using finite element analyses of prototypical reactor components.

An appendix to this report lists mechanical properties for several potential clad materials. This list does not take into account corrosion in specific MSR salt chemistries nor does it consider the effects of radiation damage. Future modeling work will assess the clad materials, and the compliant/elastic design process itself, for suitability if either the clad or base material swells significantly when exposed to radiation. This will be especially important for fuel-salt concepts where the structural materials will undergo much higher radiation exposure than in other advanced reactor or LWR designs.

The next step will be developing a complete set of design rules. This will involve selecting one of the routes described in Chapter 2 and developing it into a complete design method. As noted in the introduction, part of this development must include identifying and validating acceptance tests for the clad/base bond. Additionally, an experimental program will be needed to collect short-term mechanical properties for clad materials. For compliant clads this program will need to include some short-term creep and/or creep-fatigue testing. 

Finite element analysis of compliant cladding and base metal systems

July 2018

\section{Acknowledgments}

The research was sponsored by the U.S. Department of Energy (DOE), under Contract No. DE-AC02-06CH11357 with Argonne National Laboratory, managed and operated by UChicago Argonne LLC. Programmatic direction was provided by the Office of Advanced Reactor Technologies (ART) of the Office of Nuclear Energy (NE). 



\section{Bibliography}

[1] Material properties of Nickel. U.S.A. Special Metals Corporation.

[2] Mechanical and Physical Properties. Materials Handbook, 2nd Edition, Springer-Verlag, London, 2008.

[3] American Society of Mechanical Engineers. Case N-861: Satisfaction of Strain Limits for Division 5 Class A Components at Elevated Temperature Service Using Elastic-Perfectly Plastic Analysis. In ASME Boiler and Pressure Vessel Code, Nuclear Component Code Cases. 2015.

[4] American Society of Mechanical Engineers. Case N-862: Calculation of Creep-Fatigue for Division 5 Class A Components at Elevated Temperature Service Using ElasticPerfectly Plastic Analysis. In ASME Boiler and Pressure Vessel Code, Nuclear Component Code Cases. 2015.

[5] American Society of Mechanical Engineers. Section III, Division 5. In ASME Boiler and Pressure Vessel Code. 2017.

[6] M. F. Ashby and H. J. Frost. Deformation-mechanism Maps: The Plasticity and Creep of Metals and Ceramics. Pergamon Press - Science, 1982.

[7] R.T. Begley and J.H. Bechtold. Effect of alloying on the mechanical properties of niobium. Journal of the Less Common Metals, 3(1):1-12, 1961.

[8] J. E. Campbell, H. B. Goodwin, H. J. Wagner, R. W. Douglass, and B. C. Allen. Introduction to Metals for Elevated-Temperature Use. Technical report, DMIC Report 160, Battelle Memorial Institute, 1961.

[9] S H Carpenter and R H Wittman. Explosion Welding. Annual Review of Materials Science, 5(1):177-199, 1975.

[10] Bo Cheng, Young Jin Kim, and Peter Chou. Improving Accident Tolerance of Nuclear Fuel with Coated Mo-alloy Cladding. Nuclear Engineering and Technology, 48(1):16-25, 2016.

[11] B. V. Cockeram. Measuring the Fracture Toughness of TZM and ODS Molybdenum Alloys using Standard and Sub-sized Bend Specimens. Technical report, Bettis Atomic Power Laboratory, West Mifflin, Pennsylvania, 1999.

[12] B. V. Cockeram. The mechanical properties and fracture mechanisms of wrought low carbon arc cast (LCAC), molybdenum-0.5pct titanium-0.1pct zirconium (TZM), and oxide dispersion strengthened (ODS) molybdenum flat products. Materials Science and Engineering A, 418(1-2):120-136, 2006.

[13] J. B. Conway. Mechanical and physical properties of refractory metals and alloys. Refractory alloy technology for space nuclear power applications. Technical Information Center, Office of Scientific and Technical Information, US Department of Energy, Oak Ridge, pages 227-251, 1984. 
[14] G. R. Cowan, O. R. Bergmann, and A. H. Holtzman. Mechanism of bond zone wave formation in explosion-clad metals. Metallurgical and Materials Transactions B, 2(11): $3145-3155,1971$.

[15] Fran Cverna, editor. ASM Ready Reference: Thermal Properties of Metals. ASM International, 2002.

[16] A. L. Feild, R. L. Ammon, A. I. Lewis, and L. S. Richardson. Research and Development of the Tantalum and Tungsten Base Alloys. Technical report, Westinghouse Research Laboratories, Pittsburgh 3F, Pennsylvania, 1961.

[17] M. F. Gittos and T. G. Gooch. The interface below stainless steel and nickel-alloy claddings. Welding Research Supplement, pages 461-472, 1992.

[18] W. R. Grimes. Molten-Salt Reactor Chemistry. Nuclear Applications and Technology, 8(2):137-155, 1970.

[19] W.C. Hagel, J.A. Shields, and S-A. Tuominen. Processing and Production of Molybdenum and Tungsten Alloys. pages 98-113, 1984.

[20] Mohd Azhar Harimon, Nafisah Arina Hidayati, Yukio Miyashita, Yuichi Otsuka, Yoshiharu Mutoh, Shinichi Yamamoto, and Hitoshi Aoyama. High temperature fracture toughness of TZM alloys with different kinds of grain boundary particles. International Journal of Refractory Metals and Hard Materials, 66:52 - 56, 2017.

[21] K. Ishio, K. Kikuchi, M. Kusano, M. Mizumoto, K. Mukugi, A. Naito, N. Ouchi, and Y. Tsuchiya. Fracture toughness and mechanical properties of pure niobium and welded joints for superconducting cavities at 4K. 1999.

[22] P. J. Karditsas and M.-J. Baptiste. Thermal and Structural Properties of Fusion related Materials. UKAEA FUS 294, 1995.

[23] P. J. Karditsas and M.-J. Baptiste. Thermal and Structural Properties of Fusion related Materials. UKAEA FUS 294, 1995.

[24] V. V. Karpov, A. V. Abramov, A. Yu. Zhilyakov, S. V. Belikov, V. A. Volkovich, I. B. Polovov, and O. I. Rebrin. High-temperature corrosion of metals in the salt and metallic melts containing rare earths. AIP Conference Proceedings, 1767(1):020011, 2016.

[25] J. W. Koger and A. P. Litman. Compatibility of Molybdenum-base Alloy TZM with $\mathrm{LiF}-\mathrm{BeF}_{2}-\mathrm{ThF}_{4}-\mathrm{UF}_{4}\left(68-20-11.7-0.3\right.$ mole\%) at $1100^{\circ} \mathrm{C}$. Technical report, ORNLTM-2724, Oak Ridge National Laboratory, 1969.

[26] C A Lavender, D M Paxton, M T Smith, A Soulami, V V Joshi, and D E Burkes. Concept Feasibility Report for Using Co-Extrusion to Bond Metals to Complex Shapes of U-10Mo. Technical report, Pacific Northwest National Laboratory, 2013.

[27] B. S. Lement and K. Kreder. The Tensile Ductility-Transition in Molybdenum. Technical report, Air Force Materials Laboratory, 1964. 
[28] Todd Leonhardt. Properties of tungsten-rhenium and tungsten-rhenium with hafnium carbide. JOM, 61(7):68-71, Jul 2009.

[29] H. G. MacPherson. The Molten Salt Reactor Adventure. Nuclear Science and Engineering, 90(4):374-380, 1985.

[30] W. T. Matthews. Plane Strain Fracture Toughness (KIC) Data Handbook for Metals. page 92, 121973.

[31] G. E. Metzger. Survey of structural materials for the molten salt experimental (MOSEL) reactor. Nuclear Engineering and Design, 1(7):29-39, 1968.

[32] Mujtaba Al Mudhaffar, Nathera A. Saleh, and Asmaa Aassy. Influence of Hot Clad Rolling Process Parameters on Life Cycle of Reinforced bar of Stainless Steel Carbon Steel Bars. Procedia Manufacturing, 8(October 2016):353-360, 2017.

[33] Y. Mutoh, K. Ichikawa, K. Nagata, and M. Takeuchi. Effect of rhenium addition on fracture toughness of tungsten at elevated temperatures. Journal of Materials Science, 30(3):770-775, Jan 1995.

[34] C. Navas, R. Colaço, J. de Damborenea, and R. Vilar. Abrasive wear behaviour of laser clad and flame sprayed-melted NiCrBSi coatings. Surface and Coatings Technology, 200 (24):6854-6862, 2006.

[35] H. Otte, editor. Materials Science Research: Volume 2 The Proceedings of the 1964 Southern Metals/ Materials Conference on Advances in Aerospace Materials. Springer Science \& Business Media, Technology \& Engineering, 1964.

[36] Peter L. Raffo. Yielding and Fracture in Tungsten and Tungsten-Rhenium Alloys. Technical report, NASA, 1968.

[37] R. N. Raoelison, Y. Xie, T. Sapanathan, M. P. Planche, R. Kromer, S. Costil, and C. Langlade. Cold gas dynamic spray technology: A comprehensive review of processing conditions for various technological developments till to date. Additive Manufacturing, 19:134-159, 2018.

[38] C. E. Rense, K. W. Fife, D. F. Bowersox, and M. D. Ferran. Materials compatibility during the chlorination of Molten $\mathrm{CaCl}_{2} \mathrm{CaO}$ salts. LA-10700-MS, Los Alamos National Laboratory, 1987.

[39] R. C. Robertson, R. B. Briggs, O. L. Smith, and E. S. Bettis. Two-fluid molten-slate breeder reactor design study. Technical report, Oak Ridge National Laboratory, 1970.

[40] Konstantinos Salonitis, Laurent D'Alvise, Babis Schoinochoritis, and Dimitrios Chantzis. Additive manufacturing and post-processing simulation: laser cladding followed by high speed machining. The International Journal of Advanced Manufacturing Technology, 85(9-12):2401-2411, 2016. 
[41] Jerome Serp, Michel Allibert, Ondrej Benes, Sylvie Delpech, Olga Feynberg, Véronique Ghetta, Daniel Heuer, David Holcomb, Victor Ignatiev, Jan Leen Kloosterman, Lelio Luzzi, Elsa Merle-Lucotte, Jan Uhlir, Ritsuo Yoshioka, and Dai Zhimin. The molten salt reactor (MSR) in generation IV: Overview and perspectives. Progress in Nuclear Energy, 77:308-319, 2014.

[42] T.-L. Sham, Robert I Jetter, and Yanli Wang. Elevated temperature cyclic service evaluation based on elastic-perfectly plastic analysis and integrated creep-fatigue damage. In Proceedings of the ASME 2016 Pressure Vessels and Piping Conference, pages 1-10, 2016.

[43] S. Sharafat, R. Martinez, and N. M. Ghoniem. Design window for tungsten alloys. Apex Study Group Meeting, 1999.

[44] H. J. Shi, L. S. Niu, C. Korn, and G. Pluvinage. High temperature fatigue behaviour of TZM molybdenum alloy under mechanical and thermomechanical cyclic loads. Journal of Nuclear Materials, 278(2):328-333, 2000.

[45] G. P. Skoro, J. R. J. Bennett, and T. R. Edgecock. Experimental results and constitutive modelling for tungsten and tantalum at high strain rates and very high temperatures. 1995.

[46] I. Smid, M. Akiba, G. Vieider, and L. Plöchl. Development of tungsten armor and bonding to copper for plasma-interactive components. Journal of Nuclear Materials, 258-263:160-172, 1998.

[47] K. Sridharan and T. R. Allen. Corrosion in molten salts. F.L. Groult (Ed.), Molten Salts Chemistry, Elsevier, Oxford, 2013.

[48] J.M Steichen. Tensile properties of neutron irradiated tzm and tungsten. Journal of Nuclear Materials, 60(1):13-19, 1976.

[49] Mykhailo Stolbchenko, Olexandr Grydin, Florian Nürnberger, Andrii Samsonenko, and Mirko Schaper. Sandwich rolling of twin-roll cast aluminium-steel clad strips. Procedia Engineering, 81(October):1541-1546, 2014.

[50] Tomohiro Takida, Hiroaki Kurishita, Mamoru Mabuchi, Tadashi Igarashi, Yoshiharu Doi, and Takekazu Nagae. Mechanical properties of fine-grained, sintered molybdenum alloys with dispersed particles developed by mechanical alloying. Materials Transactions, 45(1):143-148, 2004.

[51] Robert C. Tucker, editor. Thermal Spray Technology. ASM International, 2004.

[52] K. Van Acker, D. Vanhoyweghen, R. Persoons, and J. Vangrunderbeek. Influence of tungsten carbide particle size and distribution on the wear resistance of laser clad WC/Ni coatings. Wear, 258(1-4 SPEC. ISS.):194-202, 2005. 
[53] N. Venkateswara Rao, G. Madhusudhan Reddy, and S. Nagarjuna. Weld overlay cladding of high strength low alloy steel with austenitic stainless steel - Structure and properties. Materials and Design, 32(4):2496-2506, 2011.

[54] Yanli Wang, Li Tianlei, T.-L. (Sam) Sham, and Robert I. Jetter. Evaluation of CreepFatigue Damage Based on Simplified Model Test. Proceedings of the ASME 2013 Pressure Vessels 63 Piping Division Conference, page 11, 2013.

[55] Yanli Wang, Robert I. Jetter, and T.-L. Sham. Application of Simplified Model Tests to Alloy 617 Creep-Fatigue Damage Evaluation. Technical report, 2014.

[56] Yanli Wang, T-L Sham, and Robert I Jetter. Alloy 617 Creep-Fatigue Damage Evaluation Using Specimens With Strain Redistribution. Journal of Pressure Vessel Technology, 137(2):21402, 2015.

[57] N. E. Weare and R. E. Monroe. Welding and Brazing of Molybdenum. Technical report, Defense Metals Information Center, 1959.

[58] S. Yano, H. Matsui, and S. Morozumi. Structural observations of the interface of explosion-bonded Mo/Cu system. Journal of Materials Science, 33(19):4857-4865, 1998.

[59] G. Young, T. Liu, Z. Feng, and S. Sham. Cladded components metallurgical interaction. Advanced Reactor Technologies, Advanced Materials R\&D Program Review, DOE Headquarters, Germantown, MD, 2018. 



\section{A Mechanical properties of potential clad materials}

This appendix collates various mechanical properties of potential clad materials at room temperature and $700^{\circ} \mathrm{C}$, which is a reasonable operating temperature for a future MSR. The final table also surveys the reactivity of the various materials with fluoride and chloride salts, but this information should be regarded as preliminary.

Table A.1: Nominal mechanical and thermal properties at room temperature

\begin{tabular}{llllll}
\hline & Young's modulus & $\begin{array}{l}\text { Poisson } \\
E[\mathrm{MPa}]\end{array}$ & $\begin{array}{l}\text { Yield } \\
\sigma_{\mathrm{y}}[\mathrm{MPa}]\end{array}$ & $\begin{array}{l}\text { Thermal coefficient } \\
\alpha\left[\mathrm{mm} /\left(\mathrm{mm} \times{ }^{\circ} \mathrm{C}\right)^{-1}\right]\end{array}$ & Reference \\
\hline $\mathrm{Ni}$ & 205000 & 0.3 & 105.0 & $13.3 \times 10^{-6}$ & {$[1]$} \\
$\mathrm{W}$ & 408000 & 0.28 & 941.0 & $4.2 \times 10^{-6}$ & {$[23,45]$} \\
$\mathrm{W}-25 \mathrm{Re}$ & 430000 & 0.29 & $973.0-1584.0$ & $3.7-3.96$ & {$[2,13,15]$} \\
& & & & $\times 10^{-6}$ & {$[28,35]$} \\
$\mathrm{W}-5 \mathrm{Re}$ & 405000 & 0.3 & - & 4.5 & {$[2,43,46]$} \\
$\mathrm{Mo}$ & 330000 & 0.356 & 330.0 & $5.0 \times 10^{-6}$ & {$[22]$} \\
$\mathrm{Mo}-\mathrm{TZM}$ & 284000 & 0.33 & 760.0 & $5.0 \times 10^{-6}$ & {$[22]$} \\
$\mathrm{Ta}$ & 186000 & 0.35 & 600.0 & $6.4 \times 10^{-6}$ & {$[16]$} \\
$\mathrm{Nb}$ & 104000 & 0.4 & 285.0 & $7.3 \times 10^{-6}$ & {$[13]$} \\
\hline
\end{tabular}

Table A.2: Strength properties at room temperature. UTS = Ultimate Tensile Strength

\begin{tabular}{llll}
\hline & $\begin{array}{l}\text { UTS } \\
{[\mathrm{MPa}]}\end{array}$ & $\begin{array}{l}\text { Elongation to failure } \\
{[\%]}\end{array}$ & Reference \\
\hline $\mathrm{Ni}$ & 865.0 & 39.0 & {$[1]$} \\
$\mathrm{W}$ & 1482.37 & 0.2 & {$[8]$} \\
$\mathrm{W}-25 \mathrm{Re}$ & 1370.0 & 20.0 & {$[2]$} \\
$\mathrm{W}-5 \mathrm{Re}$ & 1100.0 & 10.0 & {$[2,43,46]$} \\
$\mathrm{Mo}$ & $645.0-782.0$ & $20.0-42.0$ & {$[8,19,48]$} \\
$\mathrm{Mo-TZM}$ & $800.0-1000.0$ & 14.5 & {$[19]$} \\
$\mathrm{Ta}$ & 607.0 & 19.0 & {$[16]$} \\
$\mathrm{Nb}$ & 285.0 & 42.0 & {$[7,13]$} \\
\hline
\end{tabular}


Finite element analysis of compliant cladding and base metal systems

July 2018

Table A.3: Fracture properties at room temperature

\begin{tabular}{lllll}
\hline & $\begin{array}{l}\text { Fracture toughness } \\
{\left[\mathrm{MPa} \mathrm{mm}^{1 / 2}\right]}\end{array}$ & $\begin{array}{l}J_{\mathrm{I} c} \\
{\left[\mathrm{~J} / \mathrm{mm}^{2}\right]}\end{array}$ & $\begin{array}{l}\text { Absorbed energy } \\
{[\mathrm{J}]}\end{array}$ & Reference \\
\hline $\mathrm{Ni}$ & 6514.3 & 1.95 & 271.0 & {$[1,30]$} \\
$\mathrm{W}$ & 411.1 & 252.98 & - & {$[33]$} \\
$\mathrm{W}-25 \mathrm{Re}$ & - & - & - & \\
$\mathrm{W}-5 \mathrm{Re}$ & 347.85 & 63.246 & - & {$[33]$} \\
$\mathrm{Mo}$ & 632.46 & - & - & {$[11]$} \\
$\mathrm{Mo}-\mathrm{TZM}$ & 600.833 & - & - & {$[11]$} \\
$\mathrm{Ta}$ & - & - & - & \\
$\mathrm{Nb}$ & 1584.3 & 81.9 & 32.0 & {$[21]$} \\
\hline
\end{tabular}

Table A.4: Nominal mechanical and thermal properties at $700^{\circ} \mathrm{C}$

\begin{tabular}{lllll}
\hline & Young's modulus & Yield & Thermal coefficient & Reference \\
& $E[\mathrm{MPa}]$ & $\sigma_{\mathrm{y}}[\mathrm{MPa}]$ & $\alpha\left[\mathrm{mm} /\left(\mathrm{mm} \times{ }^{\circ} \mathrm{C}\right)^{-1}\right]$ & \\
\hline $\mathrm{Ni}$ & 174000 & 43.0 & $15.8 \times 10^{-6}$ & {$[1]$} \\
$\mathrm{W}$ & 374000 & 677.0 & $4.43 \times 10^{-6}$ & {$[23,45]$} \\
$\mathrm{W}-25 \mathrm{Re}$ & - & - & $5.51 \times 10^{-6}$ & {$[13]$} \\
$\mathrm{W}-5 \mathrm{Re}$ & - & 832.0 & $4.92 \times 10^{-6}$ & {$[46]$} \\
$\mathrm{Mo}$ & 294000 & 225.0 & $5.5 \times 10^{-6}$ & {$[22]$} \\
$\mathrm{Mo}-\mathrm{TZM}$ & 220000 & 627.0 & $5.5 \times 10^{-6}$ & {$[22]$} \\
$\mathrm{Ta}$ & 179000 & 425.0 & $6.79 \times 10^{-6}$ & {$[16]$} \\
$\mathrm{Nb}$ & 80000 & 136.2 & $7.84 \times 10^{-6}$ & {$[13]$} \\
\hline
\end{tabular}

Table A.5: Strength properties at $700^{\circ} \mathrm{C}$. UTS $=$ Ultimate Tensile Strength

\begin{tabular}{lllll}
\hline & $\begin{array}{l}\text { UTS } \\
{[\mathrm{MPa}]}\end{array}$ & $\begin{array}{l}\text { Elongation to failure } \\
{[\%]}\end{array}$ & $\begin{array}{l}\text { Time to } 1 \% \text { creep strain at } 2 \sigma_{\mathrm{y}} / 3 \\
(\mathrm{hr})\end{array}$ & Reference \\
\hline $\mathrm{Ni}$ & 105.0 & 84.0 & $4.73 \mathrm{e}+09$ & {$[1,6]$} \\
$\mathrm{W}$ & 534.0 & 15.0 & $6.77 \mathrm{e}+19$ & {$[6,8]$} \\
$\mathrm{W}-25 \mathrm{Re}$ & - & - & - & {$[6,46]$} \\
$\mathrm{W}-5 \mathrm{Re}$ & 880.0 & - & - & {$[6,19,22]$} \\
$\mathrm{Mo}$ & $435.0-559.0$ & 23.0 & $5.24 \mathrm{e}+13$ & {$[6,48]$} \\
$\mathrm{Mo}-\mathrm{TZM}$ & $624.0-798.0$ & 13.0 & $3.64 \mathrm{e}+11$ & {$[6,16]$} \\
$\mathrm{Ta}$ & $468.0-496.0$ & $9.3-14.0$ & $6.04 \mathrm{e}+12$ & {$[6]$} \\
$\mathrm{Nb}$ & - & - & $7.78 \mathrm{e}+07$ & \\
\hline
\end{tabular}


Finite element analysis of compliant cladding and base metal systems

July 2018

Table A.6: Fracture properties at $700^{\circ} \mathrm{C}$

\begin{tabular}{lllll}
\hline & $\begin{array}{l}\text { Fracture toughness } \\
{\left[\mathrm{MPa} \mathrm{mm}^{1 / 2}\right]}\end{array}$ & $\begin{array}{l}J_{\mathrm{I} c} \\
{\left[\mathrm{~J} / \mathrm{mm}^{2}\right]}\end{array}$ & $\begin{array}{l}\text { Absorbed energy } \\
{[\mathrm{J}]}\end{array}$ & Reference \\
\hline $\mathrm{Ni}$ & - & - & - & \\
$\mathrm{W}$ & 1043.55 & 1233.29 & - & {$[33]$} \\
$\mathrm{W}-25 \mathrm{Re}$ & - & - & - & \\
$\mathrm{W}-5 \mathrm{Re}$ & - & 1897.37 & - & {$[33]$} \\
$\mathrm{Mo}$ & - & - & - & \\
$\mathrm{Mo}-\mathrm{TZM}$ & - & - & - & \\
$\mathrm{Ta}$ & - & - & - & {$[20]$} \\
$\mathrm{Nb}$ & - & 30.0 & - & \\
\hline
\end{tabular}

Table A.7: Reactivity properties

\begin{tabular}{lllll}
\hline & Reactivity to chloride salts & Reactivity to fluoride salts & Neutron activation & Reference \\
\hline $\mathrm{Ni}$ & excellent & excellent & - & {$[47,59]$} \\
$\mathrm{W}$ & excellent & excellent & - & {$[24,59]$} \\
$\mathrm{W}-25 \mathrm{Re}$ & poor & poor & - & {$[59]$} \\
$\mathrm{W}-5 \mathrm{Re}$ & poor & excellent & - & {$[59]$} \\
$\mathrm{Mo}$ & excellent & excellent & - & {$[24,31,38,59]$} \\
$\mathrm{Mo}-\mathrm{TZM}$ & excellent & excellent & - & {$[25,59]$} \\
$\mathrm{Ta}$ & excellent & excellent & - & {$[24,31,59]$} \\
$\mathrm{Nb}$ & good & good & excellent & {$[31,59]$} \\
\hline
\end{tabular}





\section{Distribution List}

\begin{tabular}{|c|c|c|}
\hline Name & Affiliation & Email \\
\hline Caponiti, A. & DOE & alice.caponiti@nuclear.energy.gov \\
\hline Feng, Z. & ORNL & fengz@ornl.gov \\
\hline Garrison, L.M. & ORNL & garrisonlm@ornl.gov \\
\hline Gouger, H.D. & INL & hans.gougar@inl.gov \\
\hline Hill, R.N. & ANL & bobhill@anl.gov \\
\hline Holcomb, D.E. & ORNL & holcombde@ornl.gov \\
\hline Keiser, J. & ORNL & keiserjr@ornl.gov \\
\hline Krumdick, G.K. & ANL & gkrumdick@anl.gov \\
\hline Lesica, S. & DOE & sue.lesica@nuclear.energy.gov \\
\hline McMurtrey, M. & INL & michael.mcmurtrey@inl.gov \\
\hline Messner, M.C. & ANL & messner@anl.gov \\
\hline Qualls, A.L. & ORNL & quallsal@ornl.gov \\
\hline Raiman, S.S. & ORNL & raimanss@ornl.gov \\
\hline Robinson, B. & DOE & brian.robinson@Nuclear.Energy.gov \\
\hline Sham, T.-L. & ANL & ssham@anl.gov \\
\hline Singh, D. & ANL & dsingh@anl.gov \\
\hline Wang, Y. & ORNL & wangy2@ornl.gov \\
\hline Wright, R. & INL & richard.wright@inl.gov \\
\hline Yoder, G. & ORNL & yodergljr@ornl.gov \\
\hline
\end{tabular}






\section{Argonne}

\section{Applied Materials Division}

Argonne National Laboratory

9700 South Cass Avenue, Bldg. 208

Argonne, IL 60439

www.anl.gov 